This item was submitted to Loughborough's Research Repository by the author.

Items in Figshare are protected by copyright, with all rights reserved, unless otherwise indicated.

\title{
Against the grain: the battle for public service broadcasting in Taiwan
}

PLEASE CITE THE PUBLISHED VERSION

PUBLISHER

(C) Chun-Wei Daniel Lin

LICENCE

CC BY-NC-ND 4.0

REPOSITORY RECORD

Lin, Chun-Wei. 2019. "Against the Grain: The Battle for Public Service Broadcasting in Taiwan”. figshare. https://hdl.handle.net/2134/10981. 


\section{Loughborough University}

This item was submitted to Loughborough University as a PhD thesis by the author and is made available in the Institutional Repository

(https://dspace.lboro.ac.uk/) under the following Creative Commons Licence conditions.

\section{cc) creative}

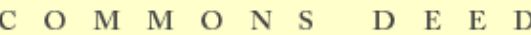

Attribution-NonCommercial-NoDerivs 2.5

You are free:

- to copy, distribute, display, and perform the work

Under the following conditions:

Attribution. You must attribute the work in the manner specified by the author or licensor.

Noncommercial. You may not use this work for commercial purposes.

No Derivative Works. You may not alter, transform, or build upon this work.

- For any reuse or distribution, you must make clear to others the license terms of this work.

- Any of these conditions can be waived if you get permission from the copyright holder.

Your fair use and other rights are in no way affected by the above.

This is a human-readable summary of the Leqal Code (the full license).

Disclaimer 민

For the full text of this licence, please go to: http://creativecommons.org/licenses/by-nc-nd/2.5/ 


\title{
Against the Grain: The Battle for Public Service Broadcasting
} in Taiwan

by

Chun-Wei Daniel Lin

\author{
A Doctoral Thesis \\ Submitted in partial fulfillment of the requirements for \\ the award of Doctor of Philosophy of \\ Loughborough University
}

October 2012

(C) by Chun-Wei Daniel Lin 2012 


\section{Thesis Abstract}

Against the Grain: The Battle for Public Service Broadcasting in Taiwan

by

Chun-Wei Daniel Lin, Social Sciences, Loughborough University, the UK

Email: headgardener2b@gmail.com

Over the last two decades public service broadcasting (PSB) around the world has faced increasing pressures from accelerating commercialisation and the fragmentation of the broadcasting landscape. This has led a number of media commentators in the system's traditional heartlands to ask whether the idea has now outlived its usefulness. Against the grain of this international trend, Taiwan has moved in the opposite direction, democratising its state-owned television system and introducing a form of public broadcasting for the first time. Against the grain of growing enthusiasm for a privatised solution supporters presented PSB as a necessary counter to the perceived deficiencies of the existing system, in serving a society moving from authoritarian to competitive party rule.

This study sets out to explore how the expansion of PSB in Taiwan has been socially defined and constructed, and by whom. The various constructions in play were mapped through in-depth interviews with a range of claim-makers involved in the process. A systematic content analysis of the mainstream Taiwanese press was then conducted to explore the ways contending positions and issues were presented in the 
public domain and to identify the key voices given a public platform.

This analysis demonstrated that the opinions and concerns of the general public were largely missing from a debate dominated by political and academic elites. Against the grain of their own claims to be representing the public key actors constructed public debate as a series of monologues, advancing their own sectional and paternalistic interpretations of the public interest.

These findings point to the supremely ironic conclusion that a process ostensibly dedicated to reconstructing broadcasting as key element in a new, democratic, public sphere, excluded the public from active participation and relegated them to the role of spectators.

Keywords: PSB (Public Service Broadcasting), Political Struggle, Mediated Debate, Taiwan, Content Analysis, In-depth Interview. 


\section{Acknowledgements}

First I would like to thank my external examiner, Professor Ralph Negrine of Sheffield University, and my internal examiner, Doctor James Stanyer, for the improvements they brought to this thesis via the Viva. With their expertise, their comments and suggestions definitely took this thesis to the next level.

In the process of completing this thesis, I was incredibly lucky to be supervised under two brilliant mentors, Professor Graham Murdock and Professor David Deacon. I have learnt from the best.

Deep bows to both of my supervisors who took a torturous task to refine this thesis from pulp to print.

Professor Graham Murdock is a big inspiration for this study. This thesis was just a rough idea until he breathed life into it. Graham has pushed me to grow from a novice to the author of this thesis with his patience whilst allowing me the room to work in my own way. I cannot thank him enough for his incredible support.

Professor David Deacon is a cheerful and critical coach who has guided me through this lonely and painful writing process. His warm tutorials with insightful and encouraging comments have made this thesis a pleasure to write. I thank him for guarding the little flame of hope for me to keep me in the faith that I can do it.

This thesis couldn't have been completed without my sponsors' support. Special thanks to the Taiwan Ministry of Education, The Chiang Ching-kuo Foundation and the Public Television Service Foundation for their generous funding.

The Department of Social Science has provided the support and equipment I need to produce my thesis. I have been aided for many years by Deirdre Lombard, our clerical officer for Postgraduate. I thank her for supporting me to overcome all pitfalls in the path. Also, in my daily work at Loughborough I have been blessed with a friendly and warm group of colleagues and friends. Thank you all for your theoretical arguments, academic inputs, social supports, and, of course, party fun. 
Sincere thanks to my interviewees, the key actors who involved in Taiwanese PSB debate and the others who preferred to remain anonymous within corporate walls. I thank them for generously sharing their opinion and experience which have broadened the view of this thesis.

Last but not least, this thesis is dedicated to my family members who always encourage me and love me through it all.

I could not possibly name everyone who has contributed significantly to my understanding of the subject. My apologies if I have inadvertently omitted anyone to whom acknowledgement is due.

Without doubt in this thesis there will be errors, omissions and over-simplifications. I assume alone full responsibility for all the remaining shortcomings. I hope this end result does not let down my supervisors, sponsors, colleagues, friends and family who have supported me all along, as well as readers who are patient enough to explore this work.

Chun Wei Daniel Lin 


\section{Contents}

LIST OF TABLES

1.1 SYStem FaILURE OF MEdia RePresentation

1.2 Media Reform in a Blue-Green Poltical Divide

1.3 Controversial PSB DEBATE IN TAIWAN

1.4 A SEQUenCEd OVERVIEW OF THESIS StRucture

CHAPTER 2 PUBLIC SERVICE BROADCASTING: A CONTESTED CONCEPT

2.1 SigNIFICANCE OF BRITISH MOdEL IN TAIWAN'S PSB EXPANSION

2.1.1 A DOMINANT PSB IN MEDIA LANDSCAPE

2.1.2 PROFESSIONAL BACKGROUND OF KEY PSB ADVOCATE

2.1.3 OTHER RELEVANT MODELS IN NEIGHBOURHOOD

2.2 The Media As Public Sphere

2.2.1 THE HABERMASIAN PUBLIC SPHERE AND THE MEDIA

2.2.2 THE PUBLIC SPHERE AND PSB

2.3 PSB AS A CONTESTED CONCEPT

2.3.1 DEFINITIONS OF PSB

2.4 FROM CONCEPTS TO PRACTICE

2.4.1 THE UNITED KINGDOM: THE BBC 27

2.4.2 THE UNITED STATES: PBS

2.4.3 Other PSB MOdELS IN TAIWAN'S NEIGHBOURHOOD 32

2.4.3.1 Japan: NHK 
2.4.3.2 South Korea: KBS and MBC 34

2.5 THREATS AND OPPORTUNITIES FACING PSB 36

2.5.1 The DeCLINE AND FALL OF PSB 36

2.5.2 Challenges for PSB IntROduction into Transitional Countries 38

2.6 SUMMARY 39

CHAPTER 3 TRANSITIONAL TAIWAN AND ITS BROADCASTING LANDSCAPE

$\begin{array}{llr}3.1 & \text { National Profile of taiwan } & 41\end{array}$

3.2 EXTERNAL AND INTERNAL TENSIONS ON TAIWAN 443

\begin{tabular}{lr}
3.3 & BRIEF OVERVIEW OF TAIWAN'S HISTORY \\
\hline
\end{tabular}

$\begin{array}{llr}3.3 .1 & \text { ECONOMIC ASPECT } & 47\end{array}$

$\begin{array}{llr}\text { 3.3.2 } & \text { POlitical ASPECt } & 48\end{array}$

$\begin{array}{lr}\text { 3.3.3 Culture AND SOCIAL ASPECt } & 49\end{array}$

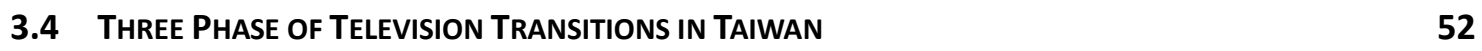

3.4.1 TELEVISION WITHIN FRONTIERS: SCARCITY (1949-1987) 55

3.4.2 TELEVISION WITHOUT FRONTIERS: CHOICES (1988-1999) 57

3.4.3 TELEVISION BEYOND FRONTIERS: ABUNDANCE (1999- TO DATE) 63

$\begin{array}{lll}3.5 & \text { THE POLITICS OF REPRESENTATION: SYSTEM FAILURES } & 68\end{array}$

CHAPTER 4 RESEARCH OBJECTS, RESEARCH QUESTIONS AND METHODOLOGY 71

4.1 CASE Description: Two WaVes Of the PSB Demands 71

4.1.1 THE INCEPTION OF PTS (1980-1997)

4.1.2 CREATION AND DISILLUSION WITH PTS (1998-1999) 76

4.1.3 FORMULATION OF PLANS FOR PSB EXPANSION (2000-2006) 77

4.1.4 THE IMPLEMENTATION OF THE NEW PSB SYSTEM (2006-TO DATE) 83

4.2 RESEARCH AIMS AND QUESTIONS

4.3 Research METHOdS

CHAPTER 5 CONSTRUCTIONS OF PSB DEBATE: COMPETITIONS FOR CLAIM-MAKERS 95

$\begin{array}{ll}5.1 & 96\end{array}$

\begin{tabular}{lr}
5.2 & LEgISLATORS' CONSTRUCTIONS \\
\hline
\end{tabular}

$\begin{array}{llr}\text { 5.2.1 } & \text { PSB IN THE BLUE-GREeN DIVIDE } & 98\end{array}$

$\begin{array}{llr}\text { 5.2.2 } & \text { PSB AS A GoVernMENT MOUTHPIECE } & 99\end{array}$

$\begin{array}{lr}\text { 5.2.3 PSB AS A POLITICAL PLOT } & 101\end{array}$

$\begin{array}{ll}\text { 5.2.4 PSB AS A COMPROMISED RESULT } & 103\end{array}$

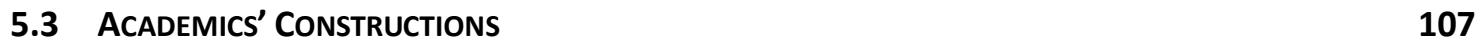

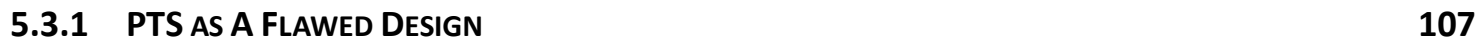

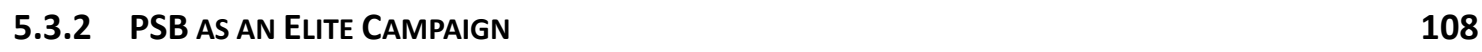

$\begin{array}{lrr}\text { 5.3.3 } & \text { PSB AS A SOCIAL MOVEMENT } & 109\end{array}$

$\begin{array}{lr}\text { 5.3.4 PSB AS A LONG-TERM AND BOTTOM-UP REFORM } & 110\end{array}$

$\begin{array}{lr}5.4 & 112\end{array}$

$\begin{array}{llr}\text { 5.4.1 A PSB WITH INTERNAL TENSIONS } & 113\end{array}$

$\begin{array}{ll}\text { 5.4.2 } & 116\end{array}$

$\begin{array}{ll}\text { 5.4.3 A PSB WITH INSUFFICIENT FUNDING } & 118\end{array}$

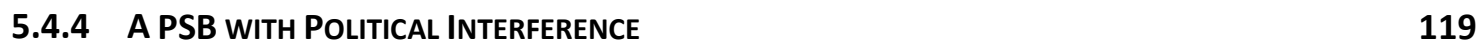

$\begin{array}{lr}5.5 & 121\end{array}$ 
$\begin{array}{ll}\text { 6.1 Analytical Method of the Content Analysis } & 124\end{array}$

$\begin{array}{ll}\text { 6.1.1 SAMPLING } & 125\end{array}$

6.1.2 METHOD OF SAMPLING 126

6.1.3 Construction of the Coding Categories 127

$\begin{array}{ll}\text { 6.1.4 INTER-CODER RELIABILITY } & 127\end{array}$

6.2 Findings: The PATteRn OF Press CoVerage 128

6.2.1 Five Distinguishing Peaks 128

6.2.2 LOCATION AND GENRE

$\begin{array}{ll}\text { 6.2.3 NEWS SOURCES } & 140\end{array}$

6.2.3.1 Sources Cited in News Reports 140

$\begin{array}{ll}\text { 6.2.3.2 The Absence of the Public } & 143\end{array}$

6.2.3.3 Significant Activist-Academics 143

$\begin{array}{ll}\text { 6.2.4 MaIN TOPICS AND SUB-THEMES } & 145\end{array}$

$\begin{array}{lll}6.3 & \text { SUMMARY } & 148\end{array}$

CHAPTER 7 MAINSTREAM NEWSPAPERS AS CLAIM MAKERS $\quad 150$

$\begin{array}{lll}\text { 7.1 Political Biases of NewSPaPers } & 151\end{array}$

$\begin{array}{lll}\text { 7.1.1 NEWSPAPERS RESTRICTION } & 151\end{array}$

7.1.2 Patron-Client Relationship 152

$\begin{array}{lll}7.2 & \text { VALANCE OF EDITORIAL } & 154\end{array}$

$\begin{array}{lll}\text { 7.2.1 The Main CONCERN OF THe Editorials } & 154\end{array}$

$\begin{array}{ll}\text { 7.2.2 Chronological Distribution } & 156\end{array}$

$\begin{array}{ll}7.3 & 159\end{array}$

$\begin{array}{lll}\text { 7.3.1 THE PROPOSAL PHASE } & 160\end{array}$

$\begin{array}{lll}\text { 7.3.2 THE POLICY PHASE } & 161\end{array}$

$\begin{array}{ll}\text { 7.3.3 The Programme PhaSe } & 166\end{array}$

$\begin{array}{lll}7.4 & \text { SUMMARY } & 167\end{array}$

CHAPTER 8 REPRESENTING 'PUBLIC' OPINION: LETTERS TO THE EDITOR

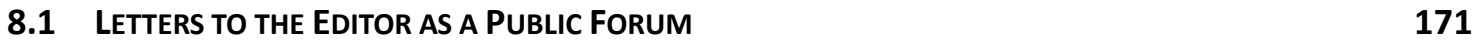

8.2 Principles for the Examination OF LetTERS 172

$\begin{array}{lll}\text { 8.2.1 CODING CRITERIA For LETTERS } & 173\end{array}$

8.2.2 INTER-CODER RELIABILITY (REASONS OF WRITING LETTERS)

$\begin{array}{lll}8.3 & \text { FABRICS OF THE SAMPLED LETTERS } & 174\end{array}$

$\begin{array}{lll}\text { 8.3.1 INTERVENTIONS IN THE LeTtER SECTION } & \mathbf{1 7 5}\end{array}$

$\begin{array}{ll}\text { 8.3.2 The MAIN CONCERNS EXPRESSED IN THE LETTERS } & 176\end{array}$

8.3.3 THE REASONS FOR WRITING

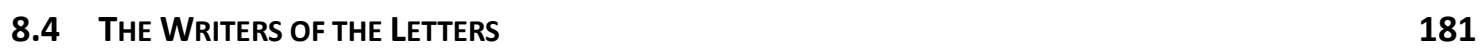

$\begin{array}{lll}\text { 8.4.1 SELECTIONS OF WRITERS } & 181\end{array}$

$\begin{array}{ll}\text { 8.4.2 FORMATION OF 'PUBLIC OPINION' } & 184\end{array}$

8.5 StRINGS OF LETTERS: DIALOGUE OR MONOLOGUE?

$\begin{array}{lll}\text { 8.5.1 CONFIGURATION OF LETTER DEBATE } & 185\end{array}$

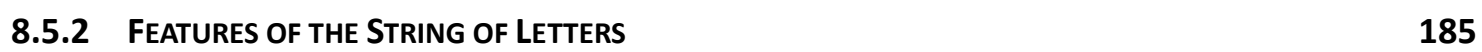

$\begin{array}{lll}8.6 & \text { SUMMARY } & 190\end{array}$ 
9.1 Three Key Dimensions OF TAIWAN's PSB 193

$\begin{array}{ll}9.2 & 195 \\ 9 & \end{array}$

$\begin{array}{ll}\text { 9.3 Conceptual and Structural Confusions } & 197\end{array}$

9.4 TRANSPLANTING A WeStern TREe INTO AN EASTERN LAND 198

9.4.1 A REVERSE DEVELOPMENT FROM OtHER ICONIC PUBLIC BROADCASTERS 199

9.4.2 Paternalistic Characteristics 199

$\begin{array}{ll}\text { 9.4.3 A TOP-DOWN APPROACH } & 199\end{array}$

$\begin{array}{ll}\text { 9.4.4 AN UNREALISTIC COMPRESSED TRANSPLANT } & 201\end{array}$

9.5 REMARKS $\quad 201$

9.6 RESEARCH LIMITATIONS AND SUgGeStions 202

APPENDIX 1: THE DETAILS OF INTERVIEWEES AND INTERVIEW DATE $\quad 204$

APPENDIX 2: THE INFORMATION SHEET FOR INTERVIEWEES $\quad 206$

APPENDIX 3: THE QUESTIONS IN THE INTERVIEWS $\quad 210$

APPENDIX 4: CODING MANUAL OF PRESS CONTENT ANALYSIS

APPENDIX 5: CODING MANUAL FOR REASONS OF WRITING LETTERS 


\section{List of Tables}

Table 3.1. Basic Data of Taiwan 43

Table 3.2. Key Events in Taiwan's History (1624-2011) 45

Table 3.3. Media Profile of Taiwan 53

Table 3.4. Landmark Dates in Taiwan Television History 54

Table 3.5. Three television stations and their shares distribution (1962-1986) 56

Table 3.6. Numbers of Broadcasters in Taiwan $\quad 61$

Table 3.7. Television Channels Market Share 2003-2004 (by genre) 65

Table 3.8. The Ratio of languages on broadcasting programming 66

Table 4.1. Chronological Overview of PSB in Taiwan 74

Table 4.2. Channels of TBS 84

Table 4.3. Members of TBS and Their Financial Sources 85

Table 4.4. Studies of PSB in Taiwan: 1998-2008 89

Table 6.1. Sample Size of Press Content Analysis 127

Table 6.2. Distribution of Coverage by location 139

Table 6.3. Distribution of coverage by Genre $\quad 139$

Table 6.4. Actors in the press representation $\quad 142$

Table 6.5. Actors in Readers' Letters $\quad 144$

Table 6.6. Topic of Items $\quad 145$

Table 6.7. Themes in Coverage $\quad 147$

Table 7.1. Topic of Editorial $\quad 155$

Table 7.2. Frequencies of Editorials from Three Press over Time 157

Table 8.1. Frequencies of Letters to the Editor from Three Press 175

Table 8.2. The Main Topic Addressed in the Letters 177

$\begin{array}{ll}\text { Table 8.3. Reasons of Writing Letters } & 178\end{array}$

Table 8.4. Reasons For writing Letters in Different Newspapers $\quad 179$

Table 8.5. Variation of Reasons over Time 180

Table 8.6. Composition of the Letter Writers in the Three Newspapers 182

\section{List of Figures}

Figure 3.1. Map of Taiwan 42

Figure 6.1. Comparison of news coverage on three main newspapers 129 


\section{List of Abbreviations}

$\begin{array}{ll}\text { BBC } & \text { British Broadcasting Corporation } \\ \text { BRU } & \text { Broadcasting Research Unit } \\ \text { CCTV } & \text { Campaign for Citizens' TV } \\ \text { CHA } & \text { Council for Hakka Affairs } \\ \text { CMR } & \text { the Campaign for Media Reform } \\ \text { CT } & \text { China Times } \\ \text { CTS } & \text { Chinese Television System } \\ \text { CTV } & \text { China Television Company } \\ \text { DGSTTI } & \text { The Statute Regarding the Disposition of Government } \\ & \text { Shareholdings in the Terrestrial Television Industry } \\ \text { DPP } & \text { Democratic Progressive Party } \\ \text { GIO } & \text { The Government Information Office } \\ \text { HakkaTV } & \text { Hakka Television } \\ \text { ITV } & \text { Indigenous Television } \\ \text { KMT } & \text { Kuomintang / the Chinese Nationalist Party } \\ \text { LT } & \text { Liberty Times } \\ \text { NCC } & \text { National Communications Commission } \\ \text { OCAC } & \text { Compatriot Affairs Commission } \\ \text { PFP } & \text { People First Party } \\ \text { PSB } & \text { Public Service Broadcasting } \\ \text { PTL } & \text { Public Television Law } \\ \text { PTOC } & \text { Public Television Organising Committee } \\ \text { PTSF } & \text { Public Television Service Foundation } \\ \text { PTS } & \text { Public Television Station } \\ \text { TBS } & \text { Taiwan Broadcasting System } \\ \text { TMTV } & \text { Taiwan Macroview Television } \\ \text { TTV } & \text { Taiwan Television Enterprise } \\ \text { UDN } & \text { United Daily News } \\ \text { UNESCO } & \text { United Nations Education, Scientific and Cultural Organisation } \\ & \end{array}$




\section{Chapter 1}

\section{Introduction}

In Mar 2011, a devastating earthquake struck Japan and then caused a massive tsunami and a nuclear power-plant's meltdown. The disasters immediately attracted intense media attention across the world, including in one of Japan's closest neighbours, Taiwan.

While media outlets across the globe resonated with the deadly earthquake and its aftermath, the dramatic ways the Taiwanese media represented the disasters soon triggered a series of criticisms about unnecessary doses of sensational and panicking exaggerations. For instance, the word 'doomsday' flashed across the headlines; 'flee' was used in screaming headlines, instead of a neutral word 'evacuate', to describe how Japanese moved out from the damaged areas (Taipei Times, 13/03/2011, p. 8). Another example was a rumour that a Japanese pornography actress might be caught in the tsunami which became a prominent breaking news item (Je, Apple Daily, 16/03/2011, p. A23). Other dramatic features included the mix editing of actuality footage with devastating scenes from Hollywood films, and frantic voiceovers from reporters and news anchors. Critics complained that the media frenzy brought 'nothing but unnecessary agitation to viewers' (Taipei Times, 14/03/2011, p. 8).

Since the channel of Japan's public service broadcaster, NHK, is also accessible in Taiwan's television system, in comparison with local media, many viewers soon discovered that NHK projected a much less sensational coverage 
of these disasters and provided more useful information to help viewers' to a better understanding of the crisis. As one press editorial pointed out, in contrast to the professional performance of NHK, 'the screaming catastrophic disaster show' orchestrated by Taiwan's media gains themselves sneers (United Evening News, 17/03/2011, p. A2). Another editorial noted that 'we surely have a thing or two to learn from Japan when NHK provided better quality to serve their audience and to gain the respect the media deserves as the fourth estate' (Taipei Times, 14/03/2011, p. 8). Similar sentiments from the general public were also published in the section of letters to editor. For example, 'Even though I speak no Japanese, I prefer watching NHK rather than Taiwan's local media' (Hong, Liberty Times, 13/03/2011, p. A15; Young, United Daily News, 16/03/2011, p. A15).

\subsection{System Failure of Media Representation}

Surely it is debatable whether NHK's close ties to the Japanese government may have prevented it from revealing certain inconvenient truths in relation to the disaster (Huang, 2011). However, the specific criticisms of the performance of Taiwan's media were not new at all. Again, this incident raised alarm-bells and exposed the old problems in Taiwan's media environment where audience ratings are the predominant concern. It not only exposed the way commercialisation has trivialised and sensationalised media content, but also the extent to which commercial pressures have shaped a television system driven by viewer ratings and the power of advertisers. Under pressures from uncertainty of funding as audiences and advertising fragments, the system relegates fundamental principles of media professionalism a long way behind commercial considerations and consumers' choices. By doing so, it fails to address public affairs and the full range of issues of contemporary society.

To address the consequences of media commercialisation, mirrored again by the Japan earthquake, some media professionals pointed to the potential capacity of the fledgling (Public Service Broadcasting) PSB system in Taiwan but also indicated the challenges preventing PSB from providing a corrective influence in the media landscape. Drawing comparisons with the BBC in the UK and NHK in Japan, a veteran journalist He Rong-xing raised the key question of whether Taiwan's PSB could raise its standard to match NHK's. He argued that 
'the main reason why the PSB group in Taiwan have no power to balance the twisted commercial market is mainly because of the lack of a long-term and deliberate media policy' (He, China Times, 16/3/2011, p. A15). Echoing this view, He Guo-hua, a public broadcaster and the manager in the News division, indicated that 'different extents of financial supports to the two public service broadcasters in Japan and Taiwan led to different results in their influences (He, Apple Daily, 17/3/2011: A23). Both these views underline the political and economic difficulties facing PSB and its uncertain future in Taiwan.

The introduction of PSB in Taiwan dates back to 1998 when the Public Television Station (PTS), a free-to air television station, was established. Its finance mainly relied on government subsidies. Unlike many Western contexts, where established PSB services have declined due to the impact of market forces, the plan to introduce a similar service in Taiwan was motivated by a wish to ameliorate the effects of 'overwhelming market forces'. The birth of Taiwan's PSB can therefore be viewed as a birth pushed by 'the concern over overwhelming market forces (Chin, 1997, p. 90)'.

Charged with a mission to introduce quality television programming, the Public Television Station (PTS) never managed to achieve more than a minority audience in the highly commercialized media landscape and it was clear that 'the private media will continue to dominate' (Chin, 1997, p. 91). In 2006, a PSB expansion project led to a merger of PTS with another national terrestrial television station and three other television channels to establish an umbrella broadcasting organisation named the Taiwan Broadcasting System (TBS).

As was observed above, it can be easily argued that the introduction of PSB was motivated by a desire to alleviate the symptoms of the overwhelming commercialism in Taiwan's media landscape, one of key reasons why PSB is defended in other countries around the world. However, in Taiwan's social context, to explain the inception of the PSB solely in terms of concerns over commercialism represents only half of the picture. The challenges facing Taiwan's young PSB must also be understood in Taiwan's political context which situates it in an uncharacteristic PSB position. It is to these matters that the discussion now turns. 


\subsection{Media Reform in a Blue-Green Political Divide}

Taiwan's rapid industrialization during the 1960s and 1970s, combined with the democratic revolution that began with the lifting of martial law in 1987, were of deep historical importance to this transitional society. In the following decade Taiwan's 'political miracle' matched the earlier 'economic miracle' by creating a vibrant liberal democracy completing with competitive multi-party elections.

The establishment of PTS and the subsequent expansion to the TBS system can therefore also be seen as one of the achievements that marked the emergence of a democratic society, a conclusion reinforced by the fact that PSB expansion coincided with an unprecedented period of political transition with the electoral defeat in 2000 of the Kuomintang (KMT) party, which had ruled Taiwan since the end of World war II, and its replacement in government by the main opposition party, the Democratic Progressive Party (DPP).

During the KMT's long tenure in power, despite the commercialization of the media market, national terrestrial television stations were still controlled predominantly by the KMT party-state. The DPP strongly protested this KMT control, as did many media academics, commentators, and social activists. The huge change in the political climate created by the DPP's electoral victory in 2000 ignited 'a new hope for social activists and media academics to free state-run television' from political control and establish a system that was closer to the model of 'relative autonomy' that characterised public service broadcasting elsewhere (Feng et al, 2002).

The significance of this dispute about the degree of state control of broadcasting was also rooted in the profound differences in both political parties' vision of the future and autonomy of the Taiwanese nation. This conflict was between one side supporting eventual reunification with China and the other one envisaging Taiwanese independence from the mainland China.

In order to fully understand the PSB expansion in Taiwan, this antagonistic and polarised political divide needs to be considered. The political divide is a spectrum between 'reunification with China' and 'Taiwan independence'. On the pro-Taiwan Independence side the political coalition led by the DPP came to be known as 'Green' force because this is the predominant colour of the DPP flag while the pro-Chinese Reunification side, led by the KMT, came to be referred to as the 'Blue' force due to the political colours of the party. 
This 'Blue-Green divide' has been identified as one of the most salient issues in Taiwan's politics (Hughes, 2011; Fell, 2011; Rigger, 2011). As Fell observes severe polarisation around this central issue occurred during the second half of the 2000s and 'paralysed the polity over important issues (Fell, 2011, p. 93)'.

On the issue of the democratisation of terrestrial television, a number of ideas had been put forward during the KMT's tenure in power suggesting possible ways that national television could be improved, but most of them were ignored by then KMT government. Following the new hope to free state-run television' from political influence ignited by the 2000 political change, two of the most popular proposals in the pursuit of the democratisation of terrestrial televisions resurfaced. The first, which was very much in line with the general shift in economic policy away from the previous heavy reliance on state management and toward a more market driven system, advocated privatising the state-owned television channels. This proposal was strongly supported by the KMT which had just lost its power. The alternative, which went against the grain of the market-led thinking, proposed transforming the state-owned television asset into a new, extended, public service broadcasting system. This solution, which was endorsed by numerous media academics and social activists, had one of the promises made by the DPP in their election campaign. After a period of debate and political struggle which will be examined in detail in subsequent chapters, this option outran the privatisation plan and became the preferred policy. In this proposal, the key concept, in mandarin Chinese, is named 'Gong Gong Hua' (公共化). This term 'Gong Gong Hua' conceptually means a transformation of the state-owned terrestrial televisions to a corporation in the public sector under the authority of the state. Specifically, this entails all political parties, the state, and the military relinquishing all control over terrestrial television and ceding its administration and operation to an independent corporation in the public sector. This proposal was seen by its advocates as a way of creating space within the broadcasting landscape for a greater degree of freedom and independence in the pursuit of the ideals of public service. In contrast with the privatisation plan, the 'Gong Gong Hua' transformation also frees the television channels from commercial pressures by providing government financial support. 


\subsection{Controversial PSB debate in Taiwan}

During the KMT's three decade long rule before 2000, the KMT party-state's actions had the effect of uniting the various and diverse groups standing on the opposite site, including the main opposition party DPP and many social movement camps from different corners. After the DPP defeated the KMT and began to operate government for the first time, the redistribution of power soon became a problem. In the process of power restructuring, idealists often became the victims of realpolitik. The 'Gong Gong Hua' proposal is one example. As the DPP government's resolve to implement PSB expansion in this form dwindled, so did the chances of a healthy configuration of the PSB establishment. In 2002, media academics who strongly endorsed the 'Gong Gong Hua' held a furious protest to protest the DPP government's tardiness in implementing its promise. This conflict inside the ranks of the former alliance between the DPP and social activists attracted a lot of media attention, such as 'Media scholars who offer endorsement for DPP now face ordeal (China Times, 24/9/2002, p. 13)', 'Media academics say goodbye to DPP President' (United Daily News, 11/10/2002, p.4), 'Scholars declare a return to social movements (China Times, 11/10/2002, p. 6)'.

Informed by different mixtures of partisan interests, commercial profits, or conceptions of the public good, interpretations of 'Gong Gong Hua' varied according to the positions the key players occupied in the debate. The divergent versions of 'Gong Gong Hua' held by government, political actors, social activists and media academics soon led to many disagreements, especially when it came to concrete practice and policy implementation.

At the beginning of 2006, debates over the 'Gong Gong Hua' entered a new chapter when the passage of 'the statute regarding the disposition of government shareholdings in the terrestrial television' established the institutional form that PSB expansion would take. The proposal was to merge the existing PTS with one other state-owned terrestrial television channel CTS (Chinese Television System), together with two ethnic and one overseas channels fund by government.

This new consolidated TBS grouping held out the prospect of a public service system with sufficient critical mass to make a noticeable countervailing difference to the competitive media landscape. The increasing power and 
potential social influence of TBS however inevitably made it a political target and prompted partisan competition over the leadership of this new broadcasting group.

Throughout the various phases of the development of PSB policy, from inception, to implementation and concrete experience, decisions made behind closed doors by key players had periodically caught press attention. In 2004, a controversial appointment fuelled disillusion with the DDP government among PSB advocates. Hsia Chiang, an actress famous for her ties with the DPP and her close friendship with the (then) president's family, was appointed as CEO of CTS by the DPP government. The appointment was widely viewed as a return to the familiar KMT tactic of exercising control by gerrymandering key appointments in media. Chiang's appointment kicked up quite a stir in media circles because it was believed to be motivated by partisan political expedience rather than being a decision based on proven ability to do the job (Taipei Times, $25 / 06 / 2004$, p 2). One of the reasons this appointment proved so controversial was that Chiang had stated that she would ban soap operas imported from China. This could have been interpreted as a move designed to provide more opportunities for local production but it was widely taken as evidence of her strong allegiance to the stance of the DPP on Taiwanese independence. Some critics claimed that the DPP government had not been slow to learn tricks from the KMT in using state financed broadcasting as a means of furthering its own political objectives. For instance, 'DPP's media manipulation even worse than the old KMT' (United Daily News, 12/07/2004, p. 4).

In 2008 the political struggle inside the TBS group reached a new peak when the KMT recaptured the presidency. Soon after returning to power, the KMT legislative caucus, Lin Yi-shih, first froze the budget for PTS, and then came up with a proposal that all programme budgets should be reviewed and approved in advance by the regulator, the Government Information Office (GIO), in order to avoid unnecessary waste of public money (Taipei Times, 13/12/2008, p. 3). Critics claimed that these actions were aimed at using the budget reviews to threaten the independence of the PSB, and attracted headlines such as 'Auditing or intervening? (Liberty Times, 20/12/2008, p. 4)'. Media scholars asserted that these changes would soon 'destroy the PSB's core value of being independent from any kind of political interference (Tang \& Jian, 2008, p. 8)'. 
The KMT legislative caucus, Lin Yi-shih, also suggested increasing the number of directors on the board of the PSB group, which was a move that soon invited a huge amount of criticism, expressed in headlines such as 'Do parties, state, and military really withdraw their control from the media?' (China Times, 14/12/2008, p. 11), 'Media Scholars moan Death of Democracy' (Liberty Times, 19/12/2008, p. 2).

Despite this vocal opposition an amendment was quickly passed by the KMT dominated legislature in 2009 to install eight extra directors on the TBS board. A renowned political critic, Lin Cho-shui, fired a warning shot in a letter published in the Liberty Times in which he wrote: 'President Ma's Army invades the TBS at stormy night (Lin, 23/8/2009, p. A15)'.

After the arrival of the new directors, the board soon split into rival factions over the issue of the chairmanship. The acting chairman Cheng Tung-liao and a director on the other side, Chen Shih-min, both wrote letters to mainstream newspapers to justify their actions and invite public support. The power struggle reached another new peak when the directors on both sides filed lawsuits to prevent each other from exercising the right to execute in the boardroom. The lawsuit fight paralysed the board since its consequence was that 'only five out of the 21 directors left in the board can legally execute their positions' (Taipei Times, 28/04/2010, p. 3). Subsequently, the Chairman Tung-liao Cheng and the CEO Hsien-hsien Feng, who had been accused of being 'loyal DPP warriors' by the KMT (United Daily News, 19/12/2008, p.10), were edged out and stepped down in a reshuffle of personnel.

Although these accelerating conflicts exposed the continuing undercurrent of political struggle behind the closed doors of the boardroom, the debates and disputes surrounding the PSB group appeared in the media only fragmentally and scattered overtime. As a consequence, it was hard for the general public to piece together what was really happening in the process of PSB expansion, especially when different mainstream newspapers, with their attendant political biases, produced polarised interpretations of the same incidents and offered different versions of the same events.

The lack of public engagement in the PSB system was one of concerns voiced by a former CEO of the PTS and TBS, Hu Yuan-Hui (2007, p. 207) when he discussed the challenges facing Taiwan's PSB. From his experience of 
being the BBC's Director-General, Mark Thompson, has argued that PSB has to be a 'conscious civic choice and that 'any country that wants to develop a PSB tradition needs to begin to think about how to develop 'widespread public support' (Thompson, 2006, p.4). It was precisely, the level of public debate necessary to foster public support that was conspicuously absent in Taiwan.

Starting from the tension between 'rich media, poor democracy' highlighted in Robert McChesney's resonant phrase (McChesney, 2000), this thesis examines how competing views of PSB, and the policy making process that led to its eventual institutionalisation, have been constructed in mediated debates in this very young democracy. This thesis examines the Taiwanese case as an instance of the triangular interactions between market, state and civil society drawing particularly on the critical political economy perspective on inquiry and conceptualisation. Murdock \& Golding (2000) note that critical political economy differs from mainstream economics in four main respects. It is: 'holistic', 'historical', centrally concerned with 'the balance between capitalist enterprise and public intervention', and most importantly, goes beyond technical issues of efficiency to engage with 'basic moral questions of justice, equity and public good' (Murdock \& Golding, 2000, p. 61). Work within this tradition has paid particular attention to the shifting relations between states and markets in structuring the operating environment for media in democratic societies. Furthermore, this perspective focuses on the limitations of commercial media in providing full resources for citizenship, and the role of government in addressing 'market failures' through regulation and financial support for public communications initiatives. In recent years the balance struck in the post war period has been substantially tipped in favour of private enterprise by the processes of marketisation. In this light, Taiwan's case, pushing against this grain of marketization, offers an important example of the tensions around this process.

This thesis firstly questions the widely held belief that the commercialisation of the media necessarily leads to democratization, that 'free' markets foster free expression, adopts a political economy approach to examine the reasons for the emergence of PSB in an over-commercialised media landscape, and details the debates surrounding the formation of policy around PSB's institutionalisation paying particular attention to how PSB expansion has been 
social defined, and by whom.

\subsection{A Sequenced Overview of Thesis Structure}

This thesis is composed of 9 chapters. Following this introductory chapter, the second chapter contextualises this present study within general debates around the contested concept of public service broadcasting and its relation to ideals of the public sphere and outlines several conceptual and practical PSB models around the world that inform this study.

The third chapter details the contextual background to the research presented here emphasising that Taiwan is a transitional society politically, economically and culturally, and explores the extent to which the commercialised media system can be said to have failed to provide the cultural resources required for informed and engaged citizenship in an emerging democratic polity.

The fourth chapter traces the history of Taiwanese PSB and the main issues that have attended different phases of its development and then outlines the central research questions tackled in this thesis and the research methods employed to address them.

The fifth chapter draws on interview with decision makers and key players involved in PSB expansion documenting their differing attitudes towards the process and the ways they attempted to construct the debate. This chapter intends to illustrate boundaries of inclusion and exclusion by investigating the clash of claims that stem from differences in the interests and priorities of different groups.

Following this mapping of the competing constructions of the various players, the sixth chapter charts the public debate around PSB on the basis of a content analysis of press representations. Taking the three leading national daily Taiwanese newspapers, with their contrasting political allegiances, as key public channels of information and argument, it presents a detailed analysis of similarities and differences in their patterns of coverage.

Building on this general overview of press representation, the seventh chapter is the first of two that deal with the detailed ways in which debates around PSB expansion, and the contending positions in play, were afforded or denied explicit platforms in the three newspapers. 
Chapter seven focuses on the way press editorials interpret 'popular' themes, in relation to their own political stance or bias, to enhance the political arguments. In the eighth chapter the focus turns to letters to the editor and the way the press presents itself as providing a 'public forum', offering opportunities for 'ordinary ' citizens to voice their opinions and reach a national audience. The analysis interrogates this claim and attempts to identify reasons why some voices resonated more loudly than others in this mediated 'public opinion forum' orchestrated by editors.

The ninth and final chapter, offers overall reflections on the study and the career of Public Service Broadcasting in Taiwan ,exploring how power operated to shape the course of PSB expansion - how it was deployed, enacted, and what the outcomes and consequences were, and evaluating to what extent the PSB experiment has succeeded in Taiwan. 


\section{Chapter 2}

\section{Public Service Broadcasting: A Contested Concept}

This chapter firstly explores the ways in which experiences of other public service broadcasters around the world were referenced in Taiwan's PSB expansion. Then the second section traces the roots of the idea of Habermasian public sphere and examines its relationship with the institutions of PSB. The third section elaborates on the definitions and principles of PSB, reviewing the founding notions of John Reith, the first director-general of the British Broadcasting Corporation from 1927 to 1938, and then moving on to more recent elaborations developed in different academic discussions and policy documents. The fourth section examines the way that the theoretical concepts underling PSB has been put into practice, further investigating selected models and highlights the features of particular relevance to the expansion of PSB in Taiwan.

The purpose of this chapter is firstly to discuss the extent to which Habermas' idea of the public sphere fits the case of public service broadcasting (PSB), and secondly to explore the way PSB presents itself as acting on behalf of the formation of public opinion. These aims require us not only to revisit fundamental theoretical concepts, but also to review the practical organisation of PSB in relevant contexts in order to assess the political, social and cultural problems posed by different ways of institutionalising its basic ideals.

This chapter concludes with a discussion of the challenges and opportunities now facing PSB and the role it plays in the empowerment of an informed and active citizenry. 


\subsection{Significance of British Model in Taiwan's PSB Expansion}

The PSB expansion was introduced in Taiwan as a key to the solution for existing problems as well as the future of Taiwan's media landscape.

As was briefly mentioned in Chapter 1, actually the initial practice of PSB concept in Taiwan dates back to 1998 when the Public Television Station (PTS) was established under the demands for PSB which emerged in the mid-1990s. However, charged with a mission to provide quality television programming, this initiative never managed to achieve more than a minority presence in the commercialized media landscape.

Similar to the model of the PBS in the US, the function of the PTS was 'to provide that programming that was unprofitable for the commercial broadcasters to produce' (McChesney, 1999, p. 247). Compared with other existing commercial media, PTS was too late for its entry and too small to compete with its commercial competitors in Taiwan. For instance, the usually less than 1 percent of the audience share of the PTS (PTS, 2001) was one of salient examples to see its minority role in the media environment and its questionable claim to be a national broadcaster. A significant figure of PSB advocate, Feng Chien-san (馮建三), argued that this very PTS is not a real public broadcasting since the PTS is only to compensate for the inadequacy of commercial television. In Feng's view, a real PSB should function as a mainstream role in the media environment which can have real impact to alleviate the symptoms of the overwhelming commercial media and political forces (Feng, 1999).

With huge disappointments with the marginal role of the PTS and the remaining overwhelming commercial broadcasting, in 1999 a group of critical media academics began to explore more effective ways to achieve substantial media transformation. A second wave of PSB demands gathered momentum when a policy window was opened by the unprecedented political transition in the 2000 presidential election.

This window opened the way for renewed political struggles, social movement activity and academic debate, centred around two competing proposals for reforming the terrestrial television stations, with advocates of 
privatisation on the one side and supporters of PSB-oriented proposal on the other.

Against the privatisation ideas, the PSB-oriented proposal proposed transforming the state-owned television asset into a new, extended, public service broadcasting system. In this proposal, the key idea conceptually means a transformation of the state-owned terrestrial televisions to a corporation in the public sector. Specifically, the proposal entailed all political parties, the state, and the military relinquishing all control over terrestrial television and ceding its administration and operation to an independent corporation in the public sector.

This proposal was seen by its advocates as a way of creating space within the broadcasting landscape for a greater degree of freedom and independence in the pursuit of the ideals of public service. This key idea mainly generated from the ideal model of the BBC in the UK: 'a national, popular, and pluralistic broadcasting' (Scannell, 1996, pp. 25-31).

\subsubsection{A dominant PSB in media landscape}

The British model is always a significant case in PSB debate since the BBC has been towering in the PSB history from the very beginning where the concept of public service broadcasting emerged in Western Europe after World War II (Blumler, 1992) and found it most influential early institutional expression when the BBC was established in 1927 and started its regular television broadcasting in 1936 . The reasons why the British model was a significant model referenced in the second wave of the PSB advocate in Taiwan were not only because its long-term track record in the PSB history, but also the mainstream and dominant role of the $\mathrm{BBC}$ in the UK which reflected why Taiwan's PTS failed to serve as a PSB. In comparison, the British model provided a living example and prime solution to the failure of the PTS with its marginal role in Taiwan's media landscape.

As was mentioned earlier, most of the key PSB advocates, such as Feng, believed that only a mainstream PSB can really deliver what the PSB promises to the media environment and achieve substantial media transformation in Taiwan. 


\subsubsection{Professional background of key PSB advocate}

Another reason why the British model was significant in Taiwan's PSB expansion is that, among the key advocates, some active media academics gained their PhD degree from the UK and had a particular understanding of the BBC model. For example, the key figure in the long-term PSB campaign, Feng Chien-san (馮建三), was awarded a PhD at Leicester University. Another key player, Wei Ti (魏玓), studied his PhD at Loughborough University. With their professional knowledge of the BBC, the ethos of British model was highlighted in the second wave of the Taiwan's PSB expansion (more details of their view will be addressed in Chapter 5 with interview data).

The PSB proposal, raised by the active academics to against the privatisation plan on the state television stations, was viewed as a more positive, tangible and democratic vision for change in Taiwan's broadcasting policy and practice to fix the flaws in the first PSB, PTS, which served as a marginal alternative to the commercial market (more details for the PSB development will be addressed in Chapter 4 with more detailed social and political context of Taiwan).

\subsubsection{Other relevant models in neighbourhood}

Apart from the two fundamental models in UK and US, in Taiwan's neighbourhood there are also two empirical examples from countries whose histories and cultures overlap with those of Taiwan: Japan and South Korea.

The PSB models in Japan and South Korea were often referenced in the Taiwan's PSB debate since the two countries, with the similar historical and cultural background, can provide examples of transformations from former state-owned televisions under military control to PSB.

Thus, the aims of the following sections are not only to revisit fundamental theoretical concepts, but also to review the practical organisation of PSB in relevant contexts to assess the political, social and cultural circumstances posed by different ways of institutionalising an ideal PSB.

\subsection{The Media as Public Sphere}

The relationship between the media and democracy has long been a significant 
research field in media studies since the improvement of democracy is viewed as one of the media's major functions (Garnham, 1990). Within broadcasting studies, Jürgen Habermas' key concept of the public sphere has been 'the most influential variant of this ideal' (Dahlgren, 1995; Murdock, 2005, p. 177) because the issues he addresses and the problems he poses seem to be fundamental for the study of modern societies and the contributory role of modern media (Scannell, 1984).

This section does not attempt to provide a definitive critical analysis of Habermas' work, but rather approaches his theoretical assumptions as a departure point to critically understand the role of PSB in democratic societies as 'providing a mechanism for the coming together of a public consensus' (Price 1995, p. 35). Two points of view taken from Habermas' work by Scannell (1984) are followed in this study as principles to observe the role of PSB: 'a historical approach to the formation of broadcasting's public sphere' and 'a concern with the rational character of communication in everyday actual contexts' (Scannell, 1984, p. 136).

\subsubsection{The Habermasian public sphere and the media}

The public sphere, in Habermas' work, is 'the realm of social life where the exchange of information and views on questions of common concern can "take place" when citizens, exercising the rights of assembly and association, gather as public bodies to discuss issues of the day, especially those of political concern' (Dahlgren, 1995, p. 7). Calhoun (1992) observes that 'the importance of the public sphere lies in its potential as a mode of societal integration' (Calhoun, 1992, p. 6).In Habermas' account, the original public sphere developed in face to face deliberations on public issues that took place in the coffee and chocolate houses that emerged in mid-seventeenth century London. With the complexity of modern society today, the public flow of information and debate has increasingly come to rely on the range of mass media which have come to supplement of information. As Murdock \& Golding (2005) indicate, for most people for most of the time the world is understood politically, economically and culturally primarily via media representations. With the result that the media 'play a pivotal role in organising the images and discourse through which people make sense of the world (Murdock \& Golding, 2005, p. 
60),' Dahlgren (1995) argues that the media 'have become the major institutions of the public sphere since the scale of modern society does not allow more than relatively small numbers of citizens to be physically co-present' (Dahlgren, 1995, pp. 7-8).

The contemporary public sphere then, is no longer limited to locations stratified by class or to media dependent on relatively high levels of literacy. The zone of public sphere has shifted to a dynamic space characterised by multiple forms of mediated public participation. However, since its technological base allows for the possibility of universal, inclusive and synchronous coverage, broadcasting has come to be seen as the pivot of the mediated public sphere.

Three virtues of the concept of the public sphere for rethinking the relationship between the media and democracy have been identified by Garnham (1992, pp. 361-362). The first is the focus on the indissoluble link between the institutions and practices of mass communication and the institutions and practices of democratic politics. The second is the emphasis on the necessary material resource base for any public sphere. And the third is the potential it offers to escape from the simple dichotomy of free market versus state control that dominates so much thinking about media policy.

Higgins further notes 'the public sphere emerges from a view of politics as a process of dialogue, and is meant to describe a platform for negotiating and reconciling competing interests, so that the formation of public policy is aided by the informed interventions of concerned citizens' (Higgins, 2008:27).

Some critics however have questioned the utility of the notion of the public sphere and pointed to its ambiguous status in Habermas' work, arguing that 'it appears both as a normative ideal to be strived for and as a manifestation of actual historical circumstances in early bourgeois Europe' (Dahlgren, 1995, p. 10).

Reviewing commentaries on Habermas' conception of the public sphere, mainly from Garnham (1992), Peters (1993), Fraser (1992) and Thompson (1990), Dahlgren outlines four analytic dimensions of the public sphere in media studies; 'media institutions, media representation, social structure and sociocultural interaction' (Dahlgren, 1995, p. 11).

The dimension of sociocultural interaction refers to both the inter-face between the media and citizens and non-mediated face-to-face encounters 
between citizens. The dimension of social structure points to factors which constitute the historical conditions and institutional background of the public sphere, such as patterns of social stratification and the power alignments rooted in economic, political and legal organisation.

The other two dimensions, media institutions and media representation, have generally received rather more attention in media studies and figure at the centre of policy debates. The dimension of media institutions covers media organisation, financing and regulation while the dimension of media representation focuses on patterns of media coverage. Each of these four dimensions offers an entry point for both theoretical and empirical inquiry into the public sphere and the four interlock with each other and constitute reciprocal conditions for one another (Dahlgren, 1995).

In particular, in discussing the dimension of media institutions, Dahlgren argues that 'the most explicit appropriation of Habermas' public sphere concept has been with in the British debates where it has been utilised as a platform from which to defend public service broadcasting' (1995, p. 13). Within this debate media critics have tended to associate public service broadcasting with the realisation of the public sphere and to view the commercial model of financing as a threat to it (Garnham, 1983; Scannell, 1989).

In the following section, the relationship between the public sphere and the public service broadcasting will be further discussed.

\subsubsection{The public sphere and PSB}

Over last decade, as supporters of commercial options have become more confident and vocal, the question of how far PSB, as currently organised, is able to embody the ideals the public sphere and serve as 'a means of the realisation of the public sphere' (Dahlgren, 1995) has been raised with increasing urgency. In attempting to identify how far PSB is able to form a forum of public consensus, Price (1995) argues, we need to pay particular attention to the various ways in which public-service entities are 'governed, financed, regulated and perceived' since these factors 'help determine, though hardly conclude, whether furthering the public sphere is an internalised civic and spiritual quest, or left to the margin, a hoped-for product of market interaction' (Price 1995, p. 36). 
According to Price (1995), the first key condition for the effective operation of PSB is how far it is able to achieve relative autonomy from the state. The function of this independence is 'to encourage and nourish the formation of a "public" that is the quintessential aspect of the public sphere' (Price 1995, p. 32). Price further points out that 'the keystone, often proclaimed but seldom perfectly achieved, is the development of a system that is immunised from direct government intervention, a refrain familiar as an element of Habermas' Ideal Speech Situation' (Price 1995, p. 36). As Raboy (1996, p. 9) argues, the government must see itself more 'as architect than as engineer'. 'The role of the state is to design and facilitate the functioning of a multifaceted national broadcasting system, rather than as the directive patron of a dedicated national broadcaster' (Raboy, 1996, p. 9). Thus, the questions of how to minimise influences from the government has been a key issue of policymaking and academic research.

Secondly, the mode of financing public broadcasting organisations is also a key determinant of PSB's ability to identify and nourish a public sphere (Price 1995, p. 34). Tracey (1998) breaks this point down in a simple way: 'in a public system, television producers acquire money to make programmes while in a commercial system they make programmes to acquire money' (Tracey, 1998, p. 18). Price (1995) notes that it is possible to have a PSB system which encourages the public sphere which is financed directly by the government through the Legislature, but he notes, taking the United States as an example that 'the direct financing of public broadcasting carries with its perils of interference' (Price 1995, p. 34). On the other hand, the major commercial financing model, advertising support, transforms the 'public' into 'audience' and installs the pursuit of the goal of maximising audiences rather than serving citizens at the centre of the system. It is against the background of the problems posed by these two models, that Price (1995), and other observers, argue that automatic funding devices are crucial to allow the relationship between broadcasting and its public to be largely unencumbered by political and market forces (Price 1995, p. 34).

The third, and arguable most important condition that allows PSB to nurture of mediated public sphere is the culture of the organisation since the way the ambitious goals of a broadcasting origination are stated and implanted in those 
who create its identity' has a crucial impact on the way staff view their role (Price 1995, p. 35). The defining identity of PSB has been viewed in various ways by different players in the PSB debate. For example, the commercial broadcaster Rupert Murdoch argues that 'populist television should be left to commercial stations and that public television should plug the gaps, delivering programmes that the market system does not' (Tracey, 1996, p. 159). In reply, PSB defenders hold that 'PSB should be seen as an instrument of social and cultural development, rather than as a marginal alternative service on the periphery of a vast cultural industry' (Raboy, 1996, p. 9).

The three determinants mentioned above all interact in complex ways with political and market forces. However, as Graham Murdock argues, 'the crucial choice is not, as many commentators suppose, between state licensing and control on the one side and minimally regulated market mechanisms on the other. It is between policies designed to reinvigorate public communication system which are relatively independent of both the state and the market, and policies which aim to marginalize or eradicate them' (Murdock, 1992, p. 18).

In answer to the question posed by critics of 'actually existing' public service broadcasting and enthusiasts of 'free' markets in representations as to 'why the future should be modelled on an institutional ideal that has so often failed to live up to its promises in the past', Murdock (1999) states that, 'restructured and re-imagined, public service broadcasting offers the most open, flexible and inclusive solution to the problem of underwriting the cultural rights of citizenship' (Murdock, 1999, p. 16).

Murdock has elaborated this argument by outlining 'four basic sets of cultural right' (Murdock, 1999, pp. 11-12). They can be summarised as follows:

1) Rights to information: citizens have rights of access to the relevant information about the conditions that structure their range of choices, and about the actions of significant social, political and economic actors, such as state agencies, the government, corporations, opposition parties and social movement;

2) Rights to experience: citizens have rights of access the diversity of representations of personal and social experience;

3) Rights to knowledge: citizens have rights of access to frameworks of 
interpretation that points to links, patterns and processes of changes, and suggests explanations which translate information and experience into knowledge;

4) Rights to participation: citizens have rights to speak about their own lives and aspirations in their own voice, and to picture the things that matter to them in ways they have chosen.

Seen in this light, the next section will address the definitions and principles of PSB by reviewing the notions of John Reith and more recent points of view offered by academics and policy documents.

\subsection{PSB as a Contested Concept}

The concept of public service broadcasting emerged in Western Europe after World War II (Blumler, 1992) and found it most influential early institutional expression when the British Broadcasting Corporation (BBC) was established in 1927 and started its regular television broadcasting in 1936. Although it is well known that broadcasting in Britain is based on the principle of public service, defining exactly what that means, can, on close inspection, prove 'elusive' (Scannell, 2000, p. 45). When the 1986 Peacock Committee in Britain, turned to the broadcasters for their interpretations of public service they remained unenlightened. Their report observed, 'we had some difficulty in obtaining an operational definition from broadcasters' (Peacock, 1986, p. 130, cited in Scannell, 1989, p. 135).

Market competitors have seized on the fuzziness of the concept to offer a revisionist definition that perfectly fits their own interests. Rupert Murdoch, for example, states that 'anybody who, within in the law of the land, provides a service which the public wants at a price it can afford is providing a public service' (quoted in Ellis, 1994, p. 1; cited in Raboy, 1996, p. 8). At the same time, if we look at the way the concept has been championed by its supporters we can identify some consistent and enduring themes.

\subsubsection{Definitions of PSB}

In his foundational definition of public service broadcasting, the first Director-General of the BBC, John Reith, indicated that it should have four facets (McDonnell, 1991, p. 1): 'First, it ought to be protected from commercial 
pressures. Second, it aims to serve the whole nation. Third, it should have a monopoly position. And, finally, it aims to provide a high standard of programmes'.

Reith also famously summarised the core purposes of the BBC, as to 'inform, educate and entertain'. The key term here is 'educate', in the original sense taken from the Latin, 'educare', meaning to provide a lead. Reith considered that 'only a few viewers knew what programmes they need and want, so the public service broadcasters should produce good programmes for the audiences and play an edifying role (Congdon, 1992).

In Reith's brief and trenchant manifesto for a public service broadcasting system there was 'an overriding concern for the maintenance of high standards and a unified policy towards the whole of the service supplied' (Scannell, 2000, p. 47). This initial conception of PSB was not only based on Reith's own beliefs, it was also rooted in technological constraints. 'The scarcity of the spectrum frequencies is considered the main justification for the monopoly position' (Seaton, 2003, p. 367). Although Reith's formulation has been consistently challenged by critics, and dismissed and derided by advocates of commercial solutions, as unacceptable paternalistic, his ideas, revised and updated, have continued to inform debate down to the present (Hearst, 1992).

After reviewing conceptions of PSB over time, Collins (1998, p. 54) concluded that although its proponents offered definitions based on different approaches, they shared common ground in viewing PSB and the market as oppositional categories (Collins 1998, p. 73).

In an attempt to devise a definition of PSB that fits contemporary conditions, Scannell $(1990$, p. 25) has argued that the core objective is to provide a 'mixed programming on national channels available to all.' There are two essential elements in this argument: a mix of programming and universality. Since Scannell believes that PSB still has cultural and democratic missions, he sees its essential role as guaranteeing 'equal access for all to a wide range of common informational, entertainment, and cultural programmes carried on channels that can be an important citizenship right in mass democratic societies.' (Scannell, 1990, p. 26)

In response to the threat to PSB posed by commercial television, Blumler (1992, pp. 30-39) identified seven core values of PSB: 1) programme quality; 2) 
diversity; 3) cultural identity; 4) independence of programme sources from commercial influences; 5) the integrity of civic communication; 6) welfare of children and juveniles; and 7) maintenance of standards. This conception builds on Reith's original emphasis on the educational and cultural roles of PSB by highlighting the welfare of children and juveniles as a distinctive value.

In recent studies, Van Dijk, Nahuis and Waagmeester (2006, p. 254) have reiterated that the objectives of PSB should include pluralism and diversity, independence, quality and accessibility.

Heap (2005, p. 116) summarising reports of the objectives of PSB from the European Union, has identified four defining roles: 1) Aiding informed citizenship through impartial and independent news, information and comment; 2) supporting democratic values through the encouragement of public debate that involves and respects the human rights of all groups in society; 3) offering a wide range of quality programmes in all genres; and 4) promoting social cohesion and vitality of national cultures.

Hujanen (2005, p. 58) has argued that PSB is defined by five key features: 1) universal accessibility; 2) diversity of programmes; 3 ) information distributions; 4) provision of education; 5) promotion of culture and 6) development of democracy.

Papathanassopoulos (2002, p. 11) considered that there were four essential characteristics of PSB: 1) a universal service available to all irrespective of income or geographical location; 2) a commitment to a balanced output and to balanced scheduling across different programme genres; 3) a balanced and impartial political output; and 4) a degree of financial independence from both government and commercial bodies.

As these various definitions clearly demonstrate, despite a core of agreement on basic principles, conceptions of PSB are both a contested and dynamic over time.

There is then, no easy answer to the question of what principles public service broadcasting should follow, but a reasonably thorough attempt at consolidation and synthesis was made in the mid-1980s by the UK's Broadcasting Research Unit (BRU, 1985). The main principles in the BRU document can be summarised as follows:

1) Universality of availability (geographic); 
2) Universality of appeal (general tastes and interests);

3) Particular attention on minorities (especially disadvantaged minorities who should receive particular provision);

4) Special relationship to the sense of national identity and community;

5) Broadcasting should be distanced from all vested interests, and in particular from those of the government of the day;

6) Direct funding and universality of payment;

7) Broadcasting should be structured so as to encourage competition in good programming rather than for numbers; and

8) The public guidelines for broadcasting should be designed to liberate rather than restrict the programme makers.

Some of these principles, such as 'universal availability', 'good programming', and 'direct funding' follow Reith's ideas, the other characteristics have been developed in response to social and cultural changes. For instance, the concept of 'particular attention to minorities' is mentioned, because against a background of increasing migration and the assertion of minority rights there was a growing sense that 'general and national programmes could not satisfy the needs of minorities' (Tracey 1998, p. 28).

These general principles as listed by the $\mathrm{BRU}$, at first glance, seem to be both comprehensive and clear, but they may well provoke arguments when translated into in concrete practices. For example, while the aim of making 'good programmes' and serving 'the interests of minorities' might command wide support as principles, their operationalization is problematic. Is 'good' to be defined by professional or by aesthetic and ethical criteria? Which minorities merit particular attention? A further problem is posed by the ambiguity of key principles such as 'national identity'. The question of nationhood is not fully resolved in many countries, including the UK (Raboy, 1996, p. 7), and it is even more controversial in Taiwan caught as it is in the cultural and political crossfire between China, the U.S. and Japan. (More details about Taiwan's specific situation will be given in the next chapter).

In 1992 the UK Department of National Heritage published the White Paper 'The Future of the $B B C$ ', in which eight objectives that public service broadcasters should try to achieve were listed: 1) Focus on audiences; 2) Quality; 3) Diversity and choice; 4) Accessibility; 5) Editorial independence; 6) 
Efficiency and value for money; 7) Accountability; 8) National identity (DNH 1992).

Compared to the BRU's principles, these objectives place more emphasis on the audience perspective, an indication that in a more commercially competitive environment public service broadcasters were being urged to become audience-oriented institutions instead of producer-oriented institutions.

Changes in the concept of PSB are also evident in other European countries. With the development of communications technologies, free markets, and the liberalisation of east European, the concept of PSB has been challenged. In order to cope with these changes, both the Council of Europe (in the Prague Resolution of 1994) and the European Parliament (in the 1996 Resolution) have tried to identify certain core principles. The 1994 Prague Resolution includes nine principles: 1) A common reference point for all members of the public; 2) A forum for broad public discussion; 3) Impartial news coverage; 4) Pluralistic, innovative and varied programming; 5) Programming which is both of wide public interest and attentive to the needs of minorities; 6)Reflection of the different ideas and beliefs in multicultural societies; 7) A diversity of national and European cultural heritage; 8) Original productions by independent producers; 9) Extended viewer and listener choice by offering programmes not provided by the commercial sector (Raboy, 1996, p. 15).

The 1996 European Parliament Resolution also identifies this nucleus of common features in PSB. Rumphorst (2007) summaries the key features as follows: 1) an aid to informed citizenship, an agency of representative pluralism bringing together different groups in society in a common conversation that shapes public opinion; 2) offers a wide range of quality production in all genres to the whole population; 3) sets quality standards in popular programmes followed by mass audiences; 4) serves minority interests and caters for every section of the population; 5) provides unbiased and fully independent information, both in mass coverage and in-depth factual programming, capable of earning the audience's trust and of representing a reference point in the rapidly expanding information market; 6) plays a major role in encouraging the public debate that is vital for the proper functioning of democracy and provide a forum for debate for all groups and organizations in society; 7) ensures that the general population has access to events of general public interest, including 
sports events (Rumphorst, 2007).

The Office of Communications (Ofcom), the regulator of communications in the UK, addressed the purposes of PSB as part of its review of the performance of PSB (Ofcom, 2004), identifying three key features: 1) to deal with a wide range of subjects; 2) to cater for the widest possible range of audiences - across different times of day and through different types of programme and; 3) to maintain high standards of programme-making.

In a later document, published in 2005, after a series of consultations and discussions Ofcom set out a more comprehensive definition of PSB based on four public service purposes and five public service characteristics (Ofcom 2005, pp. 7-8). The four public service purposes were: 1) informing our understanding of the world; 2) stimulating knowledge and learning; 3) reflecting UK cultural identity; and 4) representing diversity and alternative viewpoints. The five characteristics are: 1) high quality; 2) original; 3) innovative; 4) challenging; 5) engaging; 6) widely available. These purposes and characteristics became the criteria that Ofcom employed to review the performance of public service broadcasters in its second PSB review in 2009 (Ofcom, 2009, p. 21).

The various definitions and principles outlined above clearly show that the concept of PSB is dynamic and unfolding as commentators and government and intergovernmental agencies respond to changing conditions and contexts. As Raboy has pointed out, however, the main challenge is not 'how to perfect the list' but 'how to apply such a set of concepts and principles' (Raboy, 1996, p7) and it to this question of operationalization that we now turn.

\subsection{From concepts to Practice}

From last section we can see that there is no shortage of defensible working definitions of PSB. Translating them into institutional forms and practices however is 'rendered problematic by a series of political, economic, technological, ideological, and developmental constraints' (Raboy, 1996, p. 2). In this section I want to examine how these constraints operate by looking at selected instances of actually existing public service broadcasting.

Compared to commercial broadcasting which is run in order to generate 
profits and has been financed historically mainly by selling audiences to advertisers, public broadcasters receive funding from diverse sources including license fees, individual contributions, public financing and commercial financing.

Historically, PSB was the dominant form of broadcasting in Europe and in many of the former colonial territories, led by India, which gained their political independence after World War II. Over the last thirty years however, boosted by the expansion of commercial cable and satellite services, commercial broadcasting has entered these hitherto monopoly or protected markets placing public service broadcasting under increasing pressure. In this section, four contrasting models of PSB, illustrating four different historical trajectories and responses to current conditions will be briefly reviewed: the BBC in the UK, PBS in the U.S., NHK in Japan, and KBS and MBC in South Korea.

\subsubsection{The United Kingdom: The BBC}

Of the all broadcasting organisations in the world, 'the BBC has been the most widely admired but has none the less proved difficult for others to copy successfully' (Smith, 1995, p. 80). The British Broadcasting Corporation (BBC) is an autonomous public service broadcaster that operates under a Royal Charter and a Licence and Agreement from the Home Secretary. Scannell (1996) broadly divides the organisation's development into three periods:

1) 1927- 1954: The period of National service;

2) 1954-1977: The period of Competition;

3) 1977-1995: The period of Cultural pluralism.

'Each of which was shown to have a core characteristic: first as national, then as popular, and finally as pluralistic' (Scannell, 1996, pp. 25-31).

In the national service period, from 1927 to 1954, the BBC was established as a state - regulated monopoly, 'Its original mandate, set out in its founding constitutional documents, was to provide a national service in the public interest' (Scannell, 1996, p. 25).

The BBC was, from the outset, colonised by highly educated, white, middle-class (middle-aged) men. Finding the right tone of voice - a voice that could speak to people of all class - has always been difficult (Scannell, 1996, p. 27). Class remains a sensitive issue. 
In the second period, the competition period from 1954 to 1977, a commercial television system, Independent Television (ITV), was set up within the PSB system. Although funded by advertising revenues, the ITV companies were subject to public service requirements as a condition of holding their licences, and obliged to make a range of programmes which, while socially valued, were not necessarily profit maximising. At the same time they took advantage of the BBC's reputation for paternalism and high mindedness and 'staked out the ground upon which the battle for audiences was to be fought as popular programming (Scannell, 1996, p. 28). Initially BBC audiences fell sharply, but by the mid-1960s, after the Corporation had responded by enhancing its own popular programming, the total available television viewing audience was shared between the BBC and ITV on a more or less equal basis, to the satisfaction of both parties (Scannell, 1996, p. 29).

In the third period, 1977 to 1995, 'pluralism' became the leitmotiv (Scannell, 1996, p. 30). In order to create a wider range of programmes for those minorities and social groups whose needs, interests, and tastes were not adequately served under the existing arrangements, in 1980, the new Conservative government brought in a Broadcasting Act, which created what was called Channel 4 (Scannell, 1996, p. 27). This was given a PSB remit, with a specific responsibility to cater for minority interests, but, in contrast to the $\mathrm{BBC}$, was funded from advertising revenues rather than taxation

Scannell (1996) argues that the core characteristics of the three periods above stand out as distinctive strands woven into the fabric of British broadcasting system today.

Within the United Kingdom the BBC is funded principally by an annual television licence fee, charged to all British households, companies and organisations using any type of equipment to receive live television broadcasts. The level of the fee is set annually by the British Government and agreed by Parliament. The BBC use the income from the licence fee to provide a range of radio and television services including 10 national television channels (BBC One, BBC Two, BBC Three, BBC Four, CBBC, CBeebies, BBC News, BBC Parliament, BBC Alba, BBC HD), BBC Red Button interactive TV, 10 national radio stations (Radio 1, 1Xtra, Radio 2, Radio 3, Radio 4, Radio 4 Extra, Radio 5 Live, 5 Live Sports Extra, 6 Music, BBC Asian Network), National TV and 
radio services for Scotland, Wales and Northern Ireland, and over 40 local radio stations for England, $B B C$ Online, and BBC World Service (BBC, 14/01/2012).

BBC also has a commercial arm, BBC Worldwide as well as a number of other commercial ventures. Profits from these activities are returned to the BBC for investment in new programming and services. The BBC Trust, as the governing body of the $\mathrm{BBC}$, is separate from the Executive which manages the BBC's day-to-day operations. The function of BBC Trust is to represent licence fee payers and make sure the Executive delivers the programmes and services required by its remit, while ensuring that the $\mathrm{BBC}$ is accountable and open. The BBC Trust also protects the independence of the BBC from commercial or political influence. It holds the Executive to account for the BBC's performance through reviews of its services in the areas of television, radio, online, news, sport and the BBC World Service (BBC Annual Report, 2010, p. 14).

In December 2011, in the conclusions of 'Putting Quality First', the BBC Trust identified four primary objectives for the BBC between then and 2016. These objectives, which require a challenging programme of organisational and cultural change, include:

1) Increasing the distinctiveness and quality of output by increasingly focusing on its five editorial priorities across its portfolio of services;

2) Improving value for money for licence fee payers: to reduce the share of its expenditure allocated to running costs in order to direct a greater share of the licence fee into making great content;

3) Serving all audiences: to meet our audiences' expectations by progressing key digital projects.

4) Set new standards of openness and transparency: the objectives are monitored by a range of different measures, including audience research, financial analysis, external audit, and an assessment by the BBC Trust (BCC, 2010, p. 36).

Meeting these goals presents major challenges. Firstly because the BBC has recently been given the additional responsibilities, for the Welsh Channel 4 and the World Service, adding to the pressures on its already stretched finances. Secondly, because the arguments coming from advocates of market based broadcasting, for privatising some of the corporation's more popular services, 
allocating some of the licence fee income to other providers of public service programming, or even selling off the organisation completely, show no signs of weakening.

In 2000 the White Paper, A New Future for Communications, affirmed that 'we will continue to rely on PSB for one clear reason - it works' (DTI \& DCMS, 2000). In the decade since then this general endorsement has been consistently challenged by the new market. Even so, for the moment, the BBC remains the cornerstone of the British system, and a number of observers continue to endorse the argument put forward by Graham and Davies (1997, p. 35) that the success of the British broadcasting industry can be attributed to the $B B C$ and the BBC should play an important role and use its advantages, such as experience, expertise and economies of scale to help the development of the broadcasting industry in the digital age'.

\subsubsection{The United States: PBS}

From the close of the Second World War until the late 1970s, public broadcasting organisations in Europe had stood in powerful, resilient opposition to commercial systems. This was in marked contrast to the United States, 'where public broadcasting had been much slower to develop and had far fewer resources' (Tracey, 1998, p. 40).

Headquartered in Arlington, Virginia, the Public Broadcasting Service (PBS) (formerly National Educational Television) is a non-profit television network with 354 member TV stations in the United States which hold collective ownership (PBS, 2012).

PBS was founded on October 5, 1970, at which time it took over many of the functions of its predecessor, National Educational Television (NET). PBS and its member stations claim to be 'America's largest classroom, the nation's largest stage for the arts and a trusted window to the world' (PBS, 2011).

Unlike the model of America's commercial broadcasting television networks, in which affiliates give up portions of their local advertising airtime in exchange for network programming, PBS member stations pay substantial fees for the shows acquired and distributed by the national organization.

This relationship means that PBS member stations have greater latitude in local scheduling than their commercial broadcasting counterparts. Scheduling 
of PBS-distributed series may therefore vary greatly from market to market. This can be a source of tension as stations seek to preserve their localism, and PBS strives to market a consistent national line-up. However, PBS has a policy of 'common carriage' requiring most stations to clear the national prime-time programs on a common broadcast programming schedule, so that they can be more effectively marketed on a national basis.

PBS stations are commonly operated by non-profit organizations, state agencies, local authorities, or universities in their city of license. Compared with other public broadcasters in most other countries, PBS does not own any of the stations that broadcast its programming.

PBS was founded to provide diversity in programming at a time when in the U.S. most television broadcast over the public airwaves was provided by only three privately owned national networks. Compared with the BBC which regarded their mandate as providing a service to the entire nation, U.S. public broadcasters realised that they could only survive politically by not taking listeners or viewers away from the commercial networks. As a consequence, 'the function of the public or educational broadcasters was to provide that programming that was unprofitable for the commercial broadcasters to produce' (McChesney, 1999, p. 247). Echoing this view, Tracey (1996) argues that the logic of PSB is that any programme which is too popular should more properly appear on commercial television. As he notes, 'one of the basic conceits of American public television is "if you are attracting too many viewers and if you are too popular, then you must be doing something wrong" (Tracey, 1996, p. 162)'. However, 'at 2 percent of the audience share, one has to question public television's claim to be a national broadcaster' (Tracey, 1996, p. 162).

Nowadays there is debate as to whether or not the PBS system has outlived its public necessity. Proponents maintain that the original mandate, to provide universal access, particularly to rural viewers and those who cannot afford to pay for the private television services, remains vital. In addition, they argue that PBS provides some types of television shows which would not be shown at all on the commercial broadcasting television networks and television channels.

Apart from subsidy, since $53 \%$ to $60 \%$ of public television's revenues come from private membership donations and grants (PBS, 2012), most stations solicit individual donations by methods including fundraising, pledge drives or 
telethons which can disrupt regularly scheduled programming. Some viewers find this a source of annoyance since normal programming is often replaced with specials aimed at a wider audience to solicit new members and donations. As Smith (1995) points out, public television stations in American remained starved of funds and the non-profit stations have often been accused of spending as much air time raising funds as the commercial stations do with their advertisements' (Smith, 1995, p. 90).

In McChesney's opinion, given the obstacles PBS faced, U.S. public broadcasters still have done 'a remarkable job of establishing and maintaining a loyal, albeit small, audience' (McChesney, 1999, p. 251). However, 'the already compromised commitment to "public service" - meaning service to the entire population based on non-commercial determinants- has withered over the years' (McChesney, 1999, p. 251).

Tracey (1996) argues that the PBS problems fashioned by the Public Broadcasting Act of 1967 are both conceptual and structural. At the conceptual level, the Act maintained public television's educational role but added a more general role, such that is now matched the definitional trinity of most public broadcasting organisations - informing, educating and entertaining. Structurally, the two axes which constituted 'the system' were local and national. 'This duality in both concept and structure was, and remains, an inevitable source of tension' (Tracey, 1996, p. 162). To this we can add the absence of autonomous public funding, and PBS's consequent vulnerability to politically motivated efforts, at both national and state level, to reduce the size of the direct grant.

\subsubsection{Other PSB Models in Taiwan's Neighbourhood}

Apart from the two fundamental models in UK and US, the seeds of PSB concepts have landed in different soil to grow into various forms within different social and cultural contexts. In Taiwan's close neighbourhood, there are two empirical examples from countries whose histories and cultures overlap with those of Taiwan; the former imperial power of Japan, and South Korea, which like Taiwan, was a Japanese colony. In Japan, NHK presents a successful model of PSB supported by license fees, while in South Korea KBS and MBC provide examples of transformations from former state-owned televisions under military control to PSB. 


\subsubsection{Japan: NHK}

The Broadcasting system devised after Japan's defeat in World War II was a combination of British-style public service broadcasting, financially supported by licence fees, and U.S.-style commercial broadcasting, dependent on advertising revenues. Within this mix public broadcaster, Nippon Hoso Kyokai (NHK), or the Japan Broadcasting Corporation, is supported almost entirely by a licence fee system (NHK, 2011; Shimizu, 1996, p. 141).

NHK originally introduced a radio service in 1925 and a television service in 1953. It was originally modelled on the British Broadcasting Company, the precursor to the British Broadcasting Corporation created in 1927. Much like the BBC, it was funded by a "receiving fee" payable by every Japanese household, with no commercial advertising and the maintenance of a position of strict political impartiality.

The Japanese public network was established under the 1950 Broadcast Law, with the aim of 'promoting public welfare through nationwide broadcasting' (NHK, 2011). To ensure that the public interest is served as far as possible, the law provides for a specific structure for NHK, with a board of governors as its highest decision-making organ (Shimizu, 1996, p. 144). The Board is the decision-making body for every important matter concerning NHK's management policy and operation, including the annual budget, operational plan and basic programming policy. There are twelve members, appointed by the prime minister and approved by both Houses of the Diet on behalf of the Japanese public. They bring a broad range of experience and expertise to NHK (NHK, 2011).

NHK runs two national terrestrial TV stations (NHK General and NHK Educational) and three satellite-only services (NHK BS-1, BS-2 and the hi-definition NHK Hi-Vision services). It also runs 3 national radio services and a number of international radio and television services, akin to the BBC World Service. NHK has also been an innovator in television, developing the world's first high definition television technology in 1964 and launching high definition services in Japan in 1981 (NHK, 2011).

In Japan, the launch of digital satellite TV broadcasting in December 2000 was followed by the first digital terrestrial broadcasts in December 2003. The core technology is Hi-Vision (HDTV), which delivers clear, vivid pictures and 
CD-quality sound. All the programming on General TV is now produced and aired in Hi-Vision. NHK has been conducting research on even more advanced technology (NHK, 2011).

According to NHK's 'Corporate Plan for 2009-2011' (NHK, 2009), in order to reach the two management goals of increasing both the audience contact rate and the payment rate for the receiving fee, nine courses of action are outlined. They are: 1) making all efforts to reform the organizational culture of NHK to heighten public trust; 2) directly addressing domestic and global issues; 3) fulfilling NHK's role as a public broadcaster by offering new services in the coming era of the fusion of broadcasting and communications media; 4) Becoming a base for revitalizing regional areas; 5) broadcasting Japan and Asia to the World; 6) effectively prioritizing efforts for the smooth and complete transition to digitalization; 7) increasing the receiving fee value by structural reforms; 8) strengthening efforts for equitable sharing of receiving fee burden; 9) promoting environmentally-aware operations (NHK, 2009, p. 2-3).

\subsubsection{South Korea: KBS and MBC}

Since mid-1999, the 'Korean Wave' of television programmes and popular cultural products spreading into East Asia has caught many media commentators' attention, so has the South Korean television industry.

Compared with NHK, which is financially supported by licence fees, public service broadcasting in South Korea has developed a significantly different model shaped by its specific political and social conditions.

The crucial intervention occurred under the Chun-Doo-Whan regime which forcibly reshuffled 29 broadcasters into an oligopoly of two public Broadcasters, the Korea Broadcasting System (KBS) and the Munhwa Broadcasting Company (MBC) (Shim, 2008, p. 23).

Altough tagged as 'public' broadcasters, KBS and MBC have increasingly come to rely on advertising for their finances. By the early 1990s, KBS relied more on advertising (61\%) than on the reception fee/license fee (39\%) while $98 \%$ of MBC's revenue came from advertisements (Kim, 2001).

\section{KBS}

Today KBS is South Korea's leading public services broadcaster and relies on 
both licence fee and income from the advertisements to operate its three TV, seven radio and four DMB channels (KBS, 2012).

KBS began its first radio broadcasting service back in 1927 and launched Korea's first television broadcasting service in 1961. The headquarters is located at Yeouido in Seoul. There are 18 regional stations and 11 overseas bureaus as well as eight subsidiary companies such as KBS Media which manages the local and global marketing of KBS content.

Around $37.8 \%$ of its revenue currently comes from a mandatory Television License Fee, while $47.6 \%$ comes from commercial advertisement sales (KBS, 2012). For national or governmental programs such as the International Radio service (KBS World Radio) and the Radio service for physically handicapped people, KBS receives public funds directly from the South Korean government.

\section{MBC}

In the name of the Munhwa Broadcasting Company (MBC), Munhwa in Korean means 'Culture'. Unlike KBS, MBC is a public broadcaster that receives no government subsidy and derives its income almost entirely from commercial advertising (MBC, 2012). Although operating under the title of 'public', MBC is actually the oldest of all the commercial broadcasting networks in South Korea. Since its inception in 1961, it has contributed to the development of the Korean broadcasting industry based on its nationwide network of 19 regional stations and 9 subsidiaries.

MBC's flagship terrestrial television station is channel 11 on VHF in Seoul. The network is owned by the Foundation of Broadcast Culture (70\% of the company's stock), while the Jung-Su Scholarship Foundation owns 30\%.

In its earlier history, MBC used to be a private commercial network but when the Chun Doo-hwan regime closed private commercial radio and TV networks MBC was forced to give most of its shares to the government, losing its position as a private broadcaster. In $1980,70 \%$ of the MBC network's stock was given to the Korean Broadcasting System (KBS).

The Foundation for Broadcast Culture, which currently holds $70 \%$ of MBC shares, was created in 1988. The Foundation helped to free MBC from external constraints, thus resulting in greater independence. According to the Foundation for Broadcasting Culture Act, 15\% of the operating profit must be 
returned to the Foundation for public use. Moreover, the Korean Broadcasting Law requires the $\mathrm{MBC}$ to contribute $4.75 \%$ of its total advertising revenue to the Broadcasting Development Fund operated by the Korean Broadcasting Commission, which undertakes broadcasting development tasks as well as arts and cultural projects (MBC, 2012).

\subsection{Threats and Opportunities Facing PSB}

Paddy Scannell once remarked that, 'if the PSB simply is a series of pragmatic, instrumental solutions to problems as they arose initially, it should, indeed have disappeared as those problems were overcome' (Scannell, 1996, p. 24). However, PSB has shown no signs of vanishing in Britain or elsewhere in East Asia. From the practical examples outlined in the last section, it seems the public service broadcasting still thrives in many countries. However, over the last two decades public service broadcasters around the world have faced increasing pressures from both accelerating commercialisation and the fragmentation of the broadcasting environment. A widespread assault can also be seen on the importance, even legitimacy, of public service broadcasting in the major industrialised democracies (Tracey, 1998, p. 40).

\subsubsection{The Decline and Fall of PSB}

Scannell (1996) notes that a combination of new technologies and a new political climate in the 1980 s seemed to put a question mark against the continuing relevance of public service broadcasting. Critics claimed that its original rationales had disappeared; that PSB had been merely a pragmatic response in the early twentieth century to the problems of spectrum scarcity and of financing broadcast services' (Scannell, 1996, p. 23). With new information technologies seen as solving the problem of channel scarcity and the payment mechanism, and with fibre-optic cabling and geo-stationary satellites delivering a range of services hitherto unimaginable, the need for PSB seems simply to wither away as the market took over.

However, Scannell (1996) argues, such arguments have been market-led. They start from 'the assumption that broadcasting is a business like any other that its business is the profit-driven production programme commodities and that these are produces for consumption like any other commodities' (Scannell, 
1996, p. 24).

The defenders of PSB take a different view of broadcasting. Broadcasting certainly is a large scale business, but its business is not just the production of media commodities but of a communicative relationship (Garnham, 1994).

The question of whether a market- led approach to broadcasting is better or worse than a public service- led view cannot be settled definitively one way or another (Scannell, 1996, pp. 24-25).

On the basis of his review of various public service broadcasters around the globe, Tracey (1998) identifies a number of major challenges facing the PSB. They can be summarised as follows (Tracey, 1998, p. 17):

1) The Structural challenge: created on the one hand by the desire to shift the 'burden' of funding away from the public purse and on the other by the desire to develop high-tech cable and satellite with all the consequent implications for a multi-channel environment;

2) The ideological challenge: the assumption that the social good flows not from collective activity organised from the top down, but from myriad individual decisions organised from the bottom up;

3) The development and character of new technologies: new technologies offer plentiful possibilities for interactive communication which emphasise the visual, immediate, and sensual at the expense of the deliberative and cerebral;

4) Social practices: the inclusive 'public' character of broadcasting is challenged by the increasing mobility of listening and viewing, as people increasingly jettison the set schedules devised by broadcasting organisations and access programming across a widening range of platforms at times of their own choosing.

Facing these challenges, PSB defenders continue to argue that the central role of PSB in guaranteeing diversity of representation cannot be easily replaced by the multi-channel environment. This is because the television industry has high fixed costs and low marginal costs (Graham \& Davies, 1997, p. 11) a characteristic which leads to concentration of ownership and similarity of programmes as companies compete for the same audiences and advertising by concentrating on already popular formats, matching like with like. As a consequence, although it seems that viewers have more choice in the multi-channel environment but actually it is more of the same' (Seaton 2003, p. 
375). According to this argument, developments in communications technologies may have solved the problem of spectrum scarcity but have not fostered a more diverse television market. This position supports the view that PSB remains a necessary corrective to the failures of the market system (DTI \& DCMS, 2000) and continues to merit public funding.

\subsubsection{Challenges for PSB Introduction into Transitional Countries}

In many parts of the 'transnational' world, public service broadcasting is a distant ideal but a working reality. The main reason is that even when the leaders in these countries have embraced that ideal, 'the lack of a receptive political and professional culture is often the next hurdle' (Raboy, 1996, p. 2). Raboy indicates that problems of financing, mandate, and interpretations of purpose are 'all indications of a more fundamental problem of political will' (1996, p. 2).

From long term observation, Rumphorst (2007) highlights the challenges facing the introduction of PSB in o countries with state broadcasting on the one hand and commercial broadcasting on the other.

According to Rumphorst (2007), in countries with state owned systems, it may not be easy to convince those in power to give up their direct control over broadcasting and transform it into truly independent public service broadcasting. However, in many such countries democratic ideas and principles have gained ground over recent years and 'put the citizen increasingly at the centre of attention' (Rumphorst, 2007, p. 10).

At the same time, the communications environment has also been changing in fundamental ways with global deregulation in the telecommunications field, commercial broadcasting virtually everywhere with little regulation, satellite broadcasting with no national borders, cable distribution of foreign programmes, technical developments like digitisation and compression which offer possibilities for many additional programme channels, and the arrival of the Internet which carries unlimited numbers of audio and audiovisual programmes. In the situation, in Rumphorst's view (2007, p. 11), though it may be clear that state broadcasting is no longer viable, 'It certainly takes courage for those in power to install and to live with truly independent public service broadcasting'.

On the other hand, in countries which so far been dominated by commercial 
broadcasting, it will also be difficult to obtain the necessary support for introducing public service broadcasting (Rumphorst, 2007, p. 12). For one of the pillars of a truly independent public service broadcasting, a system of obligatory licence fee funding, may be very difficult to establish among viewers who are accustomed to 'free' programmes.

However, in countries where commercial broadcasting has only functioned in conformity with the logics of the market, it also can be observed that audiences may increasingly feel the need for 'different' content.

All forms of broadcasting are ultimately financed by consumers and citizens. The financial support might come from tax payers in the form of direct state funding, from consumers via additions to the price of purchased goods designed to offset the costs of commercial advertising, from subscribers to pay-tv channels, or from a mandatory levy or licence on receiving sets. Each of these forms of payment carries with it certain assumptions.

1) Tax-payers: the state makes the programmes in the best interests of the state;

2) Consumers: the commercial broadcasters choose the programmes to maximize both its audience share and its profits;

3) Subscribers: in the same situation as consumers in 2);

4) Licence-fee payers: a public service broadcaster produces programmes for citizens (Rumphorst, 2007, pp. 10-12).

\subsection{Summary}

As we have seen in this chapter, PSB in many countries is in a situation of retreat with its values and funding mechanisms placed under acute pressure. Against this background its expansion in Taiwan seems to contradict a significant global trend. Basically, the battle for public broadcasting in Taiwan can be addresses with two streaks:

1). Taiwan was going against the grain of international trends of PSB while a number of media commentators in the PSB traditional heartlands have been asking whether the PSB idea has now outlived its usefulness;

2). The argument for PSB was going against the grain of the growing enthusiasm for privatisation and market-led solutions - not just in broadcasting but within the economy as a whole as it moved from state management. 
On the other hand, in terms of the necessarily context-specific prescriptions for Taiwan's PSB in Taiwan, in the domestic political background, withdrawing state and party control from broadcasting were viewed as a departure point rather than programme quality and market failures.

Similar to other public broadcasters around the world, the discussions on the institutionalisation of Taiwan's PSB has been led by political and media elites. It is hard to escape a conclusion that the elite-oriented streak has played a key role in most public broadcasters. However, compared with the earliest conceptualisation of public broadcasting, the paternalistic Reithian idea that elites have a responsibility to decide and determine what the public interest is and how it should be catered for, nowadays the public engagement in the PSB system is a key reason of a healthy PSB (Hu, 2007, p. 207; Thompson, 2006, p.4). As Mark Thompson argued that it is about how to develop 'widespread public support' (Thompson, 2006, p.4).

Seen in this light, the main task of this thesis is to assess the context specific political, social and cultural forces that have shaped the recent PSB expansion in Taiwan. In pursuit of this aim the following two chapters will address firstly the national peculiarities of Taiwan's media landscape and secondly the way Taiwan's PSB has developed within this specific context. These contextualizing chapters are then followed by 4 chapters which draw on interview data, press content analysis, and the close examination of editorials and letters to the editor, to develop an analysis of how the idea of PSB and the intention to expand it has been socially defined and contested. 


\section{Chapter 3}

\section{Transitional Taiwan and Its Broadcasting Landscape}

In the opening chapter it was briefly mentioned that some features of how commercial pressures and rating-driven competitions are played out in Taiwan's media landscape and how this lead to insistent calls for the introduction of proper PSB media to temper this environment. These issues are explored in greater detail in this chapter by looking at how the origins of the current media environment have been shaped by wider political, social and economic transformations in Taiwan.

This chapter begins with a national profile of Taiwan and goes through a brief history and different groups of people that have inhabited the island. Then some key aspects in political, cultural and social changes in this transitional society will be highlighted to demonstrate their relevant influences on the media landscape. As further background, a chronological overview of Taiwan's media history will be presented that identifies three main periods of television development in Taiwan, named as 'scarcity', 'choice' and 'abundance' (Pauwels, 2010). These features are useful to highlight the shifting process from a stated-controlled media environment to the current highly-commercialized media landscape where the fledgling PSB is struggling to survive.

This chapter concludes with a discussion of the systematic failures of media representations in the profit-driven Taiwanese media environment.

\subsection{National Profile of Taiwan}

Geographically, Taiwan is situated in the western Pacific between Japan to the 
north and southern China to the west (See Figure 3.1 above). It lies along the major air and sea transportation routes in the region. As an oceanic nation of 23 million people (See table 3.1 above), the Republic of China (ROC) government comprises the main island of Taiwan, the archipelagos of Penghu, Kinmen, and Matsu, and a number of other islands.

Figure 3.1: Map of Taiwan

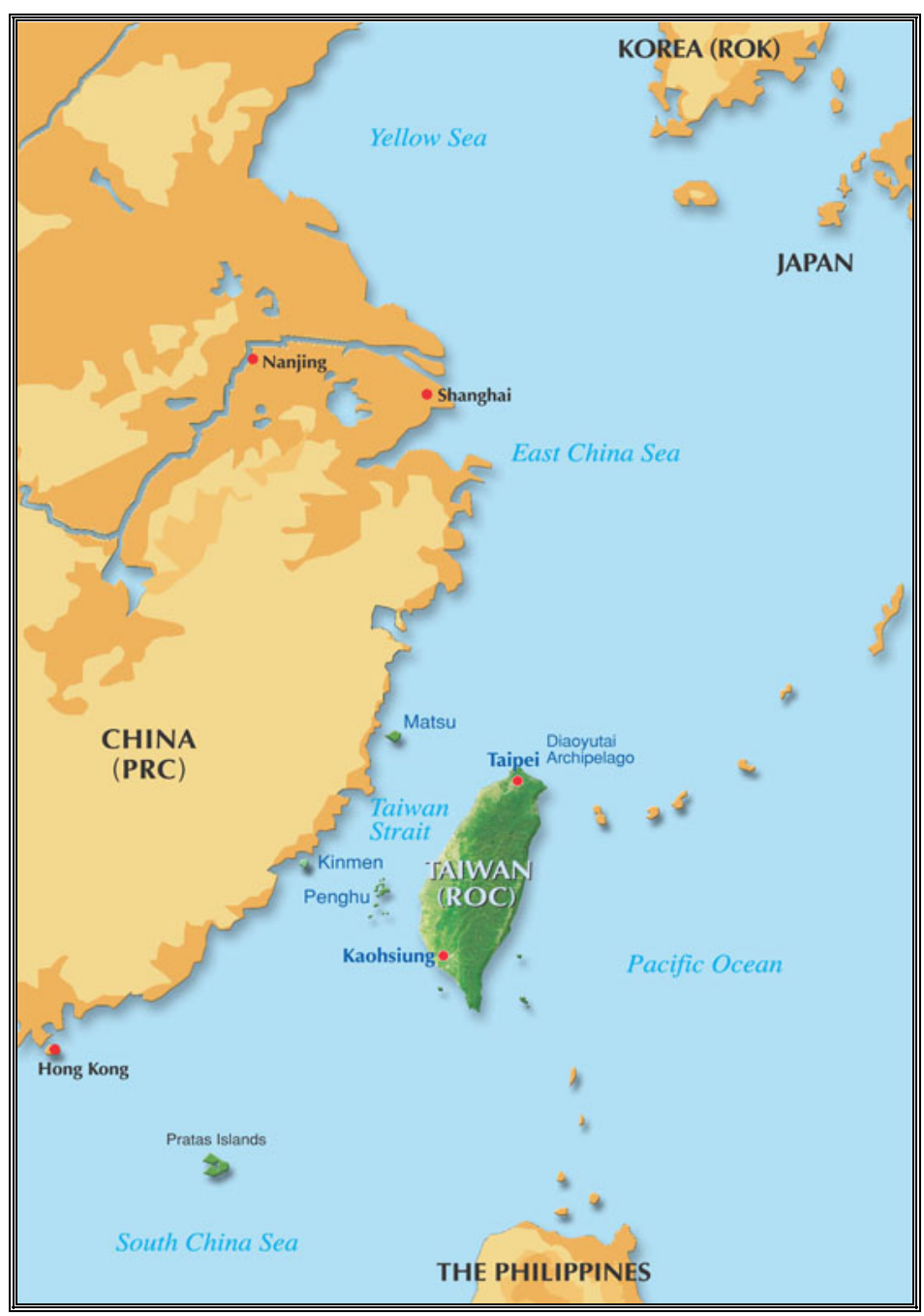

(Source: Government Information Office, 2012b) 


\begin{tabular}{lr}
\hline & Table 3.1. Basic Data of Taiwan \\
\hline Area & $\begin{array}{r}36,200 \mathrm{sq} \text { km (13,900 sq miles) } \\
\text { (Taiwan proper and associated islands) }\end{array}$ \\
\hline Population & 23.23 million (July 2012) \\
\hline Capital & Taipei City \\
\hline Official Language & Mandarin (Chinese) \\
\hline Other Languages & $\begin{array}{r}\text { Holo (Chinese, one of Han subgroups) } \\
\text { Hakka (Chinese, one of Han subgroups) } \\
\text { Austronesian languages }\end{array}$ \\
\hline GDP Per Capita & US Dollars $\$ 5,112(2011)$ \\
\hline Economic Growth Rate & 1.89\% (2011) \\
\hline & (Source: Government Information Office, Feb 2012) \\
\hline
\end{tabular}

Over 95 percent of Taiwan's population is of Han Chinese ancestry, with the remainder composed of indigenous peoples and recent immigrants (GIO, 2010). Han Taiwanese are the descendants of immigrants that arrived in two main waves: first, in the 17th century a huge wave of immigrants moved to Taiwan when the Ming dynasty on mainland was invaded, and later, in 1949, when the ROC government, led by KMT party, relocated to the island (Taiwan Year Book, 2007). Mandarin Chinese, the official language, is almost universally spoken and understood, while large segments of the population also speak Holo and Hakka. In addition, Taiwan's indigenous groups have their own Austronesian languages while immigrants speak a variety of tongues (GIO, 2007).

\subsection{External and Internal Tensions on Taiwan}

Judged by its population and size, Taiwan would not catch too much international attention. However, Taiwan keeps remaining in the global eye due to its geo-strategic location, and its complicated relationships with China and the United States.

One of the main international concerns is that 'If one day there is a conflict between America and China the spark will most likely be Taiwan since America underwrites the security of democratic Taiwan' (BBC, 14/Jan/2012a).

A significant example can be seen in January 2012 when democratic elections of presidential and parliamentary were held in Taiwan, an island which is just over 100 miles from China. The elections were closely watched by many global media since the election results might have created a new source of instability in Asia if the DPP party that supports Taiwanese independence won, 
which neither America nor China would have wanted to occur. Ironically, the peaceful character of this election was commented upon as 'unusual' because on this occasion there were none of the troubles that marred previous elections ('in 1996 China lobbed missiles into the sea near Taiwan, in 2000 China issued warnings about the electoral outcome, in 2004 one of the presidential candidates was shot and there were several corruption scandals during the 2008 campaign') (the Economist, 2012, p. 54).

In the 2012 election, the KMT and pro-Chinese candidate Ma Ying-Jeou secured a second term in office, beating Tsai Ing-Wen, a female candidate from the main opposition and pro-independence party, DPP. It was a close win for KMT since President Ma took $51.6 \%$ of the vote to challenger Tsai's $45.6 \%$. Many international media reported that the final result was 'a relief to both China and America' (BBC, 14/Jan/2012a; Guardian, 14/Jan/2012a; Guardian, 14/Jan/2012b; Washington Post, 14/Jan/2012; Financial Times, 15/Jan/2012; The Sunday Times, 15/Jan/2012; the Economist, 2012, p. 54) since the result also reaffirmed KMT's policy of establishing closer ties with Beijing.

The election not only epitomizes the external pressures outside Taiwan, but also how internal tensions form a controversial political divide between pro-China and pro-independence.

The issue of the extent to which Taiwan can assert autonomy from China has been a running sore in Sino-US relations for more than six decades since in 1949, the ROC government, led by the KMT, relocated to Taiwan when the Chinese Communist Party established the People's Republic of China (PRC) on mainland China. In the section that follows I will examine how Taiwan has developed from the historical context since the KMT's relocation to Taiwan in 1949.

\subsection{Brief Overview of Taiwan's History}

A brief summary of milestone events towering in Taiwan's history from the traces of early inhabitants to the latest developments is provided in following section in a chronological overview table (see Table 3.2. below). 


\begin{tabular}{|l|l|}
\hline \multicolumn{2}{|c|}{ Table3.2. Key Events in Taiwan's History (1624-2011) } \\
\hline European colonization \\
\hline 1624 & $\begin{array}{l}\text {-Beginning of Dutch colonization } \\
\text {-Beginning of Spanish colonization (northern Taiwan) }\end{array}$ \\
\hline 1642 & $\begin{array}{l}\text {-Spanish driven out by the Dutch; Reign of the Jheng family } \\
1621-1622\end{array}$ \\
-Han administration after Jheng Cheng-gong defeated the Dutch
\end{tabular}


As Table 3.2 outlines above, after China's defeat in the First Sino-Japanese War, in 1895 Taiwan was ceded to Japan under the Treaty of Shimonoseki (GIO, 2005). The Japanese colonial government undertook several infrastructure developments to remake this island to a base where Japan could expand southward. Under a half-century of colonial rule, which sought to make Taiwan an agricultural base serving Japan's strategic needs, Taiwan's agricultural had been commercialised and given a strong foreign trade orientation (Garver, 2011). Also, culturally the government conducted 'Japanisation' to naturalize Taiwan's residents into Japanese way. For example, Taiwanese were forced to give up their heritage by adopting Japanese names, cuisine and lifestyle. Chinese languages and customs were discouraged. Under the colonisation, Taiwanese were denied the right of self-governance and were kept out of key positions in all facets of society $(\mathrm{GIO}, 2007)$.

At the end of World War II in 1945, following Japan's defeat and surrender, Japan relinquished Taiwan and the Republic of China assumed control of Taiwan. In 1949, the KMT government in China relocated to Taiwan after losing a civil war against the Chinese Communists. The influx of soldiers and immigrants from the mainland China to Taiwan changed the island's character by getting it involved in the Cold War.

When the Korean War happened in 1950, the USA dispatched its Seventh Fleet to protect Taiwan from the communists and began to provide Taiwan with economic and military aids (GIO, 2005). In 1958 the US and ROC government issued a joint communiqué reaffirming their solidarity. This prevented Taiwan from being conquered by the communists in China through the 1950s and 1960s (GIO, 2007).

From 1951 to 1965, large amounts of economic and military aid came from the United States. Much of the aid was used to improve Taiwan's infrastructure and the agricultural sector. With industrialization and modernisation, rapid economic development has shifted Taiwan form a former colony to a energetic exporter of high-tech products after 1980s (Booth, 2011). After the lifting of Martial Law in 1987, a process of democratization began (Wang, \& Lo, 2000). The democratisation was implemented by transforming the government from single-party rule of KMT to a government determined by democratic elections. 
A high point of the democratisation appeared in 2000 not only when the main opposition party Democratic Progressive Party (DPP) defeated long-term dominant KMT in election, but also the executive power was handed over peacefully (GIO, 2010).

In the transitional history outlined above, some eye-catching features can be underlined in economic, political, cultural and social aspects.

\subsubsection{Economic Aspect}

Taiwan's economic growth, from a former colony with a defeated power in 1945 to 'an Asian tiger' in the 1960s and 1970s', and 'a formidable producer and exporter of medium- and high-technology products after 1980', is one of distinctive features that shaped the character of the transitional society (Booth, 2011, p. 101).

Between 1962 and 1985, Taiwan's economy experienced its rapid growth. In the early 1980s, items such as garments, footwear and toys were still the key products contributing to the economic growth, but by the end of the 1990s, their shares had become negligible. That is because at the beginning of 1980s, the government carried out a series of plans to shift the economy by forcing the labour-intensive industries, once the mainstay of Taiwan's economy, to give way to technology-intensive or capital-intensive industries. In the 1990s, the electronics and information-technology sectors expanded rapidly to become Taiwan's main industries, accounting for more output and exports than any other sector in the manufacturing industry. By 2002, the largest share went to electronic goods, information and communication products, basic metals, non-garment textiles and machinery. All of these new exports were capital- or skill- intensive or both (Chu \& San, 2011).

In this rapid economic development, a significant economic trend worth noticing was the rise of investments in China in the 1980s by Taiwan's business community (Taiwan Yearbook, 2007). The sharp increase of Taiwan's exports to China beginning in the 1990s decreased the island's dependence on the US market (GIO, 2012c).

Compared with mainland China, a key element in Taiwan's steady economic growth was the wide range of implementation of education throughout the island to raise literacy rates (GIO, 2006). For example, in 1951, 34.6 percent of 
the population six years and older were illiterate. This figure had dropped to 15.3 percent by 1969 and to 2.84 percent of the population over 15 years of age in 2004 (Taiwan Yearbook, 2007).

Another key element was Taiwan's enterprising spirit which has been viewed as an important drive to help Taiwanese overcome the difficulties in economical and political situation and brought about globally-acclaimed economic achievements (GIO, 2007). The remarkable transformation of Taiwan, from a poor and agriculture-based economy into a knowledge-based economy, has been seen as a part of a broad set of changes often labelled as 'globalisation'. Taiwan entrepreneurs have been important drives of the process of the globalization, and the Taiwan economy has naturally been one of its largest beneficiaries (Naughton, 2011).

\subsubsection{Political Aspect}

Taiwan's rapid industrialization during the 1960 s and 1970s, combined with the democratic revolution that began with the lifting of Martial Law in 1987 were of deep historic importance.

Looking over the history of Taiwan's democracy, Schafferer (2005, p. 1) roughly draws three periods of development in the history of Taiwan's political field:

1) Limited pluralist authoritarian party system (1945-1986);

2) Pluralist party system with one dominant party KMT (1986-2000), and

3) Polarized pluralist party system.

A limited pluralist authoritarian party system developed in Taiwan under the KMT regime between 1945 and 1986. The relocation of the ROC government to Taiwan at the end of the Chinese civil war opened the beginning of Martial Law (1949-1987) in Taiwan. This imposed press censorship, banned new political parties, and restricted freedoms of speech, publication, assembly, and association. During that time, the KMT government allowed opposition candidates to take part in local and national elections, and to form loosely connected political organizations, but 'restricted the political power of the opposition' (Schafferer, 2005, p. 1). In 1975, after the death of the KMT leader and President Chiang Kai-shek, his son Chiang Ching-Kuo came to power to continue the dominant ruling. In 1987, shortly before Chiang Ching-Kuo's death, 
he lifted the Martial Law, which made the democratization possible (Wang, \& Lo, 2000).

The late 1970s and early 1980s, some opposition movements against the one-party authoritarian rule of KMT were undertaken by opposition leaders. The formation of the Democratic Progressive Party (DPP) on September 28, 1986 was a landmark moment in Taiwan's progression towards multi-party democracy (Schafferer, 2005).

Taiwan's first direct presidential election was held in 1996, and the KMT incumbent Lee Teng-hui was re-elected. But the real test of Taiwan's democratic progress came with the first transfer of power in March 2000. DPP candidate Chen Shui-bian won the second presidential election, ending the KMT's half-century hold on the presidency. According Rawnsley \& Rawnsley (2012, p. 16) a conclusion can be drawn from Taiwan's experience that liberalization and democratization are phases of political change presenting the least problems, but 'this can only apply to transitions that are as atypical as Taiwan's - smooth, non-violent, consensual, incremental and elite-driven' (Rawnsley \& Rawnsley, 2012, p. 16).

In March 2004, President Chen Shui-bian was re-elected. As of June 2006, a total of 118 political parties had registered with the Ministry of the Interior. Currently, the six largest parties are the ruling Democratic Progressive Party (DPP), the Kuomintang (KMT), People First Party (PFP), Taiwan Solidarity Union (TSU), Non-Partisan Solidarity Union (NPSU), and New Party (NP)- all have seats in the Legislative Yuan (Taiwan at a Glance, 2007).

In 2008, KMT candidate Ma Ying-jeou won the election and led the KMT back in power. In 2012, President Ma Ying-Jeou secured a second term by beating DPP candidate Tsai Ing-wen.

\subsubsection{Culture and Social Aspect}

Over the next decade after 1987, Taiwan's 'political miracle' matched its earlier 'economic miracle', and the continuation of these achievements came along with the new challenges surfacing when group consciousness emerged as a reaction to the decades-long suppression of cultural diversity under Martial Law. For instance, 'the social movements of women, labour, and environmental issues all played an increasingly engaged role in trying to guide government 
policy' (Fell, 2012, p. 234). As different social groups competed fiercely to exert their political subjectivity, the politics of difference among various groups have generated the arising conflicts from their struggle over political recognition. In the arising conflicts, cultural differences often become the boundary of groups.

Although Taiwan is a predominantly Chinese or Han society, its heritage is much more complex than this generalization could imply since the succeeding waves of Han immigrants from mainland China belonged to a wide range of groups with various languages and different customs (GIO, 2009). In modern Taiwan, distinctions among the groups may have become blurred due to extensive intermarriage and universal use of the Mandarin Chinese language, but the ethnic composition can still be roughly separated into several groups, such as indigenous peoples, Han People, the Holo, the Hakka, and the immigrants arriving with ROC government after 1949 (Taiwan Yearbook, 2007).

Before the arrival of any immigrants from China, indigenous people, possessing diverse cultures and languages, were the only inhabitants of Taiwan. Now they contribute about two percent of the whole Taiwanese population. Among them, there are 12 major different groups of indigenous peoples. Despite intensive exposure to Chinese and Western culture, the indigenous groups have maintained some of their unique lifestyle and distinctive cultural traits (GIO, 2007).

On the other hand, the ancestors of Taiwan's Han people started to migrate from China's south-eastern provinces to Taiwan in the 17th century. The majority of these early immigrants were composed of the Holo from southern Fujian Province and the Hakka from eastern Guangdong Province in China. Most of them moved to Taiwan for longing for better lives and seeking shelter from upheavals during the transition from the Ming dynasty to the Ching dynasty. After about three hundred years, another big wave of Han people moving into Taiwan again in large numbers of immigration. The ROC government led by KMT relocated to Taiwan in 1949 and brought about 1.2 million people from China (GIO, 2006). Unlike earlier immigrants, the influx of the immigrants composed of people from every province of China. They are not only Han Chinese but also minority peoples from Mongolia, Tibet, and south-western China. These immigrants brought their own customs and cultural traditions to Taiwan, which are as distinctive and rich as those of the Holo, 
Hakka, and indigenous peoples. The cultural influence of these immigrants on Taiwan can be seen in diversity of food, songs, art and literature.

The languages and dialects spoken in Taiwan also have their own origins. Common Han languages used in Taiwan include Mandarin, Holo Taiwanese and Hakka while the indigenous groups use their own indigenous languages (GIO, 2007). After the KMT government moved to Taiwan in 1949, Mandarin Chinese was decided to be the official language and was forced to promote through the educational system.

Following Taiwan's democratization in the late 1980s, social pluralisation was accompanied by a growing emphasis on local languages. Public and private efforts have been devoted to teaching students their mother tongues and preserve the languages and dialects of smaller ethnic groups. For instance, to help preserve indigenous culture, the government has included the study of indigenous languages in Taiwan's compulsory education system. In 2005, more than 40,000 elementary and junior high school students took indigenous language courses, and 40 languages and dialects were taught. (Taiwan Yearbook, 2007).

In a review of transitional changes in cultural way, Lee \& Wu (2006, pp. 5-7) roughly coin 'five phases of the development of civil society' in post-war Taiwan. They can be briefly summarised as follows. The first phase from 1965 to 1978 is a period when the society experienced rapid modernisation. The concept of 'right' was emerging but the different groups from various concerns still remain in the relationship of patron and client with the state. In the second phase from 1978 to 1986, with the growing numbers of groups representing different voices in the society, the role of these group gradually shifted from clients to 'watch dogs' which are without rather than within the configuration of the state. The third phase from 1986 to 1990 is the time when some sociologists introduce the concept of civil society from the Western countries while social movements of women, labour, politics were emerging. The seed of civil society and pluralism grew its impact during the fourth phase from 1990 to 2000 and reached a high peak in 2000 when the unprecedented power shift occurred in the presidential election. In the fifth phase, from 2000 to date, the concept of civil society has gained a solid foundation and become a ideal model in most discussions of social development. 
Combined with the political and economic background discussed earlier, from authoritarian society to young democracy, from agricultural system to a showcase of capitalism, Lee \& Wu (2006) indicate that shaping of the civil society echoes with the governmental intervention from the state and the ideology of capitalism behind the rapid economic growth. However, compared with the capitalism-orientated civil society in Hong Kong and authoritarian society in China, Lee \& Wu also (2006) note the civil society in Taiwan is somewhere between the both types.

As discussed in Chapter 2, the media plays a pivotal role in the empowerment of civil society. The interaction of media with the transitions to democracy and the civil society in Taiwan will be addressed in next section.

\subsection{Three Phase of Television Transitions in Taiwan}

Having summarized some of the key aspects in the process of transforming Taiwan, this section further examine the shaping of the media landscape in that social context to become a competitive market driven by maximizing rating and profits. The section looks at the both ways in which the democratization in Taiwan has influences and been influenced by the media.

A media profile of modern Taiwan can be seen in table 3.3. below. 


\begin{tabular}{|c|c|}
\hline Table 3.3. Media Profile of Taiwan & (Jun, 2011) \\
\hline Radio stations & 171 \\
\hline Terrestrial (wireless) television stations & 5 \\
\hline Cable television companies & 69 \\
\hline TV \& radio program production companies & 7,160 \\
\hline Audio (compact disc, etc.) production companies & 10,098 \\
\hline Satellite broadcasting program providers & 107 \\
\hline Satellite broadcasting service operators & 9 \\
\hline Newspapers & 2,156 \\
\hline Magazines & 8,122 \\
\hline Book publishers & 13,257 \\
\hline Foreign media with correspondents in Taiwan & 61 \\
\hline Source: Government Information Offic & $2012 d)$ \\
\hline
\end{tabular}

As table 3.3. shows, a very crowded media market can be seen with the size of Taiwan and its population. As discussed in the first chapter, this hyper competitiveness has tended to foster sensationalism and triviality in much of the sector. Several media scholars identify the 'invasion' of a HK newspaper, Apple Daily, in 2003 as a key factor in exacerbating 'tabloidisation' in the Taiwanese media during the early years of the twenty first century. (Lin, 2008; Lo, 2008; Lee \& Li, 2006, Ko, 2003). According to these sources, the notorious tabloid style and values of the Apple Daily stimulated a competitive emulation in other Taiwanese titles that significantly reshaped the media landscape. However, not all agree, for example the academic We Ti, adopting a political economic perspective, held that most of these increasingly accentuated features were 'home grown' (Her, 2006) with their roots in the shaping history of Taiwan's Media environment. In other words, the 'uni-causal' offered by the Apple Daily invasion might obscure deeper economic imperatives that have shaped the Taiwanese mediascape over a far longer period of time. Here We Ti's view (Her, 2006) is taken as a departure point for this section to review the shaping process of the contemporary media landscape to identify the 'home-grown' problems and to see how the PSB expansion can serve as a solution.

A brief overview of iconic events in Taiwan television history is shown in Table 4.4. below. 


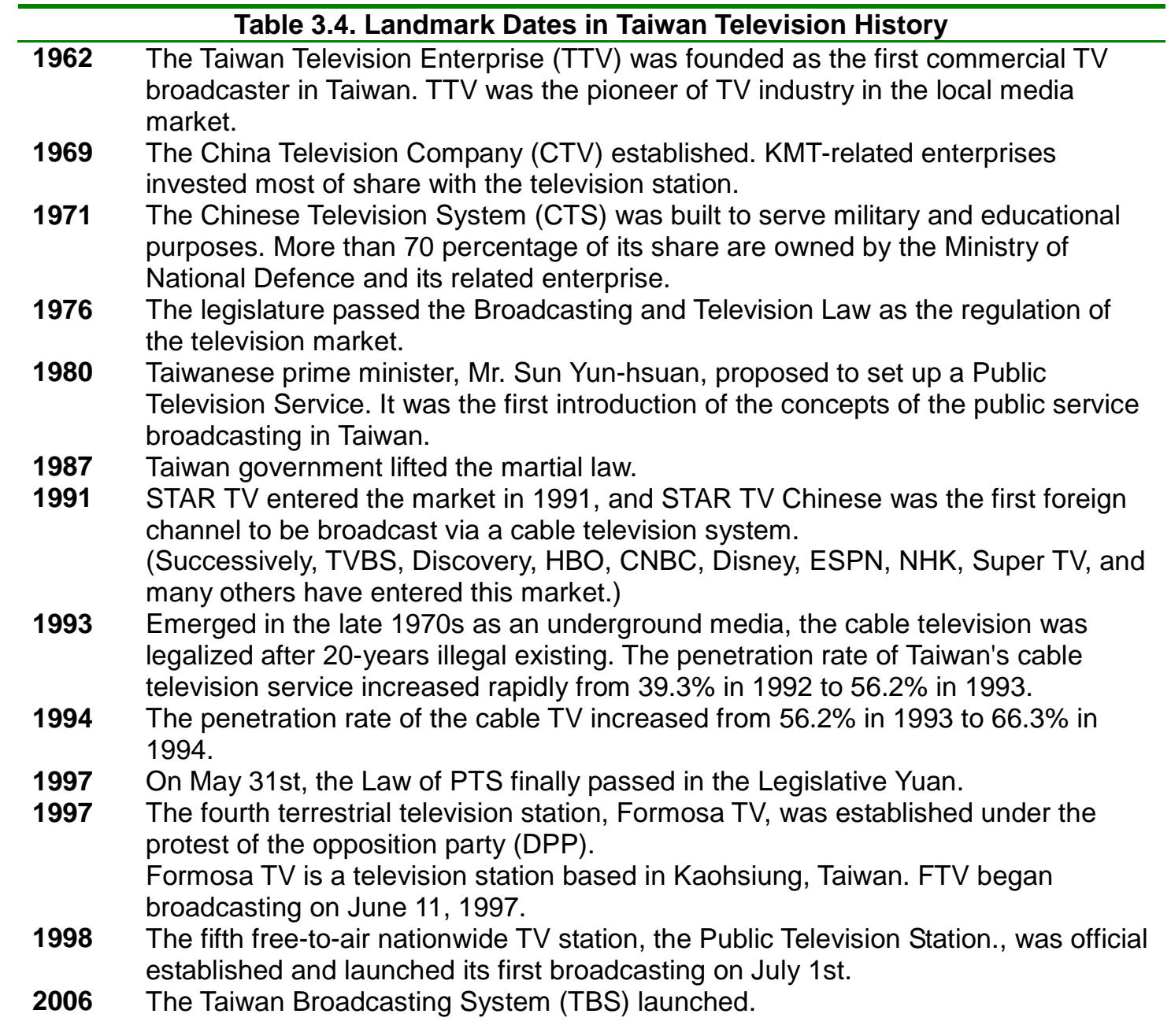
Source: Government Information Office: Taiwan Year book/Media (2012d)

In Pauwels' analysis (2010) of television history in Europe, a chronological overview is presented by coining three main periods of the history:

1) Television within frontiers' period;

2) Television without frontiers' period; and

3) Television beyond frontiers' period.

The three periods respectively show three key features in the periods of the history: scarcity, choice and abundance (Pauwels, 2010). This categorisation can also reflect the features of Taiwan's broadcasting development, and for this reason the frame is adopted in this section to distinguish different phases of the media development in Taiwan. To some extent, the three periods might overlap 
each other in this categorisation.

\subsubsection{Television within Frontiers: Scarcity (1949-1987)}

In most authoritarian countries, it can be seen that those in power often 'put the media under tight control in order to consolidate their ruling power' (Hallin \& Mancini, 2004, pp. 119-121). This feature was clearly evident in Taiwan in the period from 1949 to 1987 . The implementation of the Martial Law in 1949 declared a state of emergency, and rights of assembly, association, and the right to form political parties were suspended. In the thirty-eight years that followed, political rights and freedom of the media were limited (Lee, 2000, p. 125; Jhou, 2007).

In such a period, Taiwan's first television system was in 1961, when the experimental National Education Television began broadcasting two hours of educational programming every day. This was followed by the establishment of Taiwan Television Enterprise (TTV) in 1962, China Television Company (CTV) in 1969, and Chinese Television System (CTS) in 1971. These three television stations were responsible for broadcasting television programmes to whole Taiwan because local television stations were not permitted. As Seaton notes in discussion of the monopoly period of BBC, 'the scarcity of the spectrum frequencies is considered the main justification for the monopoly position' (Seaton 2003, p. 367), this was also an excuse for the KMT to justify their control on the monopoly television broadcasting system.

Since the national economy was too impoverished to finance a non-commercial television system, non-commercial models were never contemplated (Lee, 1980). Take the first television station TTV ( from 1962 to 1986)for example, apart from shareholding of government-owned Industries (48.95\%), its shareholders also included private Japanese enterprises like Fuji, Toshiba, NEC and Hitachi, Ltd.

The second television station, China Television Company (CTV), received its $50 \%$ investment from BCC (Broadcasting China Corporation: the main and largest radio network run by the $\mathrm{KMT}$ ) and the other $50 \%$ came from other radio stations owned by domestic businesses in Taiwan. As a 'television Company', CTV claimed they were the first commercial television station in Taiwanese media history when it was established in 1969. However, since its 
most investment were from the KMT-related enterprises, the management and programs of CTV were heavily influenced by KMT and the decisions for its management were made on political rather than professional grounds (Rawnsley \& Rawnsley, 2012, pp. 4-5). The third one, CTS, was originally built to serve military and educational purposes. More than $70 \%$ of its share was owned by the Ministry of National Defence and its related enterprise.

In this period, Taiwan remained in a serious military conflict with communist mainland China, and in order to against communist's anti-capitalism, the KMT state tended to harness and shape the state-owned but commercial-run television industry to showcase its commitment to free enterprise for the international community (Lee, 1980). In the state-owned and commercial-run model, the method of control was through a system of media ownership which not only privileged the regime but also embedded the media within the state structure. Table 3.5. below shows the ownership of three television which were under the control of a tri-power alliance of government, the ruling party, and the military between 1962 and 1986.

Table 3.5. Three television stations and their shares distribution (1962-1986)

\begin{tabular}{|c|c|c|c|}
\hline & TTV & CTV & CTS \\
\hline $\begin{array}{l}\text { Taiwan province government-owned } \\
\text { Industries }\end{array}$ & 48.95 & & \\
\hline KMT-owned Industries & & 68.32 & \\
\hline Ministry of National Defense Investment & & & 40.15 \\
\hline National Defense Ministry Related Industries & & & 46.30 \\
\hline Private Industries & 51.05 & 31.77 & 13.55 \\
\hline Total & 100.00 & 100.00 & 100.00 (Percentage) \\
\hline
\end{tabular}

Table 3.5. illustrates a pattern of media ownership that does not conceal political influence and motives during the era of Martial Law. The KMT government, like their Communist counterparts in China (de Burgh 2003; Keane 2003, pp. 169-187) further created a labyrinthine patron-client network via the ownership control. The party-state incorporated the 'patron-client relationship' (or 'clientelism') into media control by rewarding certain media proprietors with high-ranking positions in the KMT or other economic benefits to ensure that media coverage presented the government in a favourable light (Lee, 2000; Lin, 2000). Some significant characteristics of the media in the 
period were identified by Rawnsley \& Rawnsley (2012, pp. 4-5). They can be summarised as follows:

1) The media industries under the authoritarian system showed clear signs of clientelism, including important appointments and ownership;

2) In order to reflect the political agenda, the news agenda and news coverage were politically controlled or influenced;

3) Laws and legal systems were used to influence or intimidate the media. It led to a heavy self-censorship by media workers and the self-censorship was necessary for their survival;

4) An autonomous public sphere was missing in the media.

The features of this period outlined above mirror the inclination to perceive and practice the television stations as political instruments of state control. There was little room for the media to play an independent role isolated from political force and the political communication was a one-way, top-down process that transmitted the political will without a genuine public sphere for deliberation and dialogue.

\subsubsection{Television without Frontiers: Choices (1988-1999)}

Until the beginning of liberalization and democratization in 1987, the KMT maintained its control on the three national television stations via ownership which held by an overlapping party/state/military political authority that defined the martial law era. Economically, the three terrestrial television stations also accounted for a significant portion of the economic value in the monopolized market. After Martial Law was lifted in 1987, the oligopoly of the three main terrestrial televisions was changed by multi-channel competition coming alongside the prevalence of cable and satellite televisions and the launch of two other terrestrial television stations, Formosa Television (FTV) and the Public Television Station (PTS).

The feature of the changing political economy in the post-martial law period was increased capital concentration and a new alliance of money. One striking character in this period was the emergence of the cable television system which offered alternative 'choices' from the mainstream terrestrial televisions.

Cable television initially grew out from community antenna television. The community antenna, which was first appeared in 1969, was originally designed 
to improve the reception quality in remote areas and mountainous terrain. Some operators began to offer illegal programmes and services by installing cheap transmission equipment in 1976. Taiwanese audience quickly embraced these cable channels due to the paucity of programming provided by the three terrestrial television stations. Cable television also captured a social and civic need by providing alternative political views from officially sanctioned information (Lee, 2000). Cable television soon became a profitable venture despite being illegal. Operators spread rapidly all over Taiwan. It was estimated that by 1984 there were over two hundred cable television (Weng, 1993), and over six hundred by 1993 (GIO, Jun/2003).

Around this time, STAR TV Chinese became the first foreign channel to be broadcast via a cable television system when the satellite television system STAR TV entered the market in 1991. After that, TVBS, Discovery, HBO, CNBC, Disney, ESPN, NHK, Super TV, and many others have successively entered this market. These companies have competed with domestic satellite channels since the 1990s. These companies became increasing absorbed within the cable system and became the most important content providers.

Wen (1993) highlighted several reasons for the prevalence of cable television, including 1) multiple choices of programmes; 2) technological progression; 3) appearance of the videotape and satellite providers; 4) subscription fee of cable television was much lower than buying a video player and videotapes; 5) no proper regulation on cable television operators for more than 20 years; and 6) an underground economy where pirate videotape factories supplied cheap American and Japanese movies, sex videos and latest releases to cable television operators. This cut down the cost for cable television operators to survive in the market.

The rapid proliferation of the cable television soon raised two problems for the KMT government. This first problem was a growing threat to their ruling legitimacy. Some cable television systems were directly run by members of opposition parties and often delivered their own political points of view and alternative news sources challenging the monopoly of the state broadcasting. For example, the main opposition DPP's fight for a reorganized media system, through the cable television, posed a challenge to the state. In the late 1980s, the DPP legislators often involved in physical fight with fists against the KMT 
legislators to pass or reject special bills. Since the KMT's media control, the physical confrontations in the legislature were always portrayed the DPP party in a negative way. The DPP legislators complained whenever the three main terrestrial television stations showed the fighting scenes, the DPP were portrayed in an unfair representation with bias. In order to balance television coverage, some DPP members utilised the videotapes to show their own perspective of what really happened in the Legislative Yuan through cable television system.

As a substitute to mainstream media and programming of a local nature, cable television offered the possibility for forging stronger social relationships between sources and the audience. Such a narrowcasting, however, also divided the audience seeking out those programmes that corresponded to their own political orientation. As Robinson (1996) points out, coverage and talk shows on cable television did not make for notably more objective comment but promoted competition in biased reporting. Rawnsley (2001) indicated that in the period biased reporting was used to promote the political views associated with the opposition parties. 'Bias for the opposition is warranted by the opposition parties because it can balance the bias of the mainstream media which favours the KMT government and remedy an already unbalanced media environment under KMT control' (Rawnsley, 2001: p76).

The second problem is that most of cable television violated copyright policy by broadcasting pirated films. Some U.S. film distributors were enraged for their loss of business interests and condemned the illegal behaviour. Under pressure from the film industry, American Trade Representatives strongly lobbied for a new legal regime for cable and an official crackdown on illegal cable television systems. In March 1991, these issues were presented on the main agenda during the Taiwan-American copyright and patent protection Negotiations (Chin, 1997).

Under pressures respectively from the opposition party (DPP), the cable television operators, and American officials, the KMT state compromised upon the existence of cable television. In 1993, the Cable Television Act was formulated under cross-pressure from various interest groups including political parties and private sections. After cable television was officially legalised in 1993, the industry experienced tremendous changes in terms of its market 
scale and structure (See table 3.6. below). The penetration rate of Taiwan's cable television service increased rapidly, from 39.3\% in 1992 to $56.2 \%$ in 1993 and grew to $66.3 \%$ in 1994.

After the Cable Television Act in 1993, the Taiwanese government formulated the Satellite Act in 1999 to regulate the satellite operators and satellite program suppliers (See table 3.6. below). Since the satellite and cable television industry attracted both local and foreign entrepreneurs, their appearance introduced more competition and led to increased capital concentration and a new alliance of money and power in the seeming multiple-choice media environment (See table 3.6. below). 


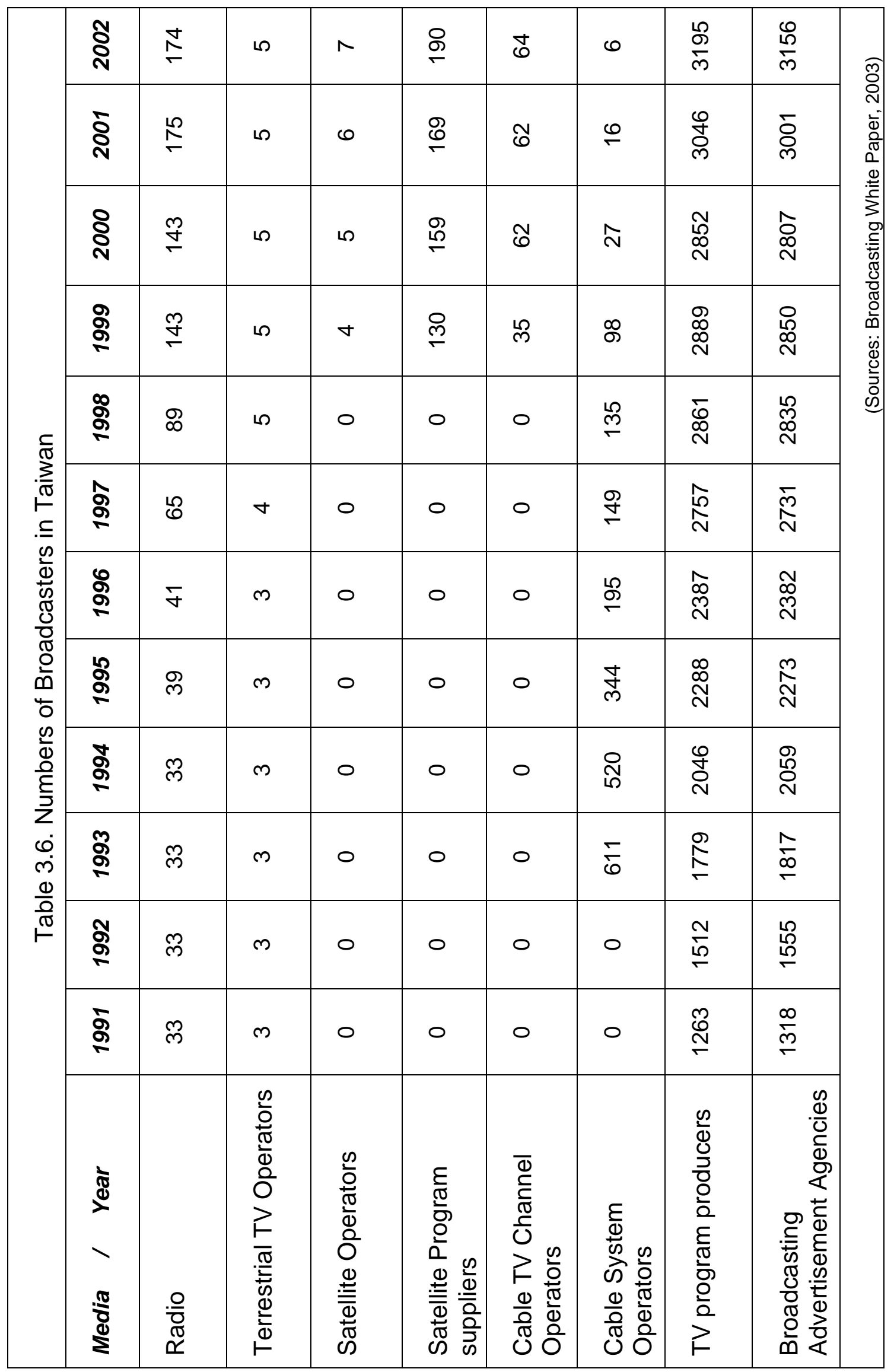


As part of the global trend toward broadcasting deregulation, Taiwan's cable industry brought coalition between political groups and financial interests to another level, and the cable television itself may serve as a conduit for international capital (Feng, 1995). Although state control waned, the state still could allocate resources to maintain influence via alliance with their capital. Thus, political power and commercial capital developed a new dialectical relationship in this period. The cable and satellite competitive market also reflect a wide spectrum of political orientation in Taiwan. Although no cable system is directly run by any political parties, some systems are indirectly affiliated to political powers, including the opposition parties of DPP, NP (New Party), and the ruling party (KMT).

Apart from cable and satellite television, in this period two more terrestrial televisions were established: Formosa Television (FTV) was inaugurated in 1997, and the Public Television Service was established in 1998.

After the main opposition party DPP had constantly lobbied for 'the fourth terrestrial television license since the late 1980s' (Independent Evening Post, 28 July 1987, p3), in 1997 the KMT state finally allowed one more terrestrial television station, Formosa Television (FTV), to be established. On June 11, 1997, the fourth terrestrial television station FTV was launched with major investment from members of the main opposition party DPP. Some researchers (Feng, 1995; Lee, 1998) view this open-up of the KMT state as a means to co-opt dissent and protect its own continued monopoly. After DPP attained its coveted television station, DPP showed no more genuine interest in building the 'public sphere' Feng $(1995 ; 1998)$. On the other hand, FTV also adopted 'biased reporting and media coverage' to 'balance the bias of the pro-KMT terrestrial televisions and remedy the already unbalanced media environment under KMT control' (Rawnsley, 2001: p76).

On the other hand, in 1991, a committee for Public Television Preparatory was set. Specialists and scholars in Law and Media were enlisted to formulate a draft for a Public Television Act. In 1997 the Public Television Act was passed and the first Board of directors and supervisors in the Public Television Service Foundation was approved. In 1998 the Public Television Station officially delivered its broadcasting service (more details about the development of the 
PTS will be addressed in next chapter about the PSB history in Taiwan).

In this the period of 'choices' (1988-1999), the shift from the state to market seemingly opened up more consumer choices. However, the market did not have a positive impact upon programming diversity in broadcasting. According to Li \& Chiang's study on the extent in which the programming diversity was affected by the changing structure of the media market (2001), the results indicated a negative relation between market competition and programming diversity. Li \& Chiang (2001) argued that although the market competition increased from 1986 to 1996, this study discovered that the degree of programming diversity was reduced year by year. Furthermore, there were growing concerns as the market pressures and competition gradually formed the increased capital concentration. On the one hand, the new alliance of commercial power developed a new form of censorship power. On the other hand, the ferocious competition had impacts on the quality of media output as the competition mainly focused on ratings and advertising revenue.

\subsubsection{Television beyond Frontiers: Abundance (1999- to date)}

Following the period of television without frontiers (1988-1999), new problems arose in this 'abundance' period while liberalisation and deregulation encouraged more competition at the expense of quality of media output. As competition intensified, the media became less willing to invest in innovative programming and instead battled to capture the same middle-ground audiences with the same already- popular formats. This raises the question as to whether programme quality has always been apparent in Taiwan's broadcasting. From the previous discussion, one would conclude not, with the rise of partisanship to ameliorate (partially) state monopoly

With accelerating competition and an ever more crowded market, 23 million people not only shared five terrestrial television stations but also numerous cable and satellite broadcasting service. For instance, in 2004, a total of 60 domestic and 19 foreign companies were offering 93 and 42 satellite channels. In 2005, 63 cable TV systems were in operation and the cable penetration rate was 60.4 percent (GIO, 2006). In 2006, domestic and foreign companies were offering 92 and 43 satellite channels (GIO, Apr/2007), respectively, including NHK from Japan; Home Box Office (HBO), Disney, and Discovery from the 
United States; and groups of specialized, satellite-based channels operated by local media conglomerates, such as Eastern Broadcasting, TVBS, ERA, CTI, Video-land, San-lih Entertainment Television (SET), and Gala Television. In 2007, with 130 cable television channels, Cable television was viewed by about 80 percent of the population (GIO, 2008).

In this period, Taiwan's five terrestrial television stations were facing growing pressure when the rise of cable television gradually shared more and more advertising revenue in the existing market. For example, the three pro-KMT terrestrial commercial television stations had been losing money year after year from 2002 (Feng, 2009, pp. 21-42) while the cable television industry kept competing for viewers in the same market with the terrestrial televisions without any intention to create separate market or to cultivate their own targeted audience (Cheng, 2005). Furthermore, Cheng (2005) indicates that the cable television operators actually focused on short-term interests rather than long-term development. With their dominant position in the market, their position prevented them from investing more on pay-television or any other new technology since the possible re-structure of the whole market coming with any innovative change might bring risks to damage their existing profit (Cheng, 2005). The phenomenon of cable television industry in Taiwan actually has been following a terrestrialising' path (Cheng, 2005) which means the cable television system gradually to replace the free-to-air system with its multi-channels package including the terrestrial television programming. Thus, in 2005, the DPP government (GIO, 2007) instituted a national standardised allocation system for the cable channels with some reserved slots for main terrestrial television, public-interest programming of PTS, Hakka TV, TITV, CNN, or NHK.

In a national wide survey in 2004 which focused on the cable television viewers' watching behaviour and satisfaction (Zchi \& Tsai, 2005), the result showed that $66 \%$ of the population spend 2 hours per day watching television and $17 \%$ of the population are heavy television users who spend more than 5 hours every day in front of television. The popularity of the programming between terrestrial and cable televisions are shown in table 3.7. below. 


\begin{tabular}{llr}
\hline & News & $\mathbf{1 8 \%}$ \\
\cline { 2 - 3 } Cable and Satellite Channels & $\mathbf{1 7 \%}$ \\
\cline { 2 - 3 } & Gentertainment and Drama & $\mathbf{1 3 \%}$ \\
\cline { 2 - 3 } & Mandarin Film & $\mathbf{7 \%}$ \\
\cline { 2 - 3 } & Western Film & $\mathbf{7 \%}$ \\
\cline { 2 - 3 } & Children's Cartoon & $\mathbf{1 1 \%}$ \\
\cline { 2 - 3 } & Other* & \\
\hline \multirow{2}{*}{ *includes leisure and education, financial news, Japanese $^{*}$ Programming, sports, music, and shopping channels. } \\
& \multicolumn{2}{c}{ Source: ROC Yearbook 2003-2004, GIO. }
\end{tabular}

As Table 3.7. show, news is the most popular format in the cable television system. Since it is a profitable format, in Taiwan there are six 24-hours news channels competing in the market, including TVBS-N, FTV news, ERA news, the San-lih news, the CTI news, and the Eastern Television (ETTV) news channel. Whit the number of the all-news channels, it is hardly a surprise to see the news channel decline to sensationalism and triviality as discussed in opening chapter.

In the Table 3.7., the second popular genre is Entertainment and Drama. In an effort to strengthen competitiveness by lowering the cost, both terrestrial television and cable television operators increased importing programmes from China, Hong Kong, Japan, and South Korea (GIO, 2007). Here it mirrors serious problems in the national terrestrial television stations since they are supposed to have more ability to customize output for local audiences that those cable channels.

In Taiwan, although different languages like the Holo Taiwanese, the Hakka and different indigenous languages were spoken in Taiwan, most news programs are still broadcasting in Mandarin since Mandarin Chinese is the official language (See table 3.8.). Compared with Mandarin programming, other minority ethnic language programming like Hakka or Indigenous programming have a smaller percentage (See table 3.8.). 
Table 3.8. The Ratio of languages on broadcasting programming

\begin{tabular}{|l|l|r|r|}
\hline \multirow{5}{*}{ Radio Programming } & \multicolumn{1}{|c|}{ Languages } & \multicolumn{1}{c|}{2005} & \multicolumn{1}{c|}{2006} \\
\hline & Mandarin Chinese & $38.86 \%$ & $37.00 \%$ \\
\cline { 2 - 4 } & Holo Chinese & $48.02 \%$ & $50.30 \%$ \\
\cline { 2 - 4 } & Hakka Chinese & $10.18 \%$ & $9.86 \%$ \\
\cline { 2 - 4 } & Austronesian languages & $0.25 \%$ & $0.32 \%$ \\
\cline { 2 - 4 } & English & $1.93 \%$ & $1.73 \%$ \\
\cline { 2 - 4 } & Japanese & $0.02 \%$ & $0.22 \%$ \\
\cline { 2 - 4 } Oerrestrial TV & Others & $0.74 \%$ & $0.57 \%$ \\
\hline \multirow{5}{*}{ Programme } & Mandarin Chinese & $82.99 \%$ & $83.30 \%$ \\
\cline { 2 - 4 } & Holo Chinese & $11.21 \%$ & $10.94 \%$ \\
\cline { 2 - 4 } & Hakka Chinese & $0.43 \%$ & $0.34 \%$ \\
\cline { 2 - 4 } & English & $4.22 \%$ & $4.27 \%$ \\
\cline { 2 - 4 } & Japanese & $0.23 \%$ & $0.19 \%$ \\
\cline { 2 - 4 } Satellite TV & Others & $0.90 \%$ & $0.95 \%$ \\
\hline Programming & Mandarin Chinese & $58.18 \%$ & $57.85 \%$ \\
\cline { 2 - 4 } & Holo Chinese & $6.67 \%$ & $8.65 \%$ \\
\cline { 2 - 4 } & Hakka Chinese & $1.88 \%$ & $1.68 \%$ \\
\cline { 2 - 4 } & Indigenous languages & $0.10 \%$ & $0.23 \%$ \\
\cline { 2 - 4 } & English & $18.91 \%$ & $17.50 \%$ \\
\cline { 2 - 4 } & Japanese & $13.98 \%$ & $13.95 \%$ \\
\cline { 2 - 4 } & Others & $0.28 \%$ & $0.14 \%$ \\
\hline
\end{tabular}

Sources: The 2006 Annual report, National Communication Commission, 2007

In order to preserve the languages and cultures of smaller ethnic groups, a Hakka television station (Hakka TV) was set up in July 2003 with funding from the Council for Hakka Affairs. Likewise, funded by the Council of Indigenous Peoples, Taiwan Indigenous Television (TITV) was inaugurated on July 1, 2005. However, Feng (2006, p. 14) also points out the establishment of the ethnic broadcasting services are not only due to consideration about minority interests but also political consideration by the DPP government 'since these broadcasting services can also effectively reach and focused ethic groups with well-crafted messages during elections' (Feng, 2006, p. 14).

Actually, with either the shift from state to market or the power shift from KMT to DPP, the media has never really been immune from political interference. Rawnsley \& Rawnsley (2012, p. 8) identified two salient examples to illustrate the way the DPP government threatened media with government interference after 2000. The first example happened in March 2002 when the authorities raided into offices of Next magazine to prevent distribution of an article that 
revealed a secret bank account with US $\$ 100$ million allegedly used by former President Lee Teng-hui to buy influence abroad. The reporter was accused of having endangered national security and his home was searched as well (Apple Daily, 24/04/2010). Employees of the China Times, involved with investigating corruption in the National Security Bureau, were subjected to similar intimidation. The second example happened in August, 2004 when Taiwan's High Court upheld for reasons of national security the conviction of reporter Hong Zhe-zheng of Power News. The case revolved around an article that the reporter had written in 2000 reporting Taiwan's regular military exercises. Hong was sentenced to eighteen months in prison, suspended for three years (Liu and Tsai, 2009, p. 274). Apart from the two examples with magazine and newspaper, in terrestrial television the DPP government also adopted the KMT's old tricks to developed their 'patron-client relationship' into media control by rewarding certain media proprietors with loyal DPP members to ensure that media output represented their image in a favourable light. For instance, in 2004 when the DPP government appointed a local actress Chiang Hsia, who is known as a loyal family friend of President Chen Shui-bian, to be the general manager of the state-owned CTS, this appointment stimulated lots of complaints from political actors. 'Actress Chiang Hsia, a long-time supporter of DPP, took over as general manager of state-controlled CTS amid harsh attacks from opposition legislators on her professionalism and her political loyalties (Taipei Times, 25/06/2004, p. 2). This appointment also evoked criticism from academic circles and pressure groups which expecting the DPP government can establish a proper PSB as the government promised.

These examples illustrate that even after 2000 that 'the year of the historic presidential election when fifty years of government by the KMT gave way to the DPP, the new government were still closely monitoring the media' (Rawnsley \& Rawnsley, 2012, p. 8).

To respond to the demand for an independent oversight away from the state, in 2006 the government launched the independent National Communications Commission (NCC), charged with regulating the country's communications and broadcasting industries. The new regulatory body consolidates responsibilities formerly shared by the Government Information Office (GIO) and the Ministry of Transportation and Communications. 
Besides having a new regulator, another key issue in this period was the expanding public broadcasting group which prompted by higher public expectations. In January 2006, the law on disposing of public shares in terrestrial TV stations was given the green light. The Legislative Yuan passed a media reform bill regulating the sale of government-owned stock in TV stations and allowing the PTS, Taiwan's first public television channel, to merge CTS, Hakka TV, TITV and Micro TV to form a PSB group, Taiwan Broadcasting System (TBS), which is meant to be isolated from commercial and political influence.

According to the statute, one of the state-owned terrestrial television Taiwan Television Enterprise (TTV) should sell all of its shares to the market through a public and transparent procedure and another state-owned terrestrial television Chinese Television System (CTS) would be transformed into a member of the PSB group. The government would spend approximately NT\$2 billion (US\$63 million) to buy back its privately owned shares before donating them to the planned public television group, TBS.

In this 'abundance' period, the market competition, which discouraged innovative programming but sacrificed its quality, mirrors the rise of consumerism and the decline of programming addressing audiences in their roles as citizens. Also, the political interference did not fade away from the media landscape while the media deregulation and governments' changes occurred in this period.

In next section, by combining features from the three periods, the politics of media representation will be outlined to show the systems failures in the media landscape.

\subsection{The Politics of Representation: System Failures}

When looking at the relation between market structure and programme innovations, a positive relation between oligopolistic market structure and programmes innovations was claimed by some media economists (Burnett, 1992; Schumpeter, 1950). Basically, in an oligopolistic market, since a few firms control most of the market share, there will be a high degree of market concentration. These economists believe that only in an oligopolistic market 
structure, firms can have sufficient financial resources to test different types of products, develop new programmes, and pass the costs of innovations on to consumers. Thus, they state that an oligopolistic market increases the innovation and diversity in mass media market (Burnett, 1992; Schumpeter, 1950).

On the contrary, some other media economists claim that they found a negative relation between market concentration and product innovation (Coser, Kadushin, \& Powell, 1982; Litman, 1979; Peterson \& Berger, 1975; Rothenbuhler \&Dimmick, 1982). They hold the view that when a few firms dominate a market they have little incentive to innovate because what each firm strives to do is to gain the largest share of a market. In this situation, each firm will try to produce products that please and satisfy as many consumers as possible. This process leads to homogeneity because the oligopolistic market reduces the possibility of innovation and makes programmes less diversified. With open competition among many firms, the best strategy is to differentiate their products from others to cater separate needs. That means that a market with many competitors induces innovation and increase diversity in mediascape (Coser, Kadushin, \& Powell, 1982; Litman, 1979; Peterson \& Berger, 1975; Rothenbuhler \& Dimmick, 1982).

The dispute over the two theories is not settled definitively due to insufficient and inconclusive empirical data. However, both of the assumption backgrounds happen to be in the developing process of Taiwan's media landscape and neither oligopolistic market structure nor open commercial competition could bring the diversity and innovation highly expected to the media market.

As was observed earlier in the three periods of the media history in Taiwan, some features can be summarised as follows.

First, the political change from single-party rule to multi-party gradually brought liberation to the media landscape that used to be under single-party control. However, the multi-party environment could not secure adequate or fair representation because of the government's continuing interference on the media. Second, the rise of consumerism alongside consumer oriented television led to the decline of programming addressing audiences as citizens. Thirdly, the inability of the commercial television system fails to reflect the range of issues of contemporary Taiwanese society. Fourth, the argument 
around the need to protect national culture based around domestic production as against filling channels with imported programmes. Finally, the demands of ethnic groups for greater representation on the television screen are rising.

This chapter has illustrated the key moments in the process of the transition of the media landscape and outlined some system failures in the media representation. In recent years the focus of local media research have shifted to examining the capability of Taiwan's fledgling PSB group, TBS, asking questions such as, is it a right decision to expand the PSB while other public broadcasters around the world in retreat and is the PSB expansion capable to rectify the system failures in Taiwanese media landscape. Here the answers are still being heatedly debated, especially in the light of domestic concerns over Blue-Green political divide. However, here the discussions just began. By the end of this thesis, with display of enough materials and evidences, this thesis will explain the way how the PSB expansion in Taiwan has been socially defined and constructed, and by whom.

The next step, in the chapter to follow, is to illustrate the details in the PSB history in Taiwan and then generate research questions and research methods. 


\section{Chapter 4}

\section{Research Objects, Research Questions and Methodology}

Our examination of the contested definitions and practices of PSB around the world in Chapter 2 and the system failures in the Taiwanese media landscape in Chapter 3, has aimed to develop a better understanding why Taiwan has undertaken to expand PSB at a time when, in most other countries around the world, it is in retreat and international media commentators question whether it PSB has outlived its usefulness.

The purpose of this present chapter is to illustrate the teething troubles and the endemic difficulties facing this fledgling PSB system, and to generate research questions for this study by reviewing the history of PSB in Taiwan together with relevant research findings.

\subsection{Case Description: Two Waves of the PSB Demands}

Table 4.1. provides a chronological overview for the key moments in the development of PSB in Taiwan. Two main waves of the demands for public service broadcasting can be identified in the timeline.

The first wave emerged in the mid-1990s and resulted in the creation of a single channel Public Television Station (PTS). However, this initiative never 
managed to achieve more than a minority presence in the commercialized media landscape.

The model of PTS was similar to the model of the PBS in the US which discussed earlier in chapter 2. 'The function of the public or educational broadcasters was to provide that programming that was unprofitable for the commercial broadcasters to produce' (McChesney, 1999, p. 247).In other words, with the mission to fill the gap the market cannot or would not to fill, the logic of this model is that any programme which is too popular should more properly appear on commercial television (Tracey, 1996).

With huge disappointments with the marginal role of the PTS and the remaining overwhelming commercial broadcasting, a second wave gathered momentum when a policy window was opened by the unprecedented political transition in the 2000 presidential election.

This window opened the way for renewed political struggles, social movement activity and academic debate, centred around two competing proposals for reforming the terrestrial television stations, with advocates of privatisation on the one side and supporters of PSB-oriented proposal on the other. Against the privatisation ideas, the PSB-oriented proposal proposed transforming the state-owned television asset into a new, extended, public service broadcasting system. In this proposal, the key idea conceptually means a transformation of the state-owned terrestrial televisions to a corporation in the public sector. Specifically, the proposal entailed all political parties, the state, and the military relinquishing all control over terrestrial television and ceding its administration and operation to an independent corporation in the public sector. This proposal was seen by its advocates as a way of creating space within the broadcasting landscape for a greater degree of freedom and independence in the pursuit of the ideals of public service. This key idea mainly generated from the ideal model of the BBC in the UK, 'a national, popular, and pluralistic broadcasting' (Scannell, 1996, p. 25-31).

The reasons why the British model was a significant model referenced in the second wave of the PSB developments in Taiwan were mainly because the failure the PTS with its marginal role in the media landscape. The supporters for the PSB-oriented proposal believed that only a mainstream PSB can really deliver what it promised to the media environment. Also, among key supporters, 
some active media academics gained their PhD degree from the UK and had a good understanding of the BBC model. For example, a key figure in the long-term PSB campaign, Feng Chien-san (馮建三), was awarded a PhD at Leicester University. Another key player, Wei Ti (魏玓), studied his PhD at Loughborough University. With their deep knowledge of the BBC and other Western European PSBs, the ethos of British model was highlighted in the second wave of the PSB expansion in Taiwan.

After a period of debate and political struggle, which will be examined in details in subsequent chapters, this option outran the privatisation plan and became the preferred policy. The direction of PSB expansion was finally cemented with the passage of legislation in 2006.

In order to illustrate the main features of these two waves conceptually and practically over time, the following discussion will be divided into four phases: the inception of PTS (1980-1997); creation and disillusion with PTS (1998-1999); formulation of plans for PSB expansion (2000-2006) and the implementation of the new PSB system (2006 to date). 
Table 4.1. Chronological Overview of Public Service Broadcasting in Taiwan

\begin{tabular}{|cl}
\hline Year & \\
\hline 1980 & Premier Yun Suan Sun first calls for the establishment of a Public Televisic \\
1983 & $\begin{array}{l}\text { The Government Information Office (GIO) drafts an outline for a centre } \\
\text { Producing Public Television Programmes. }\end{array}$ \\
1984 & $\begin{array}{l}\text { The Public TV Program Production and Broadcasting Committee were } \\
\text { under the GIO. Time slots are requisitioned from three main terrestrial TV } \\
\text { to broadcast programs. }\end{array}$ \\
1986 & $\begin{array}{l}\text { Program production is given to the Public TV Program Production and } \\
\text { Broadcasting Team under the Chinese Public Television Broadcasting } \\
\text { Development Foundation. }\end{array}$
\end{tabular}

1991 The Public Television Preparatory Committee is established after the Executive Yuan approves guidelines for installation. Seven specialists and scholars are enlisted to formulate draft legislation for the Public Television Act.

1993 The Public Television Act is submitted to the Legislative Yuan for approval.

1996 Social activists from media academia form the Public Media Lobbying Alliance.

1997 (31 May) The Public Television Act passes in the Legislative Yuan.

1998 The Nomination and Review Committee of the Legislative Yuan approves 18 nominees for the 1st Board of Directors and Board of Supervisors of the Public Television Service Foundation.

1998 (1 July)The Public Television Service Foundation is established and officially launches broadcasting services.

2003 (9 Dec) The Legislative Yuan passed amendments to the Broadcasting and Television Act, Cable Television Act, and Satellite Broadcasting Act. These amended laws prohibit the government, political parties, party affair personnel, appointed government officials, and elected public officials from investing in the broadcasting and television industries. In addition, government and political parties must withdraw their investments within two years after implementation of these three laws. Based on the government's initial plan, Chinese Television System (CTS) would become publicly or privately owned.

2006 (3 Jan) The Legislative Yuan passed the Statute Regarding the Disposition of Government Shareholdings in the Terrestrial Television Industry, ushering in a new era of media free of political parties, government, and military.

(16 Jan) Liming Foundation donated CTS shares to the PTS Foundation.

(31 Mar) The special CTS shareholders meeting elected the new CTS board of directors and supervisors. The board was composed of 11 PTS directors and supervisors, six experts recommended by PTS, and six representatives from private shareholders. The first meeting of the new board of directors and supervisors was convened, and PTS chairman, Dr. Louis Chen was elected CTS chairman without remuneration. During the meeting, the appointments of Yuan Li as CTS president, Wu-sung Kao as vice president, and other executives were also approved. CTS became a public entity in due process. The establishment of the Taiwan Broadcasting System (TBS), composed of PTS and CTS, was set into motion.

2006 (1 Jul) The Chinese Television System (CTS) went into the PSB umbrella structure. The Taiwan Broadcasting System was formed.

2007 (1 Jan) Hakka Television, Taiwan Indigenous Television and Taiwan Macroview Television merge to the TBS to become a PSB television family.

(Summarised from Public Television Service Foundation 2007 annual report, p. 2) 


\subsubsection{The inception of PTS (1980-1997)}

The emergence of PSB in Taiwan dates back to the 1980's when then-Premier, Yun Suan-sun, announced that the society needed a public service alternative to commercial programming (Feng, Shy, \& Kuo, 2002). In response a ten-minute-long programme named the 'public TV programme' was broadcast via the three main terrestrial televisions.

One of these stations, the Chinese Television System (CTS), could have been the first public broadcasting television station in Taiwan since its original aim was to deliver educational programming. However, since the commercial-run state-owned model was seen to be operating effectively in the two other television stations, TTV and CTV, it was extended to CTS, forcing it give up its initial aim of providing an educational service. The first CEO of CTS, Liu Hsien-Yun, later recalled regretfully that the channel had missed the opportunity to deliver a distinctive service to the society (Chen, 2005). In his view, since CTS was as named after 'a system' rather than 'a company', its core mission was to provide a general education service rather than to make money. In his reminiscences he states:

'I deeply understand that earning maximum profit should not be the aim of the CTS. However, this commercial model put most of our programming under pressure from the advertisers who pay money to us.......We could not get rid of this (pressure) even though we realized that this pressure would damage the basic value of broadcasting....As CEO, I feel very ashamed. That is why I offered to resign my position several times' (Chen, 2005, p. 324).

During the martial-law period, in the name of national security, the three terrestrial television channels were mainly owned by the government, the KMT party, and the military, respectively (Cheng, 1993). The lifting of Martial Law in 1987 ushered in a rapidly growing multi-channel media landscape alongside satellite and cable television development. However, this rapid change failed to 
bring diversity in programming. Research on this changing structure shows that while the intensity of market competition dramatically increased from 1986 to 1996, the degree of programming diversity was reduced year by year (Li \& Chiang, 2001). In response, in 1991, a committee for Public Television Preparatory was established and seven specialists and scholars in Law and Media were enlisted to formulate draft legislation for public television. The resulting Public Television Act was finally passed in 1997 and subsequently 18 nominees for the first Board of Directors and Board of Supervisors in the Public Television Service Foundation were approved. In 1998 the Public Television Station officially delivered its new broadcasting service.

\subsubsection{Creation and Disillusion with PTS (1998-1999)}

In order to maintain its isolation from commercial pressures' (ibid, Chapter IV, article 41), PTS was barred from receiving income from commercial advertisements. The Government Information Office (GIO) was appointed as regulator (the Public Television Act, I, 3) and the Public Television Service Foundation, which was responsible for administering the service, received funds from five main sources: 1) government contributions allocated from the annual national budget; 2) interest from operating the funds; 3) contributions from public and private institutions, organizations, or individuals; 4) income from the channel's cultural businesses and activities; 5) income from producing programs on commission; and other sources of income (ibid, III, 28).

The core obligations of PTS were outlined in the Public Television Act. They included 'safeguarding the citizens' freedom of expression', 'raising cultural and educational standards' and 'advancing the development of democratic society'. Most of these aims echoed principals followed by other public service broadcasters around the world. However, the most important mission listed in the Act, in the very first article in the first chapter, is that PTS should play a complementary role and 'compensate for the inadequacy of commercial television':

This Act is enacted to promote the effective development of public 
television, establish a public service mass media system, compensate for the inadequacy of commercial television, and safeguard the citizens' freedom of expression and right to know, raise cultural and educational standards, advance the development of democratic society, and enhance social wellbeing through diversified planning. (The public television act, I, 1)

This emphasis on 'compensation' had the effect of placing PTS in a subordinate or secondary role providing programming for marginalised audiences ignored by the commercial television. As Chin (1997) noted, although commercial forces gave a birth to the public television station it is clear that the private media will continue to dominate' (Chin, 1997, p. 91).

As one channel in a market with more than one hundred commercial channels for viewers to choose from, it was not a surprise to find that PTS was not only unable to provide an effective counter to the commercialised media market, but also failed to satisfy the mounting demands for more effective political insulation of the media prompted by the continuing political influence over the three terrestrial televisions, TTV, CTV, and CTS.

\subsubsection{Formulation of Plans for PSB expansion (2000-2006)}

The 2000 presidential election ended the unbroken rule of the KMT and installed a government dominated by the main opposition party, the DDP, for first time in post-war Taiwanese history. This political shift opened a window of opportunity for media reform since the three terrestrial televisions had been under KMT's control. As Feng, Shy, \& Kuo (2002) point out, before the early spring of 2000 , privatisation was the dominant and mainstream option for changing the ownership of terrestrial television while the PSB-oriented proposal, 'Gong Gong Hua', was mostly supported by and confined to media academics. However, once the DPP presidential candidate, Chen Shui-Bian, adopted the 'Gong Gong Hua' proposal in his campaign, it joined privatization as the other main option contesting in the policy-making arena for the reform for the terrestrial television (Feng et al., 2002).

One controversial event in 2001 accidentally accelerated the contest 
between two proposals in a dramatic way. A DPP legislator Lin Chung-mao, insulted another prominent legislator, Sisy Chen, calling her 'a shameless prostitute' ('Lawmakers rise to decry Sisy Chen 'prostitute' jibe', Taipei times, 12/12/2001, p. 3). Lin Chung-mao's claimed that, Sisy Chen, who was also a very popular television and radio host of political talk shows, had abused her media power to criticise President Chen Shui-bian in inappropriate ways, arguing that 'when Sisy Chen abuses her media influences to criticise the President Chen abusing his power, it looks like a prostitute is criticising the sex industry' (Taipei times, 12/12/2001, p. 3). The resulting public furore soon sparked a furious debate on the interplay between politicians and media. Alongside media and public prurience at Lin's insulting choice of words the dispute also promoted a degree of serious discussion on the potential abuses of political patronage and the operation of political interference in terrestrial television, as signalled in this story:

'Curse incident' shifts to "politicians out of the media". Sisy Chen called on the DPP to use the same standard to examine themselves......The debates about 'Legislator Lin Chung-mo abuse of legislator-elect Sisy Chen' yesterday shifted to 'if all politicians should withdraw their power from the media.'...(Sisy Chen calls on political power out of terrestrial televisions, United Daily News, 14/12/2001, p. 3)

Seizing the opportunity presented by calls for political power to be removed from the media, critical media academics and pressure groups renewed their efforts to press the case for PSB. For example:

While a debate over terrestrial television ownership rages in political circles, a growing number of media academics are urging the [DPP] government to 'get out of the media' at the same time.......The debate over the collusion of political organisations and media was introduced last week in the wake of a fight between DPP legislator Lin Chung-mo and independent legislator Sisy Chen. (Taipei Times, 17/12/2001, p.3)

Following the renewed debate about effective insulation of terrestrial television 
from political influence, and how to cut the strong ties between the channels and the government, positions of the political parties soon became the core of the debate.

Although the PSB-oriented proposal was in the DPP's Election Manifesto, after party came to power its attitude towards this proposal seemed to become more reserved. The proposal demanded serious political commitment because it entailed breaking the traditional ownership patterns inherited from the KMT period. First, the government would surrender its shares in two of the terrestrial televisions, TTV and CTS, undermining the entrenched liaison between economic interests and political power. The next step would be to restrain partisan and state influence in the media. The DPP administration afterwards claimed that the project 'cannot be put into practice right away and needs further deliberation', because it would cost much more than the government could then afford (Lin, 2001). Around the same time, the contest between advocates of privatisation and the PSB-oriented proposal in the Blue-Green political struggle flared up again. AS the Taipei Times noted:

DIVISIVE ISSUE: Two competing visions for reducing political influence on the media threaten to derail reform efforts and the two sides are being urged to cooperate. ...... (Legislators split on how to reform media, Taipei Times, 26/12/2001, p. 2)

The PSB-oriented proposal were driven by a political alliance called the democratization of terrestrial television (ADTV) while the privatisation plan was supported by an alliance led by the People First Party (PFP) legislator Diane Lee. She argued that forcing the government and political parties to sell their shares in terrestrial TV to private investors was the only way to solve the problem. The ADTV worried that if the government sold its shares and the two televisions stations were privatized there would be no effective means of control over program quality. Lee, however, claimed that the government in Taiwan is not 'mature enough' to practice the ADTV's PSB-oriented proposal (Taipei Times, 26/12/2001, p. 2).

'The two sides should reach a consensus on the issue as soon as 
possible; otherwise, I am afraid nothing will change.' KMT legislator Apollo Chen said.... (Legislators split on how to reform media, Taipei Times, 26/12/2001, p. 2)

The two sides, both advocating 'more effective insulation of terrestrial televisions from political influence' but disagreeing on the best way to achieve this, privatisation or 'Gong Gong Hua', kept pushing their proposals into the policymaking process while the DPP government kept its distance from both sides. In 2002, a campaign group the Campaign for Citizens' TV (CCTV), held a protest and a press conference to blame President Chen for his broken promise on reducing political interference in the state-owned terrestrial television channels. This campaign took out half-page newspapers advertisement titled 'We Will No Longer Tolerate [DPP government]' to express their disappointment with the government's inaction on media:

'The 'Campaign for Citizens' TV (CCTV) held a press conference to condemn President Chen Shui-bian and the Executive Yuan for delaying the practice of 'public television' and other media commitments from his presidential campaign promises. Three campaign members, Lin Hsiao-hsin, Shih Shih-hao and Kuo Li-hsin, now offer their resignations as directors of local terrestrial TV stations to show a serious protest.......'CCTV' Convenor Feng Chien-san urged President Chen and the ruling party to immediately fulfil its media reform ....Presidential campaign promises. (Protest against the delay of media reform, China Times, 11/10/2002, p. 6)

The protest, which demanded that the 'DPP must keep promises on media reform' (Taipei Times, 10/10/2002, p. 8) was written by campaign members who including the Director of TTV, Lin Hsiao-hsin, the Director of TTV, Shih Shih-hao and the Director of CTS, Kuo Li-hsin (2002). The campaign argued that the most urgent task was to turn remaining two state-run television, TTV and CTS, (the third one, CTV, was already privatised and the main shareholders were KMT-related private firms), together with the Public Television Service (PTS) into a larger and more efficient 'public TV group'. Their view tallied precisely 
with Chen's policy, laid out in the cultural policy section of the DPP' $s$ White Paper published for the presidential campaign in 2000. In their announcement, the Campaign members stressed that they had pushed the DPP to implement the policy since the party came to power, but the DPP government had failed to put this important policy into effect to date and that consequently the campaign group condemned them for their equivocation on their own promises. They urged President Chen and the ruling party to immediately fulfil their campaign commitment to a proper media reform and called for a clear timetable for reform that included plans for the establishment, step by step, of a 'public TV group' (The 'Campaign for Citizens' TV, 2002).

This disillusion with the DDP's foot dragging was partly informed by recognition that once in power it had seemed to go down the same path of political bribery, or patron-clientelism, as its predecessor KMT in dealing with the terrestrial television. One example is the way the DPP government dealt with the nomination of high-ranking personnel to run the two terrestrial television stations.

Key positions in state-owned or controlled media had long been treated as rewards from the ruling party to those helping them to win elections or maintain power. This ability to pay political debts is one reason why control of the media remained within the inner circle of power elites. The nomination from the DPP administration was controversial because it seemed to be continuing this pattern, with the Pan-Blue camp regarding it as a political reward for the nominees' patronage rather than for their professional ability. For instance, the DPP government's appointment of a local actress, Chiang Hsia, to be the general manager of the state-owned CTS in 2004, prompted widespread disappointment and complaints from media scholars and pressure groups arguing for PSB since it was widely regarded as a reward for Chiang Hsia's loyal support for President Chen Shui-bian during his election. Critics claimed that it demonstrated that the President was not heeding warnings to avoid political appointments to senior media management positions. Chiang herself did not deny that her appointment was a political reward for her loyalty. More controversially, in her new role as general manager she claimed that she would ban all Chinese soap operas immediately to protect local programme productions. Although supporting local production commanded widespread 
support, achieving this aim by banning Chinese made programming was widely seen as a politically motivated move, informed more by the DDP's long standing opposition to any move toward reunification with the mainland than by a desire to encourage programme diversity.

Actress Chiang Hsia, a long-time supporter of the Democratic Progressive Party (DPP), yesterday took over as general manager of state-controlled Chinese Television System (CTS) amid harsh attacks from opposition legislators on her professionalism and her political loyalties.......In a TV interview broadcast last night, the outspoken Chiang told the host, "My new position is indeed a reward and it makes perfect sense because I support President Chen Shui-bian." ......Atop her priorities for her new job will be banning soap operas produced in China. (Pro-DPP actress takes CTS helm, Taipei Times, 25/06/2004, p. 2)

This continuation of the practice of using appointments to reward political loyalty disappointed many social activists and critical media academics and confirmed their disillusion with the DPP government's betrayal of their promise to keep media free from political control. Ironically, when the DPP was in opposition before 2000, it had strongly criticized the ruling party KMT monopoly on media ownership, claiming that the media were being used as a government mouthpiece and advocating the removal of party politics from the media. In the context of the Chen government's failure to enact the promise to reform the media made in the DPP white paper in 2000 (Editorial, Taipei Times, 29/06/2004: 8), it is not surprising that the appointment of Chiang Hsia drew criticism from supporters of the DDP as well as the opposition (KMT).

In response to the mounting demands for more effective insulation of the main terrestrial televisions from political pressure, the legislature eventually passed the 'Statute Regarding the Disposition of Government Shareholdings in the Terrestrial Television Industry' in 2006 (Liberty Times, 04/01/2006, p. 6; United Daily News, 04/01/2006, p. 2) which specified that the government's $74 \%$ share of CTS would be transferred to a Public Service Foundation. 
In spite of the concern about possible pitfalls, the passage of this statute was viewed by the civil society organizations campaigning for 'Gong Gong Hua' reform, as a preliminary but significant progress (Wei, 2007).

\subsubsection{The Implementation of the New PSB System (2006-to date)}

The 'Statute Regarding the Disposition of Government Shareholdings in the Terrestrial Television Industry' in 2006 laid out a general framework for the future direction of PSB expansion by outlining a project to enlarge the scope of public television by combining the PTS with a state owned commercial television station and several ethnic channels.

In July, 2006, PTS, at its $8^{\text {th }}$ anniversary ceremony, officially 'married' the 35-year-old, previously state-owned Chinese Television System (CTS) and were then major terrestrial networks merged to form the Taiwan Broadcasting System (TBS). Starting from 2007, two other television stations, Hakka TV, Indigenous TV, representing ethnic minority interests, together with Taiwan Macroview TV, joined the group under the administration of PTS to provide a more broadly based public service broadcasting system (details about the channels of TBS please see table 4.2. below). 


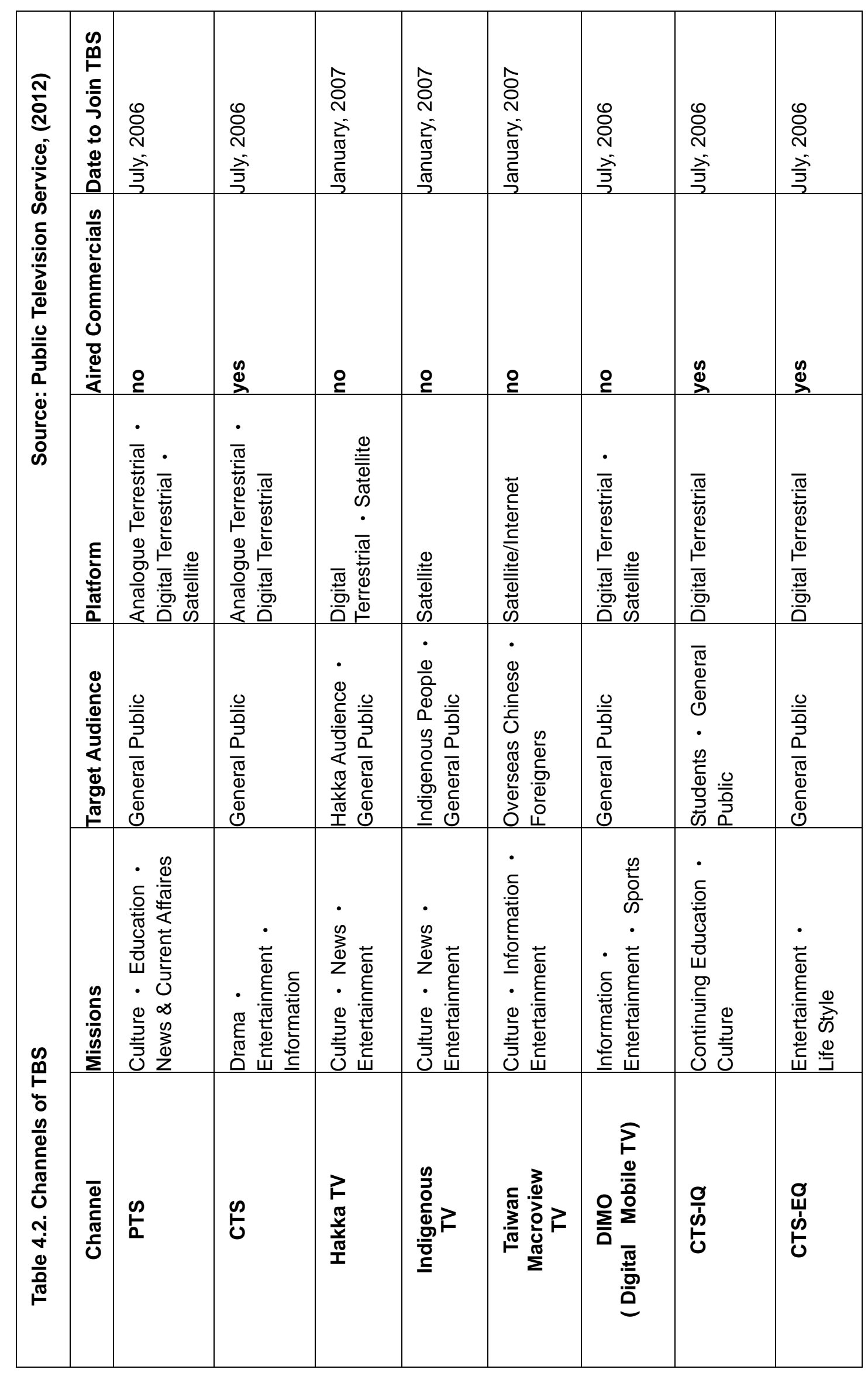


Within the group, Hakka Television (Hakka TV), Taiwan Indigenous Television (TITV) and Taiwan Macroview Television (TMT) received their funding from different government sectors to carry out their missions to provide service to Hakka people, indigenous people and overseas Taiwanese citizens. In contrast, CTS was to remain a commercial television station relying on advertising revenue as its only source of income and assuming sole responsibility for its operational profit and loss. Table 4.3. details the differences in the financial sources of the stations.

Table 4.3. Members of TBS and Their Financial Sources

\begin{tabular}{lrrr}
\hline $\begin{array}{c}\text { Television } \\
\text { Station }\end{array}$ & $\begin{array}{c}\text { Revenue (2006) } \\
\text { (million / US Dollar) }\end{array}$ & \multicolumn{2}{c}{ Financial Sources } \\
\hline PTS & 45.5 & $60 \%:$ & $\begin{array}{r}\text { Government appropriation } \\
\text { Other incomes }\end{array}$ \\
\hline CTS & 50.0 & $100 \%:$ & Commercial Advertisement \\
& $(2005)$ & & \\
\hline Hakka TV & 13.4 & $97 \%:$ & Government appropriation \\
\hline TITV & 10.6 & $95 \%:$ & Government appropriation \\
\hline TMT & 4.4 & $97 \%:$ & Government appropriation
\end{tabular}

Source: the official webpage of TBS, Q\&A, 2007

CTS's continuing reliance on commercial advertisements, while the other channels receive various government appropriations, undermines the financial and administrative coherence of the group and threatens its ability to fulfil its aim of bringing 'public value' to the media landscape.

In order to assess the delivery of 'public value', a research team was organised to establish a public value assessment system. The team 'identified 25 indices in five dimensions of public value measure framework: reach, audience appreciation of program quality, impact, public service, and efficiency of financial and business operations' (Tsao, Peng, \& Lin, 2008, p.130). These five assessment dimensions and their data sources can be summarized as follows (Tsao, Peng, \& Lin, 2008): 
1) Reach is evaluated from three indices: reach rate, viewing hours, and reach rates of new platforms. Data sources tested are viewer surveys and website click statistics;

2) Satisfaction with program quality is evaluated from five indices: number of programs entering as finalists in competitions, program diversity, program creativity, program profundity, and program fairness. Data sources tested are programming information provided by TV stations and evaluations of program satisfaction by viewers, NPO representatives, and experts and scholars;

3) Influence is evaluated from five indices: ability to form a civil society, social influence, credibility, demands, and international visibility. Data sources tested are information provided by TV stations and evaluations of TV station influence by viewers, NPO representatives, and experts and scholars;

4) Pubic service is evaluated from seven indices: resource sharing, improvement of broadcasting environment, viewing share, digital development, promotion of ethnic group communication rights, exaltation of ethnic languages and cultures, and audience preferences. Data sources tested are information provided by TV stations and evaluations of each broadcaster, viewers, NPO representatives, experts and scholars.

5) Efficiency of financial and business operations is evaluated from four indices: operation transparency, efficient use and development of resources, increasing flexibility and specialty of human resources, and fair working conditions. Data sources tested are operating information provided by TV stations and questionnaires completed by employees.

The intention of this system for assessing pubic value was to provide a more comprehensive alternative to the Nielsen rating system, and to enable the public to effectively evaluate TBS's performance. According to the TBS Chairman, Chen Sheng-fu (2011, p. 1), 'TBS has a greater social responsibility compared to other commercial broadcasters, and its performance is assessed not only through viewer ratings'. Since public service broadcasters worldwide have developed a system of accountability, which focuses on the self-regulation of the media, it is 'this system of accountability that serves as the basis for public value assessment at TBS' (Chen, 2011, p. 1). 
In order to reflect the strengths and weaknesses of TBS in the fulfilment of its duties as a public broadcaster, the first Public Value Assessment Survey was carried out in 2007, with a second survey in 2009 (TBS annual report, 2009). Although the 2007 survey results were clamed, by the then management team, to provide a good reference point for TBS in the formulation of improvement strategies and a blueprint for future development, in his later account, the TBS Chairman, Chen Sheng-fu, points out that whereas the 2009 survey covered an entire year the 2007 survey only covered a six-month period, with the consequence that the 2009 survey was able to provide more concrete and substantial results (2011, p. 1).

The 2009 survey showed that although CTS scored the highest in viewer satisfaction, 'its market positioning is still not clear' (TBS annual report, 2009). Seizing on this, supporters of the public television system argued that if CTS's performance was to be assessed by a public value test, it should have access to the public budget rather than relying solely on advertising revenue (Trend Spotting Marketing Research Co. Ltd., 2009).

Another member of the new PSB consortium, Taiwan Indigenous TV (TITV), also faced the problem of unclear positioning, according to the survey. TITV was established under the Indigenous Education Act and received it budget from the Council of Indigenous People under the Executive Yuan. Starting 2010, the Indigenous Peoples Cultural Foundation took charge of TITV's budget, while the PTS Foundation was entrusted with the day-to-day operations. This division of responsibilities posed issues for overall planning and the channels' ability to fulfil its role as a public broadcaster and led the compilers of the 2009 survey to argue that the status of TITV should be clarified as soon as possible to facilitate its long-term development (Trend Spotting Marketing Research Co. Ltd., 2009).

The 2009 survey also concluded that TBS should consider ways to integrate resources from the television stations, and specifically to find ways to build a collaborative platform that enables sharing of resources and staff in the face of limited funding and resources (Trend Spotting Marketing Research Co. Ltd., 2009).

The survey also suggests that as a public broadcaster TBS should take the initiative to establish a mechanism for public and social participation, and at the 
same time increase interaction with the viewers of the four television stations under its umbrella (TBS annual report, 2009).

\subsection{Research Aims and Questions}

Since, as we have seen, the expansion of PSB has long been in dispute in Taiwan, it has been a much debated topic and a particular focus for media academics.

These scholars' long record of media scrutiny placed them in a strong position to influence public debate and a number translated their ideas into practice and became active participants in campaigns and lobbies to advance the case for PSB. Their interventions took variety of forms, such as publishing research papers in journals, holding seminars, joining political conferences, organising campaigns and lobbying, engaging in demonstrations, or engineering a letter campaign in mainstream newspapers.

In the decade from 1998 to 2008, academic concern about PSB yielded over 100 PSB-related studies and reports in academic and general journals and conference papers identified in Dai's bibliography analysis (2008, see Table 4.4. below). To these it can be added over 100 more published by public broadcasters. 
Table 4.4. Studies of PSB in Taiwan: 1998-2008

\begin{tabular}{|c|c|c|c|c|c|c|c|c|c|c|}
\hline $\begin{array}{c}\text { Types } \\
\text { Year }\end{array}$ & $\begin{array}{c}\text { Publications } \\
\text { of } \\
\text { public } \\
\text { broadcaster }\end{array}$ & $\begin{array}{c}\text { General } \\
\text { Mournals/ }\end{array}$ & $\begin{array}{c}\text { Conference } \\
\text { Magaziners }\end{array}$ & $\begin{array}{c}\text { Academic } \\
\text { Journals }\end{array}$ & $\begin{array}{c}\text { Official } \\
\text { Reports }\end{array}$ & Books & $\begin{array}{c}\text { PhD } \\
\text { Thesis }\end{array}$ & $\begin{array}{c}\text { Master } \\
\text { Theses }\end{array}$ & Others & Total \\
\hline $\mathbf{2 0 0 8}$ & 13 & 0 & 0 & 0 & 0 & 0 & 0 & 0 & 2 & 15 \\
\hline $\mathbf{2 0 0 7}$ & 14 & 3 & 4 & 2 & 0 & 1 & 0 & 1 & 0 & 24 \\
\hline $\mathbf{2 0 0 6}$ & 29 & 4 & 8 & 3 & 0 & 1 & 0 & 5 & 2 & 47 \\
\hline $\mathbf{2 0 0 5}$ & 21 & 4 & 3 & 5 & 0 & 0 & 0 & 3 & 7 & 43 \\
\hline $\mathbf{2 0 0 4}$ & 9 & 4 & 9 & 3 & 1 & 0 & 0 & 2 & 0 & 22 \\
\hline $\mathbf{2 0 0 3}$ & 3 & 1 & 0 & 4 & 0 & 0 & 1 & 2 & 0 & 11 \\
\hline $\mathbf{2 0 0 2}$ & 7 & 5 & 2 & 1 & 0 & 1 & 0 & 1 & 0 & 17 \\
\hline $\mathbf{2 0 0 1}$ & 29 & 11 & 28 & 1 & 3 & 0 & 0 & 4 & 0 & 50 \\
\hline $\mathbf{2 0 0 0}$ & 2 & 15 & 2 & 0 & 2 & 0 & 0 & 2 & 0 & 23 \\
\hline $\mathbf{1 9 9 9}$ & 0 & 9 & 1 & 4 & 0 & 0 & 0 & 0 & 1 & 15 \\
\hline $\mathbf{1 9 9 8}$ & 0 & 5 & 2 & 1 & 0 & 0 & 0 & 1 & 0 & 9 \\
\hline $\begin{array}{c}\text { No } \\
\text { Date }\end{array}$ & 11 & 0 & 0 & 0 & 0 & 0 & 0 & 0 & 0 & 11 \\
\hline Total & 138 & 61 & 59 & 24 & 6 & 3 & 1 & 21 & 12 & 287 \\
\hline
\end{tabular}

(Sources: Adapted from results in Dai, 2008, p. 319)

As table 4.4. shows, the overall number of PSB-related studies peaks significantly in 2001 and then again in 2006. The first peak coincides with the policy window opened by the government change in 2000. Then there is a progressive drop from 2001 onwards. The second peak coincides with passing of the legislation for PSB expansion in 2006.

These studies adopted a wide range of points of view to approach the analysis of PSB including: PSB and media policy (Cheng, 2003), PSB and media performance (Tsao, Peng, \& Lin, 2008, Weng, 2006; Cheng, 2005; Lin, 2006; Feng, 1999;1995), legislation establishing the legal status of PSB (Feng et al , 2002), the options for financing PSB (Feng, 1998), personnel and media accountability (Weng, 2008; Tsao et al, 2008), and PSB and national identity (Chen, 2008, p. 213).

Despite the diversity of topics, the majority of the studies have perpetuated the political controversy around PSB because most reinforced the argument 
that incompetent government(s) and the Blue-Green political divide were the primary barriers to its full realization. Few maintained that the elite-based PSB debate only managed to reach preliminary achievement because the values and rhetorics employed by the campaigns lacked a strong connection with the general public (Jiang, 2006; Wang, 2004; Lin, 2003). The lack of public engagement was however one of major concerns of a former CEO of the PTS and TBS, Yuan-Hui Hu, when he identified main challenges facing Taiwan's PSB (Hu, 2007, p. 207). His concern echoes the views expressed by the BBC's former Director-General, Mark Thompson when he argued that PSB has to be a 'conscious civic choice' and that any country that wants to develop a PSB tradition needs to think about how to develop 'widespread public support' (Thompson, 2006, p. 4).

More work is needed to examine the extent to which the 'public', who are the central symbolic figures in debates on public service broadcasting, are actually involved and participate in the discussions conducted in their name.

In order to fill the gap, this thesis draws on four main areas of inquiry and conceptualisation:

1) Critical Political Economy: Murdock \& Golding (2000) note that critical political economy differs from mainstream economics in four main respects. It is 'holistic', 'historical', and centrally concerned with 'the balance between capitalist enterprise and public intervention'. Most importantly, it goes beyond technical issues of efficiency to engage with 'basic moral questions of justice, equity and public good' (Murdock \& Golding, 2000, p. 61). Work within this tradition has focused on the shifting relations between states and markets in structuring the operating environment for media in democratic societies, paying particular attention to the limitations of commercial media in providing full resources for citizenship and the role of government in addressing 'market failures' through regulation and financial support for public communications initiatives. In recent years the balance struck has been substantially tipped in favour of private enterprise by the processes of marketisation. Taiwan offers an important instance of this process in action. This thesis questions the widely held belief that the commercialisation of the media necessarily leads to democratization, explores the reasons for the emergence of PSB in an over-commercialised media landscape, and details the history of the debates 
surrounding the formation of policies for PSB and its subsequent institutionalisation;

2) Politics of Media Representation: When we look into the history of Taiwan's television industry, it is clear that continuing political domination of the terrestrial television networks, political interference in the media, the rise of consumerism, and debates around domestic production as opposed to filling channels with imported programmes, have been central to debates on 'market failure'. These features erode the media system's ability to function as a public sphere (Habermas, 1989). The argument that PSB should address these deficiencies but should confine itself to providing programming that the market could not or would not provide' (Murdock, 1999) removes any effective counter to the commercial sector's domination of popular programming and in so doing sells citizens short by eroding their right to access to full range of cultural resources needed to support engaged social participation (Murdock, 1999). On the other hand, the structural relationship to government entailed in public subsidy renders broadcasting organisations potentially subject to government control or harassment sparking a continual struggle to maintain the relative autonomy of key editorial and administrative decisions and prevent public broadcasting from becoming state broadcasting. At the same time, commercial media protect their own interests by lobbing and other political expenditures and the cultivation of political relationships (Herman \& Chomsky, 1988). Thus, one important focus of work in this area is on the alliances and networks formed by civil society groups and by business interests and the ways these formations attempt to intervene in the policy marking process by building public and media support and influencing parliamentarians. Consequently, one the central concerns of this thesis is with the organisation of pressure group politics and the competing constructions of present situations and future possibilities that various alliances advance.

3) The Role of PSB: Conceptually Garnham (1997) argues that the essence of public service broadcasting is provision to all citizens on equal terms and Keane (1991) holds that it is driven by higher aspirations than solely to provide entertainment. From this perspective, one strand in the classic debate of PSB is of particular concern in this thesis; the question of what role (if any) PSB can and should play in a tele-visual environment where consumer choice has been 
extended by the proliferation of cable and satellite channels. This thesis explores how far channel plurality can address the market failures of terrestrial systems and what distinctive role PSB can play in the multi-channel age. The Taiwanese case, characterised by the centrality of commercial television, offers a valuable addition to contemporary debates.

4) Transitional Societies: In common with a number of countries involved in the third wave democracy (Huntington, 1991), Taiwan has experienced a double transition, economically from state management to market driven growth and politically from authoritarian rule to multi party representative democracy. A number of the Taiwanese PSB-related studies mentioned earlier, have suggested that the history of PSB in Taiwan may throw useful light on the wider processes involved in social reform, the transition to democracy, and the empowerment of civil society (Tsao, Peng, \& Lin, 2008, Weng, 2006; Cheng, 2005; Lin, 2006; Feng, 1999; 1995). Precisely because broadcasting is simultaneously a key industry and the major source of symbolic resources for political citizenship its constitution and future is central to understanding the wider politics of transition. Hence, the detailed case study presented here is intended to contribute to more general arguments on future of democratic culture in transitional societies as well as more specific debates on the future of PSB.

On the basis of these four general areas of interest and concern this study has two main aims. The first is to critically examine the course of debates around the expansion of PSB in Taiwan by addressing the following questions:

1) Which interest groups have been involved in the debate?

2) What are the main arguments and propositions they have put forward?

3) What points of reference have they drawn on and what experiences from other countries have been seen as relevant?

4) Which arguments have played a central role in policy formation?

The second aim is to explore the dynamics of the policymaking process by exploring the following questions:

1) Why have some arguments been accorded greater credibility and weight than others in policy formation? 
2) Who has the power to draw the boundary of inclusion and exclusion in the debate?

3) What are the consequences of this process of inclusion and exclusion?

In order to answer these questions, this research drew on three main sources of empirical evidence: 1 ) in-depth interviews with a range of actors involved in the debate; 2) documentary analysis, and 3) press analysis.

\subsection{Research Methods}

In-depth interviews were conducted to address the various constructions of the PSB debate within different groups and the competing dynamics among them. Identified from preliminary press and documentary reviews, interviews were conducted with four main groups of key actors: parliamentarians, public broadcasters, social activists, and media academics. Data from the completed interviews were analysed to identify themes and associations using recognised techniques (Backer \& Bryman, 2004) and coded in such a way as to allow for quantitative analysis of both the frequency with which certain themes appear and the extent to which they are emphasised by the different parties involved.

Documentary analysis was undertakes to review the major written sources relating to the PSB debate. Combined with the interview data, this work attempts to establish an understanding of the key events in the debates around the extension of PSB and its subsequent implementation. The main sources include: government reports and papers, parliamentary debates, papers produced by stakeholders' in the television and media industries, papers produced by civil society groups, papers produced by groups campaigning for the institution of the PSB, and comments by academic analysts.

A press analysis was conducted to provide a detailed picture of the ways the arguments and debates were presented for public consumption in Taiwan's major national daily newspapers. A systematic content analysis was conducted of the coverage given in PSB-related news stories, editorials, commentary, and letters to the editor.

The results of these various research exercises are explored in the next four 
chapters. Chapter 5 draws on interviews with key decision makers and players in the debate, documenting their differing attitudes towards PSB expansion and their constructions of the situation. It explores the boundaries of inclusion and exclusion by investigating the clash of ideas that stem from differences in the interests and priorities of different groups.

Chapter 6 reports the results of the press content analysis presenting newspaper representations as one of the outcomes of the clash of ideas identified in the previous chapter.

Chapter 7 and Chapter 8 go beyond news reporting to explore the role firstly of editorials and secondly of letters to the editor, as respectively, codifications of the political and social positions occupied by the national titles selected for analysis, and as potential spaces for public expression and engagement. 


\section{Chapter 5}

\section{Constructions of PSB Debate: Competitions for Claim-Makers}

In previous chapters it has been noted how certain issues existing in Taiwan's media landscape generated urgent demands for the introduction of a PSB service in Taiwan. The purpose of this chapter is to look at the way how these issues have been defined as 'problems' and how the need for the PSB have been defined as 'a solution to the problems' by examining a series of claims-competitions among various claim-makers.

The departure point for this chapter is the version of the social constructionist perspective developed by David Buckingham (2011) who maintains that social problems or issues 'are not simply given, but actively constructed' (Buckingham, 2011, p. 7). More specifically, he argues that, in the process of construction, groups of people, who have their own claims and assumptions toward certain issues, 'identify, select and name' the social problems: 'problems must be categorised and typified in particular ways in order to become the focus of public attention' (Buckingham, 2011, p. 7). To this here it can be usefully added Loseke's view (2003) that, in the more diverse and fluid context of contemporary societies, there is less space left for reaching consensus among the groups which often leads to the construction of social problems becoming a contested process. In this process, 'the action of claims-makers plays a central 
role' (Loseke, 2003). The key claims-makers, who usually include experts, academics, campaigners, politicians, media commentators, seek to 'define a social problem and increase its public visibility', but also 'in pursuit of their own sectional interests' (Buckingham, 2011, p. 7).

Following Buckingham's lead, this chapter engages the perspective of social construction to examine the particular ways in which the actions of various claim-makers have constructed the 'problems' and 'solution' in Taiwanese media landscape.

This chapter is informed by a combination of findings from semi-structured interviews with key claim-makers in this PSB debate, and their claims published in the press or in archival documentary evidence. Key claim makers identified in this study include legislators, media scholars, social activists, activist-academics and broadcasters.

By an examination of their claim-making and claim-fighting process, this chapter intends to gain a better understanding of the clash of ideas and the conflict of powers in the social construction of PSB expansion. The aim to explore the claims through different key claim-makers is not only to illustrate the reasons why they believe their concerns to be 'problems need to be sorted out at that time', but also to show the extent in which the claims-competitions might marginalise or prevent other ways of approaching the issues when they were constructed in specific ways.

\subsection{Identifying Key Claim-makers}

In order to collect information which is unlikely gained by observation or textual analysis alone (Berger, 2000), this chapter intend to explore different claims and to illustrate the clash of interests and priorities among groups by in-depth personal interviews. 20 key actors were identified from preliminary document and press review. The semi-structured interviews were conducted in interviewees' workplaces in Taiwan between January and April 2008. In order to show the social construction of the PSB debate at certain key moments during the policy formulation and implementation time, the focus of interviews is placed on the processes side rather than outcomes side.

These interviews, averaged from one to two hours in length, were 
tape-recorded, transcribed and coded. The names and affiliated professions of the interviewees, as well as the dates of interviews are listed in Appendix 1.

According to the interviewees' affiliated professions and the positions of their claims, this chapter broadly separates the interviewees into three categories: 1 ) legislators (parliamentarians) from different political parties; 2) media scholars, social activists and activist-academics; and 3) broadcasters.

In respect of the likely differences in the details of their responses (Marshall \& Rossman, 1989), different interview schedules were designed for each category of interviewee. Public broadcasters were asked about their perceptions and experiences in PSB practice, the challenges they face and the possible solutions they seek. Social activists, media academics or activist-academics were asked about their visions for media reform and actions they took to realise these visions. Legislators were asked about their position, judgments and experiences during the policy formation and implementation. All interviews included general questions about why public broadcasting was deemed to be in crisis, how the problems should most appropriately be defined, who exerted most influence over public definitions in this area and what kinds of cultural and social resources were accessed in defining the issues as social problems. To help interviewees address these issues more effectively press coverage of some PSB news events were used as prompts during the interviews.

\subsection{Legislators' Constructions}

As discussed earlier, the PSB expansion came along with a policy window opened by this unprecedented political transition in the 2000 presidential election. When the DPP came to power, with the re-distribution of powers after 2000 , it was alleged that there was a significant watering down of the PSB proposals. More specifically, on the surface it seems there was a very high level of agreement, between the two main parties, DPP and KMT, that the state-owned terrestrial television has been a 'problem' since the televisions served as propaganda tools to produce and spread partial political bias for a long time. Both parties came to agree that it was time to reform terrestrial television and loosen the control of the state. However, there was no consensus as to what path should be followed. 


\subsubsection{PSB in the Blue-Green Divide}

After coming to office after 2000, the DPP government seemed to reconsider its initial views on the democratisation of terrestrial televisions. For instance, in 2001 the Government Information Office (GIO) claimed that the plan to withdraw all government control and ownership from terrestrial televisions was possible but 'it is impossible to reduce all the problems in the media landscape in a once-for-all action since the current problems in the media have deep roots which started from KMT's long-term media control' (Taipei Times, 18/12/2001, p. 3). The DPP government claimed that they were working on a proposal to 'possibly minimize government influences' on the televisions but 'no timetable can be expected' (Taipei Times, 27/12/2001, p. 3). The then DPP Premier Chang Chun-hsiung also echoed this tone, commenting: 'it does take time and effort to conceive a comprehensive plan for the media reform' (Taipei Times, 27/12/2001, p. 3).

On the other hand, the KMT party advocated privatising televisions services out of fear that the DPP government would benefit from their influence over terrestrial televisions in the same way the KMT did. For instance, the KMT lawmaker Hung Hsiu-chu claimed 'the DPP government keeps extending their control over the media by sending their loyal members into the television boardrooms'. Another legislator, Lee Ching-an, from People First party (PFP), a coalition partner of the KMT, accused that 'before President Chen Shui-bain became a President, he used to criticise KMT's media control policy and advocated that the KMT government should release all its shares in televisions to free market. How can he immediately change into another face after he came to power? (Taipei Times, 18/12/2001, p. 3).'

In Taiwanese political background, it is not a surprise to see the claims, made by political actors standing on two sides of the Blue-Green political divide, contradicted to each. Also, it is not hard to detect the main concerns in the problem defining process are more on the partisan interests rather than the possible benefits the media reform can bring to the media landscape and the society. In this light, in the next section I further consider the issues created by excessive government control of publicly funded broadcasting. 


\subsubsection{PSB as a Government Mouthpiece}

As the well-known Peacock Committee in the UK when seeking to obtain a clear definition of 'public service broadcasting', 'we had some difficulty in obtaining an operational definition from broadcasters' (Peacock, 1986, p. 130, cited in Scannell, 1989, p. 135). In Taiwan, definitive definitions remain similarly elusive. Most of the legislators interviewed in this study showed little conviction or confidence in their explanations as to how the concept of PSB expansion could work to the benefit of Taiwan and its media.

For example, Lee Yong Ping, a PFP legislator who gave her full support to the PSP proposals, expressed some doubts in the interviews as to the viability of the public model in Taiwan.

Here some alert readers may already question, as a PFP legislator from a KMT coalition party, why would Lee Yong-ping support the PSB proposal rather than the privatisation plan supported by other KMT and PFP legislators mentioned earlier?

The answer probably lies in her earlier political background as a DPP member and a director of the DPP's Women's Affairs department, but in her interview she insisted that the decision to support the PSB proposal was out of her professional judgement based on her media expertise which combines with her master degree in media in NYU, New York, and practical experiences of being a manager in private television stations in Taiwan.

Even with her media expertise, Lee Yong-ping frankly admitted that one of key challenge is to explain everyone including herself what the PSB really means. In her interview she revealed that she was not confident enough that a workable system of the PSB concept can really be established. According to Lee Yong-ping:

'At that time, not many people understand what the public service broadcasting really means. To be honest, when the formulation of the Act really began, actually I didn't have a clue about how to generate a mechanism to operate a real public-oriented media since we had no practical experience before.'

The failure to agree an operational definition had major political ramifications as 
it meant the concept could be turned and twisted according to the particular points of view of different claims makers. Lee Yong-ping pointed out the PSB plan was easily characterised as a lousy method for DPP government to control the media. According to Lee Yong-ping:

'The most difficult thing to sell the PSB idea in the Legislative Yuan is that no one really believes the value of public service broadcasting. And the KMT-oriented press were always trying to stigmatise that the PSB is another way of government control since the PSB is associated with government funding. The plan was seen to be a very lame excuse for the $[D P P]$ government to exercise its malicious interference into the televisions. I spent lots of time disputing with other legislators to clarify that the PSB would serve the whole public but the [DPP] government. '

Although Price (1995) notes that it is possible to have a PSB which encourages of the public sphere but is financed directly by the government through the Legislature, in Taiwan's case PSB was interpreted as another form of state control by political claim-makers against the plan. Since simple claims are usually more effective than complicated ones (Loseke, 2003), compared with the elusive and suspicious concept which is difficult to explain to most Taiwanese who had rare PSB experience before, the concept of privatisation seems to be a much easier proposal to be understood in a environment where private media are prevalent.

As a main advocator for the privatisation plan, another PFP legislator Lee Ching-An (李慶安) held the view that the essential solution to get to the root of the 'problems' was to sell government shares of terrestrial television stations to the market. When asked why she placed her belief in privatisation rather than the PSB proposal, Lee Ching-an shared her sceptical feelings on the PSB concept. According to Lee Ching-an:

'Let the market mechanism decide! In my view it is the simplest way to isolate the manipulations from political parties and government.' 
With experiences and knowledge of political struggle, many politicians in KMT and PFP camps held more scepticism and stronger objections than Lee Ching-an who adopted a euphemistic way to claim that market mechanism could do better. Another KMT legislator Hung Hsiu-chu, unlike Lee Ching-an's, directly stated that the PSB project was exactly a political plot of the DPP government. According to Hung Hsiu-chu:

'The PSB plan is the DPP government's lame plot for holding its shares and control over the two televisions (TTV and CTS).'

When asked further about her strong objection at that time, Hung Hsiu-chu described the PSB concept is just a political tool serving to make the ugly political game look better in the public eye. In her words:

'After The DPP came to power, the taste of power makes them unwilling to release its shareholdings of televisions. The DPP government keep saying that they are planning to separate the ownership from the management to isolate the media from political intervention. This is nonsense. I know this very well because this is exactly the old tricks in the book that the old-time KMT used to play.'

In other words, the plan was seen as a plot aimed at expanding the DPP's influence under the disguise of the PSB. This leads us to the next section that address the way the PSB was viewed as a political plot.

\subsubsection{PSB as a Political plot}

To justify their delay on media reform, DPP political actors also fought back by claiming that the wealthy $\mathrm{KMT}$, even after losing power, still exerted influential media control through their commercial connections and therefore had no legitimate right to criticise the DPP government (Taipei times, 12/12/2001, p. 3). At the same time, the KMT seemed to conveniently forget their own past record of state patronage abuses and kept presenting allegations of DPP intervention as unprecedented and of likely concern to the international community. In their eyes, privatization was the most compatible strategy for Taiwan with wider 
trends in international markets. As the KMT spokesman Justin Chou stated it, 'although the KMT holds the most resources in media organizations among political parties, we think that the privatisation of all the media organizations is an international and modern trend. We want to draw a clear boundary between political powers and the media freedom' (Taipei Times, 24/12/2001, p. 2). Echoed with this argument, two pro-KMT newspapers China Times (CT) and United Daily News (UDN), also drew on neo-liberal arguments in their editorials to address that the privatisation of the media is an international trend and it is the best way to improve and modernise the media industry (CT, 28/12/2001, p. 2; UDN, 23/12/2001, p. 2).

As a main advocator for the privatisation plan and a believer of market mechanism, the PFP legislator, Lee Ching-an, raised a bold proposal by tabling an amendment to the Broadcasting and Television Act which would force the DPP government and all political parties, including $\mathrm{KMT}$, to sell all of their shares in all terrestrial TV to the free market.

In 2001, if KMT and PFP can co-work to produce a political alliance for voting, the Blue coalition parties could have easily passed any legislation in the parliament without the DPP legislators' votes. However, sectional interests concerned about their respective shareholding in media not only split the political parties into rival factions but also generated significant disagreements on the amendment. The amendment eventually remained stalled in the parliament (Taipei Times, 27/12/ 2001, p. 3). The result mirrored the long existing distrust and interest calculations among different parties in Taiwanese politics. This claim-competition among political actors also reflected that the construction of 'an urgent media reform the society really needs' focused on political interests rather than rational consideration about the future of media development proposed by media academics and social activists (More detailed analysis on this issue will be addressed in following section focusing on media academics and social activists).

After the 'fierce debate over the future of the two terrestrial television stations with legislators' (Taipei Times, 27/12/ 2001, p. 3), the GIO Director-General Su Tzen-ping, who once strongly supported the PSB idea, soon stepped down in 2002. After Su Tzen-ping, the several successors that followed in GIO 'had no faith in public media' and mostly adopted a 'minimal change' strategy to avoid 
any possible political controversy (Lin, 2003, p. 159). With the choice of nationalizing or commercializing the government's shares in two broadcasting networks, the DPP-led Cabinet kept looking at 'both ways' (Taipei Times, 15/06/2004, p. 2).

In 2004, the government announced to take a 'one step at a time' approach to the issue of nationalizing two terrestrial television stations, CTS and TTV. The approach intended to first nationalize CTS, then deciding later whether to nationalize or privatise TTV (Taipei Times, 15/06/2004, p. 2). Also, with consideration over the high costs of nationalizing two terrestrial TV stations at the same time, the government preferred to start with CTS which has higher shares in government hands (75 percent compared with 47 percent for TTV).

These developments demonstrate how the DPP government weakened its commitment to the PSB proposal which aimed to transform the terrestrial televisions into a publicly orientated format. It is difficult to escape the conclusion that once the DPP had achieved office the political benefits of retaining some form of direct control over some broadcasting became far more apparent. This is not to deny that financial factors played a significant part as well, but rather to suggest that the initial enthusiasm for a purist view of PSB started to lose ground due to pragmatic considerations about how best the party might protect and consolidate its position.

\subsubsection{PSB as a Compromised Result}

Although expanding the PSB was what the DPP party included in its Election Manifesto, it wasn't partially fulfilled under DPP's administration until 2006. Developing the mounting demands for more effective insulation of main terrestrial televisions from pressures from political rivals and media academics, in 2006 the 'Statute Regarding the Disposition of Government Shareholdings in the Terrestrial Television Industry' was eventually passed (Liberty Times, 04/01/2006, p. 6; United Daily News, 04/01/2006, p. 2). The significance of this legislation was to push forward the administration's bid to free the media from political, partisan and military influences. Precisely, it outlined that the government shares (74.95 percent) of the CTS would be donated to the Public Service Foundation for a proper public television transformation. Also, two other government-funded ethnic television stations would join the public television 
transformation to form a public television group.

In the process of the passage of the 'Statute Regarding the Disposition of Government Shareholdings in the Terrestrial Television Industry', the legislation was passed after eight rounds of cross-party negotiations.

When being asked about her reflection on her experience of participating in the legislation process which formulated the 'Statute Regarding the Disposition of Government Shareholdings in the Terrestrial Television Industry' in 2006, a interviewed DPP legislator, Lin Shu-fen (林淑芬), indicated that long negotiations over this legislation, participated in by the DPP, the KMT and other small parties in their alliance with DPP or KMT, only produced a disjointing 'compromised result' which satisfied no one. According to Lin Shu-fen:

The negotiation process was actually full of compromise and disputes among the political parties. In my view, the most important item 'political power out of the media' is still not fulfilled. For example, in the legislature the first paragraph of Article VII lines out that the team who monitors the government share transferring process should be formed by the re-presenting ratio of current political parties. The DPP legislators were strongly against this Article for its potential room for political interference (from KMT). However, the KMT and PFP, also held their strong insistence for this [the two parties totally have more seats in the parliament than the DPP legislators]. For the passage of the legislation, it finally included in the consultation conclusions.

Echoing Lin Shu-fen's observation, another indigenous representative lawmaker in KMT party, Kung Wen-chi (孔文吉), also mentioned that the 'compromised result' satisfied nobody. Kung Wen-chi indicated another example about the three other television channels going under the PSB umbrella during the negotiation. In his view:

It is ridiculous to put Indigenous TV under the PSB umbrella. The ideology of the PSB expanding project is damaging the independence of indigenous culture. Ethnic television has its very specific target while 
the PSB should provide its widespread service to the whole general public. This odd result of the legislature exposes one of the major shortcomings in the process of political negotiation.

In response to the shortcomings in the process of political negotiation and the compromised result, another former legislator, Chou Yan-Shan (周陽山), who was also a PTS director in the boardroom, shared his insightful view from his previous experience of being a legislator. According to him:

'The intention of this plan to include TITV and Hakka TV with the PSB group is actually to satisfy 'a hidden system of needs and interests'. A hidden distribution system is embedded in the plan. Certain interest groups were targeting on government budget and public money to gain their own profit. Most innocent "academic" directors in the television boardroom are too naive to realise what that really means in practical ways since they don't really have the experience to get their hand dirty in the detail. There are many people hiding behind the curtain waiting for their own interests from concerning the government funding.'

Some disconcerting issues did emerge after the other three televisions officially joined into the PSB umbrella in 2007 which appeared to provide some evidential support for Chou Yan-shan's claims. Since Hakka Television (Hakka TV), Taiwan Indigenous Television (TITV) and Taiwan Macroview Television (TMT) received their funding from different government sectors to carry out their missions to provide service to Hakka people, indigenous people and overseas compatriot. Their different targeting groups of audience, funding sources and operating models actually undermined this PSB group as well (More detailed analysis on this issue will be addressed in following section focusing on public broadcasters).

In interviews, most of the legislators agreed that a substantial move to get to the root of these 'new problems' was an urgent need for a substantial revision of the Public Broadcasting Act.

The question is, would any such revision simply open up another set of claims competitions in the legislature, since the Blue Green divide remains as 
great as ever? The then main advocate for the privatisation plan, the PFP legislator Lee Ching-an still held the view that a better solution should be selling the government shares of terrestrial television stations to the market.

II recall there was a group of media scholars acting as bulldozers to push their ideas for public televisions, some radical scholars even advocated that all Taiwanese televisions should be totally transformed into public forms, all should become Britain's BBC. Although eventually I had to accept the compromised plan to only privatise one television (TTV) and to transform another one (CTS) into a public television, in retrospect I still do not believe the PSB thing is a practical suggestion for Taiwan. Now you, this young guy, can see the PSB project turned out to be such a sorry mess by first hand. Sigh!'

There are grounds for questioning whether Lee's insights were especially prescient, as the possible option of privatisation was clearly evident from the outset. In most DPP legislators' views, privatisation would offer an open door for the wealthy KMT to buy back the terrestrial television back and control it again unofficially. Furthermore, in most media academics' claims, privatisation would only aggravate the commercial competitions and deliver little positive influences on the unbalanced and crowded media market.

In Lee's retrospective opinion, she mentioned a group of media scholars who really pushed their ideas for public televisions. This leads us to the focus of following section which discusses media scholars, social activists and activist-academics as another group of key claim-makers in the contested construction. 


\subsection{Academics' Constructions}

In this section, the focus shift to another significant group of claim-makers in the PSB debate. This group were not formally part of the party political realm but they also sought to play an active role in the process of PSB formulation and implementation.

In the eye of media academic community, the KMT's heavy control over the terrestrial televisions had been a problem for a long time. However, in an authoritarian background, 'before 1980s media academics mainly placed their criticism on the media performance or bias reporting rather than on the media structure, the ownership and the broader media ecology' (Lin, 2002, p. 121).

Following the lifting of martial law in 1987, alongside with a process of democratization with social movements of women, labour and environmental issues which played 'an increasingly engaged role in trying to guide government policy' (Fell, 2012, p. 234), and with a rapid growing commercial media market, in the early 1990s members in media academic field also raised the 'problem' existing in the media landscape and began to discuss possible actions to solve the 'problem' on two fronts: political interference and commercial forces (Lin, 2002, p. 123).

\subsubsection{PTS as A Flawed Design}

When the first PSB, Public Television Station, was officially launched in 1998, compared with the ferocious commercial media, PTS was too late for its entry and too small to compete with other commercial competitors in the media landscape. The 'usually less than 1percent rating' of PTS was one of salient examples to see the minority role of the PTS in the environment. Just like the way Tracey (1996) comments on American public television, 'at 2 percent of the audience share, one has to question public television's claim to be a national broadcaster' (Tracey, 1996, p. 162).

An interviewed media academic, Feng Chien-san (馮建三), who has been a key figure in the long-term PSB campaign, pointed the fundamental flaw in the design for PTS. In his words: 
'I disagree with the key ideology behind the Public Television Act because the meaning behind the idea shows that the public television is only to 'compensate for the inadequacy of commercial television'. It implies that the commercial television is still the dominant actor in the consideration on the media landscape. In my opinion, I think the dominant actor in a better consideration must be public service broadcasting.'

Following the disappointment that followed this first foray, in 1999 a group of critical media academics began to organise a collaborative community to discuss more effective ways to achieve substantial media transformation.

Before the 2000 presidential election, the ideas of these academics were noticed by the DPP party. Several critical media scholars were invited by the DPP's presidential campaign team to contribute their expertise into the presidential election manifesto (Lin, 2003, p. 148).

The PSB proposal, from these academics, allowed the DPP to develop its traditional complaints about KMT partisanship, control and interference in terrestrial television into a more positive, tangible and democratic vision for change in broadcasting policy and practice. Through the cooperation with political force, the academics seemed to gain more power to influence the media policy-making to fix the flaws in the first PSB, Public Television Station, when PTS served as a marginal alternative to the commercial market.

\subsubsection{PSB as an Elite Campaign}

After 2000 when the DPP came in office, these academic hoped to exploit this opportunity of power change to drive forward media reform. In November 2000, a campaign group 'Campaign for Citizens' TV (CCTV) 'was launched. The establishment of this CCTV was described as 'an unprecedented movement since it was the first pressure group organised by media academic intellectuals in Taiwan' (Lin, 2003, p. 150). .

The goal of CCTV was 'to bring public values, professional standards and democracy into terrestrial televisions' (CCTV newsletter, 15/11/2000, p. 1). The members of CCTV argued that the terrestrial televisions should not be privatized but transformed into public form. In the newsletter, active academics 
claims that 'it is the moment for active intervention by media scholars, whose long record of media scrutiny places them in a prime position to influence what happens next' (CCTV newsletter, 2000, p. 1).

In pursuing their objectives, these academics engaged in elite lobbying with the DPP political actors and developed a good relationship with the media regulator, the Government Information Office (GIO). The head of $\mathrm{GIO}, \mathrm{Su}$ Cheng-ping, used to be a journalist. With his experience of studying newsroom autonomy in Germany and being a chief editor in the Independence Post, Su was viewed as a reliable partner by these academics. 'CCTV members frequently visited Su to address importance of the PSB expansion' (Lin, 2003: 159). At the time, the CCTV members held the view that the DPP government should quickly transform two terrestrial televisions, TTV and CTS, into 100 percent public-oriented television stations and allow them to operate without any editorial meddling from government or commercial forces. However, in 2001 the head of GIO, Su Tzen-ping, stated that "he only "personally" supports CCTV's proposal' (Taipei Times, 18/12/2001, p. 3). This statement implied that although $\mathrm{Su}$, as a media expert, was personally sympathetic to the PSB proposal but the DPP government behind him apparently had different thoughts from his view. This statement soon cast a chill over both the enthusiasm of the academics and the seemingly bright picture of the PSB future.

After the GIO Director-General, Su, stepped down in 2002, the successors 'did not really have faith in the public media and adopted 'minimal-change strategy to the PSB proposal' (Lin, 2003, p. 159). The DPP government seemed not very keen to fulfil the promise after they came in power 'since the PSB expansion no longer serve as a plan for political actors to come to power but, the other way around, became a stone on the way for the government to expand its power through the terrestrial televisions' (Lin, 2003, p. 150).

As a consequence, these academics developed new strategies and new claims in their attempts to secure lasting change in the Taiwanese broadcast environment.

\subsubsection{PSB as a Social Movement}

With frustration and disillusionment, a protest against the DPP government started to gain momentum. In 2002, the pressure group CCTV held a press 
conference to announcing its dissolution. CCTV members blamed President Chen's broken promises on PSB reform for the termination of the committee. With the press conference, in order to raise the publicity of their action, the CCTV also bought half-page newspapers advertisement with the title, 'we will no longer tolerate [the DPP government]'. Three campaign members, Lin Hsiao-hsin, Shih Shih-hao and Kuo Li-hsin, offered their resignations of directors of terrestrial TV stations as further serious protest action against the DPP government (Protest against the delay of media reform, China Times, 11/10/2002, p. 6). The CCTV announcements that demanded the DPP honour its promises on media reform (see Taipei Times, 10/10/2002: 8) were written by campaign members including the Director of TTV, Lin Hsiao-hsin, the Director of TTV, Shih Shih-hao and the Director of CTS, Kuo Li-hsin (2002), these three members strongly condemned Chen and the DPP for their equivocation on their promises regarding PSB and demanded a clear timetable for reform.

The CCTV radical protest with the 'dissolution' attracted high media attention and gained huge publicity in newspaper coverage, especially in the pro-KMT newspapers. For instance, United Daily News (UDN) and China Times (CT) used the full page next to front page to report how the CCTV condemned President Chen and the DPP government. In contrast, another pro-DPP paper, Liberty Times (LT) published nothing about condemnation of the CCTV to the DPP government. As shall be shown in subsequent chapters, these specific differences were emblematic of wider trends in coverage where political partisanship had a major influence on how the PSB issue was defined by different press outlets (More details of the newspapers will be addressed in following chapters).

\subsubsection{PSB as a Long-Term and Bottom-Up Reform}

After the CCTV's dissolution, in 2003, another pressure group, Campaign for Media Reform (CMR), was launched by core members of previous CCTV. These activist-academics shifted their campaign focus from lobbying political elites to mobilising public opinion more widely. This also meant a shift in emphasis from targeting short term policy changes towards addressing longer term objectives, such as increasing media literacy and mobilising a broadly based public movement around broadcasting reform issues. 
The CMR members kept their claim to be heard by interacting with other claims from politically polarised politicians and public broadcasters to 'expand the scope of the problem to be seen in the public eye' (Hilgartner and Bosk, 1988). For example, the section of Letters to the editor in the mainstream newspaper was a battlefield for the CMR members to keep their voice to be heard in the society. The letter writing and media appearances played their part in developing this wider and longer term campaign strategy.

Alongside their reorientation of their campaign strategy, these academic critics had some major criticisms of the broadcasting reform programme that was still unfolding under the DPP's incumbency.

As was discussed in earlier chapter, 2006 saw the passage of the Statute Regarding the Disposition of Government Shareholdings in the Terrestrial Television Industry that sought to eliminate partisanship and political and military control but neither recommended complete privatisation or public (re)orientation. When asked about her view of this compromised result, an active media academic, Weng Shieu-chi (翁秀琪), who was one of directors in the PTS board, pointed out the ideal design for Taiwanese PSB went to a different thing when facing reality. According to Weng Shieu-chi:

In Taiwan, even perfect plans can turn out awfully in a surprising way when politics gets involved. What I can only confirm is the initiative motive the academics hold is good, though it might go on a bad direction after this plan involved with legislators and the government. The plan can work out perfectly if it could be carried out in a politics-free landscape. Unfortunately, it is always another story in reality.'

Apart from criticism that PSB did not go far enough under the DPP government, the interviewed chairman of the Media Watch Organization, Kuang Chung-hsiang (管中祥), indicated the PSB group is 'only half-completed' because another important half, strong connections with the public, still remained missing. In his words:

'I said the PSB is only half-competed because it doesn't meet what it 
promised. The PSB group's efforts, no matter on lobbying another better legislation or getting more financial supports, are way behind enough. From my perspective, it's not good enough because the broadcaster needs to deliver their value as a social campaign or social movements which can connects to majority members in this society. Otherwise, it is just one of many channels in the market.'

Echoing this view about the connection with the public, the interviewed CMR founder and the once core member of CCTV, Wei Ti (魏玓), arrested there are missing links between the PSB and the citizens. According to Ti Wei:

'The most programming of the Taiwanese PSB are high quality and actually attracting numerous elite audiences. Most of them not only enjoy watching it, but also donate their money to support it on a regular basis. However, just like most commercial television, the way the PSB group work so hard to compete for people's eyeballs in the media market is still treating their viewers as consumers. A real PSB needs to communicate and connect with people in order to know what the public really want to watch.'

Both of Kuang and Wei's point of view claimed that where the PSB expansion went wrong is the reforms had not engaged with citizens and inspired the majority members in this society. From the discussions in the section we saw the media academics' earlier actions and campaign, allied with political forces, had a streak of a top-down and paternalistic way which failed to stimulate the public imagination and enthusiasm. This also explained the latter refocusing of the CMR campaign towards engaging with citizens in a deeper and more dynamic way.

\subsection{Public Broadcasters' Constructions}

After a review of the claims from various political and academic sources involved in the PSB debate, it is now appropriate to move to the views of claim-makers who are within the PSB group, including CEO, presidents of 
different channels, and directors in the boardroom. With their first-hand experiences of running the PSB, their claims were strongly connected to the day-to-day difficulties that hurdle the PSB's healthy development.

\subsubsection{A PSB with Internal Tensions}

When asked how to manage the different channels within Taiwan Broadcasting System (TBS) into a cooperative group, interviewed CEO, Feng Hsien-hsien (馮賢賢), admitted that this TBS group was not working as a cooperative group yet. According to Feng Hsien-hsien:

'Two key tasks still remain unaccomplished. First, there are still 25\% shares of CTS is still private-owned. The Government needs to buy the shares back to make the CTS as a complete public media, and also the government needs to put more funding into CTS which has the deficits since 2002. Second, since Hakka TV, TITV and TMT received their funding from different government sectors to deliver their own missions respectively to Hakka people, indigenous people and overseas compatriots, how to cooperate the findings and the resources in a right way that can avoid interest conflicts is a tough challenge.'

Feng's view also displays the undercurrents of internal tensions behind the title of the Taiwan Broadcasting System. For PTS, this merger meant a significant expansion in its scale and resources. For CTS, this merger meant greater political independence from the state. For Hakka TV, TITV and TMT, the merger promised greater stability by removing their reliance on annual bids to government. Therefore, on the surface the establishment of the group seems a better solution for all members. However, alongside with the merging process, internal conflicts soon surfaced in the public eye via media coverage. For instance, the CTS, which has been an influential national terrestrial television and accumulated huge impact and assets for 35 years, was reluctant to be in a disposition under the umbrella organisation led by the fledging 8-year- old PTS. As then CEO of CTS Lee Yuan put it, 'the merger of CTS and PTS is like a 35 year-old lady married to an 8 year-old superman. Everyone is questioning what 
kind of weird baby will pop out' (United Daily News, 02/07/2006).

Some other clashes scattered in the process of merger. For instance, in a news story about 'Invisible Hand into CTS' (China Times, 26/12/2006: p4), the CEO in CTS, Yuan Lee, pointed out that CTS was losing its autonomy in the merger and claimed 'if the PTS team continues to bully the CTS and depriving their autonomy in the merging process, I will quit to protest since I cannot protect the CTS' fundamental right' (China Times, 26/12/2006, p. 4).

More serious issues emerged when the other three channels officially joined in 2007. For Hakka TV, TITV and TMT, the merger transferred their bidding project from short-term bid projects to long-term developments. The interviewed Indigenous TV President, Masao Aki (馬紹 阿紀), pointed out that the merger provide TITV with a better environment for sustainability. In his interview, Masao Aki recalled that 'before different bidders who ran the annual project had their different style so every year we had to adapt different style and programming standards from different team which executed the bid.' After joining the group TBS, the three stations still received their funding from different government sectors to carry out their own missions to provide services to Hakka people, indigenous people and overseas compatriot respectively. Their different operations undermined this PSB as a group. The interviewed Hakka TV President, Hsu Chin-yun (徐青雲), revealed the real situation behind a group-like look of TBS. According to Hsu Chin-yun:

'With different missions respectively, in fact the five stations are not running by the same standards and principals. Cooperation or synergy hardly exists in the group.'

To the issue of the internal tensions, in interview an activist-academic Feng Chien-san, as an outsider of the organisation, provided insightful analysis for the reasons that lead to the original creation of Hakka TV, TITV and TMT. Feng Chien-san pointed out the three television services were created under political considerations since these television services could reach specific and focused ethic groups during elections with well-crafted messages. They were not meant to become public media inthe first place. According to Feng Chien-san: 
'The TMT was created by the KMT government and the Hakka TV and TITV were launched by the DPP government. The DPP government invested about six hundred million [about 12 million pounds] annually for Hakka TV and Aboriginal TV. The amount is not high but it is around two-thirds funding of PTS already. In contrast, it can be easily identified that the government has 'relative generosity' for the ethnic minorities. A speculation is generated here that there are election considerations behind this arrangement. Through well-crafted propaganda targeting on the particular groups, those in power try to secure their next win in elections.'

Not only were the three members trapped in this confused grouping, another prisoner was CTS. CTS became a member of the TBS group after the Statute Regarding the Disposition of Government Shareholdings in the Terrestrial Television Industry came into effect in 2006. However, CTS remains a commercial TV station reliant on advertising revenue as its only source of income. In other words, the CTS was solely responsible for its operational profit and loss while the other members received government appropriations. Inevitable tensions between advertising revenue and public subsidy generated a constant debate between funding and operating models. The interviewed TBS CEO, Feng Hsien-hsien, mentioned that the incomplete ownership of CTS and the different funding models are also pitfalls in practice. According to Feng Hsien-hsien:

'We don't have full ownership of the CTS since there are still some private shareholders [25\%] of the CTS might express different opinions on our pubic-oriented management. They can make our work very difficult!'

These points of view above echo with observations from some legislators and media academics discussed earlier. For example, the PSB expansion including the three stations was viewed as 'an odd and compromised result from political negotiation' by legislator Kung Wen-chi, as 'an uncertainty of political games by media academic Weng Shieu-chi, and as 'a hidden system of needs and 
interests' by legislator Chou Yan-shan. The problem that the PSB is a group threatened by internal tensions not only reinforces the claim that the PSB expansion is a compromised result, but also illustrates one of the consequence that the elusive definition of the PSB played out as a disorganised and piecemeal process.

\subsubsection{A PSB with Unclear Positioning}

Another consequence from the elusive definition of the Taiwanese PSB is that the Nielsen rating system, adopted by most commercial televisions as a management tool, also became a key reference to run the PSB in 2008. 'In order to enhance the core competence and impact, the TBS CEO Feng Hsien-hsien scrutinises the Nielsen rating report everyday' (Liberty Times, 21/01/2008, p. 4).

In her interview, the CEO restated that the low view rating of the PSB programming has been one of the 'problems' that confronted her on a routine basis. She adopted a daily review of the view ratings as a problem-solving move and found it is very helpful. According to the CEO Feng Hsien-hsien:

'This move is a very effective method because after I announced the move every section in the PSB group immediately improved their efficiency under this 'number' management. After all, it should be our responsibility to face the daily examination from the viewers'choice.'

However, this move soon invited ferocious criticism from media academics who claimed the PSB group had sunk to the low level of its commercial rivals, with their fixation with audience ratings (Media Watch, 2008, p. 24). In the academic eye, the Nielsen rating system is created to assess 'commercial value' of television advertisements for advertisers and therefore the logic of the rating system contradicts with the core principles underpinning the PSB, such as universality of appeal, particular attention on minorities, and the idea that PSB should encourage competition in good programming rather than for numbers (BRU, 1985).

In interview the CEO Feng Hsien-hsien defended her decision. In her view, the ratings can also serve as a neutral survey tool to understand the viewers of 
the PSB. According to Feng Hsien-hsien:

The ratings have been demonised in Taiwan since now the ratings become currency in the world of commercial televisions. In this light, the ratings may override the other professional principals of the programming. However, in my view, the PSB programming has no concern over the commercial advertisement. Here the ratings can be used as a neutral survey tool to understand our viewers, including their gender, age, geographical distribution and their preferences. It is an important reference for the management team and the producers to make right decisions.

Following her defence on the rating management, the CEO Feng Hsien-hsien shifted to her claim that the PSB group should expand its viewership and become dominant both in the rating and the quality in the media landscape. According to Feng Hsien-hsien:

My goal is to compete with other commercial rivals. In doing so, I am not just saying to provide quality programming that commercial television cannot or unwilling to offer, but we also want to win over the mainstream audience to become a dominant role in the market.

As discussed in the PSB history, later on in 2009 a 'public value assessment system' was gradually viewed as a more reliable reference for the decision-making process. As a TBS chairman Chen Sheng-fu (2011) noted in a newsletter as a response to the result of the public value assessment system, 'TBS has a greater social responsibility compared to other commercial broadcasters and its performance is assessed not only through "viewer ratings" (Chen, 2011, p. 1)'.

The clash of over the rating issue provides another example that the elusive definition of the Taiwanese PSB. It led the group to an ambiguous position and role in the media landscape. The following sections will further examine the ambiguous role of the PSB in relation to its funding and those of the government of the day. 


\subsubsection{A PSB with insufficient Funding}

In Smith' account (1995), public television stations in American remained starved of funds and the non-profit stations have often been accused of spending as much air time raising funds as the commercial stations do with their advertisements' (Smith, 1995: 90). Similarly, in Taiwan, starving of funds is also a salient claim constantly made by public broadcasters. A former TBS CEO Hu Yuan-Hui (胡元輝) and his successor Feng Hsien-hsien both restated the insufficient funding has always been a tough challenge facing the PSB group'. The former CEO Hu Yuan-hui was in charge from 2004 to the end of 2007. With his first-hand experience with the launching of the PSB group, in his interview Hu Yuan-hui stated the initiative PSB was a disappointment, and one of the causes was insufficient funding. According to Hu Yuan-hui:

'To be honest, the development failed to meet my earlier expectations. It frustrated me. Specifically, the government didn't provide both sufficient financial resources and a sound legislation to support the transformation of the PSB. The lack of both disappoints me.'

On the other hand, a director in the boardroom which is the highest supervisory unit of the PSB group, Peng Weng-jeng (彭文正), provided a different perspective to the problem of insufficient funds. With practical media experience and academic expertise, Peng Weng-jeng claimed that lots of money was wasted due to inefficiencies in the PSB group. He claimed that staff also did not work hard enough to provide full value for taxpayers' money. In his words:

'Compared with any other commercial television stations in Taiwan, staffs in the PSB group really know how to have a good time during work. They are way out from efficiency to bring the value of the government funding. For example, if I make a phone call now [after 5:00 pm], it would hardly get answered since most of them have already gone home. With the public funding, they work like inefficient public servants who cannot survive in the competitive market. However, they keep complaining that 
insufficient funding cause their inefficiency.'

The clash over the funding and efficiency also opened a leak for political forces to squeeze in the battlefield. In 2008 when the KMT party came back to power again, the clash of claims on the ways the funding was used shifted from a PSB management dispute to a political struggle when a KMT legislator Lin Yi-shih suggested that, in order to avoid wastage of public money, the media regulator, Government Information Office, should review and scrutinise the detailed ways the PSB programming proposed to use their funding before the funding is distributed to the group. This claim was viewed as the revival of 'government control' by the public broadcaster alongside with many PSB-supporting civil groups. 'More than 60 civic organizations staged a protest outside the Legislative Yuan and demanded the KMT legislator Lin Yi-shih reconsider his ingenuous proposal on "review" the PSB budget' (Taipei Times, 13/12/2008, p. 3). The CEO Feng Hsien-hsien indicated that KMT legislators had already frozen half budget of this year for PTS and claimed the PSB group could only receive the budget after the GIO approved the budget-review proposal (Taipei Times, 13/12/2008, p. 3).

Many PSB supporters who joined the protest considered this action clearly abused the right of budget reviews and extended political influence into PSB. Some media academics claimed 'this political intervention would destroy PSB's core value which was to offer broadcasting services independent of any form of political interference' (Tang \& Jian, 2008, p. 8). This view leads us to the focus of next section addressing the claim of broadcasters in relation to political forces.

\subsubsection{A PSB with Political Interference}

One of PSB principles outlined in the BRU document is that the broadcasting should be distanced from all vested interests, and in particular from those of the government of the day (BRU, 1985). However, in Taiwan's case, the distance between the PSB group and the political forces has been a key theme in the claim-competitions. Rumours scattered in newspapers have constantly questioned whether those in charge in the PSB group are politically expedient 
appointees. For example, the election of the TBS chairman in 2007 led pro KMT papers to claim that the new chairman and CEO were both 'appointed rather than elected' by 'invisible political hand' of DPP government (Economic Times, 11/12/2007; China Times, 13/12/2007; China Times, 14/12/2007; China Times, 24/12/2007).

To help interviewees address these issues directly, the news coverage listed above was used as a prompt during the interview. The news reports in the pro-KMT newspapers, that allegedly claimed Feng Hsien-hsien can become CEO due to her hidden connection with the DPP and furthermore the PSB operations have been influenced by the power, were shown to one of interviewees, Feng Hsien-hsien. When being asked about her reflection on these reports, a furious response was given. In her words:

'Young guy! What you read in the news stories are all nonsense. I look down on these trash papers. These are all rumours and I know who is behind this. They are those political players try to intervene the PSB, they use the press as tools to make people they dislike look bad. These are not rational discussions. When these reporters wrote the reports, they had no evidence. They did not even bother to phone me to confirm and double-check.'

The related news reports in the pro-KMT newspapers also imply that thenacting chairman Cheng Tung-liao also has the connections and political preferences to the DPP. Although repeatedly approached, the chairman did not agree to be interviewed for this study.

In interview, CEO Feng Hsien-hsien, defended herself by claiming that their media expertise and professional experience gave them their current status and she operated outside of the control of political forces. However, this claim did not get through the KMT government in 2008. After the KMT return to power in 2008, a reshuffle inside the PSB group soon began. The highest supervisory unit, the board of directors, split into rival factions. The directors filed lawsuits against each other. 'It resulted in only five out of the 21 directors in the board being able to legally execute their positions' (Taipei Times, 28/04/2010, p. 3). After edging out TBS chairman Cheng Tung-liao, 'the KMT-supported board 
then forced the CEO Feng Hsien-hsien to leave office' (Taipei Times, 04/10/2010, p. 8). The deposed CEO Feng Hsien-hsien soon called for a press conference to fight back and claimed that the reshuffle was a terrible political ploy from the KMT government (Taipei Times, 30/09/2010, p. 1).

This reshuffle mirrors invisible circles and connections between broadcasters and political parties behind their claims. A director in the PSB board, media academic Fang Nien-hsuan, pointed out that after the constriction of the PSB group, the political struggle among parties was still operating inside the PSB group. According to Fang Nien-hsuan:

'Actually the power struggle inside the PSB probably mirrors what is actually happening in our current social context. It is hard for me to imagine there will be a system that can perfectly isolate the PSB from influences of political parties, governments and military force. In the current system there are many operating parts can be manipulated by politicians or governments. Eradicating all these manipulations sounds impossible now, but now what we can do is keep a healthy balance of these powers.'

In the consideration over how to reach a healthy balance of power within the $\mathrm{PSB}$, in his interview the former CEO Hu Yuan-hui pointed out the lack of public engagement and social support is a missing link to reach the balance: 'I don't think this PSB expansion has been practiced well since in institutional process of this PSB the general public should have been more aware of its existence and its importance. Unfortunately, it isn't very successful in this aspect since it has always not been a popular issue that people concerned about.'

\subsection{Features of the Claim-Competitions}

As discussed in chapter 2 that the PSB is a contested concept, the discussions on the different claims above also reflected an endemically contested process of a PSB debate involved with various key claim-makers in Taiwan. The priorities of these claim-makers were displayed when the legislators define the 'problem' in the struggle of political power, the media academics point out the 
'problem' in the media ecology, and broadcasters emphasis the 'problem' at an empirical level of PSB practice. More precisely, the legislators constructed the PSB expansion as a part of political struggle from their understandings that most policy formulations are embedded with invisible political interests and concessions. Behind the claims, it can be seen the concern of the political claim-makers was seeking to stay in power or to get back to power. Considerations about media reform were deemed a small side show of the political struggle. On the other hand, the broadcasters, with their empirical experience in running the PSB group, kept addressing the practical problems that they struggle with insufficient fund, internal tensions like channels with different goals and external pressures like political interferences to explain and justify the dysfunction of the PSB group from their position.

As the issue entrepreneur who spotted and claimed that it was time for revolutionary change, the activist-academics translated their academic knowledge into practical actions to push the PSB proposal against the wave of privatization. With their claims based on their belief of the role of media, as public goods, should play, it can be easily argued that the efforts of the academic claim-makers paid off since the proposal of privatisation was squeezed out of the arena of the claim-competitions even the privatisation plan fell in to the 'simple claims' category which are usually more effective than complicated ones like the elusive PSB proposal. The Campaign for Citizens' TV may be significant in media reform history in Taiwan but the academics still had their limits. The academics had a partial victory in keeping the privatisation option in abeyance, but their more dynamic vision of PSB reform was quickly side-lined when the DPP took power and this led them to rethink their strategy.

The competing claims, displayed via the interview data in this chapter, inevitably posed a question: what is the truth then?

In this competing process, Loseke (2003) states, what the truth is 'does not matter' since 'the term claim conveys no meaning about truth' and what matters lies in 'which are believed to be true' (Loseke, 2003, p. 35). In other words, what matters in is how the claims are perceived on all layers of society. In this light, an argument is developed that the relative success or failure of the claims may lie in the extent to which claim was explained in the mainstream media which consumed by the majority of the members in the society. 
Thus, to answer the question about which claim was believed in the society, or, in a game term, which claim won, the media seems to be one of the best sites to uncover the manifestation and interplay of various powers in defining and interpreting the claims, especially when the contemporary media 'play a pivotal role in organising the images and discourse through which people make sense of the world' (Murdock \& Golding, 2005, p. 60). Serving as one of primary outcomes of the claim-competition, a press representation of the PSB expansion will be discussed in following chapters in order to identify the dominant claim and further discover the boundary of inclusion and exclusion, which serves to focus the media attention but also detracts the attention away from what lies outside the boundary. 


\section{Chapter 6}

\section{Results of Claim-Battles: Press Representation}

This chapter serve as an overview of one of major results of the claim competition over PSB expansion throughout its turbulent history. Drawing on a systematic content analysis of newspaper coverage related to the PSB expansion in Taiwan between 2000 and 2008 it examines how the mainstream press represented the competing claims and explores to what extent the coverage reflected and constructed debates around PSB and the rights and obligations that associate with it.

The research covers the distribution and content of PSB coverage in four main categories - news stories, editorials, commentary, and letters to the editor. The analysis begins with an assessment of the overall patterns of attention focusing on temporal and thematic changes in coverage. The results indicate which claim gained more public exposure and credibility, but also provide a foundational understanding for the detailed examination of editorials and letters in the two chapters that follow.

\subsection{Analytical Method of the Content Analysis}

The aim of this section is to describe the main features of the sample employed, including the selection of the time period covered, the sampling method, the coding categories employed, and the reasons underpinning the choices made. 


\subsubsection{Sampling}

It was decided to focus on the three mainstream national daily newspapers with the highest circulations: the United Daily News, the China Times, and the Liberty Times.

In addition to their public reach (as indicated by circulation figures) these three titles were selected because they offer useful contrasts in their political affiliations. The United Daily News and the China Times are regarded as leaning towards a China-friendly position, while the Liberty Times leans toward a pro-Taiwan independence position. Disagreements on this fundamental fault line in Taiwanese politics also spill over to other public issues. As a consequence, as Kuo \& Nakamura (2005) have pointed out, the United Daily News and the Liberty Times 'tend to give different reports on certain controversial political issues' (Kuo \& Nakamura, 2005, p. 398). However, as Fell argues, although they tend to support polices advocated by the KMT, neither the China Times nor the United Daily News are simple 'mouthpieces for the KMT', as they were formerly (Fell, 2005, p. 881).

The sample period selected for analysis ranged from $1^{\text {st }}-\mathrm{Jan}-2000$ to $31^{\text {st }}$ -Dec-2008. The year 2000 was selected as the starting point because this was when the issue of PSB reform became a public issue in a way it had not been before. There were several reasons for this.

First, as noted in an earlier chapter, the unprecedented political transition in 2000 , with the defeat of the KMT and the election of a DPP led government, created a new opportunity for debate around media reform. As Feng, Shy, \& Kuo (2002) point out, before the early spring of that year privatisation was still the mainstream option for changing the ownership of state-owned television stations while 'Gong Gong Hua' was an alternative mainly confined to media reformers.

Secondly, as also mentioned earlier, in 2001 an unexpected row involving serious insults between two legislators, when the DPP legislator, Lin Chung-mo, accused KMT legislator Sisy Chen of behaving like a prostitute by abusing her media power to promote criticism of President Chan, stimulated an intense public debate on the interplay between political actors and media and breathed new life into the long standing question of whether 'all politicians should 
withdraw their power from the media' (Sisy Chen calls on political power out of terrestrial televisions, United Daily News, 14/12/2001, p. 3). Some active media scholars took advantage of the window of opportunity opened up by this incident to push the DPP government to follow through on its election promise of media reform (Scholars debating future of Taiwanese media, Taipei Times, 17/12/2001, p. 3).

The end point of 2008 was selected because it marked the KMT's return to government, placing renewed question marks against the restructuring of the PSB system that had been implemented by the outgoing PSB administration.

\subsubsection{Method of Sampling}

This press content analysis identified all items that focused principally on the PSB reform in the three newspapers. The search strategies involved key word searches of the digital news databases developed by both the United Daily and China Times. When digital archives were not available, as in the case of the Liberty Times for part of the nine year sample period, a manual search of hard copy versions held in the public library was undertaken. After initial reviewing, this archive assistance from editors at the Liberty Times was sought to double check the correctness and completeness of the sample by reference to their internal editing system.

Key words employed in the search, included: 'PTS (Public Television Station)', 'PTS (Public Television Service)', 'TBS (Taiwan Broadcasting System)', 'Media Reform', 'Terrestrial television reform', and the mandarin Chinese term for the PSB-oriented proposal, 'Gong Gong Hua' (公共化), which was used widely by Taiwanese newspapers and activist-academics to describe the transformation from a state-owned to the PSB model.

An initial review of the corpus of coverage collated revealed that some items flagged up by the key word search did not relate to debates and arguments about PSB but simply concerned the promotion of TV programmes, entertainers and celebrities. The research data base was then edited to remove these items so that sample included only items that addressed arguments and issues around PSB. In terms of genre, only news, editorial, columns, reviews, features, commentary, and readers' letter were included in the analysis. Literary articles and advertisements were excluded. In total, 603 items met the 
criteria for inclusion in the analysis (See table 6.1). Their distribution across the titles selected is shown in Figure 6.1. below.

Table 6.1. Sample Size of Press Content Analysis

\begin{tabular}{lll} 
Press name & Number of press item & Percent \\
\hline United Daily News & 204 & 33.8 \\
\hline China Times & 247 & 41.0 \\
\hline Liberty Times & 152 & 25.2 \\
\hline Total & 603 & 100.0 \\
\hline
\end{tabular}

\subsubsection{Construction of the Coding Categories}

Each item was treated as a single unit of analysis. For each item, the following details were coded: (a) the newspaper in which the item appeared; (b) the location of the item within the paper; (c) the genre of the item; (d) the main topic $^{1}$; (e) the sub-themes; (f) evaluation on the themes, (g) the actors ${ }^{2}$; $(h)$ sources (coding manual see appendix 4).

\subsubsection{Inter-coder Reliability}

A random sample of 70 news item was selected from the total sample (603) for inter-coder reliability testing. The minimum percent agreement for all variables was $\mathrm{PA}_{\mathrm{o}}=0.88^{3}$.

${ }^{1}$ The main topic was coded according to the length of the relevant discussion or the main focus of the item

${ }^{2}$ I identified three main categories of sources: political actors, economic actors and civil society actors. Within the category political actors, sub groups included, parliamentarians (Lawmaker), party president, spokespeople and members in different political parties, officials and representatives of government organisations, such as the Government Information Office, Executive Yuan (Ministers), council for Hakka affairs, council of indigenous peoples, and local governors. The category economic actors included, actors from within the broadcasting industry, the press, and general firms, including advertisers, and staff labour-unions. The category of civil society actors includes academics, media commentators, pressure groups, and the general public.

3 To reach the agreement on the codes between two coders, Holsti's method (1969; Neuendorf, 2002) was applied in this pilot. The calculation formula for percent agreement between two coders who code the same units is: $P A_{o}=2 A /\left(n_{A}+n_{B}\right)$ Where $P A_{o}$ stands for "Proportion agreement, observed," $A$ is the number of agreement between two coders, and $n_{A}$ and $n_{B}$ are the number of units coded by coders $A$ and $B$, respectively (Neuendorf, 2002). This statistic also ranges from .00 (no agreement) to 1.00 


\subsection{Findings: The Pattern of Press Coverage}

As Figure 6.1. below shows, press coverage over the sample period was marked by a series of peaks and troughs relating to significant news events in the PSB debate.

\subsubsection{Five Distinguishing Peaks}

In Figure 6.1., five significant peaks of news coverage can be clearly identified.

(perfect agreement). The percent agreement of several variables from the pilot are Genre $\left(P A_{o}=1.00\right)$; Topic $\left(\mathrm{PA}_{o}=0.92\right)$; Theme1 $\left(\mathrm{PA}_{o}=0.90\right)$; Evaluation $1\left(\mathrm{PA}_{o}=0.95\right)$; Theme2 $\left(\mathrm{PA}_{o}=0.90\right)$; Evaluation2 $\left(\mathrm{PA}_{o}=0.94\right)$; Theme3 $\left(\mathrm{PA}_{o}=0.66\right)$; Evalution3 $\left(\mathrm{PA}_{o}=0.66\right) ;$ Actor1 $\left(\mathrm{PA}_{o}=0.94\right) ;$ Actor2 $\left(\mathrm{PA}_{o}=0.79\right)$; Actor3 $\left(P A_{o}=0.92\right)$; Source1 $\left(P A_{o}=0.98\right)$; Source2 $\left(P A_{o}=0.85\right)$; Source3 $\left(P A_{o}=0.85\right)$. The percent agreement for all variables above is $\left(\mathrm{PA}_{\circ}=0.88\right)$. 


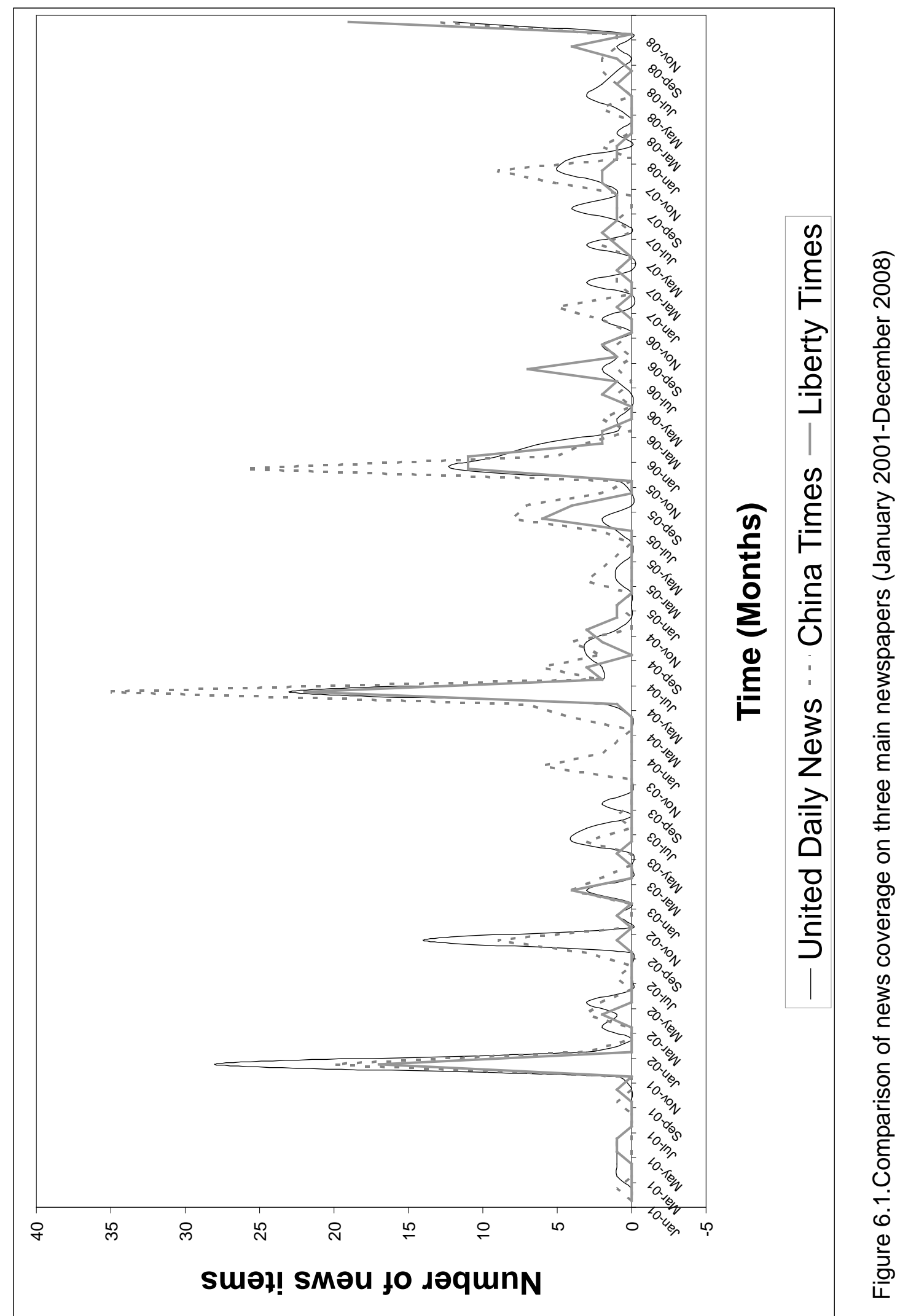




\section{The First Peak}

The first peak occurred from December 2001 to January, 2002. The main stimulus was the abusive disagreement in the parliament between legislators Lin Chung-mo and Sisy Chen, mentioned earlier, and the concern over the collusion between political organizations and the media which it reignited. Headlines included; 'Withdraw State-and-Military Control from the Media; KMT Urges to Release Its Shares to Free Market and Opposes the "Gong Gong Hua" Plan' (Liberty Times, 19/12/2001, p. 6); 'Sell them? Make them Public? Battles between Two Options' (United Daily News, 26/12/2001, p. 2); 'Hidden Interests behind Public policy Fights; KMT's and DPP's Intentions Both Doubtful' (United Daily News, 27/12/2001, p. 4); 'KMT Party Claim: Gong Gong Hua Is a Prelude of a 'DPP-lisation' of Media (China Times, 27/12/2001, p. 4).

This debate was newsworthy for the newspapers because it was full of conflicts not only between the two main political parties, but also between two proposals for possible reform of the terrestrial television stations.

The idea that political forces should withdraw from interfering with media was widely agreed, but the question of how best to cut the state-owned television stations' strong ties to political forces was the focus of heated debate between advocates of privatisation on the one hand and 'Gong Gong Hua' on the other. For instance:

DIVISIVE ISSUE: The competition of two visions for reducing political influence on the media threatens to derail the reform efforts. The two opposite sides are being urged to cooperate. (Legislators split on how to reform media, Taipei Times, 26/12/2001, p. 2)

These competing visions were most visible articulated at the time by two lobby groups, the Alliance for the Democratization of Terrestrial Television (ADTV), and an alliance led by People First Party (PFP) legislator Diane Lee.

The ADTV argued that the government should invest more public money in terrestrial television with the provision that television stations should be run by an appointed but independent, professional boards of directors.

In sharp opposition to this, the alliance led by legislator Diane Lee promoted 
privatisation, insisting that forcing the government and political parties to sell their shares in terrestrial television and creating a 'free' commercial market in broadcasting was the only way to solve the problem.

In response to this privatisation plan, the ADTV claimed that if the government sold its shares and left television solely to the market there would no effective way to exercise its control over program quality. Lee, however, replied that in its present state of development the political environment of Taiwanese society, with its relatively brief experience of democratisation, was not yet mature enough to implement the ADTV's ideal model effectively (Taipei Times, 26/12/2001, p. 2).

Other voices most notably KMT legislator Apollo Chen, called for compromise arguing that, 'the two sides should try reach a consensus on the issue as soon as possible; otherwise, I am afraid no reform can really happen' (Legislators split on how to reform media, Taipei Times, 26/12/2001, p. 2).

\section{The Second Peak}

The main stimulus behind the second peak in coverage, between September and November 2002, were the protests from the pressure group 'The Campaign for TV Democracy which had held a press conference to protest, in a very public way, at President Chen's failure to follow through on his presidential campaign promises to reform state-owned media. This campaign reinforced its bid to put the issue on the public agenda by buying half-page newspapers advertisements headed 'We Will No Longer Tolerate' expressing their disappointment with the DPP government's inaction on media reform since it accession to power in 2000.

This protest attracted news media attention because it was initialled by media academics that had played a leading role in drafting the media policy advocated in the DDP's election campaign. The ensuing disagreement between the DPP government and its erstwhile academic supporters was seen as particularly newsworthy by the KMT friendly newspapers as in the following item from the China Times:

'The Campaign for TV Democracy' held a press conference to condemn President Chen Shui-bian and the Executive Yuan for their delay on the practice of "public 
television' and other media commitments from his presidential campaign promises........ 'ADTV' Convenor Feng Chien-san urged President Chen and the ruling party immediately fulfil its media reform which outlined in his presidential campaign promises. (Protest against the delay of media reform, China Times, 11/10/2002, p. 6)

The differences in the amount of coverage given to the protest can be seen in Fig 6.1., with the United Daily News giving it the most coverage and the DDP inclined Liberty Times, the least. In addition, most of the coverage from the two KMT-friendly newspapers, the United Daily News and the China Times, adopted a hostile attitude towards the campaign's complaints. Headlines included: 'Media scholars offer endorsement for presidential campaign now face ordeal', (China Times, 24/9/2002, p. 13); 'Media academics drafting 2000 Mass Media White Paper part from President Chen', (United Daily News, 11/10/2002, p. 4); 'Return to social movements; pressure to implement 2000 Mass Media White Paper, (China Times, 11/10/2002, p. 6). More details of the political stance of the newspapers and their biases will be addressed in the next chapter when taking a closer look at editorials, the place where newspaper most clearly articulate their positions on key issues.

During this second peak, The Campaign for TV Democracy released a protest statement: 'DPP must keep the promises for a better media environment' (Taipei Times, 10/10/2002, p. 8) endorsed by three prominent television executives and key campaign members, the Director of TTV, Lin Hsiao-hsin, the Director of TTV, Shih Shih-hao and the Director of CTS, Kuo Li-hsin (2002) arguing that the Campaign had long argued that the most urgent task was to turn the state-run TTV and CTS channels into larger and more efficient public service broadcasters. This view tallied precisely with Chen's policy, as laid out in the 2000 Mass Media White Paper published during his presidential campaign. The statement concluded by arguing that Campaign members were not only condemning the DPP government for their equivocation on their own promises, but also urging them to begin implementing changes immediately and to give a clear timetable for reform (The Campaign for TV Democracy, 2002).

\section{The Third Peak}


The third peak in coverage occurred between May and July 2004. Rumours had been circulating for some time that the media regulator, the Government Information Office, was thinking of privatizing the two state-owned channels, TTV and CTS (Taipei Times, 18/05/2004, p. 2), prompting protests and press conferences by several pressure groups. For example:

Various civic groups and media watchdog organizations yesterday called for the Government Information Office (GIO) to turn TTV and CTS into a public television channels. (Activists decry privatizing TV stations, Taipei Times, 18/05/2004, p. 2)

PUBLIC PROGRAMMING: Several civic groups called upon the government to turn TTV and CTS into public stations and do the same to at least six other radio or TV stations...... (Civic groups back TV reforms, Taipei Times, 09/06/2004, p. 2)

However, the detailed content analysis suggests that the main stimulus for the coverage were the complaints and arguments that surrounded the appointment of Chiang Hsia, an actress and a long-time supporter of the Democratic Progressive Party (DPP) and a close friend of President' family , as the general manager of the state-controlled CTS.

This appointment caused a stir in media circles because it suggested that President Chen Shui-bian was not heeding warnings to avoid political appointments to media management positions. Suspicions deepened when Chiang claimed that her appointment was indeed a political reward for loyal support. According to the news report:

Actress Chiang Hsia, a long-time supporter of the Democratic Progressive Party (DPP), yesterday took over as general manager of state-controlled Chinese Television System (CTS) amid harsh attacks from opposition legislators on her professionalism and her political loyalties.......In a TV interview broadcast last night, the outspoken Chiang told the host, "My new position is indeed a reward and it makes perfect sense because I support President Chen Shui-bian." ......Atop her priorities for her new job will be banning soap operas produced in China. (Pro-DPP actress takes CTS helm, Taipei Times, 25/06/2004, p. 2)

This controversial appointment fuelled the disillusion with the DDP government already mounting among PSB advocates. Their disappointment was particularly 
sharp since before 2000, as a main opposition party, the DPP had strongly criticised then ruling party, the KMT, for using its ownership of key channels to advance its own political interests. They saw the appointment as a return the familiar KMT tactic of exercising control by gerrymandering key appointments.

The DPP's seeming abandonment its former position once in power, attracted particularly hostile comment from the two KMT inclined titles, the China Times and United Daily News. For instance, 'Chiang Hsia Designated CTS- Media Scholars and Civil Groups Show Dissatisfactions and Question on the Political Rewarding', (China Times, 13/06/2004, p. 3); 'Political Manipulation: Negative Impression for Public Media', (China Times, 13/06/2004, p. 3); 'DPP Control Media Worse than the Martial-Law Era' (United Daily News, 12/07/2004, p. 4). At the same time, the DDP inclined Liberty Times published an editorial supporting the decision, headed 'the Meaning and Controversy behind the CTS General Manager' (Liberty Times, 03/07/2004, p. 3).

In quantitative terms, this third peak is the most intense point of media comment on PSB issues throughout the whole sample period. Consequently, the difference in the newspapers' political biases can be seen more clearly. The differences in more detail will be explored in the next chapter when an examination of editorial coverage, including the Liberty Times' editorial just mentioned, is conducted to show more details.

\section{The Fourth Peak}

The fourth peak ranged from December 2005 to January 2006 and coincided with the passage of new legislation that regulated the release of government holdings in terrestrial TV stations.

This provision, 'The Statute Regarding the Disposition of Government Shareholdings in the Terrestrial Television Industry', which was eventually passed after eight rounds of cross-party negotiations, was designed to push forward the administration's bid to free broadcasting from political, partisan and military influences.

As mentioned in an earlier chapter, this legislation embodies two major changes. Firstly, the Taiwan Television Enterprise (TTV) was to become a private station while the Chinese Television System (CTS) would become a public one with the government shares (74.95 percent) ceded to a Public 
Service Foundation. Secondly, two other government-funded ethnic television stations would join the public television transformation to form an enlarged public television group.

In addition to selling its assets in the national terrestrial channel - China Television Company (CTV), the KMT also divested its interests in the national wide radio network - the Broadcasting Corporation of China (BCC) and the film production company - the Central Motion Pictures Corp to the private film, the China Times news group, which therefore benefitted financially directly from the reforms.

Some of the coverage, particularly form the two other titles, focused on the compromised nature of the settlement arrive at with headlines which included: 'Failure to the Completion of Media Freedom; GIO Blame KMT Lawmakers and Civil groups Blame GIO', (United Daily News, 26/12/2005, p. 1); 'Failure to Withdraw the whole State-and-Military Control from the Media; DPP and KMT Blame Each Other' (Liberty Times, 27/12/2005, p. 3).

At the same time, there was also discussion of possible next steps in the expansion of PSB with headlines, including: 'Passage of the Bill "the Statute Regarding the Disposition of Government Shareholdings in the Terrestrial Television Industry" to withdraw State and Military from the Media: a New Public Era Finally Arrive' (Liberty Times, 04/01/2006, p. 6); 'Party, State and Military to Withdraw from the Terrestrial Television; Completion of Legislation but an Uncertain Timetable' (United Daily News, 04/01/2006, p. 2); 'PTS Requires More Resources and Supports; CTS Claims 'Gong Gong Hua' Is an Out-of-Date Solution", (China Times, 04/01/2006, p. 4).

\section{The Fifth Peak}

The fifth peak appeared in December after the KMT defeated the DPP in the general election and was returned to government. This political shift renewed debate on PSB from two opposed groups of actors: lawmakers within the KMT party and broadcasters and pressure groups advocating an extended role for PSB.

More than 60 civic organizations staged a protest outside the Legislative Yuan yesterday, demanding KMT party caucus reconsider a proposal on controlling the 
budget for Public Television Service (PTS). The KMT caucus froze the NT\$450 million (US\$13.5 million) budget for PTS for the second half of this year and has come up with a proposal that all programming budget be approved by the Government Information Office (GIO) first. (Scores of civic groups rally in support of Public Television Service, Taipei Times, 13/12/2008, p. 3)

With the budget for PSB frozen for a year, the new legislature tried to pass a proposal that regulated the use of public broadcasting budgets. The proposal stated that details of all expenditure for planning, production and broadcasting of news and other programs must be approved by competent authorities before a budget could be implemented. Radical media academics who had been prominent in the lobby for PSB considered this actions clearly aiming at using budget reviews and control over staff appointments to extend the KMT's political influence over the Public Television Service and undermine PTS' original purpose, which was to establish a television station independent of any form of political interference (Tang \& Jian, 2008, p. 8).

Headlines included: 'Do Parties, State, and Military Really Withdraw from the Media?' (China Times, 14/12/2008, p. 11); 'Lawmaker Intervene Public Media Scholars Mourn the Death of Democracy' (Liberty Times, 19/12/2008, p. 2); 'Fight between Public TV and Lawmakers; KMT Lawmakers: Public TV Proven Themselves as DPP Political Warriors' (United Daily News, 19/12/2008, p. 10); 'Auditing or Intervening? Government Information Office and the Public Television Station in Inter-Criticism' (Liberty Times, 20/12/2008, p. 4); 'It's Time to Reconstruct the Monitoring System for Public Television', (China Times, 17/12/2008, p. 12); 'Rescue Public TV; Go for Protest on the New Year's Day', (Liberty Times, 29/12/2008, p. 2).

All five peaks in coverage detailed so far indicate that, despite their differing political orientations, editors and journalists on all three national newspapers shared the same professional sense of what was newsworthy in the debate, with the result that the coverage in all three displayed significant peaks at the same time in response to particular events or statements that were seen to have high news value (The Correlation between the three titles is significant at the 0.01 level .82).

The five peaks are all related to the PSB policy process but the focus of 
debate shifts over time as the process unfolds.

At the first peak, the main concern is with the competing proposals for restructuring state-owned terrestrial television stations, privatisation or 'Gong Gong Hua'. The second peak focused on the emerging conflict between the advocates of PSB and the DDP, which had come into government for the first time but was seen, by PSB lobbyists, to be dragging its feet on its election promises for reform. The third peak emerged around a renewed debate on the abuse of political power within the television system prompted by a controversial appointment to a senior administrative position widely seen as a reward for political loyalty to a party, the DPP, which had loudly condemned cronyism while in opposition.

Then the fourth peak shifted attention to legislative process and the negotiations between the two main political parties. At the fifth peak, with the KMT returned to power, old debates and arguments about political influences re-appeared.

Looking across the five peaks, however, they showed that they were all highly connected to political initiatives and arguments rather than to the performance of the PSB system. Looking at the two peaks related to wider political transformations (peaks 1 and 5) it is important to note that the debates occurred after, not before, the elections that led a change of government suggesting that despite being a focus of cross party conflict PSB reform did not feature as a prominent electoral issue.

\subsubsection{Location and Genre}

Quantification of the timing of PSB news coverage provides some insight into the newsworthiness of the issue, but there is a need to go beyond this and look in greater detail at the content of the sampled items to see whether the convergences noted in the overall pattern of attention are also evident in other aspects of the coverage. As a first step, this section examines the location and genres of PSB coverage during the sampled period.

Looking at the location of the articles analysed (see Table 6.2), the result revealed that more than half appeared in the main news section (55\%). In contrast, as the findings reported in Table 6.2 show, only $11.6 \%$ appeared in the entertainments/media sections even though the proposed changes in the 
media landscape would have major implications for these industries. This marginalisation confirms that when PSB issues appeared in the press, they appeared mainly as 'hard' news in the main news section, focused on political initiatives and disputes, rather than 'soft' news in the entertainments/media section exploring issues related to the range and quality of programming.

As Table 6.2 shows, however, when PSB related issues were covered in the main news section almost no stories (0.3\%) were judged important enough to be printed on the front page. This strongly suggests that while the PSB debate can be seen conceptually as having far reaching cultural and political implications for Taiwan's process of democratisation, its immediate newsworthiness was relegated to a relatively minor role by other issues. 
Table 6.2. Distribution of Coverage by location

\begin{tabular}{lll}
\hline Location & Number of press item & Percent $(\mathbf{N}=\mathbf{6 0 3})$ \\
\hline Main News pages & 330 & 54.7 \\
\hline Letters and Forum & 148 & 24.5 \\
\hline Entertainments/Media & 70 & 11.6 \\
\hline Editorial & 28 & 4.6 \\
\hline Local News & 14 & 2.3 \\
\hline Others & 11 & 1.8 \\
\hline Front Page & 2 & 0.3 \\
\hline Total & 603 & 100.0 \\
\hline
\end{tabular}

Table 6.3. Distribution of coverage by Genre

\begin{tabular}{lll}
\hline Genre & Number of press item & Percent $(\mathrm{N}=603)$ \\
\hline Pure news stories & 345 & 57.2 \\
\hline Readers' letters & 142 & 23.5 \\
\hline Commentarylanalysis & 85 & 14.1 \\
\hline Editorial & 29 & 4.8 \\
\hline Others & 2 & 0.3 \\
\hline Total & 603 & 100.0 \\
\hline
\end{tabular}

One distinguishing feature of the PSB press coverage was that the letters and forums section showed the second high rate (24\%) of amount of coverage after the main news section. This relative prominence is confirmed by the figures reported in genres of Table 6.3. which shows that although the majority (57\%) of items sampled were news stories, readers' letters accounted for almost a quarter (23.5\%).

At first sight, the relatively generous amount of space given over to reader's letters might suggest that citizens achieved a significant degree of participation in the media coverage and debate. Verification of this, however, requires further analysis of the authorship of the published letters, a matter which is addressed further in later sections.

The important role played by letters as forum for the expression of views is further confirmed by the relatively small amount of space taken up by editorials 
(4.6\%) This suggests that the coverage was relatively open to a range of opinions and social groups rather than being closed around the newspaper's own preferred position. Once again however, this conjecture needs to be examined further and it will be revisited in following sections presently.

\subsubsection{News Sources}

We can go some way towards addressing this issue by identifying the main sources quoted in the coverage and assessing whose claims were given the most prominence.

\subsubsection{Sources Cited in News Reports}

In Table 6.4., actors are shown separately for all press items and for pure news reports.

It is important to make this separation since whereas in news items, actors' views are filtered through the quotations selected by journalists and editors, in other genres, particularly readers' letters, they have actively authored the item themselves.

Looking across all press items in Table 6.4., although more than thirty groups of actors were identified, five groups stand out as major sources in the battle over PSB. They are, in order of prominence: pressure groups specifically lobbying for the PSB (15\%), public broadcasters (14\%), the Government Information Office (11\%), media academics (10\%), and press/newspaper interests (9\%). These figures confirm the prominent role played by pro PSB pressures groups and the critical media academics supporting them who together account for almost a quarter (24.6\%) of all sources mentioned. This result raises questions about why they were so successful in gaining attention, which will be addressed in the conclusion of this chapter. The Table also reveals the relative prominence of actors from the two media sectors most directly affected by proposed changes, public broadcasters and those working for state owned broadcasters, who together account for just over a quarter $(26.5 \%)$ of all sources mentioned. In contrast, Government sources only account for $14.6 \%$ of the total, led by the Government Information Office (10.8\%) with parliamentarians accounting for only slightly more (11.4\%).

The prominence of both groups increases if looking solely at news items, 
with Government sources accounting for $18.8 \%$ and parliamentarians, $15.8 \%$ but once again, these political sources are eclipsed by the attention accorded to pressure groups and their academic supporters (21.7\%) and to those working in state owned and public broadcasting organisations (26.5\%), with public broadcasters overtaking pressure group spokespeople as the most referred to sources ( $17.2 \%$ as against $14.7 \%)$

Overall, these patterns suggest that although it was successive political events and interventions that prompted surges in coverage, once in play the debate was presented primarily as a discussion between 'insiders' dominated by broadcasters with a direct institutional stake in change and lobby groups in which academics with a professional interest in the issues, played a key role. It was these groups, rather than elected parliamentarians, who took on the role of speaking on behalf of the 'public'. This relative closure of debate is confirmed by the fact that no members of the public were mentioned in the news items sampled and that they accounted for only $3.6 \%$ of the sources mentioned across all the items. 


\begin{tabular}{|c|c|c|c|c|}
\hline \multicolumn{5}{|l|}{ Table 6.4. Actors in the press representation } \\
\hline & \multicolumn{2}{|c|}{ All Press Items (603 items) } & \multicolumn{2}{|c|}{ Pure News Items (345 items) } \\
\hline & $\mathrm{N}$ & Percent & $\mathrm{N}$ & Percent \\
\hline Media Sector & 336 & $33.5 \%$ & 208 & $30.1 \%$ \\
\hline -Public broadcasters & 137 & $13.7 \%$ & 120 & $17.2 \%$ \\
\hline -Press/newspaper interests & 93 & $9.3 \%$ & 4 & $.6 \%$ \\
\hline -State-owned broadcasters & 81 & $8.1 \%$ & 63 & $9.3 \%$ \\
\hline -Staff/Labour unions \& associations & 21 & $2.1 \%$ & 19 & $2.9 \%$ \\
\hline -Private broadcasters & 3 & $0.3 \%$ & 1 & $.1 \%$ \\
\hline -TV Celebrities & 1 & $0.1 \%$ & 1 & $.1 \%$ \\
\hline Pressure Groups/Unions & 183 & $18.2 \%$ & 134 & $19.4 \%$ \\
\hline $\begin{array}{l}\text {-Pressure groups specifically lobbying for } \\
\text { PSB }\end{array}$ & 145 & $14.5 \%$ & 102 & $14.7 \%$ \\
\hline -Other civil society groups & 38 & $3.8 \%$ & 32 & $4.6 \%$ \\
\hline Governmental Sources & 146 & $14.6 \%$ & 130 & $18.8 \%$ \\
\hline -Government Information Office & 108 & $10.8 \%$ & 99 & $14.2 \%$ \\
\hline -Executive Yuan & 10 & $1.0 \%$ & 9 & $1.4 \%$ \\
\hline -Other Governmental Sources & 9 & $0.9 \%$ & 6 & $1.0 \%$ \\
\hline -President & 6 & $0.6 \%$ & 5 & $.7 \%$ \\
\hline -Local governors & 5 & $0.5 \%$ & 5 & $.7 \%$ \\
\hline -Council of Indigenous Peoples & 4 & $0.4 \%$ & 4 & $.6 \%$ \\
\hline -Council for Hakka Affairs & 2 & $0.2 \%$ & 2 & $.3 \%$ \\
\hline -Military sector / associations & 2 & $0.2 \%$ & & \\
\hline Academics/Media Commentaries & 120 & $12.0 \%$ & 59 & $8.5 \%$ \\
\hline -Media academics & 101 & $10.1 \%$ & 49 & $7.0 \%$ \\
\hline -Academics (outsides Media) & 19 & $1.9 \%$ & 10 & $1.4 \%$ \\
\hline Parliamentarians & 114 & $11.4 \%$ & 109 & $15.8 \%$ \\
\hline -Lawmaker (DPP Party) & 38 & $3.8 \%$ & 36 & $5.2 \%$ \\
\hline -Lawmaker (PFP Party) & 37 & $3.7 \%$ & 36 & $5.2 \%$ \\
\hline -Lawmaker (KMT Party) & 36 & $3.6 \%$ & 34 & $4.9 \%$ \\
\hline -Lawmaker (Taiwan Solidarity Union Party) & 3 & $0.3 \%$ & 3 & $.4 \%$ \\
\hline Private business interests & 39 & $3.9 \%$ & 25 & $3.6 \%$ \\
\hline -Professionals in Marketplace & 27 & $2.7 \%$ & 13 & $1.9 \%$ \\
\hline -Other business interests & 11 & $1.1 \%$ & 11 & $1.6 \%$ \\
\hline -Advertisers & 1 & $0.1 \%$ & 1 & $.1 \%$ \\
\hline General Public & 36 & $3.6 \%$ & $\mathbf{0}$ & $0.0 \%$ \\
\hline -General Public & 36 & $3.6 \%$ & 0 & $0.0 \%$ \\
\hline Other Party Political Sources & 29 & $2.9 \%$ & 26 & $3.8 \%$ \\
\hline -Representative(KMT) & 12 & $1.2 \%$ & 11 & $1.6 \%$ \\
\hline -Representative(DPP) & 5 & $0.5 \%$ & 5 & $.7 \%$ \\
\hline -President of Party(DPP) & 3 & $0.3 \%$ & 3 & $.4 \%$ \\
\hline -President of Party(PFP) & 2 & $0.2 \%$ & 2 & $.3 \%$ \\
\hline -Members(KMT) & 2 & $0.2 \%$ & 2 & $.3 \%$ \\
\hline -Members(DPP) & 2 & $0.2 \%$ & 2 & $.3 \%$ \\
\hline -Members(TSUP) & 2 & $0.2 \%$ & & \\
\hline -Representative(TSUP) & 1 & $0.1 \%$ & 1 & $.1 \%$ \\
\hline Total & 1003 & $100.0 \%$ & 691 & $100.0 \%$ \\
\hline
\end{tabular}




\subsubsection{The Absence of the Public}

This radical marginalisation of voices from the 'public at large' is particularly ironic in the context of a debate centred so forcefully on promoting changes in the name of serving the public. Given that public service television is expressly aimed at providing the full range of cultural resources people need to become informed and engaged citizens and members of a public with reciprocal obligations, rather than simply consumers making personal choices in the marketplace, the symbolic silencing of public views and aspirations is an obvious absence. This marginal presence of 'public voices' had the effect of reproducing Reith's foundational paternalism that viewed public broadcasting, as something best left to experts, professionals and political elites to decide on and determine since in a highly commercialised media landscape 'ordinary' people could not be expected to make wise choices without proper 'guidance'.

\subsubsection{Significant Activist-Academics}

The findings reported in Table 6.5. show that members of the general public featured more often in the readers' letters sampled (19\%), but that even here, in a space ostensibly designed to provide a platform for 'ordinary' people, the opportunities to voice opinion were more often commandeered by media academics (23\%) and pressure groups lobbying for the PSB (22\%). These results suggest that despite the prominent role played by readers' letters in the overall coverage, noted earlier, ordinary citizens were by no means the dominant voices in this context. Rather, they became an arena in which the intellectual and activist elites involved in the PSB debate battled for ascendency. 


\begin{tabular}{|c|c|c|}
\hline \multicolumn{3}{|l|}{ Table 6.5. Actors in Readers’ Letters } \\
\hline & $\mathrm{N}$ & Percent \\
\hline Academics/Media Commentaries & 46 & $27.2 \%$ \\
\hline -Media academics & 39 & $23.1 \%$ \\
\hline -Academics (outsides Media) & 7 & $4.1 \%$ \\
\hline Pressure Groups/Unions & 40 & $23.7 \%$ \\
\hline -Pressure groups specifically lobbying for PSB & 37 & $21.9 \%$ \\
\hline -Other civil society groups & 3 & $1.8 \%$ \\
\hline General Public & 32 & $18.9 \%$ \\
\hline -General Public & 32 & $18.9 \%$ \\
\hline Media Sector & 29 & $17.2 \%$ \\
\hline -Public broadcasters & 15 & $8.9 \%$ \\
\hline -State-owned broadcasters & 7 & $4.1 \%$ \\
\hline -Press/newspaper interests & 4 & $2.4 \%$ \\
\hline -Private broadcasters & 2 & $1.2 \%$ \\
\hline -Staff/Labour unions \& associations & 1 & $0.6 \%$ \\
\hline Private business interests & 11 & $6.5 \%$ \\
\hline -Professionals in Marketplace/ Private consultants & 11 & $6.5 \%$ \\
\hline Governmental Sources & 6 & $3.6 \%$ \\
\hline -Government Information Office & 5 & $3.0 \%$ \\
\hline -Military sector / associations & 1 & $0.6 \%$ \\
\hline Parliamentarians & 4 & $2.4 \%$ \\
\hline -Lawmaker (KMT Party) & 1 & $0.6 \%$ \\
\hline -Lawmaker (DPP Party) & 2 & $1.2 \%$ \\
\hline -Lawmaker (PFP Party) & 1 & $0.6 \%$ \\
\hline Other Party Political Sources & 1 & $0.6 \%$ \\
\hline -Representative(KMT) & 1 & $0.6 \%$ \\
\hline Total & 169 & $100.0 \%$ \\
\hline
\end{tabular}




\subsubsection{Main Topics and Sub-themes}

As Table 6.6. shows, the most popular topic within the sampled coverage was the transitional ownership of state-owned television networks (24\%).

\begin{tabular}{|c|c|c|c|c|c|}
\hline \multicolumn{6}{|l|}{ Table 6.6. Topic of Items } \\
\hline \multirow{2}{*}{ Topic } & \multicolumn{3}{|c|}{ Press name } & \multirow[b]{2}{*}{ Total } & \multirow[b]{2}{*}{$\begin{array}{l}\% \\
(\mathrm{~N}=603)\end{array}$} \\
\hline & $\begin{array}{l}\text { United } \\
\text { Daily } \\
\text { News }\end{array}$ & $\begin{array}{l}\text { China } \\
\text { Times }\end{array}$ & $\begin{array}{l}\text { Liberty } \\
\text { Times }\end{array}$ & & \\
\hline Debates on transitional ownership of state-owned TV networks & 55 & 47 & 42 & 144 & $23.9 \%$ \\
\hline PSB institutionalisation & 51 & 52 & 14 & 117 & $19.4 \%$ \\
\hline The reasons for TV Reform & 28 & 49 & 26 & 103 & $17.1 \%$ \\
\hline Personnel & 35 & 46 & 16 & 97 & $16.1 \%$ \\
\hline Governance, regulation and supervision on PSB & 15 & 16 & 20 & 51 & $8.5 \%$ \\
\hline Legislature & 12 & 18 & 15 & 45 & $7.5 \%$ \\
\hline PSB Performance & 5 & 9 & 8 & 22 & $3.6 \%$ \\
\hline Digitalisation/Digital Switchover & 2 & 7 & 8 & 17 & $2.8 \%$ \\
\hline Comparisons & 0 & 3 & 2 & 5 & $0.8 \%$ \\
\hline Debates on PSB Funding & 1 & 0 & 1 & 2 & $0.3 \%$ \\
\hline Total & 204 & 247 & 152 & 603 & $100.0 \%$ \\
\hline
\end{tabular}

Although, as they have been seen, there were sharp disagreements over the appropriate method of reform, between proponents of privatisation and 'Gong Gong Hua', both camps agreed that one of the main justifications for reform was the need to address the question of political bias and interference. At the same time, both sides used this rationale to bolster their preferred solution. Two examples of letters from the United Daily News illustrate how this space was used as a battleground between advocates of the opposed positions. The first supports privatisation as a dynamic force for growth and dismisses opponents' proposals as 'utopian': 


\section{Title: State-run Media: A System Full of Moral Crisis}

In Taiwan's political climate, this sort of utopian idea is almost a mission impossible..... A model full of moral crisis can hardly be called a reasonable model...... on the other hand, in Western countries the booming media industry is coming from highly competitive commercial mechanisms ..... (Shu-Ling Lin, United Daily News, 18/12/2001, p. 15)

The second, written by a leading academic campaigner for PSB, who studied for his doctoral degree in the United Kingdom, bolstered his argument by contrasting the continuing political partisanship of the privately owned British press with the more balanced presentation of the BBC:

Title: Private Media Not Better on Insulation from Political Interference

The First level is those in power intent to directly interfere the content of programme and the second one is interferences through the appointment of senior personnel. The private media, which could hinder the second level of political interference, might be deemed to run better than the public media to play the fourth estate. However, take the actual performance of British media for example, British newspapers are privately owned, but their strong partisan gains lots of criticism. By contrast, BBC can maintain a better balance on their reports on various political parties..... (Jen-San Feng, United Daily News, 20/12/2001, p. 15)

In order obtain a finer grained overview of the topics and issued covered up to four sub-themes in each item were coded. Table 6.7. below shows the distribution of these themes.

As Table 6.7.shows, all the coverage in all three newspapers sampled gave particular prominence to the sub-themes: existing political control systems and political bias in the media and transformation to pure public media (First line of the themes in Table 6.7.: UDN: 15.50\%; CT: 15.30\%; LT: 13.40\%). 


\begin{tabular}{|c|c|c|c|}
\hline \multicolumn{4}{|l|}{ Table 6.7. Themes in Coverage } \\
\hline \multirow[b]{2}{*}{ Theme } & \multicolumn{3}{|c|}{ Press name } \\
\hline & UDN & China Times & Liberty Times \\
\hline Existing political control systems and political bias on Media & $15.50 \%$ & $15.30 \%$ & $13.40 \%$ \\
\hline Transform to pure public media & $15.50 \%$ & $13.00 \%$ & $10.00 \%$ \\
\hline How the PSB project is practiced & $12.90 \%$ & $10.20 \%$ & $2.10 \%$ \\
\hline Personnel of PSB & $7.10 \%$ & $6.90 \%$ & $4.20 \%$ \\
\hline to free Market logic/competition & $5.50 \%$ & $3.50 \%$ & $4.60 \%$ \\
\hline Personnel of state-owned TV & $5.50 \%$ & $5.50 \%$ & $2.10 \%$ \\
\hline Governance, regulation and supervision on PSB & $4.70 \%$ & $3.10 \%$ & $9.20 \%$ \\
\hline Government budget and support & $4.50 \%$ & $5.10 \%$ & $5.00 \%$ \\
\hline Laws for Terrestrial TV Reform & $3.40 \%$ & $4.90 \%$ & $4.60 \%$ \\
\hline Plans for local PSB branches & $2.90 \%$ & $2.20 \%$ & $1.30 \%$ \\
\hline Debates on PSB Performance & $2.60 \%$ & $2.60 \%$ & $3.80 \%$ \\
\hline UK & $2.60 \%$ & $3.70 \%$ & $1.30 \%$ \\
\hline to a Mixed Method & $2.40 \%$ & $2.00 \%$ & $0.40 \%$ \\
\hline The performance of existing Commercial System & $2.10 \%$ & $2.20 \%$ & $4.60 \%$ \\
\hline PSB get Government Funding & $1.80 \%$ & $2.40 \%$ & $3.30 \%$ \\
\hline Debates on expanding project & $1.60 \%$ & $1.60 \%$ & $2.90 \%$ \\
\hline JAPAN & $1.30 \%$ & $2.60 \%$ & $0.40 \%$ \\
\hline KOREA & $1.00 \%$ & $1.00 \%$ & $0.40 \%$ \\
\hline Minority interests & $0.80 \%$ & $1.00 \%$ & $5.00 \%$ \\
\hline Diversity of Programme & $0.80 \%$ & $0.80 \%$ & $0.00 \%$ \\
\hline Commercial ads & $0.80 \%$ & $0.20 \%$ & $0.00 \%$ \\
\hline USA & $0.80 \%$ & $0.20 \%$ & $0.40 \%$ \\
\hline Debates on PSB legislature & $0.50 \%$ & $0.40 \%$ & $0.00 \%$ \\
\hline Digitalisation & $0.50 \%$ & $0.60 \%$ & $0.40 \%$ \\
\hline Secure Citizenship/Democracy & $0.50 \%$ & $2.60 \%$ & $2.50 \%$ \\
\hline State-owned but more PSB programme & $0.50 \%$ & $0.80 \%$ & $2.50 \%$ \\
\hline Laws for PSB legal basis & $0.50 \%$ & $0.40 \%$ & $0.40 \%$ \\
\hline Protect public goods from Privatisation & $0.30 \%$ & $0.40 \%$ & $3.80 \%$ \\
\hline Levels of Existing Public Provision & $0.30 \%$ & $0.40 \%$ & $0.40 \%$ \\
\hline Imported programming squeezes local production & $0.30 \%$ & $0.60 \%$ & $1.30 \%$ \\
\hline to Trust: to build the sovereign body & $0.30 \%$ & $1.00 \%$ & $0.00 \%$ \\
\hline Hong Kong & $0.30 \%$ & $0.20 \%$ & $0.00 \%$ \\
\hline Debates on PSB Institutionalisation & $0.00 \%$ & $0.40 \%$ & $0.40 \%$ \\
\hline Preserve National culture & $0.00 \%$ & $0.00 \%$ & $0.40 \%$ \\
\hline PSB go free market/private companies & $0.00 \%$ & $0.00 \%$ & $0.40 \%$ \\
\hline Shareholding by government & $0.00 \%$ & $0.00 \%$ & $2.10 \%$ \\
\hline Increasing number of channels bring diversity to Media & $0.00 \%$ & $1.40 \%$ & $4.60 \%$ \\
\hline Budget for digitalisation & $0.00 \%$ & $0.20 \%$ & $0.40 \%$ \\
\hline AUSTRALIA & $0.00 \%$ & $0.00 \%$ & $0.40 \%$ \\
\hline New Zealand & $0.00 \%$ & $0.00 \%$ & $0.80 \%$ \\
\hline Tailand & $0.00 \%$ & $0.20 \%$ & $0.00 \%$ \\
\hline $\begin{array}{l}\text { Total } \\
\text { Count }\end{array}$ & $\begin{array}{l}100.0 \% \\
(\mathbf{3 7 1})\end{array}$ & $\begin{array}{l}100.0 \% \\
(\mathbf{4 7 1})\end{array}$ & $\begin{array}{l}100.0 \% \\
(237)\end{array}$ \\
\hline
\end{tabular}


In relation to several other key themes however, while there was substantial convergence between the two KMT inclined titles, the United Daily News and China Times, the Liberty Times, displays a different pattern.

The themes in table 6.7 can be grouped to highlight the ways in which the newspapers are divided. A prime example is that it pays less attention to the theme 'How the PSB Project is Practiced (United Daily News: 13\%; China Times: 10\%, Liberty Times: 2\%)', but displays markedly more concern than the other two newspapers with the sub-theme 'Governance, Regulation and Supervision of PSB'. This theme appeared in the Liberty Times mostly in 2008 after the KMT was returned to power. Two examples:

Public television budget has been frozen by the Legislative Yuan. A war continued. The Government Information Office yesterday pointed the arrow to the public television, saying that the PSB chairman, Cheng, agreed them to understand the cash flow of Public TV. Now Public TV is misleading it to a story about the GIO tended to audit....... (Audit PSB? GIO and PSB Attack Each Other, Liberty Times, 20/12/2008: 4)

The war between the KMT and the PSB has confused the society with the truth. This war in the media landscape should be divided into three dimensions to view.....(PSB should be supervised by all citizens, Liberty Times, 19/12/2008: 2)

Since it was a conflict with newsworthiness, the other two titles also covered it, but with markedly less emphasis than the Liberty Times (United Daily News 5\%, China Times 3\%, Liberty Times 9\%).

These variations require further analysis of the three titles' political stances which will be addressed in next chapter with a close look at the editorials they printed.

\subsection{Summary}

This chapter has mapped the way the national daily newspapers represented the debates around PSB expansion as they unfolded over and eight year period, covering the crucial run-up to the major reform of the system and its immediate aftermath. 
The findings identified five distinguishing peaks in the coverage over time convincingly which it was argued were generated primarily by general political events rather than changes in the operation and performance of broadcasting. It was further argued, on the basis of the overall amount of coverage, which despite its cultural and political salience to arguments around Taiwan's progress towards a full and mature democratic polity the issue of broadcasting reform was never a major policy priority.

The analysis of the main actors featured in the coverage suggested that the PSB debate was driven primarily by media academics and pressure groups that successfully employed readers' letters as a platform for their views. Their relative prominence fed into a more general press framing of the debate as a cultural struggle between state power and civil society rather than a political battle between the major political parties and an issue that revolved around competing professional expert evaluations rather than political positions.

The relative dominance of media elites' was also indicative of a particularly striking point: the marginal presence of general public voices. As a consequence, the debate was rooted in a contradiction. Advocates of PSB claimed to speaking on behalf of the 'public interest' but in the major public arena of the national press, their voices were markedly more prominent. 'Members of the public' were objects not subjects, talked about and evoked but accorded few opportunities to speak for themselves.

This chapter has offered a general overview of the press representation of the PSB debate as one of outcomes of claim-competition. The next two chapters pursue this examination further with close examinations of editorials and the letters to the editor, two spaces that reveal the extent to which press institutions reinterpret 'popular' themes in relation to their own political stances and support particular positions through their own overt advocacy. 


\section{Chapter 7}

\section{Mainstream Newspapers as Claim Makers}

In last chapter an overview picture of the claim-competition in the press presentation was illustrated to show how the PSB expansion was defined by the mainstream newspapers. This chapter will further explore the picture by examining the role of the mainstream newspapers themselves as an invisible claim-maker. More specifically, since editorials are 'the spaces sanctioned for the manifest assertion of press's judgements and concerns' (Deacon and Wring, 2002 , p. 200), this chapter intends to analyse the political arguments the mainstream newspapers advanced in the debate over the PSB expansion. This analysis investigates how the broader political stances of these various newspapers affect their interpretations and evaluations of this debate.

This editorial analysis is underpinned by chronological and thematic principles. Chronologically, this chapter adopted the collective phases in the formation of public opinion identified by Foote and Hart (1953; cited in Price, 1992, p. 30) - problem phase, proposal phase, policy phase, programme phase and appraisal phase - to examine the frequency and content of the editorials in relation to the different stages of PSB implementation.

Thematically, this chapter will explore how the editorial definitions and concerns of different newspapers developed as these policy phases unfolded. Further, this chapter will consider weather and to what extent the structure of the attention of the editorials in each of the papers coincided or diverged from 
the structure of news attention outlined in the content analysis in the previous chapter.

\subsection{Political Biases of Newspapers}

News organisations are not only active participation in public debate (Le, 2003) they can be conceived of as political organisations in their own right (Cook, 2003). Seen in this light, editorials represent the most obvious manifestations of the position of the press and serve as sites 'where ideological biases can be more readily discerned (Hackett and Zhao, 1994, p. 512).' The bias and political preferences of newspapers is also anticipated to play a key role in constructing the issues they engage with and the positions they take.

In this study, in order to show the political and ideological biases of the three newspapers, this section first revisits the history of Taiwanese newspapers briefly to provide a better understanding of their political preference.

\subsubsection{Newspapers Restriction}

Since 1949 when the KMT came to Taiwan from mainland China, newspapers in Taiwan had been heavily regulated by three restrictions: control over entry, control over printing, and regulation of the number of pages. From the 1960 s to 1988 the total number of newspapers was frozen at 31 because the government would not grant new press licences. 'It is evident that most publishers of privately owned papers were more or less associated with the KMT before the deregulation in 1988 (Chen, 1991, pp. 126-132)'.

One of dominant national daily newspapers, the China Times, was founded in 1950 under the name Credit News and focused mainly on price indices as a financial news sheet. In 1968, the name changed to the China Times.

Another main competitor in the market, the United Daily News was founded in 1951, as a merger of three local newspapers, the Popular Daily, the National, and the Economic Times.

Under the KMT's authoritarian regime, political issues were deemed too sensitive for the press to touch. Unlike the China Times which focused on financial and economic news, the United Daily News tended to attract readers' attention by sensational crime news. 
During the period of the press bans, the United Daily News and the China Times gradually became the mainstream press accounting for two-third of newspaper circulation in Taiwan in the 1970s. Chen (1998) indicates that those elites who ran the United Daily News and the China Times were permitted to run the newspapers because of the loyal support they provided to the KMT. During the martial law period, owners of both parties maintained close relationships with the KMT leadership.

\subsubsection{Patron-client Relationship}

Lin (2001) applied the concept of 'patron-client relationship' to describe the relations between the KMT and the two major newspapers in an analysis of the transformation of the client press in Taiwan from 1949 to 1999. As the clients for the KMT's authoritarian regime, the two newspapers' elites enjoyed privilege in the market (Lin, 2001).

Although the two major newspapers ran as 'party-state media', they had to compete to each other. Further, the label 'pro-KMT' masked important political differences within the KMT party and to which these two newspapers aligned differently when they involved in political struggle within the KMT (Chin, 2006). For instance, in the 1970s when there were fractions between two forces conservative and liberal - with in the KMT party, 'the United Daily News leaned towards the conservative wing while the China times collaborated with the liberal wing' (Lee, 1993, p. 16).

Amid Taiwan's political transition the press ban was lifted in 1988 and this press deregulation buried the seeds of crisis for the market of newspapers (Lin, 2008). Without any further proper regulation 'concerning concentration of ownership', the existing big newspapers soon won the unfair competition by their strong positions in the market (Lin, 2008, pp. 138-142). For instance, as soon as the government lifted restrictions in 1988, both China Times and United Daily News increased their number of pages but maintained their prices at the same level as other smaller newspapers. In order to compete with the Independent Evening Post, Taiwan's most reputable evening newspaper at that time, the two newspapers also launched evening newspapers, China Times Express and United Evening News. The Independent Evening Post soon found the challenge from the aggressive marketing strategies adopted by the China 
Times Group and the United Daily News Group too difficult to deal with, and thus starting from 1994 lost influence, readers and its previous financial muscle (Lin, 2008, pp. 192-193).

When the two newspapers were dominant in the market, another alternative press, The Liberty Times, was launched in 1980 by a local businessman. As a liberal paper with alternative view and strong financial muscle, Liberty Times, became famous for supporting the DPP and their alliance (Chen, 1998). By 1997 it had the third highest circulation and in 2005 surpassed United Daily News and China Times in terms of market share and advertising revenue (Lin, 2008, pp. 198-200). The rise of the Liberty Times marked the arrival of the first modicum of political pluralism in the national newspaper sector in Taiwan.

The most distinguishing point to differentiate the mainstream newspapers is the perspective of the cross strait relationship between China and Taiwan. Since the United Daily News and the China Times' founders were mainlanders moved from China with the KMT military in 1949 and also core members of the KMT party, there was, and remains a preference to support a reunification between the mainland and Taiwan. In contrast, partially as a consequence of its roots in Taiwanese entrepreneurial culture, the Liberty Times has always placed more emphasis on local Taiwanese values and advocated independence from China.

Despite the transition from regulation to deregulation, coverage of Taiwanese politics remained firmly biased in accordance with the political preferences of proprietors. Since there were no developed professional norms to prevent direct intervention from newspaper owners, their political preference are easily passed down through core editorial staff (Hsi, 2006, pp. 302-351) and to promote the owner's political interests (Lin, 2008, p. 138). Thus, most editorials principally tended to reflect the owners' view rather than internal staff or the ideas from readers (Hsi, 2006, pp. 302-351).

Following the political and ideological biases within the history of the three national newspapers discussed above, with a further examination on the editorials related to the PSB expansion, their general political positions and the links between press owners and political/business elites will be brought into more considerations, as well as the conflicts of interest that could occur when the PSB expansion threatened their commercial and political self-interests. 


\subsection{Valance of Editorial}

Twenty nine editorials addressing PSB were found across the whole textual corpus sampled. Compared with other genres, the number ( $5 \%$ of all items) is limited. For instance, commentary pieces accounted for $14 \%$ of all the items coded and 'reader's letters' for $24 \%$. One obvious explanation for the limited amount of editorials might be explained that daily newspapers usually contain dozens of news reports but only one editorial on any given day of news production. Further, this relatively limited amount of editorials coincides with the findings in last chapter which showed that press attention toward the PSB expansion was intermittent and that the topic never dominated the front pages. Therefore, an additional reason for the rather small editorial numbers may be due to the topic's limited news value.

\subsubsection{The Main Concern of the Editorials}

Table 7.1. shows the main topics of the editorials coded in three different national newspapers, United Daily News (UDN), China Times (CT) and Liberty Times (LT). 


\begin{tabular}{|c|c|c|c|c|}
\hline & \multicolumn{3}{|c|}{ Press name } & \\
\hline Topic & UDN & $\mathbf{C T}$ & LT & Total \\
\hline The reasons for TV Reform & 5 & 4 & 0 & 9 \\
\hline Debates on transitional ownership of state-owned TV networks & 3 & 3 & 0 & 6 \\
\hline PSB Performance & 1 & 1 & 0 & 2 \\
\hline Personnel & 1 & 2 & 1 & 4 \\
\hline Legislature & 0 & 2 & 0 & 2 \\
\hline PSB institutionalisation & 1 & 1 & 0 & 2 \\
\hline Governance, regulation and supervision on PSB & 0 & 3 & 0 & 3 \\
\hline Comparisons & 0 & 1 & 0 & 1 \\
\hline Total & 11 & 17 & 1 & 29 \\
\hline
\end{tabular}

The most prominent issue addressed in the editorials was the reasons for television reform (9 editorials). The next most frequently apparent topic was the transitional ownership of stated-owned television (6 editorials).

In table 7.1. when these general frequencies are disaggregated, some notable differences emerge between the three newspapers. The most significant is the almost complete absence of editorialising on PSB by the Liberty Times. Furthermore, there was some variance between the editorial concerns of the other titles, with the China Times providing three commentaries on the 'Governance, regulation and supervision of PSB', two on the role of the legislature in the process, and one making comparisons with other media systems. None of these issues were dealt with in UDN editorials.

It is difficult to escape the conclusion that these differences reflected the different political affiliations of the titles. The higher number of editorials in the pro-KMT papers suggests they had a greater willingness to highlight political issues and difficulties associated with the PSB policies advanced by the DPP. In contrast, the Liberty Times imposed an almost total embargo on discussion, presumably in part to avoid increasing pressure on the DPP on this topic, and in part to assist the party in downplaying the significance of the policy in the 
DPP's portfolio. (For example, as was noted in earlier chapters, once the DPP attained office, its enthusiasm for PSB reform notably reduced.) The only editorial found for the LT had the headline, 'The Implication and Controversy about the Appointed CTS General Manager' (Liberty Times, 03/07/2004, p. A3). From the perspective of protecting local media production, the editorial defended the controversial personnel of CTS general manager and the manager's statement of banning imported Chinese programmes. More detailed analysis of this editorial will be addressed in the following sections.

\subsubsection{Chronological Distribution}

In order to show how the concern of the press shifted over time, it is important to examine its chronological distribution. Table 7.2. below shows the chronological changes of published editorials across the sample period. 


\begin{tabular}{|c|c|c|c|c|c|c|}
\hline & & \multicolumn{3}{|c|}{ Press name } & \multirow[b]{2}{*}{ Total } & \multirow{2}{*}{$\begin{array}{l}\text { Stages of } \\
\text { the Policy Process }\end{array}$} \\
\hline & & UDN & CT & LT & & \\
\hline \multirow[t]{9}{*}{ Year } & 2000 & 0 & 0 & 0 & 0 & \multirow{4}{*}{ Proposal Phase } \\
\hline & 2001 & 0 & 1 & 0 & 1 & \\
\hline & 2002 & 3 & 0 & 0 & 3 & \\
\hline & 2003 & 0 & 2 & 0 & 2 & \\
\hline & 2004 & 1 & 7 & 1 & 9 & \multirow{3}{*}{ Policy Phase } \\
\hline & 2005 & 3 & 3 & 0 & 6 & \\
\hline & 2006 & 1 & 0 & 0 & 1 & \\
\hline & 2007 & 3 & 1 & 0 & 4 & \multirow[t]{2}{*}{ Programme Phase } \\
\hline & 2008 & 0 & 3 & 0 & 3 & \\
\hline Total & & 11 & 17 & 1 & 28 & \\
\hline
\end{tabular}

Since the public opinion is formed through a sequence of stages, the idea of Foote and Hart (1953; cited in Price, 1992, p. 30), which outlines five collective phases in the formation of public opinion, was adapted in this section to distinguish different phases in the PSB expansion in Taiwan. The original five phases can be summarised as follow:

1) Problem phase: some situation is determined to be problematic by a particular person or group and over time becomes generally understood as such. During this early stage, a lack of definition surrounds both the problem and its consequences, and for this reason the relevant public is indeterminate.

2) Proposal phase: one or more potential lines of action are formulated for responding to the problem.

3) Policy phase: the stage during which the merits and weaknesses of alternative proposals, having now been determined, are actively debated.

4) Programme phase: the time when the approved course of action is executed.

5) Appraisal phase: periodic re-evaluations of the effectiveness of the policy are undertaken, particularly by those unconvinced minorities that formed during the course of public debate.

In this section, the five phases were reduced to three, proposal phase, policy 
phase and programme phase, to fit the sample period of the press content analysis.

As was discussed in earlier chapters, the problem in the media landscape was defined long before 2000 where the DPP came to power. The sample period, from 2000 to 2008, was selected because the 2000 power-shift and in 2001 there was an intense period of public debate about the ownership transformation of state-owned terrestrial television.

At that time, one or more potential lines of action were formulated for responding to the problem when proposals about how to transform the state-owned media surfaced. Thus, the time from 2000 to 2003 was defined as the proposal phase.

From the end of 2003 to 2006, the PSB gradually outran the privatisation plan and the PSB group was cemented in 2006. It can be viewed as a period during which the merits and weaknesses of alternative proposals, having now been determined, were actively debated. Thus, I defined this period as the policy phase.

The Taiwanese PSB group launched in 2006 and completed the merge in 2007. From 2007 to 2008 is the time when the approved course of action is executed so this time was named as the programme phase. Table 7.2. above illustrates the chronological changes of the three newspapers.

Alongside the three phases of the formation of public opinion in Table 7.2., it is clear that in the Proposal phase and the Programme phase the amount of the published editorials shows lower levels of press attention to the PSB expansion than the Policy phase from 2004 to 2006. This feature coincides with the third and fourth distinguishing peaks of news coverage amounts which were found in last chapter. In the press content analysis the third peak occurred in 2004 when there were some protests and press conferences held by several pressure groups against government's privatizing plan on the two state-owned television stations, and also stimulated by a controversial political appointment of the general manager of the state-controlled television station CTS. And the fourth peak in 2005-2006 coincided with the passage of a new piece of legislation that regulated the release of government holdings in terrestrial television stations.

In 2006, the PSB television group, Taiwan Broadcasting System (TBS), was 
officially launched and the time shifted from the policy phase to the programme phase and Table 7.2., shows a significant drop in the amount of editorials. This reduction implies the media attention toward the PSB expansion once again moved to the margins of the media agenda.

Further, there are some distinguishing points can be seen in a comparison of the newspapers. For instance, during the Proposal phase from 2000 to 2003 there are only six editorials which were all from the UDN and CT. These editorials appeared even though the PSB issue had yet to feature with any prominence in the news agenda suggests that these titles were seeking to stimulate debate on the advisability of PSB reform, rather than just reflect wider discussions in the media and political domain.

However, this is not to suggest that editorials were completely detached from the wider news agenda, as the year with the most editorials (2004) also coincided with the highest peak found for general press coverage (see previous chapter). These peaks in turn reflected a noted intensification of public debate and controversy regarding the plans. For example, this was the year when rumours began to circulate that the media regulator, Government Information Office, was thinking of privatizing the two state-owned channels, TTV and CTS channels (Taipei Times, 18/05/2004, p. 2) which in turn stimulated protests and press conferences by pressure groups advocating PSB reform (see chapter 5). Another major stimulus in 2004 was the controversial appointment of the general manager of the state-controlled CTS. Significantly, this year was the only year in which LT made the only editorial intervention on the PSB expansion to defend the appointment for the DPP government. The relationship between LT and the DPP is evidently illustrated in this example.

\subsection{Exposition of the Editorials}

Consideration of the thematic and chronological frequency of editorials provides some suggestive indications of how political predispositions shaped the editorialising of different papers on this issue. In the section that follows, the expositions in these editorials are examined in closer detail. 


\subsubsection{The Proposal Phase}

As was mentioned earlier in Chapter 5, according to legislator Lee Yong-ping's account, the KMT friendly newspapers, UDN and CT, both published their coverage with a 'sceptical view toward the 'Gong Gong Hua' proposal and claimed this proposal would be another type of government control hidden under the guise of PSB. In the sampled editorials, the two newspapers' sceptical' attitudes toward the PSB expansion were also identified.

With the sceptical tone, a CT editorial in 2001 clearly shows the paper's preference for privatisation and a belief in the free market. The CT editorial, 'Review the Debate over Political Interference' (China Times, 12/12/2001, p. A2)', claimed the DPP government should let 'the market competition' to decide the future of the state-run terrestrial televisions. Further, the editorial also claimed that what really needed to be done was to establish a proper monitoring mechanism on the unbalance media landscape. An excerpt of the editorial is as follows:

\section{Excerpt}

...... As for the TTV and CTS, please let their future decided by the market competition. What Taiwan really needs is a monitor mechanism to protect the whole media landscape from over market-oriented and over-commercialization. We can learn from France to set a supervisory committee within the Ministry of Culture to manage and sanctions the media market. ..(China Times, 12/12/2001, p. A2)

Similarly, a UDN editorial published in 2002 exposed its strong support for privatisation with a strident title: 'Privatisation is the Best Way to Withdraw Political Control from the Media: (United Daily News, 02/01/2002, p. 2)', an excerpt of the editorial is as follows:

\section{Excerpt}

To get political power out of the media is the primary mission on the agenda. In this context, "privatization", of course, is more qualified to achieve the goal than the proposal of "public television" The ultimate aim is to improve the domestic media environment and its compatibility to international media market, then the "privatization" is a more tangible approach than "public television". (United Daily News, 02/01/2002, p. A2) 
These editorials clearly aligned with the position of the KMT at that time, with the enthusiasm for the privatisation option. During the Proposal phase, the lost-power KMT seemed to be against the PSB-oriented transformation and preferred the privatisation idea. The main concept of the KMT proposal was 'to sell the state-own televisions to free market and to establish a committee to supervise the free market (United Daily News 19/12/2001, p. 4).'

What is striking is that the Liberty Times made no counter-case during this the Proposal phase, extolling the preferability of the PSB option

\subsubsection{The Policy Phase}

During the Policy phase, issues of principles tend to be foreground. In the study, among the all identified editorials, the editorials published by the three newspapers in 2004 raised questions about the principles ignited by the controversial appointment of general managers in CTS. More specifically, the limited management expertise and the overt political preference of the general manager were the main criticisms made in the CT and UDN editorials. The UDN editorial, 'A Better PSB Solution than the Executive Yuan's Plan'(United Daily News, 10/07/2004, p. A2), vented people's anger at the appointment as a political manipulation which assumes it would mean a waste of taxpayers' money on the PSB plan and an erosion of citizens' rights. An excerpt of the editorial is as follows:

\section{Excerpt}

(After the DPP came to power), it looks like the new Government tends to withdraw its hand from the media. However, in fact, the DPP Government's another hand just tries to grasp media power by the name of "government supervision." Looking on how the DPP government's involvement of the media, such as the manipulation of personnel appointment for political reward, or the abuse of "Product Placement" in programme. In the future, it is no doubt that such practices will damage the public television group. From the personnel arrangements to the program review, the PSB will be not immune to manipulation by those people in power. It will be very challenging for the PSB to stay objective, neutral or independent. And the victims are all taxpayers and citizens....... (United Daily News, 10/07/2004, p. A2) 
Politically, this excerpt from the United Daily News shows its concern about how the relative autonomy of the PSB was in danger and how the professional decisions might not be able to be insulated from shadow of the government. Economically, it implies that the PSB group would be a big money-waste since the government-funded PSB had no realistic chance of becoming neutral or independent.

With the strong sceptical view on the capability of the PSB plan to be immune from manipulation by those in power', the UDN editorial revealed its preference for funding PSB. With repeated emphasis upon possible political control from (DPP) government, the editorial concluded by advocating privatisation as the pathway to free media landscape. An excerpt of the editorial is as follows:

\section{Excerpt}

In short, to choose between the PSB group or privatization is really " a painful choice from two terrible options." With the support form taxpayers' hard-earned money, the 'public' media has no guarantee for its quality and value but has lots of suspicions about when and how the government's Black Hand will stretch into it. It would be a better solution to let the public goods go to the private sectors for collecting rents and use the rents for the existing public television's financial resources. With the regulation of the radio and television law, the private media could take into account public interest and should be more possibility for the dream of "government interferences from the media" turning into reality. (United Daily News, 10/07/2004, p. A2)

Compared with the UDN editorial, another CT editorial also projected a strong mistrust on the 'Gong Gong Hua' policy because it could possibly just be 'a transition from one political party's control (KMT) to another party's hand (DPP)' (China Times, 25/06/2004, p. A2). An excerpt of the editorial is as follows:

\section{Excerpt}

The principle is straight forward. Withdrawing the political powers from the media will be beneficial to the country and political interferences in the media is damaging to the state. Authority is responsible for the media regulation and management. However, if it is only a transition from one partisan hand to another partisan hand, the diversity of the 
media still has no room for survival. From this point of view to examine recent reports about the media personnel disputes, the answer is clearer. (China Times, 25/06/2004, p. A2).

Although the CT editorial also showed as sceptical a point of view towards the possible government control and political manipulation as the UDN did, there were differences between the two KMT-friendly newspapers in their editorialising in 2004. While UDN still acted as an advocator for the privatisation proposal, by contrast, a CT editorial seemed to reluctantly accept the coming PSB-oriented transform with a premise: a healthy governance mechanism must be needed to help the PSB isolated from political interferences. An excerpt of the editorial is as follows:

\section{Excerpt}

Some experts have advocated the public-oriented transform for the state-owned televisions, but before the social consensus to respect for the media freedom and to safeguard freedom of speech develop a solid basis, the public-oriented transform for the state-owned televisions means the government's power will expand rapidly in the absence of effective monitoring mechanism. Such a media weapon could be over powerful without balance......the freedom of the media could not just rely on the goodwill of those in power. At this critical moment, the establishment of an independent monitoring organisation is perhaps more necessary (China Times, 25/06/2004, p. A2).

From this excerpt, the emphasis on building an efficient mechanism to supervise the public media group also coincides with what were found in the distributions of the main topics which shows that CT seems to have more 'active participation in public debate' on 'the Governance and supervision on the PSB (3 Editorials)' while the other two press have said nothing on this governance topic. It is striking how these differences correlate with the wider political differences discussed earlier in these pro KMT titles. As discussed, UDN is appreciably more conservative politically than CT, which would suggest they are more likely to advance the case for full privatisation and confidence in the ability of 'the market' to deliver media freedom and plurality.

In contrast to the stance of UDN and CT, a LT editorial, 'The Implication and Controversy about the Appointed CTS General Manager (Liberty Times, 
03/07/2004, p. A3)', defended the DPP government and stated that the appointment in CTS is a professional decision. The LT editorial also summoned the ghost from the authoritarian KMT era by mentioning the abuse of patronage is the KMT's tricks not the DPP's. An excerpt of the editorial is as follows:

\section{Excerpt}

In the democratic process, those in power have the right to appoint professional people to share their expertise. The appointees are responsible for this one in power. By contrast, the term 'political rewording' is another matter. It means those in power abuse their influence on specific personnel cases to benefit their loyal and trusted servants and political partners without concern about the appointees' competence. Before, in the authoritarian era, the KMT personnel arrangements were always chosen by the appointees' political background, ethnicity, or their connection with those in power. Now, in a democratic era, we should abandon the political rewarding conventions. In fact, if the DPP government really want to benefit Chiang Hsia, the general manager of CTS which is a highly demanding job could not be deemed as a nice rewarding at all. (Liberty Times, 03/07/2004: A3)

The excerpt of the LT editorial delivers two messages. First, politically, this editorial tends to link the negative image of the political appointment to the previous KMT's ruling convention in order to remind their readers that KMT used to manipulate the media personnel as well. It also asserted that the first concern of the DPP government was the appointee's 'expertise' rather than the appointee's political preference. Refuting KMT allegations, this editorial suggests that principles of the relative autonomy of broadcasters are secured in the DPP time. Second, the editorial emphasised the professionalism of the appointee. In terms of media management issues, this editorial claimed that the DPP government arranged this appointment because they trusted the appointee's competence. This editorial also mentioned the high demands placed on the general manager of CTS which in turn demanded the appointment of somebody with high levels of professionalism and expertise.

In particular, the editorial made no mention of the claim-competition between privatisation and 'Gong Gong Hua' in the same way as the other two newspapers did. It extends the scope of the debate to the cultural implications, characterising it as an ideological fight related to local production and national 
identity, especially when it comes to the newly appointee's plan to boycott Chinese drama programme from Great China. An excerpt of the editorial is as follows:

\section{Excerpt}

Chiang Hsia's assertion on boycott Chinese drama is worth exploring further. . . . . she refuse to buy Chinese drama with clear motives aimed at enhancing the local production and protecting the prospects of Taiwanese entertainment staff. Due to cultural similarities and bargain prices, Chinese drama programme is much more capable in replacement of local drama than Japan and South Korea drama programme..... (Liberty Times, 03/07/2004, p. A3)

Central to the excerpt of the LT editorial are two themes: culturally and economically this editorial offered its support to Chiang Hsia's assertion on boycotting Chinese drama. To back Chiang Hsia's point of view, the editorial indicated that due to cultural similarities between China and Taiwan, and the inexpensiveness of Chinese drama, they are much more capable of replacing local production than other Asian countries such as Japan or Korea. In this point that importing Chinese drama programmes causes more damages to Taiwanese local programmes than other countries. Compared with criticism that Chiang Hsia's assertion came from her anti-Chinese bias rather than a professional judgement, this editorial claimed that the input of Chinese content was a cultural and economic threat and justified the banning of Chinese drama on these bases.

This editorial further suggested that the PSB has a primary responsibility for protecting and developing national culture by 'enhancing the local production and protecting the prospects of Taiwanese entertainment staff'. In pursuit of this aim, programmes should be nationally produced rather than imported.

This is a salient point that differentiated the LT editorial from the other two newspapers whose main focus was on the political intervention. This LT editorial also echoed with their political stance of pro-Taiwan independence which is also a core value of the DPP party.

The Policy phase marked the most intense period of editorialising on the PSB issue. However, it is also important to look at the tone and content of 
editorials produced during the Programme phase. It is to these matters that the discussion now turns.

\subsubsection{The Programme Phase}

Once the policy has been implemented, more practical questions tend to come to the fore to question if the policy is working efficiently. During the Programme phase, there is a change of the role of the two KMT-friendly newspapers can be identified. Both of them shifted from 'advocators of the best solution' to 'severe critics of the PSB practice' By scrutinising where the legislation had been enacted and how the institutional and financial organisation of the PSB group was being developed.

An UDN editorial, 'A Promise for the PSB future? Why Not Give Us an Explanation for the Mess First! (United Daily News, 22/12/2007, p. A2)', claimed that even if the TBS has been established, its autonomy and independence still remained with a big question mark since the sign of the political influence from the DPP government was so obvious. An excerpt of the editorial is as follows

\section{Excerpt}

When Taiwan Broadcasting System (TBS) launched in 2006, it carried with the expectations to be "everyone's media" so it also naturally benefit from the nearly 2 billion (NT Dollars) subsides a year from government's huge budget.

Today, when we have not yet been familiar with "TBS" programme, we learn lots of negative news of "TBS" first. Even those civil groups and media academics who advocated a "Public-oriented Media Reform" in the past now become sceptical on "TBS"......."TBS" started its concrete operations only more than one year, so far we cannot evaluate its effectiveness. However, the manipulation on the personnel is definitely the typical political products (United Daily News, 22/12/2007, p. A2)

In 2008, the DPP had just lost its power and ended its eight years long governance and the KMT came back in office. During this power shift, as a KMT-friendly newspaper, a CT editorial, 'Those in Power Should Remember Lessons from the Past', 14/12/2008, p. A11), addressed anger and disappointments toward the political manipulation from the new KMT government. Around the same time, unsurprisingly another KMT-friendly 
newspaper, the UDN, had no editorial on this issue (see table 7.2.). This example echoes what mentioned earlier in the review of Taiwanese press history about the difference of the two KMT-friendly newspapers in their different closeness with the KMT. An excerpt of the editorial is as follows

\section{Excerpt}

An old saying 'It will never be too late for a gentleman to take revenge' just projects what the current ruling KMT government is doing! Since last year when they came to power, the KMT legislators have battled with public broadcasters over the PSB annual budget. Recently, the legislation of the budget was passed with a bizarre resolution. It includes some agenda like expanding number of the PSB directors, future programme plans must be reported beforehand etc....... what the KMT is doing is not only doing less well than before, but also go backward into the authoritarian era.......In short, in Taiwan this strange territory where a blue (means KMT) - green (means DPP) are always against to each other, any "public" affairs could be mission impossible. (China Times, 14/12/2008, p. A11)

Further, from the CT editorial, there is the same key theme about political control. It illustrates that even if the government changed the same old problem still remained unchanged. Throughout the sampled period of the press content analysis, the concern over political control has been the key theme which has gone through the three phases of the formation of public opinion over different governments. It suggests that both political parties cannot be trusted on maintaining the independence and autonomy of the PSB. This point also echoes one conclusion in last chapter that the newspapers have portrayed the PSB debates as a cultural fight between the state power and the civil society rather than a political war between political parties. It could be defined as a professional debate rather than a political debate.

\subsection{Summary}

Comparing the attention of the editorials with the structure of news attention outlined in the content analysis in last chapter, it is evident that the two only directly coincided in 2004 when the policy was being developed and discussions of principles were to the foreground. By contrast, in the Proposal phase and the Programme phase, the attention of the editorials diverged from 
the structure of news attention outlined in the content analysis by showing very limited attentions to the debate. This feature demonstrates the mainstream newspapers, as an invisible claim-maker, actively participated in the claim-competition during the shaping time of the PSB policy.

From the editorials published during the Policy phase, it can be argued that the unsettled question of whether to go ahead with the PSB gave United Daily News and China Times space to put their arguments for privatisation and against the 'Gong Gong Hua' project which was going to be conducted by the DPP government.

When the arguments against the 'Gong Gong Hua' were deemed to be lost, the attention of the two newspapers shifted from questions of principle to criticism on practice. The two newspapers, the United Daily News and the China Times, raised issues about the workability of the PSB system and about its independence from government. It is an issue that is given added impetus because there is now a DPP government in power rather than a KMT administration, so criticism on PSB also provided a means for attacking the DDP administration.

On the other hand, 2004 was also the only year that the Liberty Times published an editorial. In this editorial the newspaper raised the question of national production and imports from Greater China. This was in line with their general pro-independence stance which is shared by the DPP. Here it could be argued that whereas in the policy formation stage the Liberty Times did not need to intervene since the case for PSB was being won. When the system was in place it was important to raise the key issue about the PSB's responsibility for defending national culture as against the emphasis on economic and political issues focussed on the two KMT supporting papers. Moreover, it was important because their case was likely to get a sympathetic hearing and be influential given that it chimed with the DPP government's own general position on independence.

It was in these editorials that the various newspapers inserted their own voices into the PSB debate. But newspapers are supposed to respond to public opinion as well as lead it, so it is important to also consider the extent to which they provided opportunities for their readers to contribute and comment on this important policy matter. It may be that when these other areas of coverage are 
considered, their collective coverage is revealed as more pluralistic and less closely politically aligned than is suggested by this analysis of editorial content. This analysis will be provided by the discussion in the next chapter, which looks at the publication of readers' letters. 


\section{Chapter 8}

\section{Representing 'Public' Opinion: Letters to the Editor}

In last chapter editorials were explored as a space in which the newspapers could express their own political positions and advocate the polices they favoured. In this chapter, the focus turns to the space where 'outside' voices appear in ostensibly unmediated form, the readers' letters column, and examine the way the selection and presentation of items operated to construct a particular version of 'public opinion'.

This may seem like a surprising choice for detailed analysis since readers' letters are not normally singled out for sustained attention in research on the press coverage of contentious issues. They may be mentioned but they tend not to be a major focus. However, as the results of the content analysis, reported in Chapter 6, showed, in the case under discussion here letters to the Editor stood out as an important component of press representation. At the first glance, this finding might suggest that the newspaper coverage was hospitable to a wide range of voices, including the voices of the ordinary citizens in whose name changes were being proposed. Existing research would lend this assumption some support since letters to the editor seem to be 'typically understood' as 'a public forum of facilitating public discussion' (Wahl-Jorgensen, 2001, p. 305) and a means 'of promoting reader participation and obtaining useful guidelines about local opinion' (Jackson, 1971, p. 152). However, the verification of this assumption requires further analysis of the published letters 
to see how far this 'forum' did in fact provide a space for the general public to participate in the PSB debate in Taiwan.

\subsection{Letters to the Editor as a Public Forum}

Over the last two decades, a number of scholars have investigated the function of the letters to the editors section of newspapers (Buell, 1975; Volgy et al., 1977; Sigelman and Walkosz, 1992; Hynds, 1994). Most of these studies set out to test 'empirically the degree to which letter writers are similar to the electorate', or whether they differ from the 'public' (Buell, 1975; Volgy et al., 1977, p. 32). Other studies have looked at the degree to which the letters page can be considered a 'public opinion thermometer' (Sigelman and Walkosz, 1992) while other again have embraced the democratic potential of the section and proclaimed letters to be 'among the few outlets available to the public for voicing opinion', 'the community's heartbeat', and 'a debating society that never adjourns' (Kapoor \& Botan, 1992, p. 5; Kapoor, 1995) Other commentators however have sounded a note of caution, arguing that letter page is, at best, 'hazy reflections of public opinion' (Grey and Brown, 1970, p. 450) since letter writers tend not to be representative of the general population.

By identifying and critiquing the rules employed in selecting which letters to publish, Wahl-Jorgensen points out that editors operate as 'gatekeepers of the public sphere' (Wahl-Jorgensen, 2001, p. 304) and determine whose voices and concerns are systematically privileged, and whose never stand a chance of being heard.

Similarly, Richardson \& Franklin (2004) argue that the readers' letters are 'selected and shaped by editorial teams whose motives were not driven by the dictates of deliberative democracy but by the need to fill the page in a balanced and interesting way' and that 'such prosaic concerns cut across the prevailing academic and professional conceptualizations of the letters' page as a public forum for deliberative debate (Richardson \& Franklin, 2004, p. 476)'.

In his analysis of the institutional goals of newspapers, Tunstall (1977) points out that the correspondence section fits very well with the commercial needs of popular papers since the letters submitted indicate which topics or stories are more appealing to readers. Pounds (2006, p. 32) similarly indicates that papers not only publish letters with the laudable intent of fostering public participation 
in the life of the community, but also because they recognize that letters have selling power.

Richardson \& Franklin (2004) however take the argument a step further, arguing that letters are selected for publication not simply according to their newsworthiness but 'to reflect the identity of the newspaper, to meet the perceived preferences of readers, as well as the more prosaic requirements of availability of space and editorial imperatives concerning balance (Richardson \& Franklin, 2004, p. 459)'. Carefully selected letters can 'echo the newspaper's concerns' and 'increase the readers' impression that the papers are representing them (Bromley, 1998, p. 151)'.

Following the chronological and thematic principles applied in the last chapter, the first aim of this present analysis is not only to identify variations in the flow of letters printed in the three newspapers over time, but also the extent to which the structure of attention of the letters in each of the papers coincided with or diverged from the structure of news attention revealed in the general content analysis. Secondly, adapting the model developed in Pounds' study (2006) this chapter proposes an analytical typology in order to further examine the role of writers and readership.

\subsection{Principles for the Examination of Letters}

Generally speaking, two main types of letter can commonly be found in newspapers: letters asking regularly featured experts or columnists for advice on specific issues (usually personal or financial), and letters addressing opinions to the editor. In this study, only the second category letters addressing opinion were sampled.

There are potentially a range of motivations that might inform a person's decision to write a letter to the editor as a way of sharing and publicising their opinions. In order to examine these motivations this study will adapt Pounds (2006)' analytical typology and divide the reasons into three main groups: 1) expression of criticism, 2) appeal for action, and 3) other reasons for writing.

Further, in order to examine the way strings of letters functioned, or did not function, as dialogues on the page (one of the key requirements of the operation of media as components in a public sphere rooted in deliberation), 
four features of presentation were considered:

1). the structure and the form of the string: indicates how far it is open only to privileged players or also to members of the general public.

2). Footing and affiliation for writers: 'Footing' is a concept derived from discourse analysis which explores how the content of a message is attributed to a source (Edwards \& Potter, 1992; Deacon et al., p. 17). The attributions accorded to a published letter by either the editors or other respondents signal to what extent the letter writer's expertise and authority is publicly acknowledged. In the PSB debate some writers' professional titles or official position were printed directly after their names to indicate their affiliation and thereby their authority to speak on the issues. Conversely, in some letters the writers use 'footing' to undermine their opponents' credibility and signal that their claimed expertise or experience gives them no special status in the discussion;

3). Presentation of the Public: this explores the extent to which the public evoked in the letter is constructed as the general public, the fictional public or invisible consumers;

4). The rationally of discussion and criticism: examine whether the way the writers expressed their opinions accords with the spirit of rational deliberation, that Habermas, following Kant's foundational definition of the principle of enlightenment, provides the cornerstone of a democratic culture. Democratic practice requires participants to reduce the emotional temper of deliberation to a minimum and to provide room for plural voices. Insisting on the self-evident validity of a single point of view or reducing argument to binary oppositions is the direct antithesis of this.

\subsubsection{Coding Criteria for Letters}

From Table 6.3. Distribution of coverage by Genre in previous Chapter 6, there were 142 of letters to the editor identified for this study. The coding data of the newspaper in which the item appeared, from chapter 6, was applied here, so did the coding data of main topic and the actors in the sampled items (coding manual see appendix 4) as identifications for the main topic of the letters and letter writers.

In order to further distinguish reasons for writing letters, this chapter adapted 
Pounds (2006)' analytical typology and divided the reasons into three groups: expression of criticism, appeal for action, and other reasons for writing. A coding manual for reasons of writing letters was generated by following this typology (detailed coding manual see appendix 5).

\subsubsection{Inter-coder Reliability (reasons of writing Letters)}

To test the coding manual for reasons of writing letters, a random sample of 20 news item was selected from the total sample (142) for inter-coder reliability testing. To reach the agreement on the codes between two coders, Holsti's method (1969; Neuendorf, 2002) was applied in this pilot. The calculation formula for percent agreement between two coders who code the same units is: $P A o=2 A /(n A+n B)$ Where PAo stands for "Proportion agreement, observed," $A$ is the number of agreement between two coders, and $n A$ and $n B$ are the number of units coded by coders A and B, respectively (Neuendorf, 2002). This statistic also ranges from .00 (no agreement) to 1.00 (perfect agreement).The percent agreement of from the pilot are Reasons of Writing Letters (PAo $=$ 0.90).

\subsection{Fabrics of the Sampled Letters}

Table 8.1. below shows the chronological changes of published letters related to the PSB debates across the study period in the three national newspapers sampled, the United Daily News (UDN), the China Times (CT) and the Liberty Times (LT). 


\begin{tabular}{|c|c|c|c|c|c|c|c|c|c|c|}
\hline \multicolumn{10}{|c|}{\begin{tabular}{l|r} 
& Year(2000-2008) \\
\cline { 2 - 3 }
\end{tabular}} & \multirow[t]{2}{*}{ Total } \\
\hline & 00 & 01 & 02 & 03 & 04 & 05 & 06 & 07 & 08 & \\
\hline UDN (Frequency) & 3 & 13 & 4 & 5 & 6 & 5 & 3 & 0 & 10 & 49 \\
\hline (Percent, $\mathrm{N}=49$ ) & 6.1 & 26.5 & 8.2 & 10.2 & 12.2 & 10.2 & 6.1 & 0.0 & 20.4 & 100.0 \\
\hline CT (Frequency) & 2 & 1 & 3 & 2 & 9 & 14 & 4 & 3 & 14 & 52 \\
\hline (Percent, N=52) & 3.8 & 1.9 & 5.8 & 3.8 & 17.3 & 26.9 & 7.7 & 5.8 & 26.9 & 100.0 \\
\hline LT (Frequency) & 0 & 3 & 0 & 0 & 6 & 4 & 10 & 10 & 8 & 41 \\
\hline (Percent, $\mathrm{N}=41$ ) & 0.0 & 7.3 & 0.0 & 0.0 & 14.6 & 9.8 & 24.4 & 24.4 & 19.5 & 100.0 \\
\hline Total (Frequency) & 5 & 17 & 7 & 7 & 21 & 23 & 17 & 13 & 32 & 142 \\
\hline (Percent, N=142) & 3.5 & 12.0 & 4.9 & 4.9 & 14.8 & 16.2 & 12.0 & 9.2 & 22.5 & 100.0 \\
\hline Policy Stages & \multicolumn{4}{|c|}{$\begin{array}{l}\text { Proposal Phase } \\
25.3 \%\end{array}$} & \multicolumn{3}{|c|}{$\begin{array}{l}\text { Policy Phase } \\
43.0 \%\end{array}$} & \multicolumn{3}{|c|}{$\begin{array}{l}\text { Programme Phase } \\
31.7 \%\end{array}$} \\
\hline
\end{tabular}

\subsubsection{Interventions in the Letter Section}

The level of editorial intervention is sometimes easier to analyse by considering the corpus as a whole rather analysing the sample than letter by letter (Pounds, 2006, p. 45).

Differences can be identified both across time and across papers. Looking at the chronological distribution shown in table 8.1., it can be seen that in the rate of letters published is highest (43.0\%) during the Policy phase when the form of the practical proposals for change was being thrashed out. It is lower in the Programme phase (31.6\%), when the new structure was up and running, and lowest during the Proposal phase (25.3\%) when competing ideas for change 
were being floated. These figures coincide with the findings for the distribution of the editorials sampled from the three newspapers. The concentration of Letters during the Policy phase also coincides with the news peak in 2004.

On the surface, this result could be seen as supporting the conclusion that readers' letters were selected primarily according to their news value. However, the variation in the distribution of letters across the three newspapers suggests that newsworthiness was not the only criterion of selection.

The peak years occurred in the UDN in 2001, in the CT in 2005 and 2008, and in the LT in 2006 and 2007. These differences in the space accorded to the 'public voice' suggests that the UDN employed letters to articulate concerns more often during the initial stage of policy process, when competing proposals were still being debated, whereas both the CT and the LT focused more concertedly on the later phases after concrete plans had been drawn up and were being implemented.

The finding clearly shows that the letters were not chosen simply according to their newsworthiness, but 'to reflect the identity of the newspaper and to meet the perceived preferences of readers' (Richardson \& Franklin, 2004, p. 459). The compositions of these differences in readership will be examined in a later section: the writers of letters.

\subsubsection{The Main Concerns expressed in the Letters}

As mentioned earlier the coding procedure adopted nominated one main topic for each item and up to three sub themes.

As Table 8.2. shows, the main concerns expressed in readers' letters were 'the reasons for TV Reform' (30\%), 'Debates on transitional ownership of state-owned TV networks' (16\%) and 'PSB institutionalisation' (15\%). 


\begin{tabular}{|c|c|c|}
\hline & & Percent \\
\hline \multirow{11}{*}{ Topics } & The reasons for TV Reform & 29.6 \\
\hline & Debates on transitional ownership of state-owned TV & 16.2 \\
\hline & PSB institutionalisation & 14.8 \\
\hline & Governance, regulation and supervision on PSB & 10.6 \\
\hline & Personnel & 9.9 \\
\hline & PSB Performance & 9.2 \\
\hline & Digitalisation/Digital Switchover & 4.9 \\
\hline & Legislature & 4.2 \\
\hline & Comparisons with Other PSBs in the World & 0.7 \\
\hline & Total & 100.0 \\
\hline & & $(\mathrm{N}=142)$ \\
\hline
\end{tabular}

\subsubsection{The Reasons for Writing}

Sharing one's opinions can take many forms, such as: expressing protest, outrage, criticism, providing or requesting clarification and information, or advocating a course of action (Pounds, 2006, p. 32). As mentioned earlier, in order to codify the main reasons for writing letters to the editor, this study adapted Pounds (2006)' analytical typology and divided the reasons into three groups: expression of criticism, appeal for action, and other reasons for writing.

Expressions of criticism are manifest in positive or negative evaluations relating to the assessment of events, states of affairs and people. Appeals for action are identified or inferred in relation to assertions of normative value grounded in evaluations of particular courses of action and the agents expected to carry them out. Other reasons for writing were also common. These included: requesting information or clarification on a particular issue, warning, and disagreeing with another correspondent. Although in most letters more than one reason could be identified, the main theme of a letter was coded as the main reason.

Following by this typology, the differences of reasons to write letters to join the PSB debate can be separated into the three groups and identified as applying this schema across the whole corpus of letter sampled produces the distributions shown in Table. 8.3.. 
Table 8.3. Reasons of Writing Letters

\begin{tabular}{|c|c|c|}
\hline & $\%$ & $\begin{array}{c}\text { TOTAL } \\
\%\end{array}$ \\
\hline \multicolumn{3}{|l|}{ Criticism } \\
\hline Criticism on existing political control on TV stations & 15.5 & \multirow{8}{*}{56.4} \\
\hline How the plan (PSB institutionalisation) is practiced & 9.9 & \\
\hline Criticism on PSB Performance & 8.5 & \\
\hline Criticism on governance, regulation on PSB & 7.0 & \\
\hline Criticism on the personnel issues of PSB & 6.3 & \\
\hline The performance of existing Commercial System & 4.2 & \\
\hline Criticism on the personnel of state-owned TV & 3.5 & \\
\hline Criticism on privatisation of media & 1.4 & \\
\hline \multicolumn{3}{|l|}{ Appeal } \\
\hline Appeal for a public media & 7.7 & \multirow{12}{*}{35.1} \\
\hline Appeal to release state-owned TV to free Market competition & 4.9 & \\
\hline Appeal a PSB to secure Citizenship and Democracy & 4.9 & \\
\hline Appeal a PSB to secure minority interests & 4.2 & \\
\hline Appeals for local PSB branches & 3.5 & \\
\hline PSB legislature & 3.5 & \\
\hline Laws for Terrestrial TV Reform & 1.4 & \\
\hline PSB Funding Model: maintain state-owned \& PSB programme & 1.4 & \\
\hline Comparison with Other PSBs (BBC in the UK) & 1.4 & \\
\hline PSB Funding Model: establish a Trust foundation & .7 & \\
\hline PSB Funding Model: PSB get Government Funding & .7 & \\
\hline Diversity of Programme & .7 & \\
\hline \multicolumn{3}{|l|}{ Others } \\
\hline Digitalisation vs. PSB & 4.9 & \multirow[t]{2}{*}{8.5} \\
\hline Replying to another correspondent & 3.5 & \\
\hline Total & $\begin{array}{r}100.0 \\
(\mathrm{~N}=142) \\
\end{array}$ & $\begin{array}{l}100.0 \\
(\mathrm{~N}=142)\end{array}$ \\
\hline
\end{tabular}

Inter-coder Reliability: a random sample of 20 news item was selected from the total sample (142) for inter-coder reliability testing. To reach the agreement on the codes between two coders, Holsti's method (1969; Neuendorf, 2002) was applied in this pilot. The percent agreement of from the pilot are Reasons of Writing Letters $(P A O=0.90)$. 
As table 8.3. shows, expressions of criticism (56\%) are more frequent than appeals for action (35\%) and criticism most often focus on questions surrounding the political control and bias on TV stations (16\%), and, to a lesser extent, how the PSB institutionalisation is practiced (9\%).

The letters appealing for action, cluster around the two opposing proposals for reform, the appeal to privatise state-owned TV (5\%) and, more prominently, the call for a new public media system (8\%) ['Gong Gong Hua'] and the associated arguments for PSB reform as a force for the greater representation of minority interests (4.2\%) and for local PSB services (3.5\%).

Although some letters express the writer's disagreement with another correspondent very few strings of argument were identified where successive writers engage with and reply to each other's positions and are prepared to modify their position when faced with a stronger case, responsiveness that Habermas identifies as central the process of truly democratic deliberation. Rather, the letter columns operated more as a space for the unilateral announcement and restatement of positions already fully formed.

The next section will explore the organisation of strings of letters further, but before this exploration the distribution of motivations for letter writing across the three sampled titles and across time needed to be examined.

\begin{tabular}{|c|c|c|c|}
\hline $\begin{array}{l}\text { Reasons } \\
\text { Press }\end{array}$ & $\begin{array}{r}\text { Criticism } \\
\text { Percent }\end{array}$ & $\begin{array}{l}\text { Appeal } \\
\text { Percent }\end{array}$ & $\begin{array}{l}\text { Others } \\
\text { Percent }\end{array}$ \\
\hline UDN & 33.8 & 38.0 & 25.0 \\
\hline CT & 40.0 & 32.0 & 33.3 \\
\hline LT & 26.2 & 30.0 & 41.7 \\
\hline Total & $\begin{array}{r}100.0 \\
(\mathrm{~N}=80)\end{array}$ & $\begin{array}{r}100.0 \\
(\mathrm{~N}=50)\end{array}$ & $\begin{array}{r}100.0 \\
(\mathrm{~N}=12)\end{array}$ \\
\hline
\end{tabular}

As table 8.4. shows, differences can be identified across papers. The highest proportion of letters articulating criticisms were published by the China Times (40\%) whereas the United Daily News published the most (38\%) containing appeals. 


\begin{tabular}{||l|r|r|r|r|r|r||}
\hline \multirow{2}{*}{ Year } & \multicolumn{6}{|c||}{ Table 8.5. Variation of Reasons over Time } \\
\cline { 2 - 8 } & \multicolumn{2}{|c|}{ Criticism } & \multicolumn{2}{c||}{ Reasons } \\
\cline { 2 - 8 } & Frequency & $\begin{array}{r}\text { Percent } \\
(\mathbf{N}=80)\end{array}$ & Frequency & $\begin{array}{r}\text { Percent } \\
(\mathbf{N}=50)\end{array}$ & Frequency & $\begin{array}{r}\text { Percent } \\
(\mathbf{N}=\mathbf{1 2})\end{array}$ \\
\hline 2000 & 4 & 5.0 & 1 & 2.0 & 0 & 0.0 \\
\hline 2001 & 11 & 13.8 & 6 & 12.0 & 0 & 0.0 \\
\hline 2002 & 3 & 3.8 & 4 & 8.0 & 0 & 0.0 \\
\hline 2003 & 5 & 6.3 & 2 & 4.0 & 0 & 0.0 \\
\hline 2004 & 10 & 12.5 & 10 & 20.0 & 1 & 8.3 \\
\hline 2005 & 8 & 10.0 & 10 & 20.0 & 5 & 41.7 \\
\hline 2006 & 10 & 12.5 & 6 & 12.0 & 1 & 8.3 \\
\hline 2007 & 6 & 7.5 & 4 & 8.0 & 3 & 25.0 \\
\hline 2008 & 23 & 28.8 & 7 & 14.0 & 2 & 16.7 \\
\hline Total & 80 & 100.0 & 50 & 100.0 & 12 & 100.0 \\
\hline \hline
\end{tabular}

However, these synoptic differences need to be placed in the context of the debates as they evolved over time. As Table 8.5. shows, the highest level of criticism is found in 2008 (29\%) when the proposals decided on were being translated into concrete experience and the DDP government, under which the proposals had been finalised, was replaced by the KMT's return to power.

The highest level letters voicing appeals occurs in 2004 and 2005, coinciding with moment when a new PSB policy was being implemented following amendments to 'the Broadcasting and Television Act, Cable Television Act, and Satellite Broadcasting Act' at end of 2003. As noted earlier, the implementation of these amendments at the beginning of 2004, required government and political parties to withdraw their investments by 2006, but left the structure of any new system open to debate. 


\subsection{The Writers of the Letters}

The content analysis findings presented in the preceding chapter showed that Letters to the Editor stood out as a major component of the overall coverage of PSB issues. However, the examination of these letter writers showed an elite-oriented streak of these writers in the debate. They were mainly media academics (23\%) and members of pressure groups (22\%). These findings coincides with the results of other studies that view Letters to the Editor as an instance of a genre dominated elite discourse rooted in claims to expertise (Fradgley and Niebauer, 1995; Sparks, 1999).

\subsubsection{Selections of Writers}

The elite-oriented streak confirmed that in the process of constructing this version of the 'republic of letters' editorial 'mediations' tend to systematically favour the voices and concerns of particular groups of actors while relegating other groups to the margins or to silence. However, these selections are not uniform across the three newspapers respectively. Letters sampled in each paper shows their particular preferences. These differences are detailed in Table. 8.6.. 
Table 8.6. Composition of the Letter Writers in the Three Newspapers Respectively

\begin{tabular}{|c|c|c|c|c|c|c|c|c|c|c|c|}
\hline \multirow{2}{*}{ Main Actors } & \multicolumn{9}{|c|}{ Year } & \multirow{2}{*}{\multicolumn{2}{|c|}{$\begin{array}{cc} & \% \\
& \\
\text { Total } & (\mathrm{N}=57) \\
\end{array}$}} \\
\hline & 2000 & 2001 & 2002 & 2003 & 2004 & 2005 & 2006 & 2007 & 2008 & & \\
\hline Academics & 0 & 6 & 0 & 1 & 3 & 3 & 2 & $c$ & 4 & 19 & 33.3 \\
\hline General Public & 1 & 3 & 2 & 2 & 1 & 0 & 1 & c & 1 & 11 & 19.3 \\
\hline Pressure Groups/Unions & 1 & 2 & 0 & 2 & $\mathrm{c}$ & 2 & 0 & $\mathrm{c}$ & 1 & 8 & 14.0 \\
\hline Private business interests & 1 & 1 & 0 & 1 & 2 & 2 & 0 & c & 1 & 8 & 14.0 \\
\hline Media Sector & 0 & 0 & 1 & 0 & C & 0 & 0 & c & 4 & 5 & 8.8 \\
\hline Parliamentarians & 0 & 0 & 2 & 0 & c & 0 & 1 & $c$ & 1 & 4 & 7.0 \\
\hline Governmental Sources & 0 & 0 & 0 & 0 & c & 0 & 1 & c & 0 & 1 & 1.8 \\
\hline Other Party Political Sources & 0 & 1 & 0 & 0 & c & 0 & 0 & c & 0 & 1 & 1.8 \\
\hline Total & 3 & 13 & 5 & 6 & 6 & 7 & 5 & $c$ & 12 & 57 & 100.0 \\
\hline
\end{tabular}

\section{China Times}

\begin{tabular}{|c|c|c|c|c|c|c|c|c|c|c|c|}
\hline \multirow{2}{*}{ Main Actors } & \multicolumn{9}{|c|}{ Year } & \multirow{2}{*}{\multicolumn{2}{|c|}{$\begin{array}{cc} & \% \\
& \\
\text { Total } & (\mathrm{N}=71) \\
\end{array}$}} \\
\hline & 2000 & 2001 & 2002 & 2003 & 2004 & 2005 & 2006 & 2007 & 2008 & & \\
\hline Pressure Groups/Unions & 0 & 1 & 3 & 0 & 6 & 7 & 3 & 4 & 4 & 28 & 39.4 \\
\hline Academics & 3 & 0 & 2 & 0 & 3 & 3 & 2 & 0 & 3 & 16 & 22.5 \\
\hline General Public & 0 & 0 & 0 & 1 & 2 & 3 & 1 & 0 & 6 & 13 & 18.3 \\
\hline Media Sector & 1 & 0 & 1 & 1 & 0 & 3 & 0 & 1 & 3 & 10 & 14.1 \\
\hline Governmental Sources & 1 & 0 & 0 & 0 & 0 & 1 & 1 & 0 & 1 & 4 & 5.6 \\
\hline Total & 5 & 1 & 6 & 2 & 11 & 17 & 7 & 5 & 17 & 71 & 100.0 \\
\hline
\end{tabular}

\section{Liberty Times}

\begin{tabular}{|c|c|c|c|c|c|c|c|c|c|c|c|}
\hline \multirow{2}{*}{ Main Actors } & \multicolumn{9}{|c|}{ Year } & \multirow{2}{*}{\multicolumn{2}{|c|}{$\begin{array}{cc} & \% \\
& \\
\text { Total } & (\mathrm{N}=41) \\
\end{array}$}} \\
\hline & 2000 & 2001 & 2002 & 2003 & 2004 & 2005 & 2006 & 2007 & 2008 & & \\
\hline Media Sector & 0 & 0 & 0 & 0 & 1 & 1 & 2 & 8 & 2 & 14 & 34.1 \\
\hline Academics & 0 & 2 & 0 & 0 & 0 & 2 & 2 & 1 & 4 & 11 & 26.8 \\
\hline General Public & 0 & 0 & 0 & 0 & 0 & 1 & 5 & 1 & 1 & 8 & 19.5 \\
\hline Pressure Groups/Unions & 0 & 1 & 0 & 0 & 3 & 0 & 0 & 0 & 0 & 4 & 9.8 \\
\hline Private business interests & 0 & 0 & 0 & 0 & 1 & 0 & 1 & 0 & 1 & 3 & 7.3 \\
\hline Governmental Sources & 0 & 0 & 0 & 0 & 1 & 0 & 0 & 0 & 0 & 1 & 2.4 \\
\hline Total & 0 & 3 & 0 & 0 & 6 & 4 & 10 & 10 & 8 & 41 & 100.0 \\
\hline
\end{tabular}

(N.B.: in the sampled letters, sometimes one letter can be co-authored by two or more than two writers. Thus, in the Table 8.6. above, the total number of all writers is 169 , which is higher than the total number of sampled letters, 142, in pervious Table 8.1. to Table 8.5.). 
As Table. 8.6. shows, the most frequent letter writers appearing in the United Daily News are academics and media commentators. For instance:

Hamilton Cheng, Lecturer in Fu Jen University.

('The plan to free state-owned TV to market only accelerates political and commercial interventions on media. Media development in free markets like the US already proved self-regulation did not work at all ', United Daily News, 26/12/2001, p. 15)

Chien-San Feng, journalism professor at National Chengchi University. ('Don't Give Me 'Green [DPP] Political Terror'. Just Give Me the PSB Legislation', United Daily News, 25/06/2004, p. 15)

In contrast, the most frequently published correspondence in the China Times comes from pressure groups. For instance:

Ti Wei, a convener of the Campaign for Media Reform Chung-Hsiang Kuang, Chairman of Media Watch Organization. ('Talks on Reform. Don't Forget State-Owned TV', China Times, 15/12/2005, p. A12)

Ti Wei \& Chad Liu, executive members of the Campaign for Media Reform. ('Reinventing New Supervision Mechanism for PSB', China Times, 17/12/2008, p. A12)

Compared with the other two newspapers, in the Liberty Times writers from the media sector are most likely to get their letter published. For example:

Fisher, Executive Director of CTS.

('How the CTS Transform to a Public TV', Liberty Times, 26/8/2005, p. 15)

Qui-Xian Chen, Director of Public TV Station.

('The Hakka News Lacks of Objectivity', Liberty Times, 12/11/2007, p. 15)

Although writers' identity and social status are always printed with their letters, in the sampled letters some writers shift their identities by utilising different titles and claims to expertise at different times. Some shift their identities from 
media professor to a member of pressure group, or from broadcasters to media academics for example.

\subsubsection{Formation of 'Public Opinion'}

In her analysis, Wahl-Jorgensen (2002) usefully identities four main editorial criteria for the selection of letters: relevance, brevity, entertainment, and authority.

Claims to authority are rooted in the demonstration of 'cultural capital' (Wahl-Jorgensen, 2002, p. 76). Consequently, letters with the expressions are ungrammatical or in unconventional styles are more likely to be rejected. The deployment of this criterion in the present sample is demonstrated by the fact that many of the letters ostensibly coming from 'the general public', were in fact written by MA students who could demonstrate their possession of higher levels of cultural capital than writers with only a basic education. For example:

Zh-Ching Lin, MA student.

('Give Me a Political-Free Media Environment', United Daily News, 14/12/2001: 15)

Ren-Jun Hong, MA student.

('PTS Is Not Servant for Political Power', China Times ,31/03/2005: A15)

Jin-Tang Lin, MA student.

('Can lawmakers name themselves 'fair people from society' to join the PTS

Directors and Supervisors Review Committee?' China Times, 09/10/2008: A22)

Graduate students are also more likely to fulfil the criterion that letters should be well written letters (Pounds, 2006). This finding suggests that far from being 'general' the 'general public' as represented in this debate was highly restrictive and that this selectivity, combined with the preference for contributions from those who could claim relevant expertise and involvement in the issues, closed the debate around letters from the 'civically minded, politically involved, knowledgeable' (McNair, 2000, p. 109). 


\subsection{Strings of Letters: Dialogue or Monologue?}

Despite the relative lack of diversity in the voices in the letters section it would still be possible to argue that it represented a (partial) demonstration of the public sphere in action, if it provided a space for genuine deliberation. As noted earlier however, a closer look at strings of correspondence reveals that that are predominantly 'monologic' rather than 'dialogic'.

Most letter writers appeared to view themselves as engaged in an implicit dialogue between themselves and an imagined rather than an actual opponent (Eemeren \& Grootendorst, 1992). This stance has two consequences. Firstly, writers are relatively disinterested in responding to points put by other contributors. Secondly, when they do respond they are more likely to restate their own position, dismissing alternative arguments rather rationally than evaluating them.

\subsubsection{Configuration of Letter Debate}

We can explore these issues further by looking at the longest string found in the sample. This was published in the China Times in 2005 when political withdraw from media by 2006 had been decided on but the future of state owned television after that date was still a matter of deep contention.

The string contains five letters written by four writers; two media academics, an executive in the transitional state-own broadcaster and a public broadcaster. It was initiated by the two media academics who wrote a letter analysing the internal clash within the CTS and appealing for a solution based on 'Gong Gong Hua'. Three days later, a reply from a CTS executive manager was published. The media academics and the CTS executive manager then responded to each other in turn. The string ends with a letter from a public broadcaster. The full details of the five letters can be found in Appendix 6 .

\subsubsection{Features of the String of Letters}

\section{Structure}

Reading the letters in published order, a clear binary structure can be discerned with the four writers expressing opposed views on how best to address the internal clash in the CTS and the best way to sort it out. These differences are also clearly rooted in their more general pro- and anti 'Gong 
Gong Hua' positions. None of them modify these stances from beginning to the end in the exchange on the page. Take the conclusions of letter 3, letter 4, and letter 5 for example. In letter 3, the conclusion represents a strong fight back from the two academics supporting an extended public service solution in response to the previous attack when the executive director of CTS claimed that the 'Gong Gong Hua' movement is more like a religion for these media academics.

Historically, when someone intends to describe certain proposal or ideas form social reform as a 'religion' or 'sacred mission,' it is always proven that he is using a suppression tactic to against the idea and concept (Letter 3, Line 59-60).

In the conclusion of letter 4, the executive director of CTS reasserts his view that he cannot accept the 'Gong Gong Hua' project:

Although the Government Information Office (GIO) ordered the CTS to merge with PTS, in this 'marriage' three parties (CTS, PTS and GIO) are lack of talks. We don't mind if the GIO has no intention to meet us, but in the GIO proposal the CTS is renamed to be the PTS 2. In this marriage, we become PTS's small mistress, how can we accept this? (Letter 4, Line 31-33)

In letter 5 , the manager of PTS concludes by defending his own institutional position, asserting that the PTS won't take all the blame for the situation because they cannot be considered 'responsible for the whole media environment':

For these issues, we do not reckon that we are responsible for the whole balance of the media environment, but we won't avoid any commitments and social expectations the public ask us to carry out (Letter 5, Line 32-35).

It is clear that genuine dialogue is not present in this exchange. All the contributors claim expertise in media matters, based either on their academic credentials or their professional practice, and present opinions based on their 'existing position' and their 'cultural acceptability' in this debate (Shattuc, 1997). Arguably, this emphasis on conflict, which is also characteristic of news reporting more generally, is the key reason why mediated discussion only 
provides opportunities for different opinions to be expressed and not for genuine deliberation as required by the ideal model of the public sphere (Livingstone \& Lunt, 1994). In this case, both sides stand firmly by their existing positions and communication between them remains at the level of 'assertion of their own belief' and 'against other's opinion.' In the other words, process is a series of monologues rather than a genuine dialogue.

\section{Footing}

In most of the letters sampled in this study the identity of the writers is clearly shown, usually by way of the individual's name and profession (e.g. researcher, student, policymaker, and broadcaster): for instance:

Letter 2

CTS with the Same Resentment as Zhao-Jun Wang's

by Fisher, Executive director of the CTS

Letter 4

Media Reform Requires Procedural Justice

by Fisher, Executive director of CTS

Letter 5

Digitalisation Can Expand PSB

by Hui-fang Hou, Marketing Manager in PTS

Even if, in their exposition, the writers speak mainly or wholly in their personl voice as individuals, the footing accorded to them may identify them as belonging to specific organizations or supporting particular interests. For example, at the end of Letters 1 (and 3) written by the two media academics, the name of the campaign group they were involved with was also printed:

Letter 1

Appeal for an Ending to the CTS farce

by Wei Ti, Chad Liu 
(Wei Ti is assistant Professor in Dept. of Mass Communication at Tam Kang University. Chad Liu is assistant Professor in Dept. of Communication at Chung Cheng University. Both of them are executive committee from Media Reform Society)

In the letters themselves, in footing the previous writer's ( $\left.s^{\prime}\right)$ name or giving the newspaper a positive mention is employed as a polite form of address:

Letter 2:

On $11^{\text {th }}$ your honourable newspaper published a letter, 'Appeal for an Ending to the CTS farce' written by Wei Ti and Chad Liu. As an executive director of the CTS, I am writing this letter to officially respond the letter you published (Line1-3).

Letter 3:

We are pleased to see a commencement of discussions since Mr. Fisher respond us from a different perspective. To the opinion of Mr. Fisher, here we would like to briefly clarify and discuss more (Line1-3).

Letter4: no footing in the opening.

Letter5

In Mr. Fisher's letter, 'CTS with the Same Resentment as Zhao-Jun Wang's', mentioned a number of issues related to the Public Television Station, I would like to clarify some points for the PTS officially (Line 1-3).

In the example of letter 2 , the writer, immediately after mentioning the previous writers' names, announces his own institutional position in order to legitimise his right to reply and confirm the authority of his opinions. Another example is as follows:

I am the Executive director of the CTS. Although this title is a no-pay and voluntary job, I still feel confident to call myself a leader in the managing team since I monitor finance and digital media development (Letter 2, Line 39-42).

On the other hand, writers from with the industry tend to use 'footing' to undermine their academic opponents' credibility, claiming that their position as 'outsiders' gives them no authority to speak on the operations of institutions 
they have no practical experience of. For example:

Maybe next time when any other television stations have personnel conflicts and internal clashes, the two scholars can help all of them just by 'Gong Gong Hua' them. If this makes sense, all professors in business and management departments can be replaced by media scholars (Letter 2, Line 19-23).

\section{Representation of 'The Public'}

In the string of letters under discussion here, 'the public' are mentioned a number of times but the figures evoked differ at different times. For instance, 'the public' in the example below refers to an imagined general public:

We won't avoid any commitments and social expectations the public ask us to carry out (Letter 5, Line 35).

In the following two examples, in contrast, 'the public' assumes a more concrete form, as actively complaining about the present state of affairs and as potential political actors in debates around PSB:

If you insist that the attempt of the CTS managing team to expand the news programme has nothing to do with political motive but only because of the news report is gaining more creditability and popularity, then we are happy to invite the whole public to make a fair judgement together (Letter 3, Line 28).

Despite there are a large number of complaints from the public and the CTS professional journalists toward this programme replacement, we can do nothing to stop this (Letter 1, Line).

In this example 'the public' is constructed even more concretely, as the constituency and audience served by a public broadcasting organisation, CTS:

Now the CTS is in a transition and it is not just a private media firm so the CTS managing team should accept any criticism from the public. (Letter 3, Line 8-10).

To sum up; the analysis presented here strongly suggests that Letters to the Editor are organised around two binary oppositions, between competing 
media reform proposals (public interest vs. private interests; pro vs. anti-'Gong Gong Hua') and competing political parties (DPP vs. KMT).

As Pounds notes newspapers not only publish the letters to foster public participation but also because of their selling power (Pounds, 2006, p. 32). Consequently, in order to dramatise debates, opposing concepts are presented less as a way of balancing the arguments, and more in an effort attract and hold the attention of readers.

The findings presented here tend to support this pessimistic view of the potential of the Letters to the Editor section to act a genuine public forum under the constraints of the commercial system.

\subsection{Summary}

Overall, the analysis of letters to the editor suggests that the newspapers employed this space, as a compliment to the overt expression of preferred opinions in editorials, to covertly construct and convey their political views and make claims. This strategy has the obvious benefit of shifting 'part of the political risk from the news organizations to the individual writers' (Lee, 2000).

In this seemingly most public of forums, typically claimed as a site 'of promoting reader participation and obtaining useful guidelines about local opinion '(Jackson, 1971, p. 152) it is ironic to find that the general public were relegated to a marginal position. Whereas members of academic, civil society, and institutional elites appeared frequently in the letter columns, 'ordinary people' tended to fall at the hurdles presented by processes of editorial selection that favoured the possession and expression of high levels of cultural capital (Wahl-Jorgensen, 2002). As a consequence, members of the 'public', though frequently evoked and referred to in the letters, almost never had the opportunity to speak in their own voice.

They were supporting actors or stage props on an elite-level platform. This situation conforms to Habermas' notion of refeudalisation (Habermas, 1962/1989) in which the public ceases to be a community of citizens, actively participating in public debates on issues of the day, and is once again relegated to the role of audience for performances orchestrated elsewhere. Since the voice of the general public was only marginally represented in 
debates around PSB expansion, the key question is 'who had the greatest impact on the formation of public opinion and policy?'

Since media academics and members of pressure groups emerge as the main letter writers, on the surface a hasty judgement would be that they had the greatest impact.

As was observed earlier, Binderkrantz's work (2005) demonstrates that the repertoires of action employed by interest groups include both direct contact with bureaucrats and parliamentarians and indirect activities such as media campaigns and mobilizations of members, and as he points out, there is no contradiction between pursuing insider access to decision-making and applying pressure on decision makers through media contacts and mobilizations (Binderkrantz, 2005).

From this perspective, being a dominant voice in the media presentation is only half of the story. The other half of the story suggests two possible scenarios. The first scenario is that pressure group activists have successfully combined insider participation in the policy making process, with strategies designed to influence decision makers by mobilising public platforms.

The second scenario is that activist elites are dominant in media space precisely because this is the only space open to them. In other words, they are in the position of surrounding the building in which the decision makers are sitting, but are unable to enter the rooms where debates are taking place and deals are being done because the doors are closed to them.

Overall, the evidence collected in the course of this present research tends to support the second scenario. This scenario can also account for why the development of the fledgling PSB has been so turbulent.

This leads us to next point. Chapters 6 to 8 , which have presented the results of the press analysis, have demonstrated that the public was, throughout the PSB debate, as Dalhgren notes, just 'a group of spectators' (Dalhgren, 1995: p8) rather than real participants.

Seen in this light, it can be argued that despite the concerted efforts of its most vociferous and mobilized supporters an expanded PSB system failed to become a significant public issue and a civic choice with wide support from the society. 


\section{Chapter 9}

\section{Conclusion}

In Chinese ancient folktales, a 'monster-revealing mirror' is known for its ability to expose the true identity of evil creatures concealed behind human-shape disguises. As was observed earlier in this thesis, the mirror held up by the process of PSB expansion did not reflect the bright vision of the PSB project initially promised but displayed the flawed face of a policy process under pressure from both political and commercial forces.

PSB was originally seen as a device for protecting citizens against the twin threats of political propaganda and the crass commercialism of market-driven programming (Keane, 1993). The Taiwanese experience provides a prime case of both these threats. Looking at the series of setbacks that threw PSB expansion into disarray, some critics argued that it was an accident waiting to happen since the PSB-oriented group, the TBS, failed to isolate itself from political forces, leading a former DPP legislator to describe the power clashes inside boardroom between 'the independently professional directors' (according to Lui's own claim)' and KMT-related directors as 'a battle between light and darkness' (Lui, 2010). In a letter to the editor headed: 'How they trash the PSB project together during those year' (Tsai, 2012; TBS, 2012b), a 
documentary producer, speaking for many programme makers, criticised the broadcasters for dancing with political forces at a dangerously close distance.

The former CEO of TBS group Feng Hsien-hsien, with her first-hand experience with the PSB expansion, claimed on a televised talk show that the political forces were targeting the PSB group due to the rich resources it commanded, which included its broadcasting facilities, valuable land in the heart of capital city, and media influence, especially during election time. She argued that the old habit of viewing terrestrial television as a propaganda tool, which had prevailed under the non-democratic rule of the KMT, had continued into the democratic era with political actors continuing to regard media as personal assets and key instruments in the political gameplays (Feng, News Wow Wow Wow, 10/08/2011).

Given by the evidence from this study, it is hardly a surprise to see the continuous disarray of the TBS group since throughout this thesis we have seen the seeds of the chaos were sowed during the process of the PSB expansion.

\subsection{Three Key Dimensions of Taiwan's PSB}

Although the British model, BBC, has been viewed as a key reference in Taiwan's PSB expansion, as Smith argued (1995), of the all broadcasting organisations in the world, 'the BBC has been the most widely admired but has none the less proved difficult for others to copy successfully' (Smith, 1995, p. 80). To address reasons why Taiwan has difficulty to copy the ideal model successfully, this thesis examined the ways in which public service broadcasting (PSB) expansion were accessed in Taiwan, and the cultural and social consequences of it. In this study, the battle for public broadcasting in Taiwan can be addressed into three key dimensions:

1. Taiwan was going against the grain of international trends of public service broadcasting while a number of media commentators in the PSB traditional heartlands have been asking whether the PSB idea has now outlived its usefulness;

2. The argument for PSB was going against the grain of the growing 
enthusiasm for privatisation and market-led solutions - not just in broadcasting but within the economy as a whole as it moved from state management;

3. The practice of the advocates of PSB went against the grain of their professed claims to be representing the general public.

To address the three dimensions, this study explored how the expansion of PSB in Taiwan was socially defined and constructed, and by whom. After introduction provided a prime example of Taiwan's media coverage of Japan disastrous earthquake to show a urgent call for PSB, Chapter 2 revisited the core values and principles of ideal PSB and argued that in practice these ideals had faced a variety of context-specific challenges in different nations, so the prescription for Taiwan's PSB expansion must be necessarily context-specific rather than just copy a model from other country.

To understand the context, Chapter 3 presented a profile of the specific social background of Taiwan, a country in the process of making the double transition from an authoritarian system to a liberal democracy and from a state directed to a more market driven system, and traced the impact of both these processes on the media landscape.

Then Chapter 4 reviewed the history of Taiwanese PSB and the main issues that have attended different phases of its development and then outlined the central research questions and the research methods. Chapter 4 argues that, there were from the outset, fundamental problems in the basic design of Taiwanese PSB.

Through the analysis of the interview data, Chapter 5 explored further to identify the reasons why the PSB expansion project was not working arguing that this was primarily because it was being pulled in different directions by various claims from different groups. Specifically, the legislators constructed the PSB expansion as a part of political struggle from their understandings that most policy formulations are embedded with invisible political interests and concessions. Behind the claims, it can be seen the concern of the political claim-makers was seeking to stay in power or to get back to power. Considerations about media reform were deemed a small side show of the political struggle. On the other hand, the broadcasters, with their empirical 
experience in running the PSB group, kept addressing the practical problems that they struggle with insufficient fund, internal tensions like channels with different goals and external pressures like political interferences to explain and justify the dysfunction of the PSB group from their position.

As the issue entrepreneur who spotted and claimed that it was time for revolutionary change, the activist-academics translated their academic knowledge into practical actions to push the PSB proposal against the wave of privatization. With their claims based on their belief of the role of media, as public goods, should play, it can be easily argued that the efforts of the academic claim-makers paid off since the proposal of privatisation was squeezed out of the arena of the claim-competitions even the privatisation plan fell in to the 'simple claims' category which are usually more effective than complicated ones like the elusive PSB proposal. The Campaign for Citizens' TV may be significant in the media reform history but the academics still had their limits. The academics had a partial victory in keeping the privatisation option in abeyance, but their more dynamic vision of PSB reform was quickly side-lined when the DPP took power and this led them to rethink their strategy.

\subsection{Inclusion and Exclusion}

Serving as one of primary outcomes of the claim-competition presented in Chapter 5, a press representation of the PSB expansion was conducted to identify the dominant claim and the boundary of inclusion and exclusion, which serves to focus the media attention but also detracts the attention away from what lies outside the boundary.

Chapter 6 first mapped the way the national daily newspapers represented the debates around PSB expansion as they unfolded over the nine-year period, covering the crucial run-up to the major reform of the system and its immediate aftermath. Five distinguishing peaks of amount identified in the findings generated primarily by general political events rather than changes in the operation and performance of broadcasting. It was argued, on the basis of the overall amount of coverage, which despite its cultural and political salience to arguments around Taiwan's progress towards a full and mature 
democratic polity the issue of broadcasting reform was never a major policy priority. Further, the analysis of the main actors featured in the coverage suggested that the PSB debate was driven primarily by media academics and pressure groups that successfully employed readers' letters as a platform for their views. Their relative prominence fed into a more general press framing of the debate as a cultural struggle between state power and civil society rather than a political battle between the major political parties.

The relative dominance of media elites' was also indicative of a particularly striking point: the marginal presence of general public voices. As a consequence, the debate was rooted in a contradiction. Advocates of PSB claimed to speaking on behalf of the 'public interest' but in the major public arena of the national press, their voices were markedly more prominent. 'Members of the public' were objects not subjects, talked about and evoked but accorded few opportunities to speak for themselves.

Chapter 7 evidently demonstrated the mainstream newspapers, as an invisible claim-maker, actively participated in the claim-competition during the shaping time of the PSB policy. It was in these editorials that the various newspapers inserted their own voices into the PSB debate. Then the analysis of letters to the editor in Chapter 8 suggests that the newspapers employed this space, as a compliment to the overt expression of preferred opinions in editorials, to covertly construct and convey their political views and make claims. It is ironic to find that the general public were relegated to a marginal position: when members of academic, civil society, and institutional elites appeared frequently in the letter columns, 'ordinary people' tended to fall at the hurdles presented by processes of editorial selection that favoured the possession and expression of high levels of cultural capital. As a consequence, members of the 'public', though frequently evoked and referred to in the letters, almost never had the opportunity to speak in their own voice.

They were supporting actors or stage props on an elite platform.

Overall, the analysis showed that the triggers for mediated debate were mainly associated with battles within the general political arena rather than considerations of public interest or the concerns of media professionals. It also demonstrated that although this contest between competing claims was being waged in the name of the 'public' it was, in practice, conducted within 
the closed circles of competing elites with the voices of viewers being largely excluded.

\subsection{Conceptual and Structural Confusions}

This elite centred debate was shown, in the analysis of readers' letters, to be conducted as a 'war of positions' with each side using the opportunities presented by periodic peaks in press interest, to restate and reaffirm their original viewpoints rather than to engage in open deliberation. Interestingly however, both of the core positions in play in the debate- the advocacy of privatisation and the argument for an extended PSB structure - derived in large part from western models.

This was less of a problem for champions of privatisation since they could claim to be riding a wave of change that had already transformed the global economic landscape in country after country and industry after industry. The proponents of extending PSB had more of a problem however. They had to explain why a model of broadcasting, which was under pressure and in retreat in many other countries, including a number of its original homelands in Western Europe, should be adopted as the preferred solution for Taiwan.

Given that in accordance with the purpose of the establishment of public television around the world, in the picture of the press representation, the significant absence of the general public is quite remarkably ironic while public television is meant to create strong connections to the general public. The marginal presence of 'public voices' in the mainstream newspapers convincingly demonstrates a vestige of the earliest conceptualisations of public service broadcasting: a paternalistic, Reithian idea that experts, professionals and political elites decide and determine what the public interests are and how the public are catered for. Two general points can be deduced here. First, this representation picture orchestrated by the sources suggests a dialogue of elites and no room for ordinary citizens. Second, it also highlights the PSB expansion seems not a partisan fight on policy but a fight between the state power and the civil society actors. It was a professional debate rather than a political debate. 
By the funnel-down analytical framework applied in this thesis, this study argues that the representation of the PSB expansion is conceptual and structure confusion.

Conceptually, what exactly that public service broadcasting means still remains contested and elusive while the key actors, in pursuit their own sectional interests, have engaged in the debate with respective monologue rather than dialogue.

When one asks a political question, one will receive a political answer. As the PSB debate is overly politicised in Taiwan, the answers produced were unavoidably political ones. As was discussed earlier in the review of the PSB concepts and practice, the core issues of PSB should have been about what PSB is, why Taiwan should have PSB and what the key difference between PSB and commercial television in Taiwan are. However, as was observed in the analysis, these issues have become inadequately addressed in the PSB debate.

Structurally, the mediated debate has lost sight of the need to remain relevant to the general public while politicians, broadcasters, campaigners and academics are competing to define what the best is for the public.

This thesis evidently demonstrated that the opinions and concerns of the general public were largely missing from a debate dominated by political and academic elites. Against the grain of their own claims to be representing the public key actors constructed public debate as a series of monologues, advancing their own sectional and paternalistic interpretations of the public interest. The findings point to the supremely ironic conclusion that a process ostensibly dedicated to reconstructing broadcasting as key element in a new, democratic, public sphere, excluded the public from active participation and relegated them to the role of spectators.

The confusions not only lead the Taiwanese PSB to face conceptual and structural obstacles, but also inevitably pose a question concerning the adaptability of the PSB idea in the specific social context of Taiwan.

\subsection{Transplanting a Western Tree into an Eastern Land}

With regards to the shifting relations between states, markets and civil society 
in structuring the operating environment for media in democratic societies, in recent years the balance struck in the post war period has been substantially tipped in favour of private enterprise by the processes of marketization and it in this context, of an over-commercialised media landscape, that the argument for PSB expansion needs to be located.

\subsubsection{A Reverse Development from Other Iconic Public Broadcasters}

The first consequence of this situation is that, compared with other historical and powerful public broadcasters (which began as public monopolies), Taiwanese PSB was created within in an already-highly-commercialised market with a mission to provide a complement to commercial forces.

This context provided PSB with a legitimate reason for its existence in Taiwan and invested it with an important cultural role. At the same time, the view of a PSB as a complement to commercial provision had the effect of confining its potential development within certain boundaries and barring it from playing a leading role in the media landscape.

\subsubsection{Paternalistic Characteristics}

In order to differentiate itself from its commercial competitors within the Taiwanese media landscape, PSB aimed to produce high quality programmes, but in implementing this goal it adopted vestiges of the earliest conceptualisation of public broadcasting: the paternalistic, Reithian, idea that elites have a responsibility to decide and determine what the public interest is and how it should be catered for. The appeal of paternalism is likely to be particularly strong in a highly commercialised media landscape, like Taiwan, where both programme quality and diversity are declining.

\subsubsection{A Top-Down Approach}

A number of media studies argue that the primary responsibility for the dysfunctional operation of TBS as a public service broadcasting grouping lies with the government since it is the responsibility of government to take the leading role in formulating policy and in ensuring that the provisions decided on are properly implemented (see: Fan, 2011; Tang, \& Jian, 2008; Weng, 
2008; Feng, 2006, Lee, \& Li, 2006; Huang, \& Huang, 2005; Cheng, 2003, Feng, Shy, \& Kuo, 2002). This thesis partly agrees with this point but argues that it overlooks the significant absence of the public voice in the development of proposals for PSB and the subsequent estrangement of the structures decided on from popular support and endorsement. As was observed, the PSB was largely the result of concerted lobbying by pressure groups organised by activist academics rather than representatives of public organisations played the leading role.

This leads to the next point of the interaction between the government and the media academics. The activist academics took full advantage of the opportunity presented by the defeat of the KMT and the formation of a DPP government on a platform that had included PSB reform (along lines that they had proposed) to drive their PSB proposal forward. Although the peaceful transfer of power from the KMT to the DPP was widely regarded and celebrated as a demonstration of the strength of democracy in Taiwan, in retrospect it is clear that it was a transfer between political parties rather than a realignment of the relations between the state and members in civil society. The activist academics' pushed to outrun the privatisation plan and pressed the case PSB expansion was premised on the assumption the incoming DPP government would follow through on its pre-election endorsement of an extended PSB system. Under this approach, the government's failure to do so left them in disarray.

In the exploration of whose claims gaining a public hearing it was argued that relative success or failure depended on how adroitly a group exploited the opportunities presented by shifts in the political environment. The evidence presented here suggests that the pro PSB campaign were more adept at seizing these opportunities and were consequently accorded more press attention. However, the newspapers consistently portrayed the PSB debate as a cultural battle between contending groups within civil society rather than a political struggle between the main parties, and the case for expansion was defined as an argument outside the orbit of parliament and government. 


\subsubsection{An Unrealistic Compressed Transplant}

This study suggests that their model for an extended role for PSB in Taiwan was not translated into a workable organisational structure. This was partly because principles inevitably bumped up against political expediency but arguably it was also because it was unrealistic to expect that working models that had been introduced in specific circumstances and been developed and adapted over a long period, by organisations like the BBC and NHK, could be transplanted without problems in a compressed period and in a media environment with a very different organisational history and structure.

\subsection{Remarks}

This thesis has sought to explore the way power operated to shape the course of PSB expansion: how it was deployed, enacted, and what the outcomes were.

This thesis is distinctive since it serves as:

1) An unorthodox case of PSB development in the worldwide PSB debate;

2) An alternative view to transitional countries and societies which intend to introduce or are introducing PSB;

3) A wake-up call to PSB advocates in Taiwan.

The results of this analysis suggest that a radical re-think of the PSB project in Taiwan is needed, not least among its most vociferous supporters. Overall, through this thesis, I can understand the reasons why the media academics chose the path, with elite campaign, the paternalistic character and the top-down approach, to push the PSB expansion forward. However, I myself disagree with that path because I do not believe that the path would lead to where I would wish the Taiwanese PSB to go.

The future of a healthy PSB will, I would argue, depend, more than anything else, on breaking the elite domination of policy debate, and bringing the 'public' into the centre of debate and decision making, not as imagined figures to be rhetorically evoked but as live voices. 


\subsection{Research limitations and Suggestions}

Looking back on the study, in a re-consideration of research methods, this study mostly relied on secondary sources- particularly press stories- when summarising or quoting from both official sources (e.g.: parliamentary debates) and the materials produced by lobby groups. This makes it difficult to identify certain arguments and statements that failed to get written up in the newspapers when there were opinions and positions that were floated but did not reach the public domain. It is the limitation of the research design to miss out the unpublished opinions.

On the other hand, while it is entirely legitimate to focus on the mainstream national press as core institutions within the mediated public sphere, this study made no mention of on-line platforms and arenas of publicity and debate. The increasingly important role of the internet in publicising campaigns and mobilising support might be able to offer possibility of circumventing the 'gatekeeping' role of established media.

This is rather ironically since, have noticing the public absence from the political debate and the media debate, they are also absent from my research design.

It was not only because of limitation of time and resources, but also because the PSB debate during 2000 to 2008 was a debate mostly held 'offline' rather than online. As was observed earlier, it was lobbying groups behind closed doors where elites talking to elites and passing scraps information on to the tanginess that has been in one way or the other. It was an elite debate between elite figures; however, within the time period this study dealt with, particularly the latter part of the period, it was changing since the media academics tried to embrace more ordinary Taiwanese people and to bring these kinds of debates closer to people.

I see this as a research opportunity for the future. Particularly now the issue entrepreneurs are going to get closer to the public. Now it is a better time to engage this research with talking this with the public about what they are hoping for the PSB reform. To get a view of what ordinary people would look for in public service broadcasting and how they would like it today and how 
people are aware of the PSB reform, audience research like quantitatively online-survey on viewers or qualitatively focus-group research with the public and analysis on the content of online debate are suggested as future research agenda. 


\section{Appendix 1: The Details of interviewees and interview date}

1. Feng Hsien-hsien (馮賢賢), the CEO of the Taiwan Broadcasting System \& PTS Foundation, 05-Feb-2008.

2. Hu Yuan-hui (胡元輝), Previous CEO, the Taiwan Broadcasting System \& PTS Foundation, 05-Feb-2008.

3. Chen Jen-ran (陳正然), President of Chinese Television System in the TBS, 21-Mar-2008.

4. Hsu Chin-yun (徐青雲), President of the Hakka TV in the TBS, 27-Jan-2008.

5. Masao. Aki (馬紹 阿紀), President of Taiwan Indigenous TV in the TBS, 31-Jan-2008.

6. Lin Leh-chyun (林樂群), President of the Taiwan Macro View TV in the TBS, 13-Mar-2008.

7. Weng Shieu-chi (翁秀琪), Previous Director of PTS/ Professor, the Department of Journalism, National Chengchi University, 21-Jan-2008.

8. Fang Nien-hsuan (方念萱), Previous Director of PTS/ Professor, the Department of Journalism, National Chengchi University, 21-Jan-2008.

9. Chou Yan-shan (周陽山), Previous Director of PTS/Previous Legislator, 29-Feb-2008.

10. Peng Weng-jeng (彭文正), Director of PTS/ Director, Graduate Institute of Journalism, National Taiwan University, 24-Mar-2008.

11. Cheng Chung-ming (程宗明), Associate Research Fellow, R\&D department in PTS, 17-Jan-2008.

12. Feng Chien-san (馮建三),Department Chair, the Department of Journalism, National Chengchi University, 24-Jan-2008.

13. Kuang Chung-hsiang (管中祥), Vice-Professor, Shih Hsin University/The Chairman of the Media Watch Organization, 4-Mar-2008. 
14. Wei Ti (魏玓), The founder of the Campaign for Media Reform/Assistant Professor, Institute of Communication Studies, National Chiao Tung University, 6-Mar-2008.

15. Hung Chen-ling (洪貞玲), Convenor of the Campaign for Media Reform/Assistant Professor, Graduate Institute of Journalism in National Taiwan University, 29-Feb-2008.

16. Lee Yong-ping (李永萍), Previous Legislator (PFP, People First Party) 20-Feb-2008.

17. Lee Ching-an (李慶安), Legislator (KMT Party), 13-Mar-2008.

18. Hung Hsiu-chu (洪秀柱), Legislator (KMT Party), 13-Mar-2008

19. Lin Shu-fen (林淑芬), Legislator (DPP Party), 25-Mar-2008.

20. Kung Wen-chi (孔文吉), Legislator (KMT Party), 10-Mar-2008. 


\title{
Appendix 2: The Information Sheet for Interviewees
}

\author{
Participant's Information Sheet in English/Chinese
}

Participant's Information Sheet / 研究介紹與訪問工作說明

Reinventing Public Service Broadcasting: Lessons from Taiwan 公共廣播之反向演進一全球公廣潮流中的台灣經驗

Chun-Wei Daniel Lin / PhD student in Loughborough University 林俊偉 /英國羅芙堡大學社會學系媒體研究組博士班

\section{What is this study all about?}

The research of this project is interested in the compelling phenomenon of expanding public broadcasting services in Taiwan by transforming formerly state-owned TV stations and ethnical TV channels into a new public broadcasting group while many public service broadcasters around the world have faced increasing pressures from the accelerating commercialization and fragmentation of the broadcasting environment. This project tries to examine the reasoning behind the forms which it has been financed and institutionalized.

\section{1. 研究介紹 :}

在高度商業化、分眾市場抬頭與利潤極大化的媒體生態中, 當前世界各國的 公共廣播體制與價值無不遭受嚴峻挑戰。台灣在既有歷史脈絡下的媒體變革方 向, 恰巧與西歐各國逆反而行, 一個以「公共廣播」為名的電視媒體集團正在台 
灣擴張。本研究將檢視公廣服務在各國的價值及建制方式上的異同, 以剖析台灣 擴大公廣服務的社會情境與主要動機, 進而探究其創設過程的各項爭議、經費來 源與社會定位，據此解釋公廣服務在台灣與全球發展軌跡中的歷史意義。

\section{Who is conducting this project?}

This project is the basis for a $\mathrm{PhD}$ study, which is conducting by a $\mathrm{PhD}$ student, Chun-Wei Daniel Lin. Mr. Lin is currently supervised by Dr. Graham Murdock from the Dept. of Social Sciences in Loughborough University in the UK.

\section{2. 研究者介紹：}

本研究是一項博士論文研究, 研究者林俊偉目前就讀英國羅芙堡大學社會學 系媒體研究組，指導教授為葛拉漢・梅鐸。

\section{How will this project be done?}

The aim of this project is to obtain a better understanding of the implications from the development of the Public Broadcasting Service. This project will be carried out the interviews on four main groups of interviewees. They are broadcasters, lawmakers, media reform activists and media academics.

All the interviews will be semi-structured.

\section{3. 研究進行方式：}

本研究為了深入研究主題, 將分別針對公廣服務及商業電視經理人、立法委 員、媒體學者及推動媒體改革運動者進行深度訪談。

訪談設計為半結構式訪問, 預先提供受訪者訪談大綱, 但會視受訪者的專長 和回應內容，在訪問進行時彈性調整訪問內容。

\section{How long will the interview take?}

Each interview would last for no longer than 60 minutes. 


\section{4. 訪談所需時間 :}

每次訪談所需時間預計為 40 到 60 分鐘，以不超過一個小時為原則。

5. How long will the whole project take?

According to the current name list, on the first stage there will be around 20 interviews in this project. This stage may take 4 weeks in all to complete though it depends on the interviewees' availability. This project is the basis for a $\mathrm{PhD}$ study, which requires 3 years to finish it.

\section{5. 研究計畫長度 :}

依據訪談名單, 本研究的深度訪談部分預計在四週內進行二十位相關人士的 訪談。本研究為一博士論文研究, 預計三年完成相關資料分析並總結研究發現。

6. Will the information collected be treated as confidential?

All information collected in this study will be treated in strict confidentiality. The raw data will not be made available to those who are outside this project.

\section{6. 資料保護：}

所有訪談內容在研究過程中不會外流給研究以外的任何人或單位機構。

7. Will participants be told about the result of this study?

A written summary of the findings will be prepared for participants who have contributed to this study.

\section{7. 訪談後與受訪者的互動：}

本研究在總結研究發現後, 將會寄給受訪者一份相關研究成果的摘要報告。 
*If you have any queries about any aspect of the project, or you would like to discuss more detail of the project, please contact either

Chun-Wei Daniel Lin <C.Lin@lboro.ac.uk>

(TEL “UK”: +44772-658-5611; TEL “Taiwan”: +886-913617513)

or Graham Murdock<G.Murdock@lboro.ac.uk>.

若您對於本研究有任何賜教, 請聯絡林俊偉 (英國羅芙堡大學社會學系媒體研究組博士班)

行動電話：0913-617-513

電郵： bcc0200@yahoo.com.tw

即時通訊: Magnus1122@hotmail.com

或

英國羅芙堡大學社會學系教授葛拉漢・梅鐸(Graham Murdock)

G.Murdock@lboro.ac.uk
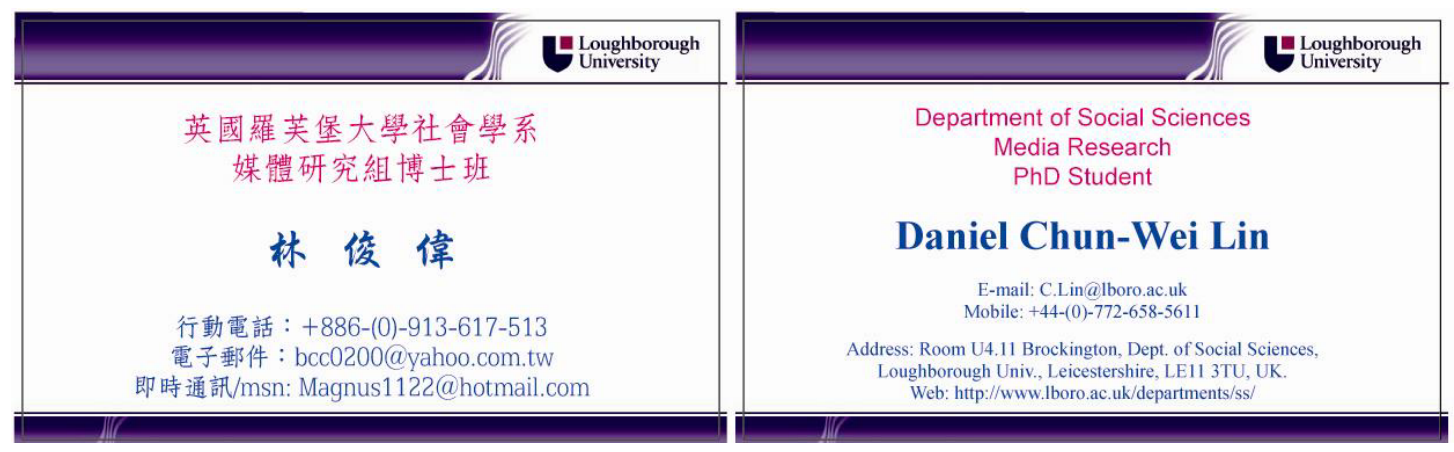


\section{Appendix 3: The Questions in the Interviews}

According to the interviewees' affiliated professions and the positions listed in Appendix 1, this study roughly separated the interviewees into three categories:

1) Legislators (parliamentarians) from different political parties;

2) Media scholars, social activists or activist-academics; and

3) Broadcasters.

In respect of the likely differences in the structuring of their responses (Marshall \& Rossman, 1989), different interview schedules and questions were also designed in the semi-structure interview for each category of interviewees.

Generally speaking, public broadcasters were asked about their perceptions and experiences in PSB practice, the challenges they face and the possible solutions they seek. Social activists, media academics or activist-academics were asked about their visions for media reform and actions they took to realise the visions. Legislators were asked about their position, judgments and experiences during the policy formation.

The overall interview for all interviewees generally include the questions like why the issues were believed to be problems, the way the problems were defined in, who has more or less power to do the defining, and what kind of cultural and social resources were accessed in defining the issues as social problems. To help interviewees address these issues more efficiently, press coverage of some PSB news events were used as prompts during the interviews. 
Appendix 4: Coding manual of press content analysis

\author{
Press \\ 1 United Daily News \\ 2 China Times \\ 3 Liberty Times \\ Page (Location) \\ 1 Editorial \\ 2 Main News pages \\ 3 Entertainments/Media \\ 4 Letters and Forum \\ 5 Local News \\ 6 Others \\ 7 Front Page \\ Genre \\ 1 Editorial \\ 2 Pure news stories \\ 3 Commentary/analysis \\ 4 Readers' letters \\ 5 Others
}

Size

The number of words 


\section{Topic}

1 The reasons for TV Reform

2 Debates on transitional ownership of state-owned TV networks

3 Debates on PSB Funding

4 Debates on PSB Performance

5 Debates on Personnel

6 Debates on Legislature

7 Debates on PSB institutionalisation

8 Governance, regulation and supervision on PSB

9 Digitalisation/Digital Switchover

10 Comparisons with other PSB provisions around the world

11 Others 


\section{Interpretation (Themes in News)}

\section{The reasons for TV Reform}

-10 Protect public goods from Privatisation

-11 The performance of existing Commercial System

-12 Levels of Existing Public Provision

-13 Existing political systems and political bias on Media

-14 Preserve National culture

-15 Secure Citizenship/Democracy

-16 Minority interests

-17 Local programme production

-18 Digital Switchover TV industry

-19 Diversity of programme

-20 Others

\section{Debates on transitional ownership of state-owned TV networks}

-21 to remain State-owned but introduce more PSB programme on the TV networks

-22 to free Market logic/competition

-23 to pure public media (Government subsidy and donation the ownership from state to PSB )

-24 to Trust: to build the sovereign body and its independent trustees.

-25 to a Mixed Method (e.g.: half public half private)

-29 Others

\section{Debates on PSB Funding model}

- 31 PSB go free market/private companies

- 32 PSB get government Funding

- 33 License fees

- 34 Shareholding by government budget

- 35 Shareholding by private sectors

- 36 Commercial ads

- 39 Others

\section{Debates on PSB Performance}

5 Debates on personnel

- 51 Personnel of state-owned TV

- 52 Personnel of PSB

6 Debates on legislature

- 61 Laws for Terrestrial TV Reform

- 62 Laws for PSB legal basis

\section{Debates on PSB Institutionalisation}

- 71 Debates on expanding project

- 72 How the plan has been practiced

- 73 Government budget and support

- 74 Plans for local PSB branches

- 79 Others

\section{Governance, regulation and supervision on PSB}

\section{Digitalisation}

- 91 Increasing number of channels bring diversity to Media landscape

- 92 Budget for digitalisation

- 99 Others

10 Comparisons

-101 USA 
-102 UK

-103 EUROPEAN

-104 ASIAN

$\begin{array}{ll}-1041 & \text { JAPAN } \\ -1042 & \text { KOREA } \\ -1043 & \text { Hong Kong } \\ -1044 & \text { Tailand } \\ -1049 & \text { OTHER }\end{array}$

-105 AUSTRALIA

-106 New Zealand

-107 CANADA

-109 Other

999

Others

\section{Evaluation on Themes in News}

1 Solely/ mainly negative

2 Solely/ mainly positive

3 Balanced (two or different sides)

4 Neutral/ descriptive / factual

9 Unclear 


\section{(Actors):}

Group A: Political Actors

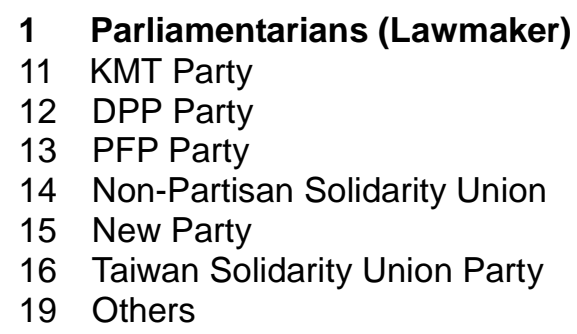

\section{Political Parties}

21 KMT Party

-211 President of Party

-212 Spokespeople \& Representative

-213 Members

22 DPP Party

-221 President of Party

-222 Spokespeople \& Representative

-223 Members

23 PFP Party

-231 President of Party

-232 Spokespeople \& Representative

-234 Members

24 Non-Partisan Solidarity Union

-241 President of Party

-242 Spokespeople \& Representative

-243 Members

25 New Party

-251 President of Party

-252 Spokespeople \& Representative

-253 Members

26 Taiwan Solidarity Union Party

-261 President of Party

-262 Spokespeople \& Representative

-263 Members

29 Other Parties

3 Officials \& Government org.

31 President

32 Government Information Office

33 Executive Yuan (Ministers)

34 Council for Hakka Affairs

35 Council of Indigenous Peoples

36 Local governors

39 Others 
Group B: Economic Actors-

\section{Broadcasters, Press and Firms}

41 Public broadcasters

42 Private broadcasters

43 State-owned broadcasters

44 Advertisers

45 Press/newspaper interests (Editorial \& Reporters)

46 Other business interests

47 Media staff labour unions / associations

48 Military sector/department

49 Others

Group C: Civil Society Actors

\section{Academics, Media Commentators and Pressure groups}

51 Members of pressure groups specifically lobbying for PSB

52 Members of other civil society groups (e.g. women's groups or ethnic groups)

53 Media academics

54 Academics (outsides Media)

55 Professionals in Marketplace/ Private consultants

59 Others

6 General Public (no stated affiliations)

$7 \quad$ TV Celebrities

9 Others

\section{Sources of the actors}

1 Authors author their own material

2 Quoted directly in stories

3 Mention Only/ have their ideas/arguments referred to

9 Other 


\section{Appendix 5: Coding manual for Reasons of Writing Letters}

\section{Criticism}

101 Criticism on existing political control on TV stations

102 How the plan (PSB institutionalisation) is practiced

103 Criticism on PSB Performance

104 Criticism on governance, regulation on PSB

105 Criticism on the personnel issues of PSB

106 The performance of existing Commercial System

107 Criticism on the personnel of state-owned TV

108 Criticism on privatisation of media

\section{Appeal}

201 Appeal for a public media

202 Appeal to release state-owned TV to free Market competition

203 Appeal a PSB to secure Citizenship and Democracy

204 Appeal a PSB to secure minority interests

205 Appeals for local PSB branches

206 PSB legislature

207 Laws for Terrestrial TV Reform

208 PSB Funding Model: maintain state-owned \& PSB programme

209 Comparison with Other PSBs (BBC in the UK)

210 PSB Funding Model: establish a Trust foundation

211 PSB Funding Model: PSB get Government Funding

212 Diversity of Programme

\section{Others}

301 Digitalisation vs. PSB

302 Replying to another correspondent 


\section{Appendix 6: Full Texts of the Letter String}

\section{Letter 1: Appeal for an Ending to the CTS farce}

by Wei Ti, Chad Liu.

The recent clash in the CTS, among vice president Li-xi Zhu, News director

2 Ji-fang Chen, and Wei-jian Hong (executive assistant of the general manager Xia

3 Jiang), not only displayed the poor profession of journalism and management, but also

4 exposed some inappropriate conduct and behaviour of the manage team in the CTS.

5 From an eye of an outsider from the TV station, this tempest in the teapot can be

6 viewed as a ridiculous farce. However, since the government is working on a reform to

7 transform CTS to become one public television in the PSB group, as members of

8 Taiwan's media watch and a general citizen, we are entitled to ask for an explanation

9 to the internal tensions within the CTS.

10 We have no intention to get involved in the clash within the managing team of

11 CTS or to judge who is right and who is wrong. However, from this clash, and also

12 from several clashes in the News section or in other departments in the CTS since Xia

13 Jiang was in charge, they evidently show that the internal management of CTS is

14 really in trouble. Furthermore, political interference and manipulating still can be seen

15 in these clashes. An ultimate solution to this situation will begin with the fundamental

16 transformation of CTS.

17 We believe that the 'Gong Gong Hua' proposal is the most effective and the best 18 way to reform the CTS. First, the main reason why Xia Jiang can be appointed as the 19 general manager for the CTS is because her close relation with President Chen. Then 20 Xia Jiang can undertake totalitarian ruling style in the CTS is due to the government is 21 the major stakeholder of the CTS. However, currently the CTS is deemed to be a 22 commercial television station which is not only has no obligation and responsibility for 23 the public but also can avoid any kinds of supervision or monitoring from parliament.

24 Recently, just before the election, the CTS managing team tended to replace all 25 programming before 18:00 o'clock by News report. The attempt to intervene election

26 by news is too obvious. Despite there are a large number of oppositions toward this 27 programme replacement from the public and disagreements from the CTS professional 28 journalists, we can do nothing to stop this!

29 Currently under consideration by the Legislative Yuan Legislative release of public 30 shares will be one hundred percent of China as the transition into a public television 
31 after the constitution will be "Public Television Act" as the basis for the CTS to serve all 32 the public, not the government or certain political parties (in the This does not exclude 33 the CTS can be certain commercial activities, or broadcast advertising as part of the financial resources. So, Congress will be able to consent by the public television directors exercise leadership guide is chaos CTS.

The company also recently set up as "news complaints handling team" for the general audience to comment on the public television news and access to treatment. "Public Television Act" the relevant provisions and the current operation of public television within the lake, of course, imperfect, must be gradual improvement, but at least the public and Congress also maintain participation and supervision of space, and will not only be angry at the side of concern.

We believe 'Gong Gong Hua' not only can sort out most of political intervention substantially, but also offer benefits to the professional performance, employee rights and job security, and autonomy of newsroom. PTV is set a few "Editorial Convention," the media, isolate the intervention of political and commercial interests, and protect the editorial staff of professional autonomy and independence. Recently, public television has, through the external consulting and internal democracy process, and actively develop "production staff professional standards", no matter what the outcome, at least in the right direction. But was even, coming to public television different from the special status of private enterprises, trade union representatives could also be considered for the board and really "independent journalists" ideal.

Earlier, the Executive Yuan proposed investment of 9.2 billion two years, the public television program, but the real problem of China as the transition is not a word.

54 Chinese Television executives have expressed support publicly, but do not agree with 55 the public as the "merger", but they saw their busy in-fighting, or ideas to increase in 56 the pre-election press time, but have not made any specific and feasible "as the 57 Chinese version of" public television blueprint.

58 We look forward to Liangzao to rein in favour of positive, but we also hope that the 59 opposition legislators, as soon as possible to appropriate the "Wireless Television

60 Enterprise release of implementing regulations", and requested the Government to 61 promote the immediate supervision of the Congress meet the public interest, maintain

62 a professional, caring staff, as the public the principles of transformation of China, from 63 China, as the fundamental solution to the problem. We agree Communications 64 Commission (NCC) with the broadcast of the legislative and importance, but letting the 65 problem worsen as China, to continue to operate under the shadow of political 66 intervention, but cannot achieve the desired social benefits of public services, which to 67 a to, the price is too great. (Wei Ti is assistant Professor in Dept. of Mass 
68 Communication at Tam Kang University. Chad Liu is assistant Professor in Dept. of 69 Communication at Chung Cheng University. Both of them are executive committee 70 from Campaign for Media Reform)

(China Times, 11/09/2005: A15) 
Letter 2: (Published on 14/09/2005 which is three days later since the first letter was published)

\section{CTS with the Same Resentment as Zhao-Jun Wang's ${ }^{4}$}

by Fisher, Executive director of the CTS

On $11^{\text {th }}$ your honour newspaper published a letter, 'Appeal for an Ending to the

2 CTS farce' written by Wei Ti and Chad Liu. As an executive director of the CTS, I am

3 writing this letter to officially respond the letter you published.

In the Han dynasty, to exchange peace and harmony, the emperor sent the beauty, Zhao-Jun Wang, to get married with the Huns, but that naive plan didn't work out. The bond of the marriage didn't stop the attacks from the Huns. Only a famous song, 'Zhao-Jun Wang's Resentment,' has been remembered and sung till today.

Now both the government and so called 'social intellectual (media academics)' are

9 determined to force the CTS to marry the Public Television Station to form the PSB

10 family. The CTS is in tears to sacrifice herself to marry the alien person. No objection

11 to the 'Gong Gong Hua' , however, it is just like what the Murphy's law says, what's

12 wrong from the very beginning will keep going wrong to the end.

" 'Gong Gong Hua' " now has become a "sacred mission" for many media

14 academics. It is already ridiculous enough. What is more unbelievable is now these

15 media academics can even use the CTS internal clash to prove the need of 'Gong

16 Gong Hua' . None institutions or organisation has zero internal clash and conflicts. It

17 is inevitable and this is totally irrelevant to the 'Gong Gong Hua' project. However, to

18 the internal clash, the media academics can even claim that 'the 'Gong Gong Hua'

19 proposal is the most effective and the best way to reform the CTS.' If so, then maybe

20 next time when any internal conflicts and clashes occur in any other television stations,

21 these two media scholars can help to sort it out just by the idea to transform them to

22 public media. If it works just like that, all professors in business and management

23 departments can be all replaced by media scholars.

\footnotetext{
${ }^{4}$ Zhao-Jun Wang is famed as one of the four breath-taking beauties from ancient China. As a palace lady in harem of a Chinese Emperor in Han dynasty, she was sent out as a gift by the Chinese Emperor to get married with the Huns tribe leader in order to strengthen their national relationship. The letter writer drew on this story as a metaphor to illustrate the situation that CTS, which is used to be a commercially profitable TV station, is reluctant to be forced by the government to transform to a public TV in the PSB group.
} 
Public television" has now become a lot of press and scholars of the "sacred mission" really Mokenaihe. CTS can be vice president of academics and the news director Chenji Fang Zhu Lixi discord between the two, being represented publicly, is incredible, in fact, no organization has the personnel struggle, in the end and the public of what relevance? Actually said, "Reform of public of China, as the constitution is still effective and appropriate means", and then later appeared in a television station personnel of any struggle, you can ask the two scholars to help them publicly, and if the truth can pass it around the world professor of management can be requested to replace the Department of Journalism.

Zhu Lixi China as the future in order to purify the news pride to a sense of admiration, however, the Department under his control, good or bad to be all worried, we cannot return his good and bad left CTS, the reason is simple, CTS Press both the reputation of clean, natural daylight that cannot Lu Asa removed the program and concentrate on good news, how they can be directed at China, as there is no evidence to 'attempt to intervene election so obvious'.

I am the Executive director of the television station in this controversy. Although my position is voluntary with no salary, I still feel confident to say I am an important role in the management team since I am responsible for finance part and also the development of digital media. I feel neutralising news report from political bias is in the

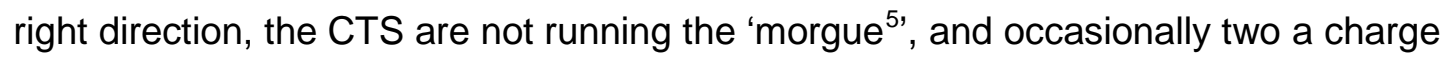
of discord, general corporate, even if common public institutions, which do not have to work to guide the Congress leadership is chaos, right?

'Gong Gong Hua' is a public debate, not a religion. should the facts to prove the point, can contemporary Manchao Chiang, Shuo-yin, who will it run into national

48 disaster. Chinese scholars say, as the government shares accounted for seventy-four

49 percent, a little basic "Company Law" are not common knowledge, private is private, 50 how can the use of state property used as private? Comparison of controversial issues 51 such as "Dawn Foundation" and so on, that people share more than half of the civil 52 fund, most people donate money, purpose is to take care of veterans, at most, only to 53 divest the dawn, so that more than half of China as the government shares, Now I 54 want people to donate money to the Public Television Foundation, does the President 55 of the communist leader to force the situation, to the extreme pressure of Defence, 56 Department of Defence and then the dawn gun off to the dead people threw money? If 57 the directors of dawn to do so, probably also in violation of good management 58 responsibility, were all arrested and in jail.

\footnotetext{
${ }^{5}$ The writer implies if the CTS were a morgue, dead people cannot cause internal conflicts.
} 
The two scholars also understand that the Executive Yuan 9.2 billion investment

60 plan, as the transformation of China's real problem is not a word, but the two scholars

61 do not understand, please put "public broadcasting and the cultural and creative

62 development of digital television for two years plan "and" lifelong learning, knowledge

63 and education to develop the project plan "look at the two plans, it seems to really like

64 the public, as surgeon, and Information Office did not even look at the view, on the

65 labeled" Government Information Office, "six words would go to the hospital! Detract

66 from the official documents also set out an incredible record of winning public

67 television over the years, let me see, "the draft law on public television," it Bacheng is

68 public television's Masterpiece? Actually serve the public as a director of CTS over

69 other provisions of public interest without written up, and the three together, just

70 someone to circumvent the law, abuse of budgeting, coupled with the merger of China

71 as nothing more, how can there be a benign the public of?

72 Media scholars also blame the CTS managing team are only busy on internal

73 fighting and clashes but has no time for a CTS version of a viable plan for " 'Gong

74 Gong Hua' ." In fact, the PTS (Public Television Station) has no intension for any type

75 of 'communication' with the CTS. As an executive director, I took the initiative to meet

76 the PTS people and then some scholars from the Campaign for Media Reform blamed

77 me as a representative of anti- 'Gong Gong Hua' power from President. In the " 'Gong

78 Gong Hua' " policy-making process, we begged policy makers to save some

79 commercial windows/opportunities for the CTS, but found that whole 'Gong Gong Hua'

80 plan has already been finalized and no room for any commercial income. The 'Gong

81 Gong Hua' project is doomed as a huge waste of public money and government

82 budget. So, before Zhao Jun Wang marries to Huns, I would also like to appeal media

83 academics to put an ending to the " 'Gong Gong Hua' " farce. (The author is

84 executive director of CTS)

(China Times, 14/09/2005: A15) 


\title{
CTS Is Public Goods Not Private Property
}

\author{
by Wei Ti \& Chad Liu
}

We are pleased to see a commencement of discussions since Mr. Fisher respond us from a different perspective. To the opinion of Mr. Fisher, here we would like to briefly clarify and discuss more.

First of all, in Mr. Fisherman' point of view, the internal conflicts happened in the CTS seem to be common things happened in any other institutions. To avoid responsibility by drawing on this kind of logic does not help to solve current problems. In fact, in the letter we mentioned: firstly, we have no intention to judge who is right or wrong in the conflict. Secondly, now the CTS is in a transition and it is not just a private media firm so the CTS managing team should accept criticism from the public.

This referred to the Government of China as the direct or indirect equity interest of seventy-four\% of the data, not the author invented, including the Information Office and other research organizations have switched recognition and use of the data.

13 "Dawn Foundation" was established by the Department of Defence funding 14 contributions and stationed in the eight fifteen directors, is typical of authoritarian era 15 coat of government control under the pretext of non-governmental organizations. And 16 its main driving the media, cultural activities, not to take care of veterans, please do 17 not accuse others knowledge, Mr. fisherman before the first check carefully.

To think from this perspective, we have observed CTV problem is not just a personnel struggle, but about political control, professional autonomy, and job rights

20 and other issues. Other media reports, the past two years, China emerged as the 21 news department of a very high staff turnover rate, this phenomenon occurs in a basic 22 working conditions and not too bad for media organizations because very carefully.

23 External observation shows that one of the largest of which are in overt or covert 24 political intervention.

If the attempt of the CTS managing team to expand the news programme has nothing to do with political motive but only because of the quality of your news report is gaining more creditbility and popularity, then we are pleased to invite the public to make a public judgement on this together. In short, let Chinese Television journalists to

29 professional autonomy, to prevent undue control system to provide the conditions for 30 public television, was clearly superior to commercial television, namely, China 31 proposed as physical transformation of public into the appropriateness of the means of 
32 justification. CTS high-level infighting and public transformation, of course, related.

33 In fact, Mr. fisherman CTS if the public really does not oppose the transformation,

34 for our ideas, should be let alone "do nothing", at best practice are different. Media

35 reform community's long-term advocate public broadcasting system was established

36 that public shares processing and wireless TV sets, CTS transition issues should be

37 "consistent with public interest and maintain a professional, caring staff" and the

38 principle of priority three, so hurry against the Government Information Office proposed,

39 and the misallocation of budgetary issues such as policy 9.2 billion two years, have

40 been publicly.

41 However, we are sorry that the CTS has not had to see a complete high-level

42 blueprint for the reform and restructuring. If CTS is really determined to promote

43 high-level public process, the specific claims? Staff plan to take care of that?

44 Expectation that the development of the "business" Why? These "opportunities" for the

45 public or the private? Should be clear. Furthermore, if the CTS 9.2 billion two-year high

46 against the policy, why do we talk to make policy-level employees saw a news bureau

47 to protest, while the top only with the author on the paper or the media to change

48 social debate? Mr. Fisherman, "Zhao Jun Fan" story to describe the transformation of

49 China as the public shows that it is still the CTS as a "private property", the goal will be

50 the transformation of public imagination as a "sacrifice" of selfishness, is incredible.

51 Finally, we need to emphasise the reason why the group of Campaign for Media

52 Reform and other social activists all support the 'Gong Gong Hua' proposal is because

53 it is a solution to the over-politicized and over-commercialized media landscape in

54 Taiwan. None of us view it as a 'religion.' It is a proposal and concept emerging social

55 reforms. Historically, when someone intends to describe certain proposal or ideas form

56 social reform as a 'religion' or 'sacred mission,' it is always proven that he is using a

57 suppression tactic to against the idea and concept. (Wei Di Tamkang University,

58 Assistant Professor, Department of Mass Communication, Liu Changde for the Chung

59 Cheng University, Assistant Professor, Department of Communication Studies; they

60 are both Campaign for Media Reform Executive Committee)

(China Times, 15/09/2005: A15) 
Letter 4: (After five Days: 16/09/2005)

\section{Media Reform Requires Procedural Justice}

by Fisher, Executive director of CTS

Although I am frustrated on the policy forcing the CTS to transform to be a public

2 television, I would do nothing to stop it since I am not really against the Disney concept

3 of a public television group. However, although I am frustrated with the policy, I believe

4 there are still procedure justices held in the transformation. The CTS has been running

5 as a private company. No matter how "improperly" the past authoritarian regime

6 established this television and owned it as political tool, in a democratic era, the CT is

7 a private company according to the "Company Law". Therefore, during the process of

8 transformation from a private company to a public of the process, we have to take the

9 procedural justice into account. Otherwise, what is the difference when there is an

10 unprecedented change in political ruling parties while old and new regimes seem to be

11 the same? Therefore, in order to clarify the dispute about whether the CTS is a

12 "private property" and whether Its main shareholder, "Dawn Foundation," is the

13 government-owned stocks, I consulted this main shareholder (Dawn Foundation)

14 before I wrote this letter. From their view, before any lawful judgement is officially

15 announced, the CTS remains a private company and therefore it is a private property.

16 We cannot view the CTS by its past 'history".

17 In fact, the Chinese Television System to the public of the law must hold a shareholder

18 meeting to obtain consent to the Board responsible for the high-level CTS, scholars,

19 there is no active public questioning "of China as the version of" I do not understand

20 why the Chinese keep up high-level academics as homework ? Scholars active in

21 promoting the public of, and have actually going to figure out why the old "Public

22 Broadcasting and Television Act", on the set of public foundations, under the

23 Broadcasting System CEO, and then set the channel or radio station the next level

24 general manager, then the new law but somehow The full return to the current "Public

25 Television Foundation", and according to the part-time public television as a director of

26 China over the post of staff unrest set off CTV, CTS, recently held an emergency

27 board to discuss response strategies.

28 Currently many challenges the CTS team need to face are really desperate. In

29 fact it is a private firm which follows the "Firm Law" but this firm now need to manage

${ }^{6}$ Here the writer implies it was established by the KMT government and the state by government budget. 
30 many interferences: media academics assert that the CTS is not a private property;

31 the PTS is ambitiously trying to merge us; and political interferences are endless.

32 Although the Government Information Office (GIO) ordered the CTS to merge with

33 PTS, in this 'marriage' three parties (CTS, PTS and GIO) are lack of talks. We don't

34 mind if the GIO has no intention to meet us, but in the GIO proposal the CTS is

35 renamed to be the PTS 2. In this marriage we become PTS's small mistress, how can

36 we accept this?

(China Times, 16/09/2005: A15) 
Letter 5: (After five Days: 16/09/2005)

\section{Digitalisation Can Expand PSB}

by Hui-fang Hou, Marketing Manager in PTS

In Mr Fisher's letter, 'CTS with the Same Resentment as Zhao-Jun Wang's',

2 mentioned a number of issues related to the Public Television Station, I would like to clarify some points for the PTS officially.

First, the public television this in the "establishment of the mass media for the public service system, to make up for the lack of commercial television", and government departments as the group of public policy statements, the contents of the future digital channel of the plan, already initiated, end of last year and set up a task

8 force to set out the process, master schedule.

Secondly, on the rollout of digital, the Government has commissioned public television for three consecutive years for "common transmission platform for building

11 wireless", "MHP interactive TV experiment", "DVB - H experimental" and "mobile TV

12 channel test" work. The channel content planning, public television is also with experts

13 and scholars and the community, after a number of evaluation and discussion.

Furthermore, the Executive Yuan passed the "Public Broadcasting and the cultural and creative development of digital television program for two years" and "lifelong learning, knowledge and education to develop project plans," the Department for the development of the next two years by the public as the budget subsidies no direct connection with the CTS. In terms of commercial opportunities, in the current draft of "the statute regarding the disposition of government shareholdings in the terrestrial television industry", it provides some room for the terrestrial television stations to run commercial advertisement and tends to maintain the spirit of vitality and efficiency in private industries. The plan and the draft are currently waiting for the final review and decision from the Legislative Yuan.

Finally, in our two-year-long plan for the public TV programming, the content about children and youth, public aesthetics, foreign language learning, and international channels, are designed to fill the gap where all commercial television stations are not able to provide. This is made to meet a high degree of public interest and needs. On the other hand, the consideration for the infrastructure for digital development laid its

30 the digital transformation, and to expand the range of public services. The priority of 31 these plans needs more discussion and it is no doubt that they all need a 
32 breakthrough progress. For these issues, we do not reckon that we are responsible for 33 the whole balance of the media environment, but we won't avoid any commitments 34 and social expectations the public ask us to carry out. 


\section{Bibliography}

Apple Daily. (24/04/2010). Monitored by the national security bureau, journalists of Next magazine lost claims. Retrieved 20 May 2010, from Apple Daily website. http://tw.nextmedia.com/applenews/article/art_id/32462655/Issuel D 120100424.

BBC. (14/02/2012). Inside the BBC. Retrieved February 14, 2012, from BBC website.

http://www.bbc.co.uk/aboutthebbc/insidethebbc/whoweare/ataglance/

BBC. (14/01/2012a). Taiwan backs Ma, but unease over China remains. Retrieved January 16 2012, from BBC website.

http://www.bbc.co.uk/news/world-asia-16563725

BBC. (14/01/2012b). About the BBC: Inside the BBC: the story of the BBC, our public purpose and how we are funded. Retrieved December 14, 2011, from BBC website. http://www.bbc.co.uk/aboutthebbc/insidethebbc/whoweare/.

BBC. (13/01/2012). China keeps close eye on Taiwan elections. Retrieved January 16 2012, from BBC website. http://www. bbc.co.uk/news/world-asia-16549753

BBC. (23/12/2011). Putting Quality First. Retrieved January 14, 2012, from BBC website.

http://www.bbc.co.uk/aboutthebbc/therealstory/delivering_quality_first.shtml.

BBC. (23/06/2011). BCC Annual Report and Accounts: part 2. Retrieved December 14, 2011, from BBC website. http://downloads.bbc.co.uk/annualreport/pdf/bbc_executive_2010_11.pdf

BBC (2009). Annual Report and Accounts 2008/09 Part Two: The BBC Executive's Review and Assessment, BBC, London.

BBC (2008). Annual Report and Accounts 2007/08 Part Two: The BBC Executive's Review and Assessment, BBC, London.

Becker, S., \& Bryman, A. (2004). Understanding Research for Social Policy and Practicethemes, Methods and Approaches. Bristol: Policy.

Binderkrantz, A. (2005). Interest Group Strategies: Navigating Between Privileged Access and Strategies of Pressure. Political Studies, 53(4), 694-715.

Blumler, J.G. (1992a). Public service broadcasting before the commercial deluge. In J.G. Blumler (eds.), Television and the Public Interest: Vulnerable Values in West European Broadcasting [1st edition], (pp. 7-21). London: Sage. 
Blumler, J.G. (1992b). Vulnerable values at stake. In J.G. Blumler (eds.), Television and the Public Interest: Vulnerable Values in West European broadcasting [1st edition], (pp. 22-42). London: Sage.

Booth, A. (2011). Is the Taiwan model of growth, human resource development and equity sustainable in the twenty-first century? Taiwan's Democracy: economic and political challenges (pp. 101-124). London: Routledge.

Breen, M. (1996). Broadcasting, Policy, and Information Technology. In M. Raboy. (Eds.) Public Broadcasting for the 21st Century, (pp 120-139). Luton: University of Luton Press.

Bromley, M. (1998) 'Watching the Watchdogs? The Role of Readers' Letters in Calling the Press to Account', in M. Bromley and H. Stephenson (eds) Sex, Lies and Democracy, pp. 147-162. Harlow: Longman.

Broadcasting Research Unit (BRU). (1985). The Public Service Idea in British Broadcasting: Main Principles, London: BRU.

Buckingham, D. (2011). The Material Child: Growing up in consumer culture. Cambridge: Polity.

Buell, E. (1975). "Eccentrics or Gladiators? People who write about politics in letters-to-the-editor", Social Science Quarterly 56(3), 440-449.

Bush, R. C. (2007). Vision 2020 - Democratic Consolidation. Taiwan Business. 37(11). Taipei: American Chamber of Commerce.

Burgelman, J. (1989). Political parties and their impact on public service broadcasting in Belgium: Elements from a political-sociological approach. Media, Culture \& Society. 11(2) 167-193.

Calhoun, C. (1992). Habermas and the public sphere. In C. Calhoun (eds.), Habermas and the public sphere [First Edition], (pp. 1-50). London: MIT press.

Chang, C. H. F. (2000). Multiculturalism and Television in Taiwan. In D. French \& M. Richards (Eds.), Television in contemporary Asia (pp. 405-419). London: Sage.

Chen, J. (1995). The Reminiscences of Mr. Hsien-yun Liu. Taipei: Academia Historica.

Chen, J. P. (04/01/2006). Party, State and Military to Withdraw from the Terrestrial TV Network. United Daily News, p. A2.

Chen, S. F. (2011). Responses on the 2009 Survey for Public Value of TBS. Retrieved March 14, 2012, from PTS website. http: // web. pts. org.tw/ web02/ptsenglish/report/2009-reply. pdf

Chen, S. Y. (1998). State, Media and Democracy in Taiwan. Media, Culture \& Society, 20(1), 11-29.

Chen, T. H. (2008). Sports Broadcasting on Public Television and the Construction of National Identity - PTS-Chien-ming Wang Experience and CBC's Hockey Night in Canada as Examples. Mass Communication Research, (96), 213-295.

Cheng, C. M. (2003). A Critical Treatise on Taiwan's Television Policy, 2000-2002; Publicizing versus digitization of terrestrial services. National Chengchi University, PhD thesis. 
Cheng, C. M. (2005). The Group of Public Service Broadcasters, a Tenable Solutions? Argument for Its Descriptive or Analytic Validity. Communication and Management Research, 5(1), 1-26.

Cheng, J. C. (1993). Deconstructing Taiwan's Broadcasting Structure. Taipei: Cheng Society.

Chin, H. (2006). A Structural Analysis of the "Mess" Media in Taiwan: a Case Study of the United Daily News and the China Times. Contemporary, 228, 16-21.

Chin, S. (1997). Broadcasting and new media policies in Taiwan. In A. Sreberny-Mohammadi, D. Winseck, J. McKenna \& O. Boyd-Barret (Eds.), Media in global context: A reader (pp. 78-93). New York: Arnold.

China Times. (17/12/2008). It's Time to Reconstruct the Monitoring System for Public Television, p. 12.

China Times. (14/12/2008). Do Parties, State, and Military Really Withdraw from the Media? , P.11.

China Times. (24/12/2007). Feng Hsien-hsien becomes the CEO of PTS. Retrieved September 5 2009, from China Times database.

http: // tol.chinatimes.com/CT_NS/freectsearchlist. aspx?keyword=

China Times. (14/12/2007). Black Horse Cheng Tung-liao wins the chairmanship of PTS. Retrieved September 5 2009, from China Times database. http: // tol.chinatimes.com/CT_NS/freectsearchlist. aspx?keyword=

China Times. (13/12/2007). Invisible hand intervene PTS and CTS personnel. Retrieved September 5 2009, from China Times database. http://tol.chinatimes.com/CT_NS/freectsearchlist. aspx?keyword=

China Times. (11/10/2002). Scholars declare a return to social movements, p6.

China Times. (24/09/2002). Media scholars offering endorsement for DPP now face ordeal, p. 13.

Chow, C.Y. (2011). Globalization, dynamic comparative advantage, and Taiwan's drive for sustainable development. Taiwan's Democracy: economic and political challenges (pp. 166-192). London: Routledge.

Chu, Y. P. \& San, G. (2011). Taiwan's industrial policy and the economic rise of the PRC: opportunities and challenges. Taiwan's Democracy: economic and political challenges (pp. 125-145). London: Routledge.

Comrie, M. \& Fountaine, S. (2005). Retrieving public service broadcasting: Treading a fine line at TVNZ. Media, Culture \& Society. 27(1) 101-118.

Cook, T. (2003) 'The Future of Institutional Media' in W. Lance-Bennett and R. Entman (eds) Mediated Politics: Communication in the Future of Democracy, Cambridge: Cambridge University Press.

Council of Europe. (1994). The Media in a Democratic Society: Political Declaration, Revolutions and Statement. The 4th European Ministerial Conference on Mass Media Policy, Prague. Strasbourg.

Cottle, S. (2007) 'Ethnography and News Production: New(s) Developments in the Field', Sociology Compass, 1(1):1-16. 
Curran, J. (2000). Rethinking Media and Democracy. In J. Curran \& M. Gurevitch (Eds.), Mass Media and Society [Third Edition], (pp. 120-154). London: Arnold.

Curran, J. (1988). Communications, Power and Social Order. In M. Gurevitch, \& G. Murdock (Eds.), Culture, Society and the Media. London: Routledge.

Dahlgren, P. (1995). Television and the Public Sphere: Citizenship, Democracy and the Media. London: Sage.

Dahlgren, P. (1991). Introduction. In P. Dahlgren \& C. Sparks (Eds.), Communication and citizenship: Journalism and the public sphere in the new media age (pp.1-24). NY: Routledge.

Dai, N. (2008). A Bibliography Analysis on Studies about Public Service Broadcasting: 1998-2008. Mass Communication Research, (96), 309-334.

Dalton, R., Beck, P., Huckfeldt, R., \& Koetzle, W. (1998). A test of media-centered agenda setting: Newspaper content and public interests in a presidential election. Political Communication, 15(4), 463-481.

DCMS (Department for Culture, Media and Sport). (2009). Government Response to the House of Lords Select Committee on Communications Report on Public Service Broadcasting: Short-term Crisis, Long-term Future? London: TSO.

DCMS. (2006a). A Public Service for All: The BBC in the Digital Age. London: TSO.

DCMS. (2006b). Digital Switchover Help Scheme. London: TSO.

DCMS. (1998). Television: The Digital Future: A Consultation Document. London: DCMS.

DCMS \& Radio communications Agency. (1998). Television: The Digital Future: A Consultation Document. London: DCMS.

Deacon, D., \& Wring, D. (2002). Partisan de-alignment and the British press. In J. Bartle, R. Mortimore \& S. Atkinson (Eds.), Political Communications: the General Election of 2001 (pp. 197-211). London: Frank Cass.

Deacon, D. Fenton, N. and Bryman, A. (1999) 'From Inception to Reception: the Natural History of a News Item' Media Culture and Society, 21, 5-31.

de Burgh, H. (2003). The Chinese journalist: mediating information in the world's most populous country. London: Routledge.

DTI \& DCMS. (2000). A New Future for Communications. London: TSO.

Economic Times. (11/12/2007). Three forces compete for the chairmanship of PTS. Retrieved December 09 2009, from UDN database. http://udndata.com/

Edwards, D. and J. Potter (1992) Discursive Psychology. London: Sage.

Fan, C. (2011). Rethinking the Role of PSB in Taiwan in the Digital Age (Unpublished doctoral dissertation). The University of Leicester, Leicester.

Fell, D. (2012). Government and Politics in Taiwan. London: Routledge. 
Fell. D. (2011). The polarization of Taiwan's party competition in the DPP era. In R. Ash, J. W. Garver \& P.B.Prime (Eds), Taiwan's Democracy: economic and political challenges (pp. 75-97). London: Routledge.

Feng, H. H. (10/01/2011). 'News Wow Wow Wow '. Retrieved January 31 2012, from You Tube website. http://www.youtube.com/watch?v=9zO4XszbjXg

Feng, J. S. (2009). The political management, economic arrangement and social supervision of public media. Yuedan Faxue 179(July): 21-42.

Feng J. S. (2006). Constructing and Expanding Taiwan's Public Television from 1990 to 2006: Roles of Academic Intellectuals, Social Campaign and Political Authority. Communication and Society, 1: 47-67.

Feng, J. S., Shy, S. H., and Kuo, L. H.(2002). Conference paper: A life story of the publicisation of terrestrial television: 1986-2002. Public Policy forum of ChengChi University: Globalisation and Taiwan. Taiwan: Taipei.

Feng, J. S. (1999). Indeterminate Publicity: Comparing Contests over Public Television in the UK, West Germany, France, I taly and Taiwan. Radical Quarterly in Social Studies, 34, 33-185.

Feng, J. S. (1998a). Public Broadcasting, Market Competition and Economic Efficiency. Radio \& Television, 3(4), 21-44.

Feng, J. S. (1998b). Big Media (in Chinese). Taipei: Yuan-liu.

Feng, J. S. (1995). The Political Economy of the Broadcast Capital Movement: on the Changes of Taiwan's Broadcast Media in the 1990s (in Chinese).Taipei: Yuan-liu.

Financial Times. (15/01/2012). China and US relief as Taiwan re-elects leader. Retrieved J anuary 16 2012, from FT website. http:// www.ft.com/cms/s/0/567625f2-3f49-11e1-ad6a-00144feab49a.html\#a xzZ1jYWFe3SP

Formosa Television (2005). Formosa TV News Feature: Taiwan Notes. Retrieved May 29, 2007, from FTV website. http://www.ftvn.com.tw/Topic/CaringTW/TWnotes/0304.htm

Fraser, N. (1993). Rethinking the Public Sphere: A Contribution to the Critique of Actually Existing Democracy. B. Robbins (Eds.), The phantom public sphere, (pp. 1-32). London: University of Minnesota Press.

Fraser, N. (1992). Rethinking the public sphere: a contribution to the critique of actually existing democracy. In C.J. Calhoun (Eds.), Habermas and the public sphere [First Edition], (pp. 109-142). London: MIT Press.

French, D. \& Richards, M. (2000). Television in contemporary Asia. London: Sage.

Garnham, N. (1997). Political Economy and the Practice of Cultural Studies. In M. Ferguson, \& P. Golding (Eds.), Cultural Studies in Question. London: Sage.

Garnham, N. (1992). The media and the public sphere. In C. Calhoun (eds.), Habermas and the public phere [First Edition], (pp. 359-376). London: MIT press.

Garnham, N. (1990). The Media and the Public Sphere. Capitalism and Communication: Global Culture and the Economics of Information (pp. 104-114). London: Sage. 
Garnham, N. (1983). Public service verses the market. Screen. 5(1).

Garver, J. W. (2011). Introduction: Taiwan's democratic consolidation. Taiwan's Democracy: economic and political challenges (pp. 146-165). London: Routledge.

Golding, P., \& Murdock, G. (2000). Culture, Communications and Political Economy. In J. Curran, \& M. Gurevitch (Eds.), Mass Media and Society. London: Arnold.

Golding, P. \& Murdock, G. (1997). The Political economy of the media, Vol. 2, 1997, Edward Elgar: Cheltenham.

Goode, L. (2005). Jürgen Habermas: Democracy and the Public Sphere. London: Pluto Press.

Government Information Office, Republic of China. (2012a). Broadcast Media. Taiwan Year book 2011 (pp. 215-218). Taipei: GIO.

Government Information Office, Republic of China. (2012b). People. Taiwan Year book 2011. Retrieved Feb 1, 2012, from GIO website. http://www.gio.gov.tw/taiwan-website/5-gp/yearbook/docs/ch02A.pdf

Government Information Office, Republic of China. (2012c). The ROC on Taiwan (1945- ). Taiwan Year book 2011. Retrieved Feb 1, 2012, from GIO website. http://www.gio.gov.tw/taiwan-website/5-gp/yearbook/docs/ch03C.pdf

Government Information Office, Republic of China. (2012d). Media. Taiwan Year book 2011. Retrieved Feb 1, 2012, from GIO website. http://www.gio.gov.tw/taiwan-website/5-gp/yearbook/docs/ch15.pdf

Government Information Office, Republic of China. (Apr/2007). About Taiwan: Mass Media. Retrieved May 30, 2007, from GIO website. http: // www.gio.gov.tw/ct.asp?xItem $=32830 \&$ ctNode $=2597$

Government Information Office, Republic of China. (Jan/2007). Taiwan at a Glance 2007. Retrieved Jul 6, 2007, from GIO website. http://www.gio.gov.tw/taiwan-website/5-gp/glance/

Government Information Office. (Apr/2006). Taiwan - More than an Island. Retrieved Jul 6, 2007, from GIO website. http://www.gio.gov.tw/taiwan-website/5-gp/island/

Government Information Office, Republic of China. (2005a). A Brief History of Taiwan. Taipei: GIO.

Government Information Office, Republic of China. (2005b). Republic of China Television Yearbook 2003-2004. Taipei: Taiwan Panorama.

Government Information Office, Republic of China. (2004). A Brief Introduction to Taiwan. Retrieved Jul 6, 2007, from GIO website. http://www.gio.gov.tw/taiwan-website/5-gp/brief/

Government Information Office. (2004). White Paper on Broadcasting. Taipei: GIO.

Government Information Office, Republic of China. (2003). Cultural Taiwan. Retrieved Jul 6, 2007, from GIO website. http://www.gio.gov.tw/taiwan-website/5-gp/culture/

Guardian. (14/01/2012a). Taiwanese president's re-election soothes Chinese fears. Retrieved January 16 2012, from Guardian website. 
http://www.guardian.co.uk/world/2012/jan/14/taiwanese-president-electionma-china? INTCMP $=$ SRCH

Guardian. (14/01/2012b). Relief in Beijing as Taiwan's pro-China president wins a second term in office. Retrieved January 16 2012, from Guardian website. http:// www.guardian.co.uk/world/2012/jan/14/taiwan-voters-return-ma-yingjeou? I NTCMP=SRCH

Grey, D., \& Brown, T. (1970) "Letters to the Editor: hazy reflections of public opinion", J ournalism Quarterly, 47, 450-56.

Habermas, J. (1989). The Structural Transformation of the Public Sphere: An Inquiry into a Category of Bourgeois Society. T. Burger (Trans). Cambridge: Polity Press.

Hackett, R. A., \& Zhao, Y. (1994). Challenging a master narrative: Peace protest and opinion/editorial discourse in the US press during the Gulf War. Discourse \& Society, 5(4), 509-541.

Hallin, D. \& Mancini, P. (2004) Comparing Media Systems: Three Models of Media and Politics. Cambridge: Cambridge University Press.

Hass, T. (1999).What's"public"about public journalism? Public journalism and the lack of a coherent public philosophy. Communication Theory, 9 (3), 346-364.

He, R. X. (16/03/2011). NHK Revelation. China Times, p. A15.

He, G. H. (2011, 17/Mar). From NHK's Performance to see the plight of Taiwan Media. Apple Daily, p. A23.

Her, K. (2006). Media: The Remix. Taiwan Journal. Taipei: GIO.

Herman, E. S., \& Chomsky, N. (1988). A Propaganda model. In E. S. Herman (Ed.), Manufacturing Consent: the Political Economy of the Mass Media (pp. 1-35) Pantheon Press.

Higgins, M. (2008). Media and Their Publics. Maidenhead: Open University Press.

Hilgartner, S. \& Bosk, C. (1988). The rise and fall of social problem: a public arenas model. American Journal of Sociology 94(1): 53-78.

Hogarth, D. (2001). Public service broadcasting as a modern project: a case study of early public-affairs television in Canada. Canadian J ournal of Communication. 26(3) 351-365.

Hong Z. Y. (13/03/2011). I prefer watch NHK even I don't speak Japanese. Liberty Times, p. A15.

Hsi, H. (2006). The Business Culture and Its Formation and Development of the United Daily News: 1963-2005, Taipei: Showwe Information.

Hu, Y. H. (2007). Media and Reform: Key Task to Rebuild Taiwan. Taipei: Business Weekly Publication.

Huang, F. (2005). A Brief History of Taiwan. Taipei: GIO.

Huang, H.H. \& Huang, C. Z. (2005). An Efficacy Appraisal of Taiwan's audio-visual media policy and implementation. Taipei: The Control Yuan of the Republic of China. 
Huang, R. M. (19/03/2011). [Do you] really prefer watch NHK even you speak no Japanese? Apple Daily, p. A23.

Hughes, C. (2011). Negotiating natioanl identity in Taiwan: between nativization and de-sinicization. Taiwan's Democracy: economic and political challenges (pp. 51-74). London: Routledge.

Huntington, S. P. (1991). The third wave: democratization in the late twentieth century. London: University of Oklahoma Press.

Hynds, E. (1994) "Editors at Most U.S. Dailies See Vital Roles for Editorial Page", Journalism Quarterly 71(3), 573-82.

Jackson, I. (1971). The provincial press and the community. Manchester, England: Manchester University Press.

Jiang, Z.Y. (2006). The Strategies engaged in social campaign: Campaign for Media Reform and the democratisation of terrestrial television in Taiwan. Thesis. Taipei: the Graduate institute of Mass communication college of social sciences in National Taiwan Normal University.

Je, R.M. (16/03/2011). NHK stands no chance in Taiwan. Apple Daily, p. A23.

Jhou, J. W. (2007) 'Taiwan's unbearable pain: the longest martial law period in the world, ' Liberty Times, 20 May.

Jung, S. (1991). Past and present of Korean Broadcasting. Seoul: Nanam.

Kahn, K. F., \& Kenney, P. J. (2002). The slant of the news: How editorial endorsements influence campaign coverage and citizens' views of candidates. American Political Science Review, 96(02), 381-394.

Kapoor, S. (1995) “Most Papers Receive More Letters," The Masthead 47(2), 5-9.

Kapoor, S., \& Botan, C. (1992). Studies Compare How Editors Use Letters, The Masthead 44(1), 5.

KBS. (2012). About KBS. Retrieved December 14, 2011, from KBS website. http://english.kbs.co.kr/About/overview/aboutus/index.html

KBS. (2012). KBS Factsheet. Retrieved December 14, 2011, from KBS website. http://english.kbs.co.kr/About/Inc/AboutKBS_factsheet_2010.pdf

KBS. (2010). 2009/2010 KBS Annual Report. Retrieved December 14, 2011, from KBS website.

http://www.kbs.co.kr/openkbs/report/download/eng0910_b_4.pdf

Keane, M. (2003). Civil society, regulatory space and cultural authority in China's television industry. In P. Kitley (Ed.) Television, regulation and civil society in Asia. London: RoutledgeCurzon, 169-187.

Keane, J. (1993). Democracy and the Media: Without Foundations. In D. Held (Ed.), Prospects for democracy: north, south, east, west. Cambridge: Polity Press.

Keane, J. (1991). The Media and Democracy. Cambridge: Polity.

Kim, Y. H. (2001). The broadcasting audience movement in Korea. Media, Chlture \& Society, 23(1): 91-107. 
Ko, Y. F. (2003). Book Review: Problems Come with Tabloid Culture. Mass Communication Research 75, 243-246.

Ku, L. L., Li, S. C. \& Liu, Y. L. (2010). The policymaking of current Taiwan Broadcasting System (Research Report: RDEC-RES-098-022). Taipei: The Research, Development and Evaluation Commission, Executive Yuan.

Kuo, S., \& Nakamura, M. (2005). Translation or transformation? A case study of language and ideology in Taiwanese press. Discourse \& Society 16(3): 393-417.

Le, E. (2004). Active participation within written argumentation: metadiscourse and editorialist's authority. Journal of Pragmatics, 36(4), 687-714.

Lee, C. C. (2000a). The paradox of political economy: Media structure, press freedom, and regime change in Hong Kong. In C. C. Lee (Ed.), Power, Money, and Media (pp. 288-336). Illinois, IL: Northwestern University Press.

Lee, C.C. (2000b).State, Capital, and Media: The Case of Taiwan. In J. Curran \& M. Park (Eds.), De-Westernizing Media Studies (pp. 124-138). London: Routledge.

Lee, C.Y. \& Li S. C. (2006). Media Competition and Content Diversity in Taiwan: Effects of Inter-Media and Intra-Media Competitions, Mass Communication Research 88, 135-172.

Lee, D. H. (2003). A local mode of programme adaptation: South Korea in the global television format business. In A. Moran \& M. Keane (Eds.). Television across Asia: TV industries, programme formats and globalisation, (pp. 36-53). London: Routledge.

Lewis, J., Inthorn, S., \& Wahl-J orgensen, K. (2005). Citizens or consumers: What the media tell us about political participation? Maidenhead: Open University Press.

Li D. C. \& Wu J. M. (2006). An investigation on the conceptualization of Taiwanese Civil society. Taipei: 2006 Taiwan Sociological Association annual conference.

Li, M. X. (04/01/2006). Public Era Arrive. Liberty Times, p. A6.

Li, S. C. S. \& Chiang, C. C. (2001). Marketing competition and programming diversity: a study of the TV market in Taiwan. Journal of Media Economics, 14(2) 105-129.

Liberty Times. (29/12/2008). Rescue Public TV; Go for Protest on the New Year's Day, p. 2.

Liberty Times. (20/12/2008). Auditing or Intervening? Government Information Office and the Public Television Station in Inter-Criticism, p. 4.

Liberty Times. (19/12/2008). Lawmaker Intervene Public Media Scholars Mourn the Death of Democracy, p. 2.

Liberty Times. (21/01/2008). Weekly Interview: Reinventing the Public Service Broadcasting by raising efficacy, p. 4.

Lin, C. S. (23/08/2009). President Ma's Army intrude in TBS. Liberty Times: A15.

Lin J. T. (2008). Rethinking the view-rating and social support for the PSB. Media Watch, 63, 24-5. 
Lin, L. Y. (2008). A Historical Experiment with Deregulation: The Changes and Challenges of the Press after the Lifting of the Press Ban in Taiwan, Mass Communication Research 95, 183-212.

Lin, L. Y. (2005) 'Authoritarian states and television: a comparative study between Taiwan and South Korea,' Mass Communication Research, 85, 1- 34.

Lin, L. Y. (2003). The Translation of Knowledge into Action: Campaign for Citizens' TV, Taiwan: A Radical Quarterly in Social Studies, 50: 145-169.

Lin, L. Y. (2001). The Contradiction and Transformation of Client Press Under Taiwan's Authoritarian Regime: 1949-1999. In L. Chang (Ed.), Culture Industries in Taiwan (pp. 89-148). Taipei: YLib.

Lin, L. Y. (2000). 'the contradiction and transformation of patron - client press industry in Taiwan: 1949- 1999,' in Chang, L. Y. (ed.) Cultural Industry: A Structural Analysis of Cultural Production. Taipei: Yuan - Liou Publishing.

Lin, L. J. (2006). Taiwan Broadcasting System Go Public, New TV Age starts. PBS Newsletter, 2006, 1-July.

Liu, Z. B. and Tsai, H. Y. (2009). A bibliographic analysis of Taiwanese discourses on communication rights, 1948-2008. Mass Communication Research 98: 245-274.

Livingstone, S. (2005). On the relation between audiences and publics. S. Livingstone (Eds.), Audiences and publics when cultural engagement matters for the public sphere, (pp. 17-41). Bristol: Intellect.

Lo, S. H. (2008). Who pays for free press? Reconsidering media and democracy in Taiwan, Mass Communication Research 95, 213-238.

Loseke, D. R. (2003). Thinking about Social Problems: An Introduction to Constructionist Perspectives. New Brunswick: Aldine Transaction Publishers.

Lui, C. S. (2010). The controversy inside PSB: a battle between light and darkness. Contemporary 240: 153-169.

Lui, L. L. \& Chen, Y. H. (2003). Cloning, adaptation, import and originality: Taiwan in the global television format business. In A. Moran \& M. Keane (Eds.), Television across Asia: TV industries, programme formats and globalization (pp. 54-73). London: Routledge.

MBC. (2012). The next three goals to realize its vision. Retrieved December 14, 2011, from MBC website. http://aboutmbc.imbc.com/english/corporateinfo/vision/index.html

MBC. (2011).Cultural Performance and Public Service Projects. Retrieved December 14, 2011, from MBC website. http://aboutmbc. imbc.com/english/corporateinfo/brief/index.html

McChesney, R. W. (1999). Rich media, poor democracy: communication politics in dubious times. Urbana and Chicago: University of Illinois Press.

Moran, A. \& Keane, M. (2003). Television across Asia TV industries, programme formats and globalization. London: Routledge. 
Murdock, G. (2005). Public Broadcasting and Democratic Culture: Consumers, Citizens, and Communards. In Janet W. (Eds.), A companion to Television. (pp. 174-198). Oxford: Blackwell.

Murdock, G. (2001). Against Enclosure: Rethinking the Cultural Commons. In D. Morley and K. Robins (Eds.), British Cultural Studies: Geography, Nationality, and Identity (pp. 443-460). Oxford: Oxford University Press.

Murdock, G. (1999). Rights and Representation: Public Discourse and Cultural Citizenship. In J. Gripsrud (Eds.), Television and Common Knowledge. (pp. 7-18). London and New York: Routledge.

Murdock, G. (1992). Citizens, Consumers and Public Culture, In M. Skovmand \& K. Schroder. (Eds.) Media Cultures: Reappraising Transnational Media. London: Routledge.

National Communication Commission. (2007). The 2006 Annual report of the National Communication Commission. P162-163. Taipei: NCC.

Naughton, B. (2011). Trade, investment, and technological upgrading: opportunities and challenges facing Taiwan. Taiwan's Democracy: economic and political challenges (pp. 146-165). London: Routledge.

NHK. (2011). NHK Profile. Retrieved December 14, 2011, from NHK website. http: http://www3.nhk.or.jp/pr/koho-e.htm.

NHK. (2009). NHK's Corporate Plan for 2009-2011. Retrieved December 14, 2011, from NHK website. http: http://www3.nhk.or.jp/pr/koho-e.htm.

Papathanassopoulos, S. (2002). European Television in the Digital Age: Issues, Dynamics and Realities. Cambridge: Polity Press.

Pauwels, C. (22/11/2010). Public Lecture: Television Beyond Frontiers: reflections on public service broadcasting in a digital Europe. London: Old Theatre in LSE.

Peters, J. D. (1993). Distrust of representation: Habermas on the public sphere. Media, Cultural \& Society. 15 (4).

Pounds, G. (2006). Democratic participation and Letters to the Editor in Britain and Italy. Discourse \& Society, 17(1), 29-63.

Price, V. (1992). Public Opinion. London: Sage.

Pritchard, D., \& Berkowitz, D. (1991). How Readers' Letters May Influence Editors and News Emphasis: A Content Analysis of 10 Newspapers, 1948-1978. Journalism Quarterly: 68 (3): 388-395.

Public Television Service. (2012). About PBS. Retrieved J anuary 14, 2012, from PBS website. http://www.pbs.org/about

Public Television Service. (2001). Taiwan Public Television online/About PTS/History. Retrieved 5 Jan, 2007, from PBS website. http://eng.pts.org.tw/about_01.htm

Public Television Service. (2001). Taiwan Public Television online/About PTS/Mission Critical. Retrieved 5 Jan, 2007, from PBS website. http://eng.pts.org.tw/about_02.htm

Public Television Service Foundation. (2000-2010). PTS annual reports (1999-2010). Taipei: Public Television Service. 
Raboy, M. (1996). Public Service Broadcasting in the Context of Globalization. In M. Raboy. (Eds.) Public Broadcasting for the 21st Century, (pp 1-19). Luton: University of Luton Press.

Rawnsley, G. \& Rawnsley, M. (2012). The Media in Democratic Taiwan. Conference: the First World Congress of Taiwan Studies, 26-28/Apr/2012. Taipei: Academia Sinica.

Rawnsley, G. D. (2001). Public Television and Empowerment. In M. T. Rawnsley (Ed.), Critical Security, Democratisation and Television in Taiwan (pp. 89-108). Aldershot: Ashgate.

Richardson, J. D. (2005). Switching Social Identities: The Influence of Editorial Framing on Reader Attitudes Toward Affirmative Action and African Americans. Communication Research, 32(4), 503.

Richardson, J. D., \& Franklin, B. (2004). Letters of Intent: Election Campaigning and Orchestrated Public Debate in Local Newspapers' Letters to the Editor. Political Communication, 21, 459-478.

Richardson, J. D. (2001). Now is the Time to Put an End to all this: Argumentative Discourse Theory and 'Letters to the Editor'. Discourse \& Society, 12(2), 143-168.

Rigger, S. (2011). The politics of constitutional reform in Taiwan. Taiwan's Democracy: economic and political challenges (pp. 37-50). London: Routledge.

Rowland, W.D. \& Tracey, M. (1990). Worldwide challenges to public service broadcasting. Journal of Communication, 40(2) 8-27.

Rumphorst, W. (2007). Public service broadcasting-model law. Retrieved September 05, 2011, from the European Broadcasting Union website. http://www.ebu.ch/CMSimages/en/leg_p_model_law_psb_210207_tcm6-5052 7.doc

Scannell, P. (2000). Public service broadcasting: the history of a concept. In E. Buscombe (Eds.), Brithish Telvision: A Reader, ( $p p, 45-62$ ). Oxford: Clarendon Press.

Scannell, P. (1996). Britain: Public Service Broadcasting, from National Culture to Multiculturalism. In M. Raboy. (Eds.) Public Broadcasting for the 21st Century, (pp 23-41). Luton: University of Luton Press.

Scannell, P. (1989). Public service broadcasting and modern public life. Media, Culture \& Society. 11(2) 135-166.

Schafferer, C. (2005). Taiwan's party system and political culture (1945-2005). Modern East Asia, 4(1) 1-25

Seaton, J. (2003). Broadcasting and the theory of public service. In J. Curran \& J . Seaton. (Eds.), Power without Responsibility: the Press, Broadcasting, and New Media in Britain [sixth edition], (pp. 363-376). London: Routledge.

Shim, D. (2008). The growth of Korean Cultural Industries and the Korean Wave. In B. H. Chua \& K. I wabuchi (Eds.). East Asian pop culture : analysing the Korean wave, (pp. 15-32). Hong Kong : Hong Kong University Press.

Shimizu, S. (1996). Japan: Public Broadcasting as a National Project. In M. Raboy. (Eds.) Public Broadcasting for the 21st Century, (pp 140-157). Luton: University of Luton Press. 
Sigelman, L., \& Walkosz, B. (1992) Letters to the Editor as a Public Opinion Thermometer: the Martin Luther King holiday vote in Arizona, Social Science Quarterly 73(4), 938-946.

Silverman, D. (2006). Interpreting Qualitative Data Methods for Analyzing Talk, Text and Interaction. London: SAGE.

Smith, A. (1995). Television as a Public Service Medium. In Anthony S. (Eds.), Television: an international history, (pp.62-91). New York: Oxford University Press.

Smith, A. (1993). Books to bytes: Knowledge and Information in the Postmodern Era. London: British Film Institute.

Taipei Times. (22/03/2011). Public hearing to be held on Public Television Act, p. 3.

Taipei Times. (14/03/2011). Editorial: Quake offers lessons for Taiwan, p8.

Taipei Times. (13/03/2011). Editorial: Sensational coverage distasteful, p8.

Taipei Times. (7/10/2010). PTS official urges review of management change, p. 2.

Taipei Times. (4/10/2010). Don't let the government take control of the media, p.8.

Taipei Times. (4/10/2010). Editorial: Shady dealings in Taiwan's media, p. 8.

Taipei Times. (30/09/2010). Opponents lambaste PTS's reshuffle as a political ploy, p.1.

Taipei Times. (28/04/2010). Six PTS board members sue GIO over injunction, p. 3.

Taipei Times. (27/01/2010). PTS dispute triggers letters campaign of Key players in the battle for control of the TV station, p. 4.

Taipei Times. (08/01/2010). Civic groups brave rain to protest Government intervention at PTS, p. 3.

Taipei Times. (13/12/2008). Scores of civic groups rally in support of Public Television Service, p.3.

Taipei Times. (25/06/2004). Pro-DPP actress takes CTS helm, p. 2.

Taipei Times. (18/12/2001). Legislators want an independent media, p. 3.

Taiwan Broadcasting System. (2012a). About TBS. Retrieved May 15, 2012, from TBS website. http://www.tbs.org.tw/

Taiwan Broadcasting System. (2012b). Those years, we reinvented the PSB project together. Apple daily. Retrieved J anuary 10 2012, from Apple Daily website: http://www.appledaily.com.tw/appledaily/article/headline/20120213/3401175 6/applesearch/

Tang, S. C., \& Jian, M. J. (2008, 20/Dec). Public TV suffering as legislators grab spoils. Taipei Times, A8.

Television Asia. (2006). Territories. Annual Guide 2006/2007. Singapore: Reed Business Information. 
Television Asia. (2003). Satellite \& Cable Annual guide 2003/2004. Singapore: Reed Business Information.

The Economist. (21/01/2012).Taiwan's Elections. 402(8768) 54-55.

The Sunday Times (15/01/2012). Ma's victory in Taiwan calms Chinese nerves. Retrieved J anuary 16 2012, from Times website.

http: // www.timesplus. co.uk/sto/ ?login=false\&url=http $\% 3 \mathrm{~A} \% 2 \mathrm{~F} \% 2 \mathrm{Fwww}$. thes undaytimes.co.uk\% 2Fsto\% 2Fnews\%2Fworld_news\%2FAsia\%2Farticle856877. ece

Thompson, J. P. (1990). Ideology and Modern Culture. Cambridge: polity Press.

Thompson, M. (28/05/2006). Speech given to the International Press Institute World Congress in Edinburgh - Whose side are we on? Retrieved September 5 2008, from BBC website.

http://www.bbc.co.uk/print/pressoffice/speeches/stories/thompson_ipi.shtml

Tracey, M. (1998). The Decline and Fall of Public Service Broadcasting. Oxford: Oxford University Press.

Tracey, M. (1996). The United States: PBS and the Limitations of a Mainstream Alternative. In M. Raboy. (Eds.) Public Broadcasting for the 21st Century, (pp 158-173). Luton: University of Luton Press.

Trend Spotting Marketing Research Co. Ltd. (2009). 2009 Survey for Public Value of the Taiwan Broadcasting System (TBS). Retrieved March 24, 2012, from PTS website.

http://web. pts.org.tw/ web02/ptsenglish/report/2009-survey.pdf

Tsai, C. L. (9/02/2012). Those years, they trash the PSB project together. apple daily. Retrieved January 10 2012, from Apple Daily website:

http://www.appledaily.com.tw/appledaily/article/headline/20120209/3401175 6/applesearch/

Tsao, W. L., Peng, Y. H., \& Lin, C. W. (2008). The Practice and Construction of the Accountability System for Taiwan Public Service Broadcasting. Mass Communication Research, (96), 129-186.

Tuchman, G. (1978). Making news: A study in the construction of reality. New York: Free Press.

Tunstall, J. (1977). 'Letters to the Editor', in Royal Commission on the Press, Studies on the Press, Working Paper No. 3, pp. 203-248. London: HMSO.

United Daily News. (19/12/2008). KMT Lawmakers: Public TV Proven Themselves as DPP Political Warriors, p. 10.

United Daily News. (12/07/2004). DPP Control Media Worse than the Martial-Law Era, p. 4.

United Daily News. (11/10/2002). Media academics say goodbye to President, p. 4.

United Evening News. (17/03/2011). Editorial: ill professionalism pushes away real professionalism, p. A2.

Volgy, T., Krigbaum, M., Langan, M., \& Moshier, V. (1977) "Some of My Best Friends are Letter Writers: eccentrics and gladiators revisited", Social Science Quarterly 58(2), 321-327. 
Wahl-J orgensen, K. (2002). Understanding the Conditions for Public Discourse: four rules for selecting letters to the editor', J ournalism Studies, 3(1), 69-81.

Wahl-Jorgensen, K. (2001). Letters to the Editor as a Forum for public deliberation: modes of publicity and democratic debate', Critical Studies in Media Communication, 18 (3), 303-320.

Walker, E. T., Martin, A. W., \& McCarthy, J. D. (2008). Confronting the State, the Corporation, and the Academy: The Influence of Institutional Targets on Social Movement Repertoires 1. American J ournal of Sociology, 114(1), 35-76.

Wang, C. T. (2004). A Rhetoric Analysis of A Media Reform Movement: The case of Campaign for Citizens' TV. Conference paper from the 2004 annual conference of the Chinese Communication Society. Macau: Institute for Tourism Studies.

Wang, G. \& Lo, V. (2000). Taiwan. In S.A. Gunaratne (Eds.), Handbook of the media in Asia (pp. 660-681). New Delhi: sage.

Wang, T.B. (2002). The Evolution of Mass Communication in Taiwan. Taipei: Asia-Pacific.

Washington Post. (15/01/2012). Taiwan wants a separate peace with China; Taiwan unlikely to move to reunify with China, despite Ma Ying-jeou's reelection.

Retrieved J anuary 16 2012, from Washington Post website.

http: //www.washingtonpost.com/world/asia_pacific/taiwan-wants-a-separatepeace-with-china/2012/01/15/glQA3ufF1P_story.html

Washington Post. (14/01/2012). Ma Ying-jeou, Taiwan's pro-China president, wins reelection. Retrieved January 16 2012, from Washington Post website. http://www.washingtonpost.com/world/asia_pacific/ma-ying-jeou-taiwans-pro -china-president-wins-reelection/2012/01/14/gIQA0CxMyP_story.html

Weng, S. C. (2008). Public Television and Accountability: A Case Study of Taiwan Broadcasting System. Mass Communication Research, (96), 187-211.

Weng, S. C. (2006). The Experience of Public Television Service in Taiwan. Hong Kong Media Digest, (6), 12-13.

Young, Z. (2011, 16/Mar). I speak no Japanese but I still prefer NHK. United Daily News, p. A15.

Yu, S.Z. (1988). Yesterday, Today and Tomorrow of Our Public Service Broadcasting (in Chinese). Bao-Xue, 8(1) 140-147.

Zchi, L. Z. \& Tsai, M. I. (2005). The 2004 survey to the cable TV viewers' watching behavior and satisfaction. Taipei: GIO. 